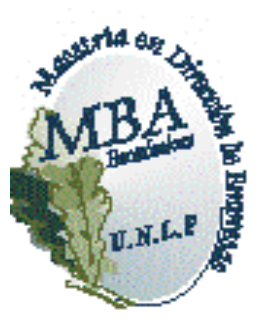

Universidad Nacional de La Plata

Facultad de Ciencias Económicas

MBA - Maestría en Dirección de Empresas

\title{
Satisfacción del Cliente de la Dirección de Obras \\ Particulares de la Municipalidad de Ensenada
}

Trabajo final para optar al título de Magister

Autor: Javier Andrés Ramírez T.

Director: Silvia Alejandra Marteau 
1. Formulación del problema

2. Objetivos de la Investigación 3

3. Evaluación del problema 4

4. Limitaciones o alcances de la investigación ___ 6

5. Marco Teórico de Referencia 7

5.1 Antecedentes de la investigación 7

5.2 Teoría y concepto de calidad 8

5.2.1 Filosofía y modelos Gestión de la calidad 11

5.2.2 Herramientas para introducir la calidad 13

5.3 La Calidad en la Administración Pública 19

5.3.1 Cambio de paradigma en la administración pública___ 20

5.3.2 La Capacidad Estatal y la Capacidad de Gestión ___ 22

5.3.3 La Nueva Gerencia Pública ___ 26

5.3.4 La administración pública Argentina. __ 29

5.3.5 Experiencia Iberoamericana y nacional.__ 30

5.3.6 La reforma del estado Argentino __ 39

5.4 Dirección de Obras particulares de la Municipalidad de Ensenada.

6 Metodología __ 51

6.1 Población y muestra _____ 51

6.2 Tipo de Investigación ___ 52

6.3 Técnicas de recolección de datos ___ 52

6.4 Técnicas de Análisis_______ 53

7 Resultados de la Investigación__ 56

7.1 Análisis descriptivo de la muestra ___ 56

7.2 Análisis Dimensión I: Elementos Tangibles ___ 59

7.2.1 Equipos

7.2.2 Instalaciones Físicas __ 62

7.2.3 Apariencia Física de los Empleados __ 64

7.2.4 Apariencia Visual de los Elementos de Comunicación ___ 67

7.2.5 Total datos Dimensión I "Elementos Tangibles" ___ 69 
7.3.1 Cumplimiento de los Empleados _ 70

7.3.2 Interés de los Empleados __ 73

7.3.3 Eficacia del Servicio _ 75

7.3.4 Tiempo de Cumplimiento del Trabajo___ 78

7.3.5 Eficiencia del servicio _ 80

7.3.6 Total datos Dimensión II "Confiabilidad" ___ 82

7.4 Análisis Dimensión III: Capacidad de Respuesta ___ 83

7.4.1 Comunicación con los Empleados___ 84

7.4.2 Velocidad del servicio __ 86

7.4.3 Disponibilidad del Servicio ___ 88

7.4.4 Disponibilidad de Atención Inmediata frente a otras Actividades ___ 91

7.4.5 Total datos Dimensión III "Capacidad de Respuesta" ___ 94

7.5 Análisis Dimensión IV: Seguridad____ 95

7.5.1 Confianza en el Comportamiento de los Empleados___ 95

7.5.2 Seguridad en las Transacciones___ 97

7.5.3 Amabilidad 100

7.5.4 Conocimiento de los Empleados __ 103

7.5.5 Total datos Dimensión IV "Seguridad"__ 105

7.6 Análisis Dimensión V: Empatía________________ 106

7.6.1 Individualización de la Atención _ـ 107

7.6.2 Conveniencia de los Horarios__ 109

7.6.3 Personalización de la Atención___ 112

7.6.4 Preocupación por los Intereses de los Clientes __ 114

7.6.5 Comprensión de las necesidades del Cliente___ 117

7.6.6. Total datos Dimensión V "Empatía" __ 119

7.7 Importancia de cada Dimensión según los usuarios del servicio de Obras Particulares de la municipalidad de Ensenada. 120

7.8 Calificación Global de los usuarios del servicio de Obras Particulares ___ 122

\section{Comparación de las dimensiones entre los resultados obtenidos en la}

Municipalidad de Ensenada y la Plata __ 127

8.1 Cuadro comparativo Detallado por dimensiones ___ 127

8.1.1. Comparación del análisis descriptivo de la muestra____ 127

8.1.2. Comparación Dimensión I: Elementos Tangibles___ 128

8.1.3. Comparación Dimensión II: Confiabilidad___ 131

8.1.4. Comparación Dimensión III: Capacidad de Respuesta ___ 135

8.1.5. Dimensión IV: Seguridad __ 138

8.1.6. Dimensión V: Empatía __ 142

8.2 Comparación del resultado total por dimensiones según la importancia. 145 
9. Conclusiones

10. Bibliografía

11. Anexos 


\section{Formulación del problema}

La competitividad de la nación es la consecuencia del alcance de la calidad de sus organizaciones y del nivel de efectividad de sus sectores. La fórmula para alcanzar esto, requiere de compañías competitivas, un estado eficiente y la efectiva participación de organizaciones sociales.

La competitividad de un país está directamente relacionada con la competitividad de las empresas y organizaciones que en el mismo se desenvuelven. La eficiencia de las empresas privadas como de las empresas u organizaciones públicas en la provisión de productos y servicios a la sociedad son igual de necesarias para que un país sea competitivo.

Para ser competitiva, toda organización debe contar con buenos productos y/o servicios obtenidos a un coste apropiado y con una buena gestión, la cual debe incluir también la posibilidad de dar a sus clientes un trato agradable. Debe desarrollar por tanto, la calidad de productos y/o servicios, la calidad de procesos, la calidad de la gestión y la calidad de atención al cliente.

Es entonces la calidad, el elemento estratégico mediante el cual una empresa puede conseguir una ventaja diferencial en el mercado volviéndose más competitiva frente a sus competidores, siendo la base de la supervivencia y del desarrollo de las organizaciones de hoy en día (privadas o públicas). La calidad y su gestión, indudablemente generan cambios, que se traducen finalmente en el nivel de eficiencia de los procesos de toda organización, mejorando el grado de satisfacción de los clientes y la cero presencia de fallos en la fabricación del producto y/o prestación del servicio.

El nacimiento de nuevos esquemas administrativos basados en la filosofía de la calidad aplicados en el sector privado, que han tenido gran acogida durante las últimas tres décadas, ha generado que los usuarios solicitantes de servicios y productos trasladen esas exigencias a los servicios que diariamente demandan de las organizaciones del estado. $Y$ es que hay servicios públicos de los que ningún ciudadano u empresa puede prescindir, puesto que únicamente el estado se encarga de proveerlos. 
Todo ello ha generado un cambio de paradigma, donde la administración pública ha evolucionado hacia formas de gestión que pretenden acercarla y adaptarla, en la medida que sea posible, a los principios que guían el funcionamiento de lo privado. Uno de los ejes que se ha seguido en este sentido, es el tema de la calidad en la gestión; dado que de ella devendrá la eficacia, eficiencia y efectividad y, conjuntamente, todos estos elementos contribuirán para una administración responsable que legitime la gestión pública.

Decir que un "servicio público es de calidad" significa que cumple en un todo con los requerimientos del usuario, por lo tanto es necesario conocer el nivel de satisfacción del interesado. Y para esto, es indispensable conocer cuál es la expectativa que tiene del servicio y cuál es la percepción que obtiene en la prestación del mismo.

Estas condiciones exigen a las organizaciones públicas a que adopten un conjunto de principios y orientaciones de calidad que le permitan entender y satisfacer las necesidades de los ciudadanos de manera continua, donde la medición de la satisfacción de los ciudadanos resulta imprescindible como retroalimentación para evaluar la situación y la percepción de las prestaciones públicas.

Aun así, son pocas las organizaciones públicas en la Argentina que conocen cual es la satisfacción de los ciudadanos, los desvíos presentados y las oportunidades de mejora de los servicios prestados. 


\section{Objetivos de la Investigación}

- Evaluar el nivel de satisfacción de los clientes del servicio de Obras particulares de la Municipalidad de Ensenada en relación a las siguiente 5 dimensiones:

○ Elementos tangibles

- Confiabilidad del servicio

- Capacidad de respuesta

- Seguridad

○ Empatía

- Detectar aquellos desvíos del servicio de Obras Particulares frente a las expectativas de los clientes, identificando oportunidades de mejora continua que lo orienten a un servicio de calidad.

- Comparar la satisfacción del cliente de servicios de Obras particulares de la municipalidad de Ensenada con la satisfacción del cliente de Obras particulares de la municipalidad de La Plata 


\section{Evaluación del problema}

Un país competitivo en el marco internacional requiere de instituciones sólidas, eficientes y eficaces, que ofrezcan productos y/o servicios de calidad y que entiendan y satisfagan las necesidades de los ciudadanos de manera continua.

Esa competitividad que en el ámbito privado determina la existencia de una empresa en el mercado, se traduce en el sector público como la exigencia de los usuarios demandantes de servicios del estado para que estos sean competitivos y de calidad, teniendo como precedente que los servicios del estado no tienen competencia natural de mercado pero si un compromiso enmarcado en la ley que obliga a la entidad pública a ser eficiente frente a sus usuarios.

El sentido común está acostumbrado, en materia de administración, a concederle a lo privado una opinión sobrevalorada en relación a lo público. Pareciera que las empresas privadas son mejores que la administración pública; basta con recibir un servicio u obtener un bien en el ámbito privado para concluir que la misma operación realizada por el sector público probablemente no hubiera sido satisfecha al mismo nivel. Esta constante comparación que realizan los usuarios, genera sobre las organizaciones públicas más exigencias para alcanzar el nivel ofrecido por las organizaciones privadas.

Este contexto, requiere en Argentina un empeño en el fortalecimiento institucional del Estado, en lograr administraciones públicas más eficientes, eficaces y transparentes. Pues como contexto general tener instituciones más competitivas genera una mayor confianza de los usuarios demandantes de servicios del estado, traduciéndose en un fortalecimiento institucional local, regional y nacional en donde si podemos comparar la competitividad con los demás países de la región.

Con la llegada y aplicación de modelos de gestión orientados hacia la Calidad total y la mejora continua, las instituciones del estado se esfuerzan por 
entender a los usuarios, identificando cuáles son sus necesidades y requerimientos y de esta forma ver como satisfacerlas.

Estas nuevas condiciones demandan de las organizaciones municipales una mayor capacidad y una administración más rigurosa de la información de sus procesos y estándares de medición, una capacitación más especializada de sus funcionarios, y la adopción más formal y comprometida de un estilo de administración.

En este contexto los argumentos que justificaron un análisis de calidad en el sector público son diversos. Entre ellos se encuentran, la magnitud de su actividad económica en el agregado de la economía, la ausencia de competencia en gran parte de los servicios públicos provistos, la necesidad de justificar resultados frente a los presupuestos establecidos, y por sobre todas las cosas, el impacto de los servicios públicos e institucionales en el crecimiento económico y el bienestar de la población.

Ese es hoy el desafío que enfrentan las organizaciones municipales responsables de la provisión de servicios públicos: "alcanzar un servicio de calidad". Y esto requirió primero conocer cuáles son las necesidades de los ciudadanos y cuales sus expectativas, luego se diseñó la mejor manera de proveerlos y por último se midió el nivel de satisfacción de los usuarios. Y este último no es menor, pues sin conocer o medir cuan satisfecho se encuentra el usuario de un servicio público no podrá declararse como un "servicio de calidad" y aún menos intentar serlo.

Esta investigación colabora en esta labor proporcionando un análisis sobre la Calidad de los Servicios Públicos Municipales, considerando que las organizaciones públicas, como cualquier organización prestadora de servicios, necesita conocer el grado de aceptación de sus servicios. Desde este análisis se desprende si los servicios prestados por la municipalidad de Ensenada más exactamente la Dirección de Obras Particulares alcanza o no los valores de calidad requeridos por los usuarios evaluando las expectativas y la percepción de los mismos. 


\section{Limitaciones o alcances de la investigación}

Los resultados que se presentan son el producto de un proyecto de investigación del MBA en Dirección de Empresas cuyo título es "La competitividad empresarial y su impacto regional", acreditado en el marco del Programa de Incentivos de la Secretaría de Ciencia y Técnica de la UNLP.

La Investigación se centrara en las siguientes áreas y servicios públicos de la Municipalidad de Ensenada:

- Licencias de Conducir,

- Obras Particulares,

- Defensa del Consumidor,

- Juzgado de Faltas,

- Recaudaciones y Cobranzas.

Y más específicamente, este documento hace referencia a la Dirección de Obras Particulares de la Municipalidad de Ensenada. 


\section{Marco Teórico de Referencia}

De manera explicativa y buscando contextualizar la investigación, se presentan los siguiente documentos referenciales que habrán de permitir un mejor entendimiento a la investigación, sus resultados y conclusiones.

\subsection{Antecedentes de la investigación}

En la última mitad del Siglo $X X$, y más aún al inicio del nuevo milenio, se adquirió la responsabilidad de gobernar, garantizando mejores resultados y mayor impacto. El objetivo de mercado del sector público es la comunidad; las necesidades no hay que despertarlas, están presentes y los recursos siempre son insuficientes para atender toda la demandas que la comunidad requiere.

Otra Consideración importante, en la dinámica gerencial, es que los ciudadanos, cada vez más, son conscientes de la importancia de su participación en las decisiones que los afectan. Ellos exigen que los resultados de la gestión pública generen confianza en las instituciones del Estado, que se garantice el derecho a la información, que haya una mayor transparencia en el manejo de la administración eficiente de los recursos, que se les rindan cuentas como mecanismos de valuación y que se disminuya los índices de corrupción. Así, estos elementos se convierten en un imperativo para la sostenibilidad y la innovación en la gestión de las entidades públicas.

Responder a estas exigencias de buenos resultados en la gestión pública no es fácil y tiene limitantes. Requiere de una gerencia pública orientada a resultados que le entregue a la ciudadanía los bienes, obras y servicios, en términos de calidad y satisfacción de sus necesidades y expectativas; que efectivamente mejoren su calidad de vida.

Por el motivo anteriormente expuesto, cuando se habla de calidad de un servicio, nunca se debe olvidar que el servicio es prestado a un usuario, el cual resulta ser la razón esencial de la existencia del servicio y por lo tanto el principal juez de que tan sobresaliente, bueno o deficiente ha sido este. De ahí 
que se prefiera hablar de la calidad del servicio percibida, que no es otra cosa que la calidad del servicio desde el punto de vista del usuario.

\subsection{Teoría y concepto de calidad}

A lo largo de la historia se observa que desde sus inicios el hombre ha tenido la necesidad de satisfacer sus requerimientos más elementales para poder subsistir, por lo que él mismo elaboraba sus productos, sin otro concepto de calidad más que la de que aquel producto elaborado cumpliera con sus necesidades básicas. Con el paso del tiempo y dada la imposibilidad de elaborar todos los productos que requería, se empezaron a realizar trueques. La población fue aumentando y con esto las necesidades, con lo cual las personas que desarrollaban los productos le daba el sello personal característico de acuerdo a su habilidad y experiencia y donde la calidad era controlada por él mismo.

Más tarde, con la llegada de la revolución industrial, los pequeños talleres se convirtieron en pequeñas fábricas de producción masiva, se buscan métodos de producción en serie y se organiza el trabajo en formas más completas, con el consecuente aumento de trabajadores a los que se les asigna una labor determinada, estén o no preparados para ejecutar dicha labor.

Estos parámetros empezaron a dar los primeros esbozos iniciales de un esquema administrativo basado en la organización de tareas; pero La teoría de la calidad como tal, tuvo su origen en la actividad privada, en las organizaciones industriales que se desarrollaron durante el siglo $X X$ y que atravesaron diferentes etapas de acuerdo a la orientación que se daba en cada instancia siendo en un primer momento, la Producción (producir grandes cantidades en serie, modelo fordista), luego las Ventas (período de Guerras Mundiales y entreguerras, donde interesa que se consuma lo que se produce) y por último, en los "70, Orientada al cliente (tener en cuenta al cliente, sus necesidades y demandas e introducirlas en las estrategias de producción para lograr mayores niveles de satisfacción y lealtad del cliente) ${ }^{1}$.

\footnotetext{
${ }^{1}$ ARELLANO CUEVA, Rolando Marketing; enfoque América Latina; Capítulo 1, págs. 7 a 12.
} 
En Japón, la calidad fue entendida desde el principio como un valor añadido al servicio, un factor de ahorro que asegura competitividad; fue adoptada por los japoneses durante la segunda mitad del siglo XIX para conquistar el liderazgo en distintos factores. Ellos orientaron sus esfuerzos de calidad hacia el desarrollo de la capacidad de los procesos para dar variedad a los productos sin elevar los costos. Los estudios de mercado y la investigación de la satisfacción del cliente pasaron a ser parte significativa de los programas de calidad $^{2}$.

La calidad asociada con las secciones de inspección y control, donde a través de un análisis estadístico se trataba de determinar si la producción cumplía con los estándares de calidad previamente establecidos. El objetivo básico en estos casos consistía en conseguir niveles aceptables de errores en la fase de producción. Posteriormente, el concepto de calidad se extendió a todas las fases de la vida de un producto o servicio, desde su concepción o diseño hasta su fabricación y posterior uso por parte del cliente, siendo el lema "Cero Defectos".

En la actualidad, los productos y servicios no sólo tienen que ser aptos para el uso que se les ha asignado sino que además tienen que igualar e incluso superar las expectativas que los clientes han depositado en ellos. El objetivo consiste en satisfacer a los clientes desde el principio hasta el fin. Esta nueva concepción de la calidad es la que se conoce como "Calidad del Servicio".

La calidad total destaca el aprendizaje y la adaptación al cambio continuo, claves para el éxito de una organización. Según Procter y Gamble, es el esfuerzo subyacente y de Mejora Continua por parte de todos los que participan en una organización a fin de entender, satisfacer y exceder las expectativas del cliente. Los principios fundamentales de la calidad total son: enfocarse en los clientes (entender bien los atributos de sus bienes y servicios), participar y trabajar en equipo (contar con herramientas, libertad y motivaciones para hacer contribuciones) y dedicarse al mejoramiento continuo de los procesos. A su vez, es imprescindible que estos principios se sustenten: en una

\footnotetext{
${ }^{2}$ MOYADO ESTRADA, Francisco Gestión pública y calidad; Hacia la mejora continua y el rediseño de las instituciones del sector público, págs. 17 a 23.
} 
infraestructura integrada (sistema administrativo básico), prácticas administrativas (actividades), y herramientas y técnicas en conjunto ${ }^{3}$.

Cuando se trata de servicios, ello implica una serie de características que lo distinguen de un bien o producto. Ellas son:

- Intangibilidad: en la mayor parte de los casos, la venta de un servicio no implica una transferencia de bienes. El cliente no puede entonces "tocar" su producto sino únicamente sentir sus resultados o beneficios.

- Inseparabilidad: es muy difícil separar el servicio de la persona que lo proporciona.

- Participación de los clientes: los clientes tienen especial importancia y participación en la apreciación del servicio.

- Perecederos: en su mayor parte, los servicios sólo se dan en el momento mismo de la fabricación y no se pueden almacenar o guardar. Sólo sirven si se consumen inmediatamente.

- Diversos o heterogéneos: es casi imposible homogeneizar un servicio, cada actividad de servicio es única y diferente a las otras, pues su resultado depende de una gran combinación de circunstancias y actores; el prestador del servicio, el receptor del servicio y sobre todo, la percepción que los clientes tengan de los resultados intangibles del mismo 4 .

En la prestación de un servicio importan la Actitud, la Comunicación interpersonal, el Trato, la Atención y el Comportamiento. El control de calidad entonces, se realiza mediante mecanismos de consulta, información y resarcimiento que aseguran el control activo de los usuarios por el resultado que muestran los organismos encargados del control. La calidad de un servicio, en términos sintéticos, es la comparación de expectativas iniciales con las cualidades reales del servicio.

\footnotetext{
${ }^{3}$ EVANS, James R. y LINDSAY, William M. Administración y control de la calidad, pág. 23.

${ }^{4}$ ARELLANO CUEVA, Rolando Marketing; enfoque América Latina, Capítulo 1, págs. 7 a 12.
} 
Según Montgomery (1985), citado por Petracci ${ }^{5}$, la calidad es el grado en el que los productos y servicios cumplen con las exigencias de la gente que los utiliza. Por eso la calidad comprende: 1) La Calidad de Diseño, que son las características de un bien o servicio con las que se pensó al crearlo (expectativa) y 2) la Calidad de Conformidad, que es el grado en que el bien o servicio está de acuerdo con la intención del diseño (percepción). Los indicadores para este tipo de calidad son los objetivos (de la organización) y los subjetivos (del cliente). Estos últimos, se pueden obtener mediante una investigación de calidad percibida o bien mediante la gestión de queja sobre el servicio.

Cumplir con las expectativas del cliente supone en un primer momento, conocer esas expectativas y anterior a esto, tener la intención de conocerlas. Es decir, cuando en una organización comienza a aplicarse calidad, se está asumiendo un compromiso que va más allá de cumplir con la producción de un bien o la prestación de un servicio. Decidir incorporar el paradigma de la calidad en una organización significa asumir la importancia del rol que tiene en el mejoramiento de la calidad de vida de sus clientes/usuarios y trabajadores. Introducir calidad es activar un proceso de Mejora Continua del cual no se conoce un final determinado, utilizando en él las herramientas que existen y desarrollando otras propias, que configurarán las particularidades de cada sistema. Cada organización puede adoptar distintas filosofías, entendiendo que entre ellas hay elementos comunes a través de los cuales se comprenden los principios básicos de este paradigma.

\subsubsection{Filosofía y modelos Gestión de la calidad}

Cuando se habla de filosofías de gestión de la calidad, se refiere principalmente a cuatro escuelas, encabezadas por sus pensadores representativos: Deming, Juran, Crosby y el enfoque japonés ${ }^{6}$. Todas

\footnotetext{
${ }^{5}$ PETRACCI, Mónica La medición de la calidad y la satisfacción del ciudadano-usuario de servicios públicos privatizados, págs. 18 y 19.

${ }^{6}$ DA VIÁ, Ana Control de calidad: Introducción a las modernas filosofías de gestión, Cátedras virtuales, Sistemas de Control de Gestión, pág. 1.
} 
ellas surgieron luego de la II Guerra Mundial y según se fue descubriendo que el mercado pronto se transformaría en el tránsito mundial de mercancías y servicios, haciéndose imperativo hacer competitivas a las empresas.

Para conocer de qué tratan cada una de estas filosofías podemos consultar el siguiente cuadro:

\begin{tabular}{|c|c|}
\hline FILOSOFÍA & DESCRIPCIÓN \\
\hline $\begin{array}{c}\text { DEMING } \\
\text { Realizar un cambio de cultura } \\
\text { organizacional, reingeniería de la } \\
\text { empresa, utilizando las técnicas que } \\
\text { brinda la estadística. }\end{array}$ & $\begin{array}{l}\text { Físico y estadístico norteamericano, desarrolló } \\
\text { principalmente la medición de la calidad en términos } \\
\text { estadísticos. Adoptado por los japoneses, difundió } \\
\text { entre las empresas de ese país, la importancia de } \\
\text { contar con controles de calidad estadísticos, que } \\
\text { permitieran luego tomar decisiones de mejora. Amplió } \\
\text { su enfoque a la importancia del liderazgo, la relación } \\
\text { entre empresa y proveedores y la Mejora Continua. Es } \\
\text { conocido su ciclo de mejoramiento constante, por el } \\
\text { cual se controlan los procesos de acuerdo a los pasos: } \\
\text { 1) Planificar; } 2 \text { ) Hacer; 3) Verificar; 4) Actuar o PHVA }\end{array}$ \\
\hline $\begin{array}{l}\text { JURAN } \\
\text { Incorporar a toda la organización en } \\
\text { el proceso de mejora, a todas las } \\
\text { jerarquías, mejorar la estructura y } \\
\text { los procesos existentes con técnicas } \\
\text { estadísticas y contables. }\end{array}$ & $\begin{array}{l}\text { Ingeniero rumano que desarrolló su carrera en los } \\
\text { EEUU y Japón, en la misma época que Deming. Orientó } \\
\text { el control de calidad a lo contable; entendiendo que la } \\
\text { alta dirección de una empresa habla el idioma del } \\
\text { dinero, se dedicó a hacerles entender que la no } \\
\text { calidad es cara. Según el autor, los costos de la calidad } \\
\text { (de prevención, evaluación, fallos internos y externos) } \\
\text { disminuyen cuando se cumple con los procesos de } \\
\text { calidad (planificación, control y mejora) }\end{array}$ \\
\hline $\begin{array}{c}\text { CROSBY } \\
\text { Cambiar desde las estructuras } \\
\text { existentes, utilizando los procesos } \\
\text { administrativos y organizacionales. }\end{array}$ & $\begin{array}{l}\text { Norteamericano que logró la vicepresidencia de ITT, } \\
\text { creó su propia consultora en temas de calidad y } \\
\text { capacitación y escribió el libro que logró que los } \\
\text { empresarios norteamericanos prestaran atención a la } \\
\text { calidad (Quality is free- La calidad no cuesta) La } \\
\text { filosofía de Crosby se orienta a lograr el cero defecto } \\
\text { para no incurrir en los costos del reproceso. Los } \\
\text { elementos fundamentales para la mejora son: la } \\
\text { determinación (tomar en serio la mejora), la educación } \\
\text { (de todo el personal acerca de los absolutos) y la } \\
\text { implantación (el cumplimiento de los absolutos) Los } \\
\text { absolutos de la calidad de los que se habla, son los } \\
\text { elementos fundamentales que deben existir en un } \\
\text { proceso de mejora?. }\end{array}$ \\
\hline $\begin{array}{c}\text { ENFOQUE JAPONÉS } \\
\text { Lograr la calidad total en todos los }\end{array}$ & $\begin{array}{l}\text { Como se dijo, los japoneses son pioneros en el tema } \\
\text { de introducir calidad en la gestión para reducir los } \\
\text { costos. Este enfoque pretende mejorar la calidad de }\end{array}$ \\
\hline
\end{tabular}

7 “Cero defectos”. EVANS, James R. y LINDSAY, William M., op. cit., págs. 108 a 109. 
componentes de la organización.

vida de los trabajadores, clientes e inversores al incorporar mejoras en la producción y provisión de bienes y servicios. Este enfoque es el que adoptan actualmente las Normas ISO de gestión de la calidad, porque se apunta a visualizar a la organización en todo su conjunto, con los elementos internos y externos a ella, comprendiendo que la misma forma parte de vidas individuales y de comunidad. Propone que a través de pequeños cambios que mejoran la gestión, se logra la calidad en el largo plazo (Kaizen)

Las filosofías expuestas comparten en sus enfoques los siguientes puntos $^{8}$ :

- La calidad es un imperativo para la competencia futura de los mercados globales;

- Es una necesidad absoluta que exista el compromiso de la alta dirección;

- Las prácticas de la calidad ahorran dinero;

- Se necesita la Mejora Continua y sin fin;

- Reconocer la importancia del cliente;

- Necesidad de cambiar la cultura de la organización.

\subsubsection{Herramientas para introducir la calidad}

Algunas herramientas o enfoques que pueden tomarse para aplicar calidad en la gestión tanto en organizaciones privadas como públicas son:

- Producción Just in Time9: Enfoque que pretende disminuir el tiempo que no agrega valor al producto, es decir, propone la producción de acuerdo a la demanda que haya, prescinde del inventario y promueve que el tiempo total en que se produce un producto, sea igual al tiempo del proceso de producción. Se guía por el tirón de la demanda a fin de ahorrar espacios y recursos.

\footnotetext{
8 EVANS, James R. y LINDSAY, William M. Administración y control de la calidad., pág. 110.

9 DA VIÁ, Ana Control de calidad: Introducción a las modernas filosofías de gestión., pág. 2 a 5.
} 
- Teoría de las limitaciones ${ }^{10}$ : Parte de pensar que todo proceso de producción es una cadena de variables dependientes, cada una de las cuales agrega valor al total. Por lo tanto, aquellos recursos de los que no se dispone en cantidad suficiente se consideran los eslabones más débiles, son los que disminuyen la calidad del producto final. Para agregar calidad, la clave está en identificar (los eslabones débiles), explotar (sacar el mayor provecho posible de esos eslabones) y elevar de esta forma las limitaciones. Este procedimiento está relacionado con la herramienta que brinda Ishikawa conocida como "la espina de pescado". La misma consiste en conocer los factores causales de un efecto (producto), mantenerlos controlados y mejorar los que se pueda, para que el resultado final no esté lejos de lo esperado.

- Benchmarking ${ }^{11}$ : Supone el trabajo con información de otras organizaciones consideradas líderes o modelos a seguir. A través del proceso de comparación y referencia con la información de la propia organización, se establecen estándares estratégicos para obtener en el largo plazo, una competitividad a tono con las mejores organizaciones del entorno. Esta herramienta puede enfocarse hacia los costos que manejan las organizaciones que se comparan como hacia los procesos, a fin de determinar mejoras y cambios. Los componentes sobre los que se recopila información para establecer pilares estratégicos de gestión son:

- Satisfacción de los clientes,

○ Motivación y satisfacción de los empleados,

- Participación de mercado,

○ Rentabilidad de los activos.

- Reingeniería de la empresa ${ }^{12}$ : Es el rediseño de los procesos de producción o prestación de bienes y servicios. Implica un cambio

12 DA VIÁ, Ana Control de calidad: Introducción a las modernas filosofías de gestión., pág. 2 a 5. 
sustancial en la forma de trabajar. Los pasos a seguir son: 1) Identificar los procesos que tienen mayores dificultades; 2) Determinar cuáles de ellos tienen mayor impacto en los clientes de la empresa; 3) Decidir cuál de ellos es más apropiado para la reingeniería; 4) Comprender el proceso seleccionado en el estado actual; 5) Entender lo que el proceso actual proporciona, teniendo en cuenta las necesidades del cliente. A partir de allí se aplica un cambio radical en la estructura de la organización, con las siguientes consecuencias:

- Los departamentos funcionales son reemplazados por equipos de procesos;

- Le gerencia se convierte en entrenador del cambio, en guía para la mejora del trabajo;

- Se trabaja multidimensionalmente;

- La estructura se vuelve plana.

- Six Sigma"13. Es una metodología desarrollada en los "80 y aplicada por primera vez en la empresa Motorola, luego adoptada por otras grandes empresas mundiales. Basada en la utilización de la estadística, pretende cumplir el ambicioso objetivo de obtener seis sigma, es decir, 3,4 errores o defectos por cada millón de oportunidades de eventos (DPMO). El término sigma se refiere a una desviación estándar decidida en el diseño del proceso.

\subsubsection{Otros Modelos de Gestión de calidad}

En el entorno actual coexisten dos grandes tendencias en la Gestión de la Calidad, las cuales proporcionan dos modelos diferentes. Cada modelo supone un instrumento que ayuda a las organizaciones a establecer un sistema de gestión basado en la calidad total:

13 EVANS, James R. y LINDSAY, William M. Administración y control de la calidad. pág 132. 
- Adoptar un enfoque de normalización y diseñar un sistema de calidad en base a normas, como pueden ser las de la serie ISO 9000. Esta opción implica la introducción de acciones planificadas que consideran que la calidad abarca a todas las áreas de la empresa, desde el diseño del servicio hasta la entrega del mismo al cliente. Incide en el diseño de un sistema de calidad que permita la estandarización de los procesos y haga más fácil mantenerlos bajo control. Se basa en asegurar que se llevan a cabo los procesos necesarios para que los productos y servicios satisfagan a los clientes. Ello conlleva el establecimiento de estándares para la prestación del servicio y la documentación de todos los procesos.

- Otro enfoque, cada vez más utilizado, es la consideración de alguno de los modelos que subyacen a los premios de calidad como base para la gestión de la calidad. Los principales premios a nivel internacional corresponden al Premio Deming en Japón, al Premio Nacional de Calidad Malcolm Baldrige (PNCMB) en EEUU, y al Premio de Calidad Europeo.

- El Modelo EFQM de Excelencia: La EFQM se crea en 1988 con el apoyo de 14 importantes empresas europeas para la promoción de la calidad en Europa. La EFQM, con apoyo de la Organización Europea para la Calidad (EOQ) y la Comisión Europea, crea en 1991 un modelo de Gestión de la Calidad, el cual representa los criterios de evaluación de un premio para reconocer la excelencia de las empresas europeas. Es lo que se conoce como el Premio Europeo a la Calidad (EQA), al cual subyace un modelo con una serie de criterios al que se denomina MODELO EFQM DE EXCELENCIA. EI Modelo ha sido el resultado de experiencias de empresarios europeos líderes en la gestión de empresas y de la experiencia de premios anteriores como el Deming en Japón y el Malcolm Baldrige en USA. 


\subsubsection{Normas de Calidad Internacionales.}

- ORGANIZACIÓN INTERNACIONAL DE NORMALIZACIÓN (ISO)

La Organización Internacional de Normalización (ISO) es una federación mundial de organismos nacionales de normalización (Comités miembros de la ISO). Los comités técnicos de la ISO se encargan por lo general de la elaboración de normas internacionales. Los comités miembros nacionales interesados por un tema particular tienen el derecho de formar parte del comité técnico creado para este efecto. Las organizaciones internacionales, tanto gubernamentales como no gubernamentales, relacionadas con la ISO participan igualmente en estos trabajos.

La publicación en 1987 de las Normas Internacionales de la serie ISO 9000 obedeció a exigencias básicas de los programas genéricos de gestión de calidad.

Las normas de la serie ISO 9000 están redactadas en términos genéricos y son igualmente aplicables a empresas de servicios tales como bancos, hospitales, hoteles y restaurantes. Se desarrollaron principalmente para ser usadas dentro de las empresas y en las relaciones entre comprador y vendedor. Esta última aplicación implicaba para las empresas la posibilidad de evaluaciones múltiples y, en cierto número de países, la práctica de confiar la evaluación de sistemas de calidad de proveedores a organismos terceros, lo cual se ha desarrollado rápidamente.

Mientras que los certificados ISO 9000 en cuestión no se entregan en nombre de la ISO, se ha considerado necesario que la ISO juegue un papel en la diseminación de información sobre los programas nacionales que operan en los países miembros.

- BS 5750, LA NORMA

La BS 5750 es una serie de normas que regulan la calidad en el Reino Unido, apareciendo antes de ISO 9000, y que sigue vigente en esta nación, siendo equivalentes sus normas a las de esta última. 
La norma BS 5750, que es la de los sistemas de calidad, tiene su origen en las compras militares. Debido a la naturaleza crucial de esos productos y a los problemas prácticos de investigar los productos defectuosos usados en las acciones, se puso énfasis en ver cómo se hacen los productos y en los sistemas de calidad de los proveedores correspondientes. Se fijaron normas apropiadas para los sistemas de calidad, incluso a nivel internacional (OTAN) para los gobiernos que cooperan y los gobiernos aliados y con normas nacionales correspondientes. En el Reino Unido hay una variedad de normas de la Defensa, por ejemplo, la 05-21.

Cuando esas normas se establecen y se dan a conocer en toda la industria, aumenta la demanda de bienes o servicios comparables, fuera de los terrenos de la defensa. Es probable que esto haya conducido en 1.979 a la BS 5750. La versión corregida en 1.987 de la BS 5750 fue más amplia y continúa siendo la norma reconocida y aceptada para los sistemas de calidad.

No solo se redactó la BS 5750 para cubrir actividades ajenas al abastecimiento militar, sino que también se trató de hacerla aplicable a nivel mundial. Por consiguiente, se puede aplicar a todos los sistemas de calidad de todas las organizaciones comerciales. Esto significa que además de ser pertinente en el caso de los fabricantes, también lo es para los proveedores de servicios; sin embargo, es improbable que un proveedor de servicios se sienta estimulado al leer la norma BS 5750. Resulta claro que el lenguaje, la terminología y las aparentes suposiciones, son más accesibles para el fabricante que para el proveedor de servicios. Incluso hay fabricantes ajenos al terreno de la ingeniería que sienten que la norma se escribió sin tomar en cuenta sus negocios. A pesar de esto, se intenta que la BS 5750 sea de aplicación universal; y, en la práctica, los elementos de fabricación de la norma se pueden adaptar en todos los casos a la situación de los servicios, aún cuando estos son la base principal. 
La serie ISO 9000 es la norma internacional equivalente para los sistemas de calidad y, al igual que la BS 5750, está disponible en una serie de documentos. Aparte de algunas diferencias sobre la forma en que se expresa, el contenido de la serie ISO 9000 es igual al de la BS 5750, y las partes claves tienen sus números de equivalencias. Estos equivalentes no son coincidencia. La serie ISO 9000 se modeló sobre la BS 5750 , que fue la pionera de los sistemas de calidad a nivel internacional.

\subsection{La Calidad en la Administración Pública}

El primer hecho relacionado con la calidad pública en un sentido moderno fue la Ley de compras de la Armada Británica del siglo XVII que estableció un sistema de normalización para asegurar la calidad de los pertrechos militares.

En cuanto a premiar la calidad la historia es un poco más reciente, tenemos como antecedentes el premio Deming de Japón de 1959, y más tarde en 1987, el Malcolm Baldrige Award de EE.UU. dependiente del (NIST) The National Institute of Standards and Technology. (Equivalente a la fundación Empresaria para la Calidad y la Excelencia FUNDACE en Argentina).

Para 1968 el ejército de los EE.UU genera la norma Military Standard. Pero el primero que se ocupa de la calidad en el Estado es el "Presidential Award For Quality" del Internal Revenue Service de 1988 que presentaba pautas para el Estado en Total Quality Management. De allí hay que esperar hasta la Carta Compromiso con el Ciudadano del Gobierno Británico (The Citizen's Charter fue una política Británica lanzada en 1991) y finalmente llegamos al premio nacional de la calidad de la republica argentina en $1993^{14}$.

\footnotetext{
${ }^{14}$ Armido I. P. Bonelli - Evolución de la Gestión de la Calidad en el Sector Público Nacional 1994 - 2010
} 
La diferencia sustancial de introducir la calidad en el sector publico radica en que el Estado es Hacienda erogativa, y como tal sus resultados deben ser medidos bajo parámetros distintos a los del sector privado, y lo mismo sucede con los conceptos de lealtad del cliente y de desarrollo de proveedores, por ejemplo. Ello indica la necesidad de la existencia de un modelo adaptado al sector, tal como ocurre en el sector privado con las empresas sin fines de lucro.

Argumentos que justifican un análisis de calidad en el sector público:

- La magnitud de su actividad económica en el agregado de la economía.

- La ausencia de competencia en gran parte de los servicios públicos provistos.

- La necesidad de justificar resultados frente a los presupuestos establecidos.

- El impacto de los servicios públicos e institucionales en el crecimiento económico y el bienestar de la población.

\subsubsection{Cambio de paradigma en la administración pública}

Los "60 fueron los años donde se acabó el sueño del Estado de Bienestar, años de crecimiento sistemático de los beneficios del Estado benefactor en las democracias capitalistas. Esto derivó en una situación en la cual el grueso de los países capitalistas tenía sectores públicos que rayaban en el orden de no menos del 35\% del PBI hasta llegar a participaciones de hasta el 50 o $60 \%$ del PBI, lo cual deriva en un crecimiento geométrico del gasto público en aras de alcanzar la meta de la igualdad.

Las causas que generaron la crisis fueron ${ }^{15}$ :

- Incrementos en el precio del petróleo o crisis del petróleo: se consideraba que estaba sucediendo una inflación generada por una

${ }^{15}$ SCHWEINHEIM, Guillermo - Política y Gestión Pública Primera parte, pág. 5. 
enorme oferta monetaria, situación que queda demostrada cuando Nixon declara la inconvertibilidad del dólar.

- Estanflación, es decir: bajó la producción pero continuó el aumento generalizado de los precios; fue una historia absolutamente inédita para la historia del capitalismo que funcionaba hasta ese momento con otras leyes. Esto deriva en un progresivo estancamiento, nunca más el capitalismo volvió a crecer a las tasas que lo hizo entre 1945 y 1970.

Y además, un fenómeno nuevo:

- En los "70 empieza a aparecer una situación de despertar de la ciudadanía en materia de demanda de servicios. Así como los teóricos del marketing hablan de la revolución del cliente a partir de esa época, también los teóricos del mercado político (especialmente en las campañas electorales) hablan de la revolución del ciudadano; así como empieza a aparecer un consumidor más exigente, empieza a aparecer también un ciudadano más exigente. La sociedad deja de ser una sociedad de masas.

Para García Delgado en "Del Estado de Bienestar al Estado PostSocial"16, las causas de esta crisis son tanto económicas (crisis del modelo de sustitución regido por la demanda interna, globalización económica) como políticas (alternancia de regímenes autoritarios y democráticos, corriente liberal) y también internacionales (finalización de la Guerra Fría, predominio norteamericano, fin de la ideología) sociales (polarización de clases sociales) y culturales (nuevo paradigma: narcisista, individualista y consumista) Todos estos componentes, sumado al surgimiento y protagonismo de los Organismos Internacionales de Crédito y las organizaciones de la Sociedad Civil, hacen que el Estado pierda soberanía e independencia en la toma de decisiones, se debilite su capacidad de 
integrar socialmente a los habitantes y de configurar una identidad cultural y nacional.

Se puede tomar este escenario como una oportunidad nueva de repensar el Estado Nación y desarrollar de la mejor manera posible sus potenciales y ventajas competitivas. Para ello se hacía necesario construir una nueva cultura organizacional que imprimiera los elementos del nuevo paradigma

\subsubsection{La Capacidad Estatal y la Capacidad de Gestión}

Según un informe del Banco Mundial en 1997 titulado "El Estado en una etapa de transición"17, la misión que deberá afrontar el aparato estatal desde la crisis de los "70 es lograr el desarrollo sustentable, es decir, enfocar su acción en unir o relacionar lo social con lo económico, el progreso social con el crecimiento económico. Para esta unión es fundamental la noción de eficacia.

Se pretende que cada Estado enfoque su acción sobre los factores fundamentales de la sociedad y para ello es necesario realizar cambios y ampliar la capacidad estatal, esto es, la posibilidad de emprender y promover políticas de interés colectivo; y también la capacidad de gestión que es la habilidad para ejecutar de forma eficiente y concreta las decisiones tomadas a nivel político.

El Banco Mundial aclara a los países que el desarrollo no se logra estableciendo una estrategia o un modo de actuar que encaje idealmente en todos los Estados porque cada uno tiene particularidades que debe conocer para saber cómo aplicar el cambio. Sin embargo, sí puede establecerse un amplio marco de referencia que sirva de guía a los países.

La estrategia para todos los Estados es entonces, por un lado, amoldar sus funciones a su capacidad, es decir, ser consciente de los recursos y

17 [En línea] Disponible en web: www.worldbank.org 
de las capacidades que tiene para saber cómo y dónde aplicarlas, y por otro lado, revitalizar las instituciones públicas, esto es, establecer normas y controles para disminuir la corrupción; exponer a las instituciones a mayor competencia para desarrollar eficacia; propiciar una mayor participación ciudadana y descentralizar los servicios.

Oszlak ${ }^{18}$ define la capacidad estatal como la disponibilidad y aplicación efectiva de los recursos humanos, materiales y tecnológicos que posee el aparato administrativo y productivo del Estado para gestionar la producción de valor público. La capacidad de gestión se manifiesta en el grado en que las organizaciones consiguen resolver las cuestiones socialmente problematizadas que componen su agenda.

Para resolver las cuestiones centrales debe conciliarse la gobernabilidad, el desarrollo sustentable y la equidad distributiva con el equilibrio macroeconómico que contribuya a un determinado patrón de desarrollo. La gobernabilidad democrática definida por el Banco Mundial implica la existencia de voz y rendición de cuentas; estabilidad política; efectividad del gobierno; calidad regulatoria; imperio de la ley y control de la corrupción.

Por otro lado, los déficits de la capacidad estatal (base para la formulación de los componentes de fortalecimiento institucional) pueden darse en las siguientes categorías:

- Relaciones con reglas de juego (normas, culturas, sanciones) establecidas entre los actores participantes;

- Relaciones inter-institucionales disfuncionales, en tanto no se logren acuerdos en casos en los que se hallen involucrados dos o más actores institucionales;

- Déficit en los esquemas organizativos y de asignación de funciones a los participantes; 
- Inexistencia o insuficiencia de recursos materiales y humanos requeridos para el desarrollo de las actividades del proyecto;

- Relaciones con políticas hacia el personal estatal involucrado;

- Falencias en materia de conocimiento, información o destrezas de las personas involucradas.

La superación de estos déficits que posibilitará la producción de valor público dependerá de: que los actores involucrados fijen y/o acepten en su interacción ciertas reglas de juego claras y previsibles; que sus responsabilidades y relaciones se basen en acuerdos y compromisos preestablecidos; que las competencias y actividades institucionales sean asignadas a los responsables de producir, intervenir o controlar las procesos de gestión; que los recursos materiales y humanos sean suficientes en cantidad y calidad y coherentes en términos de una adecuada función de producción; que las políticas de recursos humanos sean congruentes con las exigencias de una función pública profesionalizada y que las capacidades individuales de los participantes sean apropiadas en su correspondencia con los perfiles de los cargos o las asignaciones de tareas en los distintos procesos de gestión.

Para conocer la existencia y profundidad de los déficits de capacidad institucional deben procederse a estudiar los distintos sectores que componen al Estado. Los pasos que describe Oszlak son:

a) Identificación de los organismos públicos y privados que conforman el entramado institucional en los sectores definidos como estratégicos para el fomento a la creación de valor agregado estableciendo sus respectivos responsables (competencias y resultados) en el diseño e implementación de políticas sectoriales.

b) Construcción de mapas de relaciones institucionales, identificando la naturaleza de sus respectivos roles en la producción de valor, en la intervención en procesos que lo generan o en el control de estos procesos. 
c) Identificación de déficits a partir de las principales políticas y procesos de gestión internos de las mismas.

d) Estimación de la gravedad relativa de los déficits identificados y su impacto sobre las capacidades de gestión del Estado de cada una de las instituciones sectoriales.

Por lo tanto, el proceso de reforma y modernización del Estado comprende la reconstrucción de las capacidades institucionales del Estado, con una administración inteligente que pueda responder con agilidad y eficiencia en aquellas áreas que demandan su actuación y con el propósito de mejorar la eficacia, eficiencia, calidad y transparencia ${ }^{19}$.

Por su parte, el Consejo Latinoamericano para el Desarrollo (CLAD) determinó las notas principales de la reforma administrativa ${ }^{20}$ :

- Profesionalización de la alta burocracia;

- Responsabilización de los agentes públicos;

- Descentralización de servicios a entes subnacionales;

- Desconcentración en agencias especializadas;

- Control de resultados;

- Control social;

- Orientación al ciudadano.

El cumplimiento de estas notas, a través del desarrollo de sistemas administrativos, la modernización de la gestión de los procesos, la formación de recursos humanos para el manejo de tecnologías de gestión y de control de políticas públicas, permitiría que en un tiempo, lograran modificarse las conductas no sólo del funcionariado público, no sólo de los profesionales con aspiraciones en el sector público sino también de la clase política ${ }^{21}$.

19 ABAL MEDINA, Juan M. Lineamientos estratégicos para la innovación de la gestión en Argentina, páginas 8 y 9.

${ }^{20}$ CLAD, UNA NUEVA GESTIÓN PÚBLICA PARA AMÉRICA LATINA; documento oficial 1.998.

${ }^{21}$ SCHWEINHEIM, Guillermo - Política y Gestión Pública Primera parte, pág. 2. 


\subsubsection{La Nueva Gerencia Pública}

Del debate por la crisis del antiguo modelo surge la Nueva Gerencia Pública (NGP), entendida como una forma nueva de administración cuyo objetivo final es, resumidamente, satisfacer las necesidades públicas con eficiencia, eficacia y efectividad. Algunas diferencias entre el modelo burocrático y el modelo de la $\mathrm{NGP}^{22}$ son:

Orientación: El Estado, entre fines del siglo XIX y los años '70, estaba orientado por el cumplimiento de normas y procedimientos, mientras que la orientación básica del modelo de gerencia pública o gestión por resultados, tiende a la obtención de resultados de los procesos. Es una política de compromiso y responsabilidad por resultados. Los instrumentos de gestión son la previsión, planeamiento, coordinación, evaluación y control; éstos dos últimos permiten medir los resultados comparado a responsabilidades asumidas y compromisos ante la ciudadanía, la Alta Dirección, etc. La gestión por resultados implica la interacción y lectura crítica permanente entre el escenario (marco en el que se desenvuelven los actores) la estrategia (dispositivo de construcción de viabilidad política-técnica del proyecto de gobierno) y la estructura (conjunto de relaciones orgánicas, funcionales y logísticas desde donde se alinea la acción gubernamental)

Cuestión presupuestaria: Para el nuevo paradigma, el presupuesto se realiza por objetivos y resultados. Ya no importa el tamaño del gasto por partida, como era anteriormente, sino que se pone el acento en presupuestar en base a los resultados que se pretenden obtener. Es necesario entonces, desarrollar los métodos de planificación estratégica y las pautas que sistematicen los compromisos con los ciudadanos para vincular los resultados y las respuestas a las demandas de la ciudadanía y requerimientos del proyecto del gobierno.

Criterios de control: Los criterios de control del paradigma administrativo son criterios de regularidad; que las acciones de los administradores

${ }^{22}$ SCHWEINHEIM, Guillermo - Política y Gestión Pública Primera parte, pág. 6. 
públicos hayan cumplido con la norma. El criterio de control en el nuevo modelo es el de economía en adquisición de los insumos que usa en general el Estado para su producción institucional; el criterio de eficiencia en la relación entre los costos o insumos. El control está en determinar el grado de economía y efectividad, es decir, cuánto se cuidaron los recursos siempre y cuando se hayan satisfecho las necesidades tal cual las requería el usuario.

Proceso decisorio: Mientras que en un caso es un proceso burocrático, en el otro modelo el proceso decisorio es por proyectos y por objetivos.

Sobre las prestaciones: El modelo anterior se basa en el supuesto de la universalidad de las prestaciones. Esto es: el Estado le garantiza a todos las mismas prestaciones.

En el paradigma de gestión pública o por resultados, también se sostiene el principio básico de la universalidad de la satisfacción, esto es, que todos los grupos ciudadanos que requieran bienes públicos diferenciados por parte del Estado, efectivamente los alcancen. Ahora bien, la NGP plantea la necesidad de segmentar las prestaciones porque la sociedad no tiene el mismo grado de homogeneidad que tenía en los años '30 a '70; en consecuencia, es necesario identificar claramente las necesidades de bienes públicos de los distintos sectores de la ciudadanía porque si no, no es posible la gobernanza.

De esta forma, el primer modelo tenía claramente una orientación a un ciudadano universal mientras que el nuevo modelo, tiene una orientación "al cliente público" o "al ciudadano cliente" o al "ciudadano usuario". Anteriormente se subsidiaba la oferta, todo lo que el Estado producía. El nuevo modelo subsidia la demanda, es decir, focaliza la prestación de servicios de acuerdo a los sectores que más lo necesitan y está presente cuando no hay otra organización (no gubernamental o privada) que pueda cumplir con la satisfacción de una determinada necesidad. 
Carrera administrativa: El viejo modelo plantea que a la alta dirección pública se llega por carrera administrativa; un empleado obtiene un puesto y a fuerza de permanencia sube de escalafón. El nuevo modelo, en realidad, plantea la necesidad de que haya una gestión gerencial (de los estamentos directivos) por competencias y recursos. Es decir: que solamente llega a la alta dirección pública aquél que tiene competencias para el cargo y al mismo tiempo se mantiene en él y es remunerado en función de los resultados efectivamente obtenidos.

La NGP, en términos generales, supone un Estado más descentralizado, menos control jerárquico y mayor rendición de cuentas. La participación produce resultados significativos que aseguran el éxito y la efectividad. Además, esta nueva visión reclama mayor capacidad para el análisis estratégico, comunicaciones activas, potenciación de las capacidades organizacionales y construcción de redes institucionales.

El paradigma descrito, introducido en algunos países del área anglosajona (Inglaterra, Australia, Nueva Zelanda, Canadá) en los años "80, fue asumido con mucha fuerza por el gobierno norteamericano de Clinton en los años "90 y de allí promovido a varios países latinoamericanos. En nuestro caso, se introdujo enmarcado en el Consenso de Washington que conforma el paradigma neoliberal, conociéndose los resultados que en esa época tuvieron las decisiones tomadas en términos cambiarios, de mercado, financieros, de empleo y de distribución.

Actualmente, no se conoce otra alternativa al modelo de la NGP y prueba de ello en Argentina es la vigencia del decreto 103/2000 de Modernización del Estado, que propone la utilización de metodologías como: planeamiento estratégico, formulación de programas, gestión por resultados, indicadores de gestión, cartas compromiso, acuerdos, programas, gobierno electrónico, etc ${ }^{23}$.

23 SCHWEINHEIM, Guillermo - Política y Gestión Pública, Segunda parte, pág. 3. 
En definitiva, puede discutirse el modo en que fue implementada en la Argentina la NGP, más no tanto su contenido, que supone la consecución del bien común a través de una institucionalidad pública con valores arraigados.

Se llevan casi tres décadas de transformaciones en la administración pública que comprenden distintos planos: (1) Acercamiento entre las técnicas de gestión del sector privado y público; (2) Cambio de un modelo legal-funcional a uno de gestión con énfasis en los resultados y (3) Mayor preocupación por la eficiencia, la calidad y la efectividad.

Tanto la Gestión de Calidad como la Nueva Gerencia Pública (NGP), parten de la preocupación por encontrar las bases duraderas para fortalecer la competitividad y la eficiencia de las empresas e instituciones dentro de un nuevo contexto de competencia, consumo y reconocimiento de la calidad como principio catalizador de la demanda, el reconocimiento social y la legitimidad gubernamental.

\subsubsection{La administración pública Argentina.}

La administración pública es el conjunto de organizaciones que realizan actividades permanentes y concretas mediante las cuales se satisfacen intereses y/o demandas colectivas y/o individuales. Las tareas con las que debe cumplir son: seguridad exterior; orden interno; obtención de recursos; respuesta a las demandas de los individuos de la sociedad y conducción de la sociedad hacia objetivos de integración social, crecimiento económico y desarrollo sustentable.

A su vez, la administración pública se divide en estatal y no estatal. La primera es el conjunto de organizaciones que pertenecen al Estado, tienen patrimonio del Estado y los funcionarios son agentes que trabajan para el Estado. La administración pública no estatal comprende organizaciones que no pertenecen al Estado, satisfacen necesidades mediante prestaciones, no tienen fines de lucro, se basan en la 
solidaridad y el compromiso y son financiados tanto por el Estado como por aparatos del sector privado.

Dentro de la administración pública estatal, la administración centralizada comprende las organizaciones articuladas en forma piramidal, jerarquizada; no tienen personalidad jurídica propia y concentran la toma de decisiones en los vértices. Por otro lado, las organizaciones de la administración pública estatal descentralizada tienen personalidad jurídica propia y no están articuladas entre sí.

Todas estas características organizativas del Estado argentino se dan en el nivel nacional y provincial. Tradicionalmente, los rasgos de la administración pública estatal son de tipo burocráticos. Esto comprende: organizaciones conforme a la autoridad, división del trabajo, funcionamiento en base a normas, carácter de asalariados de los agentes y jefes burocráticos.

Las características descritas traen como debilidades el devenimiento de la norma como un fin en sí y no como un medio; despersonalización de las relaciones; lentitud en la tramitación y rigidez en la organización. De allí que haya surgido la necesidad de solucionar estos déficits y es a través del debate que se van configurando nuevos modelos de administración, hasta desembocar en un cambio de paradigma que supone un enfoque distinto desde el cual interpretar el funcionamiento del Estado.

\subsubsection{Experiencia Iberoamericana y nacional.}

Según las experiencias exitosas estudiadas respecto de gobiernos que buscaban mejorar la calidad de los servicios públicos a través de la modernización de la gestión del Estado (Scott y Shieff-1993; Wisnieswski y Donnelly-1996; Gaster-1996; Donnelly y Shiu; Wisniewski2001; Gutiérrez y Jorge-2008), se puede establecer que no hay una sola 
forma de asegurar mejores resultados en la calidad de los servicios prestados por las entidades del estado.

En consideración a lo anterior es importante ver el desempeño de Iberoamérica en cuanto a temas de calidad pública se refiere. $Y$ es que con el advenimiento y la evolución de la economía a nivel global las economías emergentes no podrían dejar pasar la ola de la calidad adoptadas por la Nueva Gerencia pública (NGP). Por este motivo es trascendental la decisión que se tomó en la décima Conferencia Iberoamericana de Ministros de Administración Pública y Reforma del Estado (San Salvador, El Salvador, 26 y 27 de junio de 2008) y Adoptada por la XVIII Cumbre Iberoamericana de Jefes de Estado y de Gobierno (San Salvador, El Salvador, del 29 al 31 de octubre de 2008) en donde se aprobó la Carta Iberoamericana de Calidad en la Gestión Pública de la que cito el siguiente párrafo que encamina el desarrollo de las políticas de calidad publica:

"La adopción de estrategias de innovación, racionalización y mejora de la gestión pública, orientadas por la calidad, permitirá a las Administraciones Públicas iberoamericanas posicionarse favorablemente frente a la incertidumbre, reforzar su influencia en un entorno dinámico y complejo y acometer el necesario desarrollo organizativo para la gestión del cambio y la formulación de soluciones de mejora creativas, con el fin de cumplir al máximo las expectativas de la ciudadanía, proporcionando un instrumento para lograr la coherencia en la dirección estratégica a seguir.

La Carta Iberoamericana promueve el establecimiento de un enfoque común acerca de las nociones de calidad y de excelencia en la gestión pública, a partir del cual se adopte un conjunto de principios $y$ orientaciones que sirvan de referencia a las diferentes Administraciones Públicas iberoamericanas en la formulación de sus políticas, planes, modelos y mecanismos que permitan la mejora continua de la calidad de su gestión pública. La implementación de los principios y orientaciones deberá adaptarse a la diversidad de las condiciones de las naciones 
iberoamericanas, al igual que la adopción de las correspondientes acciones e instrumentos sugeridos para la mejora continua de la calidad en la gestión pública.

Cabe señalar que, en Iberoamérica existen modelos de calidad con una perspectiva global e integral, como son los establecidos por varios Premios Nacionales a la Calidad y normas específicas para el sector público como es el caso de Argentina, Brasil, Colombia, Chile y Portugal ${ }^{-24}$.

Este avance que proporcionado por la Carta Iberoamericana de Calidad de la gestión pública junto con la nueva gerencia publica que se estaba implementando desde finales de los años '80 en Latinoamérica, desencadeno que los países de la región diseñaran nuevos mecanismos legales para encaminar el desarrollo del sector público hacia la consecución de nuevos modelos con estándares administrativos enfocados en la calidad; teniendo como objetivo satisfacer las necesidades básicas de los servicios que la comunidad demandaría.

En la argentina podemos destacar el desarrollo en el tema desde la creación del Decreto 1474/94:

El decreto del Poder Ejecutivo Nacional $n^{\circ}$ 1474/94 crea el Sistema Nacional de Normas, Calidad y Certificación, regulando así las actividades de normalización y regulación de la conformidad en el ámbito estrictamente voluntario. Este sistema está estructurado a partir de un Consejo Nacional de Normas, Calidad y Certificación, integrado por representantes de las diversas áreas del gobierno nacional convocados por la autoridad de aplicación del Decreto, la Secretaria de Industria, Comercio y Minería de la Nación (SICyM). Este organismo cuenta con la asistencia de un Comité Asesor del que participan los representantes de todos los sectores no gubernamentales involucrados.

${ }^{24}$ Carta Iberoamericana de calidad en la gestión pública ( San Salvador, El Salvador, del 29 al 31 de octubre de 2008) 
Debajo de este nivel de decisión política se encuentran los dos organismos operativos encargados de realizar la gestión de todo el sistema:

- El organismo de Normalización (IRAM).

- El organismo Argentino de Acreditación (OAA).

El primero se encarga de centralizar el estudio y aprobación de normas técnicas, base esencial de todo sistema nacional de calidad, y, el segundo está a cargo de la acreditación de los organismos de certificación, de los laboratorios de ensayo y de calibración y de los auditores, para lo cual debe seguir pautas de evaluación basadas en las recomendadas en las guías ISO/IEC correspondientes.

En el año 1995 la Secretaria de Industria, Comercio y Mineria de la Nación suscribe un convenio con el Instituto Argentino de Normalización (IRAM) por el cual se lo designa como Organismo Argentino de Normalización, a los fines de la aplicación del decreto 1474/94.

En el año 1996 se constituye el Organismo Argentino de Acreditación (OAA) dentro del esquema creado por el Decreto 1474/94 bajo la forma de asociación civil sin fines de lucro.

El sistema Nacional de Normas, Calidad y Certificación brinda instrumentos confiables a nivel local e internacional para certificar sistemas de calidad, productos, servicios y procesos a través de organismos de normalización, acreditación y certificación integrados de conformidad con las normas internacionales vigentes.

El Decreto Fundamenta la creación del Sistema Nacional de Normas, Calidad y Certificación:

- El Estado debe velar por el aseguramiento de la calidad en la organización tanto de los organismos de normalización como de acreditación para lo cual deberá celebrar convenios mediante los 
cuales se establezcan las obligaciones de las entidades que asuman dichos roles.

- Existen organismos internacionales encargados de emitir normas de calidad de cumplimiento voluntario, las que empleadas bajo estrictos modelos de organización y aplicación facilitan la aceptación de bienes y servicios bajo ellas certificados en la mayoría de los mercados externos.

- Para obtener la amplia aceptación de las certificaciones generadas por el Sistema además de contar con un eficiente sistema de acreditación y certificación resulta conveniente impulsar la celebración de acuerdos de reconocimiento mutuo con organismos similares de prestigio internacional.

\section{- IRAM}

Cada país tiene su Organismo Nacional de Normalización, en Argentina es IRAM, Instituto Argentino de Normalización y Certificación.

Es una asociación civil sin fines de lucro, que fue fundada en el año 1935 por representantes de los diversos sectores de la economía, del gobierno, y de las instituciones científico- técnicas. Los impulsaba el interés de que nuestro país contara con una institución técnica, independiente y representativa, una organización idónea para desarrollar las normas que requería una nación en pleno crecimiento.

A lo largo de los años y en mérito a su actividad, IRAM fue reconocido como Organismo Nacional de Normalización por sucesivas legislaciones nacionales. En el año 1994 fue ratificado en su función por el Decreto PEN N ${ }^{\circ}$ 1474/94, en el marco del Sistema Nacional de Normas, Calidad y Certificación.

En el campo de la normalización, IRAM es el único representante argentino ante las organizaciones regionales de normalización AMN Asociación MERCOSUR de Normalización y COPANT - Comisión Panamericana de Normas Técnicas, y ante las organizaciones 
internacionales ISO - International Organization for Standardization - e IEC - International Electrontechnical Comission - en este caso en conjunto con AEA - Asociación Electrotécnica Argentina -. IRAM lidera los comités técnicos nacionales que analizan los documentos en estudio, canaliza las propuestas nacionales, fija la posición de Argentina ante estos organismos y está presente en la conducción de varios de los comités técnicos internacionales.

En el campo de la certificación, representa a la Argentina ante las redes: IQNET - The International Certification Network - e IECEE Worldwide Systems for Conformity Testing and Certification of Electrotechnical Equipment and Components-. La actividad de IRAM en estos organismos excede lo técnico ya que participa de las instancias políticas de decisión de la mayoría de las organizaciones nombradas.

IRAM Normalización actúa hoy en los más diversos campos:

- Alimentos

- Ambiente

- Combustibles

- Construcciones

- Eficiencia energética

- Electrotécnica

- Energía

- Alimentos

- Ambiente

- Combustibles

- Construcciones
- Eficiencia energética

- Electrotécnica

- Energía

- Gestión de la calidad

- Química

- Mecánica

- Metalúrgica y siderúrgica

- Responsabilidad social

- Salud

- Seguridad

- Tecnología de la información

\subsubsection{Antecedentes de Sistemas de Calidad en Organizaciones Públicas Argentinas.}

El Sector Publico en la Argentina, desde sus municipios hasta las áreas y departamentos legislativos, de impuestos, de energía y de la magistratura, está adoptando rápidamente la norma ISO 9001:2000 
Sistemas de Gestión de la Calidad (SGC) como herramienta esencial para incrementar la eficiencia y el beneficio al público.

El sector público en la Argentina se halla en un proceso de creciente concientización sobre la necesidad de implementar la gestión de la calidad y sobre la importancia de conceptos y metodologías asociadas así como que tal gestión organizacional debe involucrarse en la acción política.

Esto se ve reflejado en el creciente número de organizaciones del sector público que introducen procesos de cambio en sus sistemas de gestión, y que alcanzan la certificación ISO 9001:2000. Esto se refleja también en los números de quienes han recibido "El Premio Nacional a la Calidad en el Sector Publico".

\section{Buenas Prácticas}

El concepto de "Buenas Practicas" está siendo rápidamente incorporado en el sector público de Argentina. La estrategia para establecer en el Sector Público de Argentina. La estrategia para establecer este mecanismo incluye el desarrollo y el acercamiento a las buenas prácticas en diferentes áreas de la administración pública que pueden convertirse en normas de referencia para la gestión pública.

\section{Municipalidades}

Se realizaron varios experimentos exitosos en diferentes lugares del país culminando en la certificación ISO 9001:2000 de Gestión Municipal. El mejor ejemplo tal vez, es la Municipalidad de Maipú en Calidad en 1994 y en 2004 habiendo alcanzado previamente la certificación ISO 9001:1994.

En el 2000, Maipú decidió certificar todos sus 24 procesos relacionados directamente con el ciudadano, completando el programa en Marzo 
2007. Como la ciudad pionera, sirve actualmente como una referencia nacional para organizaciones municipales y para procesos específicos.

Además, en el marco del IRAM, se ha desarrollado la norma IRAM 30300 , que provee una guía para la implementación de la norma ISO 9001:2000 en organizaciones municipales. La misma sirvió de antecedentes para la "ISO'S Internacional Workshop Agreement", IWA 4:2005, Sistemas de Gestión de Calidad - Guía para la aplicación de la norma ISO en los gobiernos locales.

También se han desarrollado programas para la implementación de Sistemas de Gestión de Calidad (SGC) por los gobiernos provinciales, en el marco de las actividades de la Federación Argentina de los Municipios (FAM) y a través de su centro para la Calidad y Modernización de la Gestión Municipal (CECAM).

\section{Datos Adicionales}

Se ha desarrollado una guía especial para el sistema judicial cubriendo la certificación ISO 9001:2000 en Cortes y Cámaras, con el cual cinco cortes de justicia ya han alcanzado la certificación, una de las cuales es la Corte Electoral Nacional con notables beneficios en el incremento de su efectividad.

Existen proyectos de certificación del Senado de la Nación y la Legislatura de la Ciudad Autónoma de Buenas Aires.

Se incrementaron certificaciones en organizaciones de control en todos los niveles y efecto multiplicador de esto en otras áreas de la administración pública, como los establecimientos educacionales y las construcciones públicas.

En la provincia de buenos aires se observa un progreso significativo en la implementación de SGC dentro de las organizaciones públicas. Entre los años 2004 y 2005 cuatro organizaciones mayores fueron habilitadas 
para alcanzar la certificación de calidad ISO 9001:2000: Departamento Rentas de la Provincia, Comisión de Apelaciones sobre Impuestos, la Organización Provincial de Control de la Energía y la Secretaria de Mercado. Además de ocho organizaciones de servicios claves, con soporte en capacitación intensiva y monitoreo.

En la región podemos destacar el modelo de gestión en el Estado Colombiano, que ha expedido normas como el Modelo Estándar de Control Interno, el modelo de gestión de la calidad, el sistema de desarrollo administrativo, el sistema de planeación, el sistema financiero - presupuestal, el sistema de medición, los cuales orientan su aplicación a la función administrativa de las entidades públicas.

Todo esto apoyado por El Instituto Colombiano de Normas Técnicas y Certificación, ICONTEC, que ha fijado una serie de normas para el control de la calidad, siguiendo los parámetros establecidos a nivel internacional por la Organización Internacional de Estandarización, ISO. A continuación se presentan éstas normas:

- NTCGP 1000:2009: Norma técnica de calidad de la gestión pública.

- MECl 1000:2005 Modelo estándar de control Interno.

- NTC - ISO 8402: Administración de la calidad y aseguramiento de la calidad.

- NTC - ISO 9000-1: Normas para la administración de la calidad y aseguramiento de la calidad. Parte 1: Directrices para su selección y uso.

- NTC - ISO 9001: Sistemas de calidad. Modelo para aseguramiento de la calidad en diseño, desarrollo, producción, instalación y servicio post - venta.

- NTC - ISO 9002: Sistemas de calidad. Modelo para aseguramiento de la calidad en producción, instalación y servicio post - venta.

- NTC - ISO 9003: Sistemas de calidad. Modelo para aseguramiento de la calidad en inspección y ensayos finales.

- NTC - ISO 9004-1: Administración de la calidad y elementos del sistema de calidad. Parte 1: Directrices. 
- NTC - ISO 9004-2: Administración de la calidad y elementos del sistema de calidad. Parte 2: Directrices para servicios.

- NTC - ISO 9004-3: Administración de la calidad y elementos del sistema de calidad. Parte 3: Directrices para materiales procesados.

- NTC - ISO 9004-4: Administración de la calidad y elementos del sistema de calidad. Parte 4: Directrices para el mejoramiento de la calidad.

- NTC -ISO 10005: Administración de la calidad. Directrices para planes de calidad.

- NTC - ISO 10013: Directrices para elaborar manuales de calidad.

\subsubsection{La reforma del estado Argentino}

En la década de los 90, la reforma del Estado estuvo orientada por la idea de que impulsar una gestión pública flexible y descentralizada y generar un nuevo paradigma de gestiones públicas que permitía mejorar la performance estatal, no sólo iba a redundar en un mejor desempeño del Estado sino que también iba a corregir algunos de los problemas importantes desde el punto de vista del funcionamiento de la democracia y de los problemas vinculados a la transparencia, la ineficiencia o el despilfarro en el sector público ${ }^{25}$.

\section{- PRIMERA ETAPA}

Se sanciona la Ley № 23.696 de Reforma del Estado, inaugurando así la primera etapa de Reforma. Por medio de dicha ley se declara la emergencia de las prestaciones, de los contratos y de la situación económica financiera de la Administración Pública centralizada y descentralizada. Se crean los programas de: Racionalización del sector público empresario, Privatizaciones, Emergencia del empleo y Propiedad Participada. Esta norma, otorga la posibilidad al Poder Ejecutivo Nacional, de intervenir todos los entes, empresas y sociedades del

\footnotetext{
25 SCHWEINHEIM, Guillermo - Política y Gestión Pública Primera parte, pág. 1.
} 
Estado, pudiendo cambiar la tipicidad jurídica de los mismos y además, se le otorga la facultad de crear empresas.

La Ley No 23.697 de Emergencia Económica del mismo año, pone en ejercicio el poder de policía, a fin de superar la situación de peligro colectivo que provocaba la emergencia socioeconómica. Otras medidas que se toman a través de esta norma son: Suspensión de subsidios y subvenciones así como también de los regímenes de promoción industrial y de promoción minera; Reforma de la Carta Orgánica del Banco Central; Régimen de compensación de créditos y deudas de particulares con el Estado Nacional; Régimen de compensaciones de créditos y deudas del Sector Público; Creación de una comisión para el saneamiento de Obras Sociales y Venta de inmuebles innecesarios.

Las dos leyes a las que se hizo referencia, son las que dieron comienzo al proceso de racionalización del Estado. Se las acompañó con otras normas (Decretos 435/90, 1.482/90 y 2.476/90, que profundizaron y aceleraron el proceso, poniendo énfasis en achicar el tamaño de la administración pública -con la consiguiente pérdida de puestos de trabajo- y reducir los procedimientos administrativos públicos) Además, se invitó a las provincias a dictar normas análogas, en la intención de avanzar sobre todo el territorio con este cambio ${ }^{26}$.

En esta primera etapa de Reforma, no se tomó el tiempo de planificar a dónde quería llegarse y cuáles serían los límites. De allí que sus consecuencias hayan sido un alto nivel de desempleo, la pérdida de importantes áreas (YPF, Gas del Estado, Aerolíneas Argentinas, etc.), la privatización considerada un fin en sí misma, el rol regulador del Estado no cumplido en los términos que debía configurarse y la descentralización de responsabilidades sociales sin los medios financieros para cumplirlas, lo que dejó a las provincias frente a un desafío para el que no contaban con los recursos necesarios.

\footnotetext{
${ }^{26}$ REFORMA DEL ESTADO - ETAPAS Cátedras Virtuales Organización y Gestión del Estado Documentos; diap. 1 a 15.
} 
A modo de caracterizar esta etapa de reformas, puede concluirse que se trató netamente de una reforma dura y hacia afuera (las estructuras, los procedimientos, los puestos de trabajo, etc.); donde se concentraron las energías en la acumulación financiera para otorgarle confianza al mercado nacional pero trajo como consecuencia el aumento del desempleo y a su vez generó el aumento de la brecha entre pobres y ricos. En definitiva, una reforma cuantitativa, fiscalista, cortoplacista y clientelar $^{27}$, adoptada en los términos que se planteó el Consenso de Washington, promocionado por un profesional académico -John Williamson- y que se define a través de los conceptos: disciplina o equilibrio fiscal, focalización del gasto social, reforma tributaria, liberación financiera, reforma cambiaria, liberalización del comercio exterior, apertura a la inversión extranjera directa, privatización de empresas públicas; todo ello apoyado por los organismos multilaterales de crédito $^{28}$.

\section{- SEGUNDA ETAPA}

La situación de déficit fiscal, descontento social, pobreza estructural y aumento de demandas llevó a que se pensaran dentro del Estado, nuevas reformas que atendieran las mismas, así se inicia la 2da etapa de Reforma, conocida como Modernización del Estado (Decreto 103 / 01) que significó: un proceso continuo y permanente acompañamiento de la participación del Estado y de la sociedad.

Los objetivos de esta etapa serían: cambios en el modo de gestión, fortalecimiento de las funciones indelegables del Estado y ampliación de la capacidad regulatoria del Estado. Sus ejes rectores fueron: la administración pública orientada al resultado, la gerencia pública basada en el mérito y la idoneidad y la ampliación del espacio público incrementando la participación ciudadana. La propuesta se tradujo en la gestión de los recursos humanos, la capacitación y el mejoramiento de los sistemas de compras y administración financiera.

\footnotetext{
${ }^{27}$ REFORMA DEL ESTADO - ETAPAS Cátedras Virtuales Organización y Gestión del Estado Documentos; diap. 16.

${ }^{28}$ SCHWEINHEIM, Guillermo - Política y Gestión Pública, Segunda parte, pág. 3.
} 
El marco normativo de este período está dado por:

- Ley 24.629 a través de la cual se le otorgan al Poder Ejecutivo Nacional, las facultades para: la reorganización del sector público, racionalización y eficiencia mediante la fusión, modificación, lograr la supresión total o parcial de los objetivos y las competencias superpuestas o innecesarias; la transferencia de organismos a las provincias; la supresión total de organismos descentralizados creados por ley y la privatización de servicios periféricos.

- Decreto n ${ }^{\circ}$ 558/96 que crea la Unidad de Reforma y Modernización del Estado encargada de: diseñar los cursos de acción para la culminación del Programa de Reforma; elaborar el Programa de Modernización del Estado; coordinar y realizar el seguimiento y control de las acciones; elaborar un proyecto de organigrama de la administración centralizada y descentralizada; revisar el Régimen Jurídico básico de la Función Pública, sus estatutos y escalafones; y colaborar con las provincias en sus procesos de Reforma y modernización.

- Ley 25.152 (1.999) sobre la administración de los recursos. En relación a la responsabilidad fiscal, establece el mecanismo para la elaboración del presupuesto y con la finalidad de profundizar la Reforma y aumentar la eficiencia y calidad de la gestión: autoriza al Jefe de Gabinete a celebrar acuerdos programas con unidades ejecutoras de programas presupuestarios y lo faculta a establecer premios por productividad al personal de dichos programas. Así mismo, instituye el Programa Evaluación de calidad del gasto, Información pública y de libre acceso y Fondo anti-cíclico Fiscal ${ }^{29}$.

La importancia que tuvo esta etapa fue la de crear herramientas que servirían para la transformación institucional y transversal, bajo los mismos principios y objetivos. Se incorporan así, la Carta Compromiso

\footnotetext{
${ }^{29}$ [En línea] Disponible en web: www.fcp.edu.ar, op. cit. diap. 17 a 24.
} 
con el Ciudadano, la Gestión por Resultados, la Planificación Estratégica, los Sistemas de Control de Gestión y de Calidad.

Resumidamente, se observa que la primera etapa de reforma estuvo dirigida a adecuar el tamaño y nivel de intervención del Estado a las condiciones generadas por la "crisis fiscal del Estado" y a los cambios ocasionados en la relación Estado - Sociedad a escala internacional; y que la segunda etapa, se inclinó a reformar aquello que tiene relación con el Estado como organización compleja, sus estructuras, procesos, tecnologías, valores, etc. ${ }^{30}$.

En palabras de Carlos Vilas: “Después de un primer momento que puso énfasis en el tamaño del Estado, la agenda de la reforma se orientó hacia la cuestión de la calidad de la gestión estatal, la utopía del estado mínimo dio paso a la necesidad del Estado efectivo. Adquirió preeminencia, consecuentemente, la atención a la calidad de la gestión pública, al diseño y funcionamiento real de las instituciones gubernamentales y a la modernización de la dotación de recursos humanos, operativos, tecnológicos, organizacionales..."31. Es decir, la calidad toma una nueva dimensión y ahora se la considera un activo político que impactará directamente en el fortalecimiento de la legitimidad institucional.

\subsubsection{El proceso de reforma provincial}

Los programas de reforma del sector estatal en las provincias tuvieron su origen en la crítica situación fiscal de las mismas a fines de 1995. Los gobiernos provinciales habían incrementado su nivel de gastos entre 1992 y 1994, lo que sumado a la crisis internacional y la fuerte dependencia fiscal de los tributos, hizo que los recursos cayeran incrementando la brecha con los gastos provinciales. Ésta fue la causa fundamental por la que las provincias iniciaron programas de reforma

\footnotetext{
${ }^{30}$ ESTESO, Roberto y CAO, Horacio LA REFORMA DE LAS ADMINISTRACIONES PÚBLICAS PROVINCIALES: BALANCE DE LA DÉCADA DE LOS '90 Y NUEVA AGENDA, pág. 14.

31 MOYADO ESTRADA, Francisco Gestión pública y calidad; Hacia la mejora continua y el rediseño de las instituciones del sector público, pág. 15.
} 
estructural y orientaron sus acciones a renegociar sus deudas y hacia la privatización o concesión de aquellas actividades de naturaleza empresarial.

Luego de este recorrido por el proceso de Reforma del Estado en su nivel nacional y provincial, se concluye que en esa época, los cambios en las primeras etapas estuvieron dirigidos a la aplicación de las tecnologías de la gestión privada en el ámbito de las organizaciones públicas, la racionalización de estructuras y procedimientos, la revisión de los procesos de toma de decisiones y el incremento de la productividad de los empleados públicos ${ }^{32}$. Además, el contexto que se vivía internacionalmente, proponía principalmente disminuir el déficit fiscal a través de las privatizaciones y las concesiones de las empresas y sociedades del Estado. Se trataba de reestructurar el aparato estatal a fin de dotarlo de un perfil más gerencial, tal como se presenta en las administraciones privadas. Todavía no se ve en esta época la instalación de la noción de Mejora Continua o Calidad en la Gestión, sino que se pensaba ganar eficacia a través de un Estado Regulatorio y más pequeño. Será a partir de mediados y finales de los "90 y con la 2da etapa de reforma, que comienza a pensarse en realizar reformas "hacia adentro" del Estado, haciendo caso a la tendencia denominada Nueva Gerencia Pública.

\subsubsection{La calidad en la Administración Pública Argentina}

Los cambios que se producen en "el pensar y el hacer" de la administración pública a partir de la Reforma referida, dan cuenta de la necesidad de modificar la cultura de carácter burocrático que existía en los años anteriores al '80, con el correspondiente modelo de Estado de Bienestar. La crisis en la que éste se introduce, hace de disparador para un nuevo paradigma, que es el conocido como NGP (Nueva Gerencia Pública).

\footnotetext{
32 LÓPEZ, Andrea La Nueva Gestión Pública: Algunas Precisiones para su Abordaje Conceptual, pág.9.
} 
Pero lo importante para este trabajo es dilucidar el aporte que en materia de mejoramiento de la gestión trajo este cambio de pensamiento. Se trata de desgranar el proceso, hasta obtener aquello que para la administración pública devino en proyectos y programas de mejora en su accionar, porque es a partir de este cambio que comienza a configurarse la conciencia de Calidad y Mejora Continua para el aparato público y ello se traduce en la aplicación y creación de herramientas concretas como:

- Premio Nacional a la Calidad: creado por Ley $N^{\circ} 24.127$ en el año 1.992. Es entregado actualmente por la Oficina Nacional de Innovación de la Gestión Pública, dependiente de la Subsecretaría de la Gestión Pública de la Jefatura de Gabinete de Ministros de la Nación. El Premio Nacional a la Calidad es una distinción a las organizaciones que han adoptado una filosofía de gestión que consiste en un enfoque sistemático para establecer y cumplir los objetivos de la Calidad en toda la organización. Un enfoque sistemático para desarrollarla, parte de planificar los objetivos de calidad teniendo en cuenta el conocimiento del cliente y sus necesidades o expectativas; desarrollar procesos capaces de detectar esas características; y finalmente, transferir esos planes a toda la organización.

- Gestión por Resultados: El período 2000 - 2001 puede definirse como el camino hacia una gestión por resultados instrumentado con el Plan de Modernización del Estado (Decreto 103/2.001) en el que se nombran las herramientas para realizar la transformación institucional. La Gestión por Resultados se instrumenta mediante acuerdos-programas y supone refocalizar la conducción y la gerencia de los organismos de la administración pública hacia un modelo de gestión que privilegie los resultados por sobre los procedimientos y la transparencia. Ello implica: la definición de resultados esperados realistas, basados en los análisis apropiados; la identificación de beneficiarios de programas y la elaboración de programas que respondan a sus necesidades; el seguimiento del progreso, a partir de los indicadores apropiados en función de los resultados y recursos utilizados; la identificación y la gestión de los riesgos, teniendo en cuenta los resultados y los recursos 
necesarios; el aumento de los conocimientos por medio de las lecciones aprendidas y la integración de ellos en las decisiones; y la producción de informes sobre los resultados obtenidos y los recursos utilizados ${ }^{33}$.

- Carta Compromiso con el Ciudadano: creada por Decreto 229/2.000 con el objetivo de generar un ambiente adecuado para el desarrollo de acciones tendientes a la Mejora Continua de los organismos públicos, incorporando la perspectiva de los ciudadanos en el diseño y prestación de servicios ${ }^{34}$. Por este mecanismo, el organismo interesado firma un documento por el cual se compromete a cumplir determinadas aspiraciones que ayuden a aumentar la satisfacción de los ciudadanos en contacto con ella. A partir de allí, se establecen estándares sobre las mejoras que se pretenden y se mide su desempeño en el tiempo a través de indicadores, a fin de conocer el nivel de cumplimiento de las metas, la necesidad de ajustes y el establecimiento de modificaciones pertinentes. De esta forma, el compromiso se va renovando continuamente, abarcando nuevas áreas y ampliando su radio de aplicación. Los organismos que logren resultados significativos en su accionar, son reconocidos por la Subsecretaría de la Gestión Pública a través de la difusión de su experiencia para que resulte de útil inspiración a otros organismos públicos.

- Planificación Estratégica: es el instrumento que ordena y prioriza la administración y gestión de los recursos públicos centrado en el cumplimiento de acciones o lineamientos estratégicos, en un período de tiempo determinado. El mismo permite sistematizar, ordenar y evaluar las acciones de las organizaciones del Estado con relación a las políticas públicas definidas para atender las demandas de la sociedad y de la gerencia pública comprometida con las metas institucionales. El proceso de planificación estratégica se cumple a través del establecimiento de: misión, visión y principios guía de la organización. Luego se realiza una evaluación del ambiente de la misma, definiendo las fortalezas y oportunidades, las debilidades y amenazas (FODA).

\footnotetext{
${ }^{33}$ REFORMA DEL ESTADO-ETAPAS Cátedras Virtuales Organización y Gestión del Estado Documentos; diap. 27 y 29.

${ }^{34}$ Idem.
} 
Posterior a esto, se diseña la estrategia y de ella los objetivos (dirección de la organización a largo plazo, una guía de decisiones sobre la asignación de recursos) Por último, se realizan los planes de acción ${ }^{35}$.

Las herramientas o instrumentos de gestión descriptos evidencian cómo en el nivel nacional se generó un ámbito y un espacio apto para que los organismos públicos con intención de modernizar y mejorar su gestión, encuentren el apoyo y asesoramiento correcto. Entre las normas que se dictan para instrumentar estas medidas, se encuentra el Decreto $n^{\circ} 20$ que crea en 1.999, la Subsecretaría de la Gestión Pública (ex-Secretaría de la Función Pública) a cargo de la Jefatura de Gabinete de Ministros de la Nación. Entre sus funciones se determinaron: Proponer medidas y normas reglamentarias para el diseño de la arquitectura organizacional de la Administración Pública Nacional (APN) para el desarrollo del recurso humano y empleo público; Proponer actos de simplificación y transparencia de los procedimientos administrativos, programa de calidad y mejora; Coordinar la red telemática nacional de información gubernamental; Intervenir en el diseño de pautas y criterios metodológicos con el objeto de lograr mayor eficiencia y transparencia en el sistema de contrataciones del Estado; Supervisar el Instituto Nacional de Administración Pública (INAP) ${ }^{36}$.

Se pueden mencionar dos condiciones ineludibles para embarcarse en un proceso de mejora de las capacidades estatales y de gestión continua de la calidad institucional, incorporación de los actores sociales en la gestión y perfeccionamiento de la prestación de servicios; éstos son: un contexto macroeconómico estable y sustentable y la institucionalización de procedimientos administrativos. Sucede que si en Argentina esto último no había sucedido para el momento de surgimiento de la nueva corriente de gestión pública, entonces se hace necesario buscar la forma de combinar los dos modelos y mientras se avanza hacia una administración orientada en los resultados, se trata de

\footnotetext{
${ }^{35}$ EVANS y LINDSAY - Administración y control de la calidad., pág. 223

${ }^{36}$ Disponible en web: www.sgp.gob.ar
} 
conciliar el apego a las normas y los procedimientos con la consecución de objetivos y resultados tangibles para la ciudadanía.

Queda claro que los cambios acaecidos luego de la crisis de los "70 traen como resultado una nueva forma de ver lo público, ahora considerando al ciudadano como factor activo y demandante. Esto sumado al surgimiento de las tecnologías de la información y la comunicación, crean una complejidad política y social para la que el Estado debe desarrollar instrumentos de acción y respuestas acordes a las necesidades. Se trata de un cambio cultural al interior de la lógica de lo público que deberá también transmitirse a la ciudadanía, a fin de alinear los objetivos de bien común y satisfacción de demandas.

\subsection{Dirección de Obras particulares de la Municipalidad de Ensenada.}

La Dirección Coordinadora de Obras Particulares de la Municipalidad de Ensenada atiende, asesora y realiza la aprobación municipal de los planos de construcción de viviendas uni o multifamiliares, comercios, industrias y toda otra obra civil, así como también los permisos para ampliaciones y demoliciones de obras.

La Dirección de Obras Particulares es el ámbito de la Municipalidad donde se efectúa el visado y aprobación de los planos correspondientes a las construcciones que se realicen en predios particulares dentro de la municipalidad, los cuales deberán ajustarse a la reglamentación vigente según lo que determinan los Códigos de Edificación y de Ordenamiento Urbano para la zona en la que se emplace el predio.

En esta dependencia es donde se tramitan: el permiso de obra (cuando se desea construir, refaccionar, ampliar, modificar y/o demoler obras nuevas y/o existentes); el empadronamiento (para incorporar obras clandestinas, construidas sin el permiso de obra correspondiente); y el permiso provisorio especial. 


\section{- INSCRIPCIÓN DE PROFESIONALES}

Los planos municipales que se presenten deberán estar firmados por profesionales matriculados ante los colegios respectivos (Arquitectos Ingenieros Técnicos) e inscriptos en el Registro de firmas de esta Municipalidad. Esta última se efectúa en la Dirección citada anteriormente, con la presentación de documentos personales, carnet profesional y constancia de matrícula al día.

\section{- SOLICITUD DE PERMISOS}

En caso de tratarse de obras nuevas o ampliaciones de construcciones existentes se solicitará un permiso de construcción, y una vez finalizadas las mismas se solicitará la aprobación y certificado de inspección final.

La tramitación y documentación necesaria para la solicitud de permisos de Construcción, Ampliación, Regularización, Conforme a Obra, Modificaciones Internas o Demolición, se efectuará atendiendo a lo siguiente:

a) Formularios: Se obtienen en Mesa General de Entradas.

b) Presentación Parcelaria: Se efectúa en la Dirección de Catastro. Requiere una copia heliográfica del plano municipal, una copia del título de propiedad. y listado de libre deuda de tasas municipales.

c) Visación Previa y Liquidación de Derechos de Construcción: Se efectúa en la Dirección de Obras Particulares en el término de 48 horas.

- Requisitos:

- Documentación retirada de Catastro

- Planilla de estadística forestación, de veredas y de constitución de domicilio en el partido.

- Copia de plano aprobado anterior si lo hubiere.

- En caso de demoliciones: memoria descriptiva de la demolición y certificado de desratización.

- Monto de derechos de construcción: definido según el destino de la propiedad 
d) Iniciación de Expediente con la presentación de legajo definitivo:

Se autoriza su iniciación en la Dirección de Obras Particulares ( $5^{\circ}$ piso) y se inicia, con el pago de un sellado, en Mesa General de Entradas ( $1^{\circ}$ subsuelo).

En caso de tratarse de permiso de construcción:

- Requisitos:

- Derechos de construcción abonados.

- Documentación retirada como Visado previo.

- 8 (ocho) copias heliográficas, una de ellas sellada en AySA S.A.

- Copia de plano, contrato y boleta de aportes profesionales visados en el colegio respectivo, originales $y$ dos fotocopias.

\section{Para demolición}

Acompañar memoria descriptiva y certificado de desratización.

En caso de tratarse de Plano Conforme a Obra:

- Requisitos

- Derechos de construcción abonados.

- Documentación retirada como visado previo.

- 8 (ocho) copias heliográficas.

- Plano original en papel calco $90 \mathrm{~g}$. si existe diferencia de superficie (sellado por AySA S.A.)

- Solicitud de certificado final de obra.

- $100 \%$ aportes previsionales de los profesionales actuantes.

Las consultas sobre aplicación de los Códigos de Edificación y Ordenamiento Urbano se efectúan por escrito ante la Dirección. 


\section{Metodología}

\subsection{Población y muestra}

La población objeto de la investigación está constituida por todos los habitantes de la Municipalidad de ensenada (55.629 según INDEC 2010) quienes poseen acceso a los servicios públicos brindados por el Municipio.

Se extraerá de la población definida una muestra aleatoria cuyo tamaño se calcula mediante la expresión:

$$
n=\frac{Z_{\alpha}^{2} \cdot N \cdot p \cdot q}{e^{2} \cdot(N-1)+Z_{\alpha}^{2} \cdot p \cdot q}
$$

La misma corresponde al cálculo del tamaño muestral cuando se desea estimar la proporción de éxitos $\mathrm{p}$, con universo conocido.

Dónde:

$\mathrm{N}=55.629$ habitantes, tamaño de la población.

$\mathrm{P}=$ Prevalencia (frecuencia) esperada del parámetro a evaluar, que en caso de desconocerse, se aplica la opción más desfavorable $(p=0,5)$, que hace mayor el tamaño muestral.

$Q=$ Complemento de la prevalencia esperada del parámetro a evaluar, es decir $1-p=0,5$

$Z=1,95996$ para $\alpha=5 \%$, o sea un nivel de confianza del $95 \%$

$E=6,21 \%$ error de muestreo

$\mathrm{N}=250$ personas a encuestar (tamaño de la muestra).

Como se trata de cinco áreas a estudiar, se ha distribuido el total de la muestra en iguales partes entre las mismas, lo cual implica un $20 \%$ del total para cada una de las siguientes áreas: 


\begin{tabular}{lr}
\multicolumn{1}{c}{ Área } & Encuestas \\
\hline Registro Automotor & 50 \\
\hline Dirección de Obras Particulares & 50 \\
\hline Defensa del consumidor & 50 \\
\hline Juzgado de faltas & 50 \\
\hline Recaudaciones y Cobranzas & 50 \\
\hline \multicolumn{1}{c}{ Total } & 250
\end{tabular}

\subsection{Tipo de Investigación}

Esta investigación puede ser caracterizada como descriptiva y cuantitativa, ya que busca obtener la información sobre la calidad del servicio de Obras Particulares de un municipio, de acuerdo a los objetivos propuestos.

\subsection{Técnicas de recolección de datos}

- Encuestas

El trabajo se realiza con información de fuente primaria, obtenida a través de un cuestionario de preguntas estandarizadas desarrollado en los Estados Unidos llamado escala SERVQUAL (service quality).

Se realizaron encuestas con el fin de relevar información de los ciudadanos de Ensenada con relación a cada área - servicio definido como alcance esta investigación.

Las encuestas realizadas contenían preguntas del tipo "cerradas" con el fin de facilitar la respuesta de los usuarios y posterior análisis. En el Anexo 1 se incorpora un modelo de la encuesta utilizada.

La aplicación de esta encuesta permitió obtener la información por parte de los ciudadanos, con relación al servicio que se le brinda al cliente en la 
Dirección Coordinadora de Obras Particulares de la Municipalidad de ensenada.

La encuesta, en general consta de cinco ítems, que responden al objeto de estudio. Éstos son:

I. Elementos Tangibles: Apariencia de las instalaciones físicas, equipos, personal y materiales de comunicación.

II. Confiabilidad: Habilidad para ejecutar el servicio prometido de forma confiable y cuidadosa.

III. Capacidad de Respuesta: Disposición y voluntad de los empleados para ayudar al cliente y proporcionar el servicio

IV. Seguridad: Conocimiento y atención mostrados por los empleados y sus habilidades para inspirar credibilidad y confianza

V. Empatía: Atención individualizada que ofrece la organización a los clientes.

Se solicitó a cada encuestado que califique su Expectativa y su Percepción de cada punto de cada dimensión en una escala del 1 a 5, correspondiendo el 1 a la mejor calificación y 5 a la peor opción.

Para llevar a cabo las encuestas, los encuestadores se presentaron en las oficinas municipales pertinentes para encuestar a los clientes que acudieron a dicha repartición municipal.

\subsection{Técnicas de Análisis}

El análisis de la información se llevó a cabo luego de la confección de una base de datos donde se tabulo la información obtenida de las encuestas. (Ver anexo 2 Base de datos)

Una vez confeccionada la base de datos -matriz de datos brutos- se realizaron técnicas de análisis Univariado sobre cada pregunta de la encuesta realizada, 
con el fin de evaluar "El Nivel de Satisfacción de los Clientes del Servicio del Obras Particulares de la Municipalidad de Ensenada".

Para cada una de las preguntas se medirá lo siguiente:

\section{- Distribución de Frecuencias:}

La distribución de frecuencias representara gráficamente la cantidad de respuestas para cada valor posible de respuesta.

\section{- Nivel de Satisfacción del Cliente:}

Nivel de satisfacción del cliente resulta de la resta entre la calificación otorgada a la expectativa que un cliente tiene sobre un aspecto del servicio y la percepción respecto del servicio obtenido. Dado que las calificaciones, para ambos aspectos, se definieron las categorías según la tabla que sigue:

\begin{tabular}{|c|c|c|c|}
\hline Expectativa & Percepción & Brecha & Situación \\
\hline 5 & 1 & 4 & Satisfacción Absoluta \\
\hline 5 & 2 & 3 & Mucho más que Satisfecho \\
\hline 4 & 1 & 3 & Mucho más que Satisfecho \\
\hline 5 & 3 & 2 & Bastante más que Satisfecho \\
\hline 4 & 2 & 2 & Bastante más que Satisfecho \\
\hline 3 & 1 & 2 & Bastante más que Satisfecho \\
\hline 5 & 4 & 1 & Algo más que Satisfecho \\
\hline 4 & 3 & 1 & Algo más que Satisfecho \\
\hline 3 & 2 & 1 & Algo más que Satisfecho \\
\hline 2 & 1 & 1 & Algo más que Satisfecho \\
\hline 5 & 5 & 0 & Satisfecho \\
\hline 4 & 4 & 0 & Satisfecho \\
\hline 3 & 3 & 0 & Satisfecho \\
\hline 2 & 2 & 0 & Satisfecho \\
\hline 1 & 1 & 0 & Satisfecho \\
\hline 4 & 5 & -1 & Algo Insatisfecho \\
\hline 3 & 4 & -1 & Algo Insatisfecho \\
\hline 2 & 3 & -1 & Algo Insatisfecho \\
\hline 1 & 2 & -1 & Algo Insatisfecho \\
\hline 3 & 5 & -2 & Bastante Insatisfecho \\
\hline 2 & 4 & -2 & Bastante Insatisfecho \\
\hline 1 & 3 & -2 & Bastante Insatisfecho \\
\hline 2 & 5 & -3 & Muy Insatisfecho \\
\hline 1 & 4 & -3 & Muy Insatisfecho \\
\hline 1 & 5 & -4 & Insatisfacción Total \\
\hline
\end{tabular}




\section{- Media aritmética (para Datos Agrupados en Tablas de Frecuencias):}

Para una serie agrupada en serie simple con frecuencias para obtener la media aritmética, se multiplica la variable $(x)$ por la frecuencia respectiva (f), luego se obtiene la suma de todos estos productos y luego a este valor se lo divide para el número de elementos (n).

Fórmula matemática:

$$
\bar{X}=\frac{\sum X f}{\sum f}=\frac{\sum X f}{n}
$$

X: Valor posible de cada respuesta.

f: Cantidad de respuestas para cada valor posible (Frecuencia).

n: Total de frecuencias o total de respuestas.

Luego, se medirá de cada Dimensión:

\section{- Media aritmética:}

Se calculará el cociente de la suma de los valores de la variable por el número total de respuestas.

$$
\bar{X}=\frac{\sum_{i=1}^{n} X_{i}}{n}
$$

X: Valor posible de cada respuesta.

n: Total de respuestas.

Por último, se medirá el "Nivel de Satisfacción del servicio": Valor que se obtiene de la diferencia de los valores obtenidos en la Expectativa y los valores obtenidos en la Percepción de los usuarios después de haber obtenido el servicio. 


\section{Resultados de la Investigación}

\subsection{Análisis descriptivo de la muestra}

Se realizaron 50 encuestas, siendo el perfil de los encuestados el siguiente:

\section{Género}

El $88 \%$ de los encuestados fueron Hombres:

\section{GENERO}

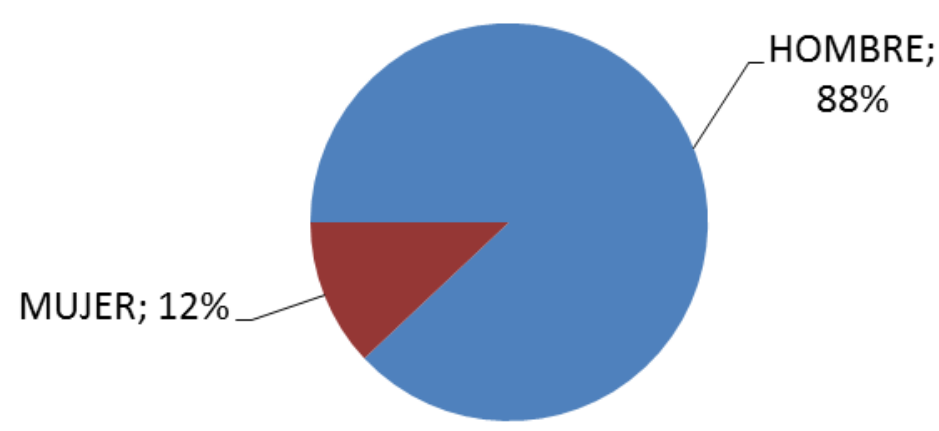

\section{$\underline{\text { Rango de edad }}$}

Ninguno de los encuestados tiene más de 60 años. El $30 \%$ de los encuestados tiene entre 30 a 40 años y el $28 \%$ de 50 a 60 años siendo el rango de edad el siguiente:

\begin{tabular}{cc|c|c}
\hline & EDAD & $\%$ & $\boldsymbol{f}$ \\
\hline 1 & Hasta 20 años & $0 \%$ & 0 \\
\hline 2 & De 20 a 30 años & $8 \%$ & 4 \\
\hline 3 & De 30 a 40 años & $34 \%$ & 17 \\
\hline 4 & De 40 a 50 años & $30 \%$ & 15 \\
\hline 5 & De 50 a 60 años & $28 \%$ & 14 \\
\hline 6 & Más de 60 años & $0 \%$ & 0 \\
\hline \hline & Total & $100 \%$ & 50
\end{tabular}




\section{EDAD}

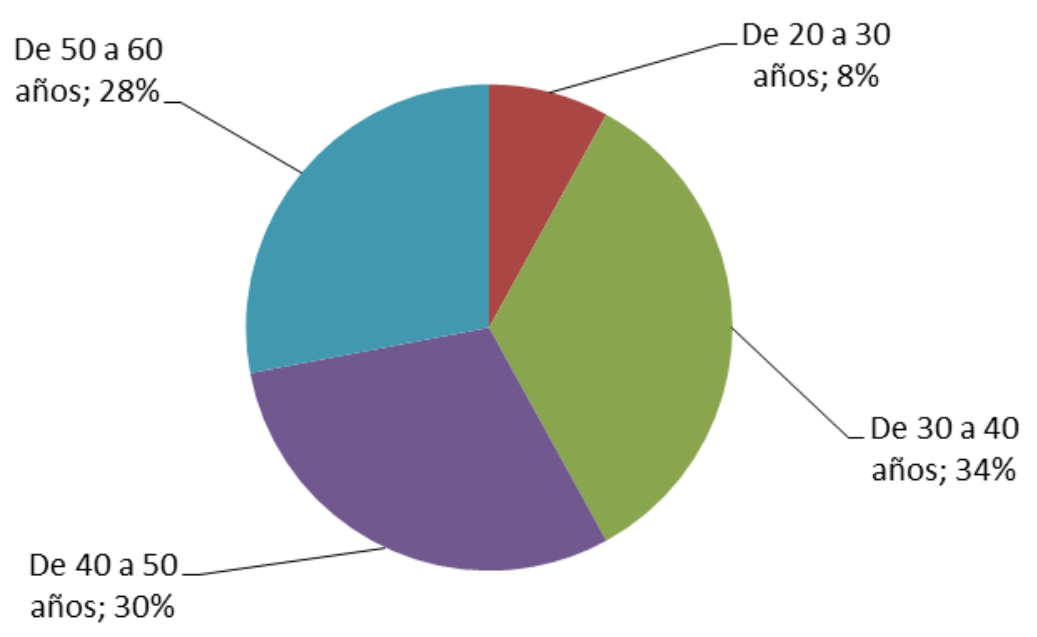

\section{Ocupación}

Ninguno de los encuestados tiene por ocupación Jubilado, Desempleado u otro. El 58\% de los encuestados tiene por ocupación "Empleado" y $42 \%$ "Independiente":

\begin{tabular}{llcc}
\hline \multicolumn{3}{c}{ Ocupación } \\
\hline 1 & Independiente & $42 \%$ & 21 \\
\hline 2 & Empleado & $58 \%$ & 29 \\
\hline 3 & Jubilado & $0 \%$ & 0 \\
\hline 4 & Desempleado & $0 \%$ & 0 \\
\hline 5 & Otro & $0 \%$ & 0 \\
\hline \hline & TOTAL & $\mathbf{1 0 0 \%}$ & $\mathbf{5 0}$
\end{tabular}

\section{OCUPACIÓN}

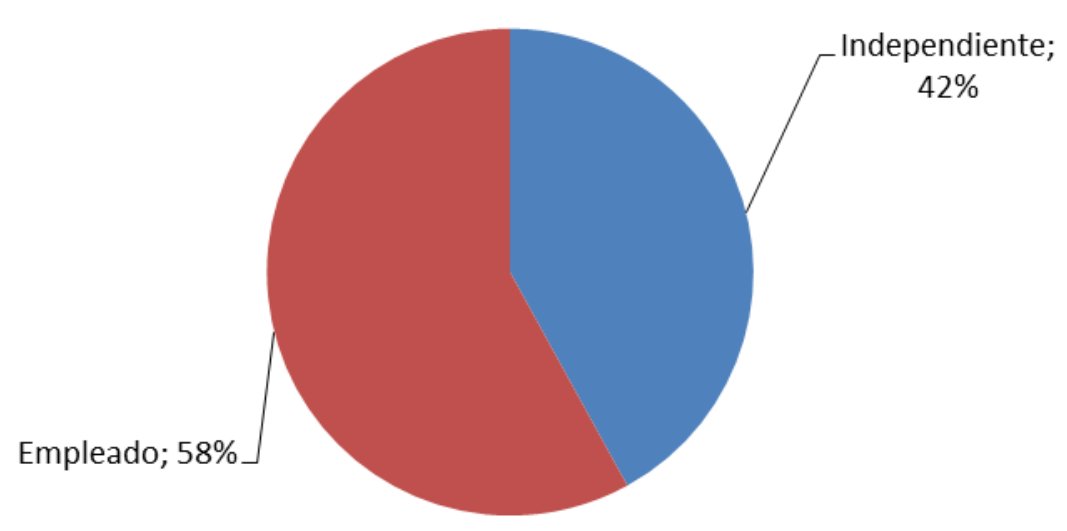




\section{Frecuencia de Utilización del Servicio}

Es un servicio que tiene un alto porcentaje de utilización Varias veces a la semana con el $46 \%$ seguido de una vez a la semana con el $30 \%$ y Ninguno de los encuestados utiliza el servicio a "Cada varios años",

\begin{tabular}{llcc}
\hline \multicolumn{4}{c}{ Frecuencia Utilización del Servicio } \\
\hline 1 & A diario & $4 \%$ & 2 \\
\hline 2 & Varias veces a la semana & $46 \%$ & 23 \\
\hline 3 & Una vez al mes & $30 \%$ & 15 \\
\hline 4 & Una vez cada seis meses & $12 \%$ & 6 \\
\hline 5 & Una vez al año & $8 \%$ & 4 \\
\hline 6 & Cada varios años & $0 \%$ & 0 \\
\hline \hline & Total & $100 \%$ & 50
\end{tabular}

\section{Frecuencia del Servicio}

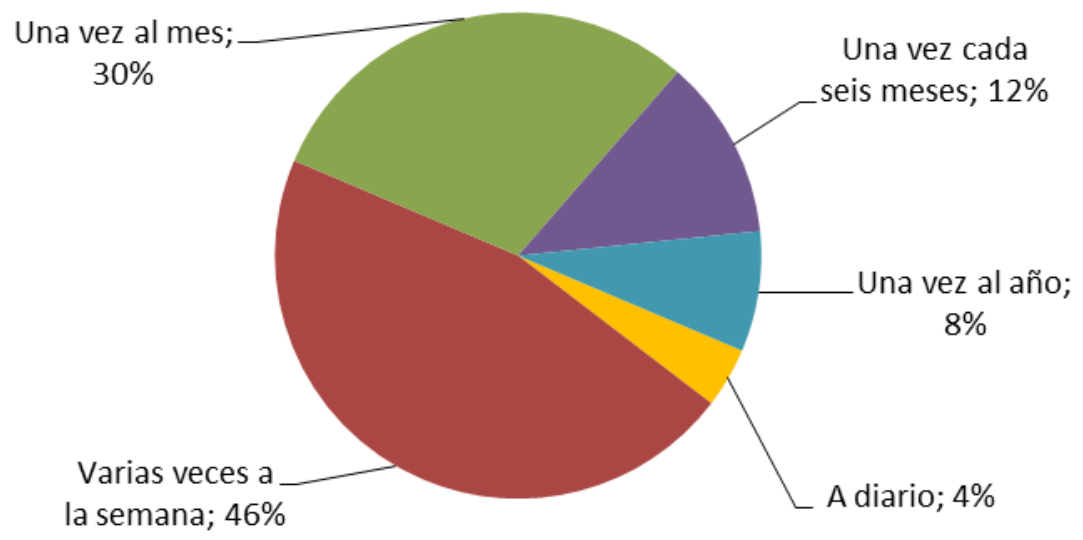

\section{Calificación de la Organización Integral del servicio}

Ningún encuestado califico al servicio como "Pésimo". El $70 \%$ califico al servicio como "Bueno", un $22 \%$ califico al servicio como "Regular" y solo $418 \%$ como "Malo".

\begin{tabular}{llcc}
\hline \multicolumn{4}{c}{ Calificación Organización del Servicio } \\
\hline 1 & Excelente & $4 \%$ & 2 \\
\hline 2 & Bueno & $70 \%$ & 35 \\
\hline 3 & Regular & $22 \%$ & 11 \\
\hline 4 & Malo & $4 \%$ & 2 \\
\hline 5 & Pésimo & $0 \%$ & 0 \\
\hline \hline & Total & $100 \%$ & 50
\end{tabular}




\section{Calificación del Servicio}

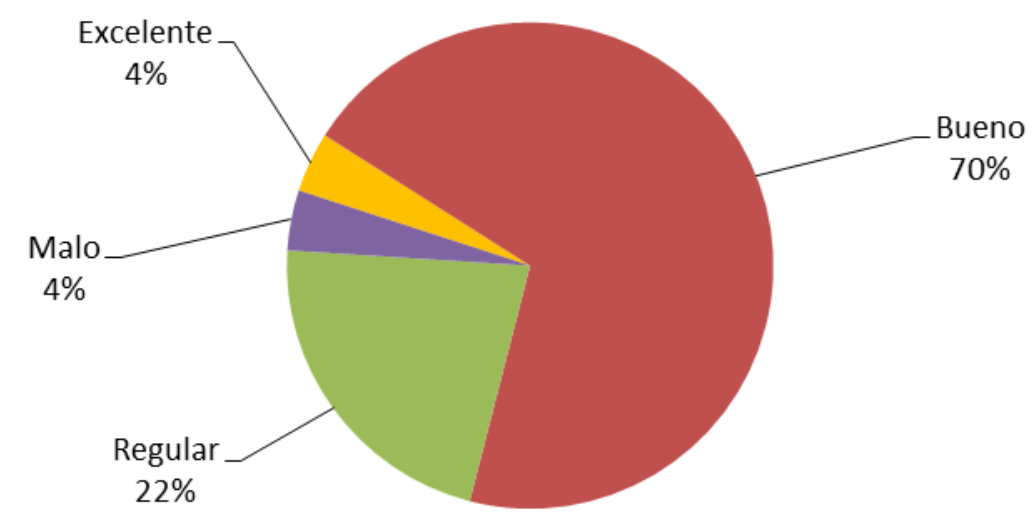

\subsection{Análisis Dimensión I: Elementos Tangibles}

A continuación se exponen los resultados en la Dirección de Obras Particulares respecto de la apariencia de los Equipos utilizados, Instalaciones Físicas, Apariencia Física de los empleados, y, Apariencia Visual de los elementos de comunicación.

\subsubsection{Equipos}

Este elemento se evaluó bajo la escala siguiente:

\begin{tabular}{c|c}
\hline & Escala \\
\hline 1 & Moderno \\
\hline 2 & Bastante moderno \\
\hline 3 & Regulares \\
\hline 4 & Poco Obsoleto \\
\hline 5 & Obsoleto \\
\hline
\end{tabular}

- Expectativa

Los encuestados esperan que los Equipos que se utilizan en el servicio Obras particulares sean "Regulares" con tendencia a "Obsoletos".

Media aritmética: 3,30. 


\section{Expectativa Equipos}

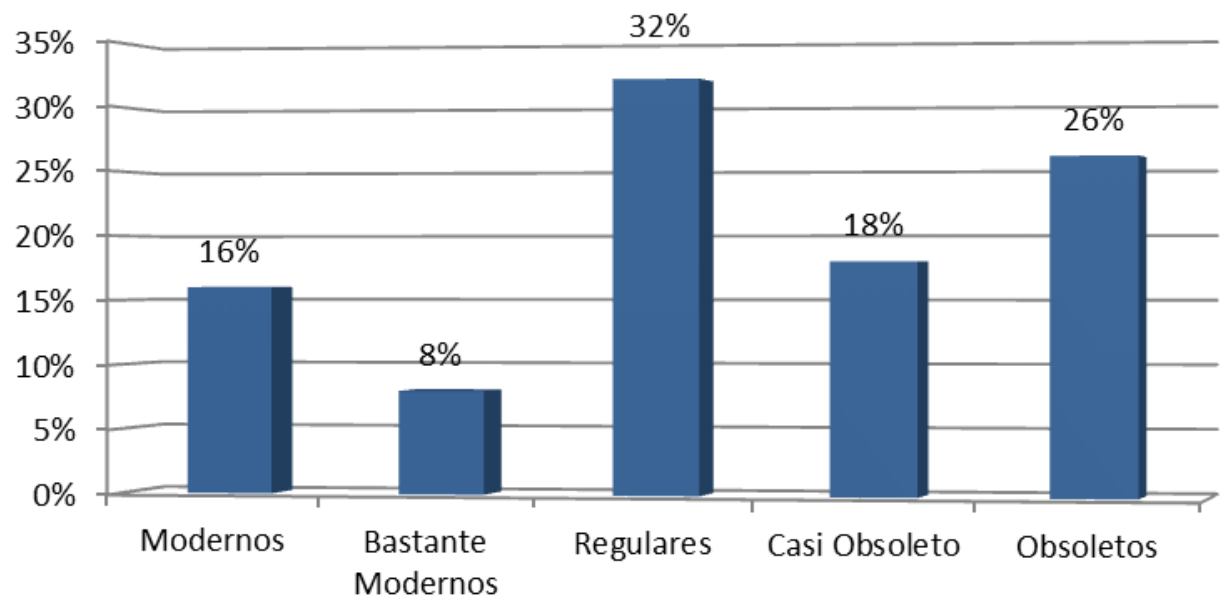

- Percepción

Los encuestados perciben que los Equipos que se utilizan en el servicio de obras particulares, son "Regulares" con tendencia a "Casi Obsoletos" Media aritmética: 2,36 .

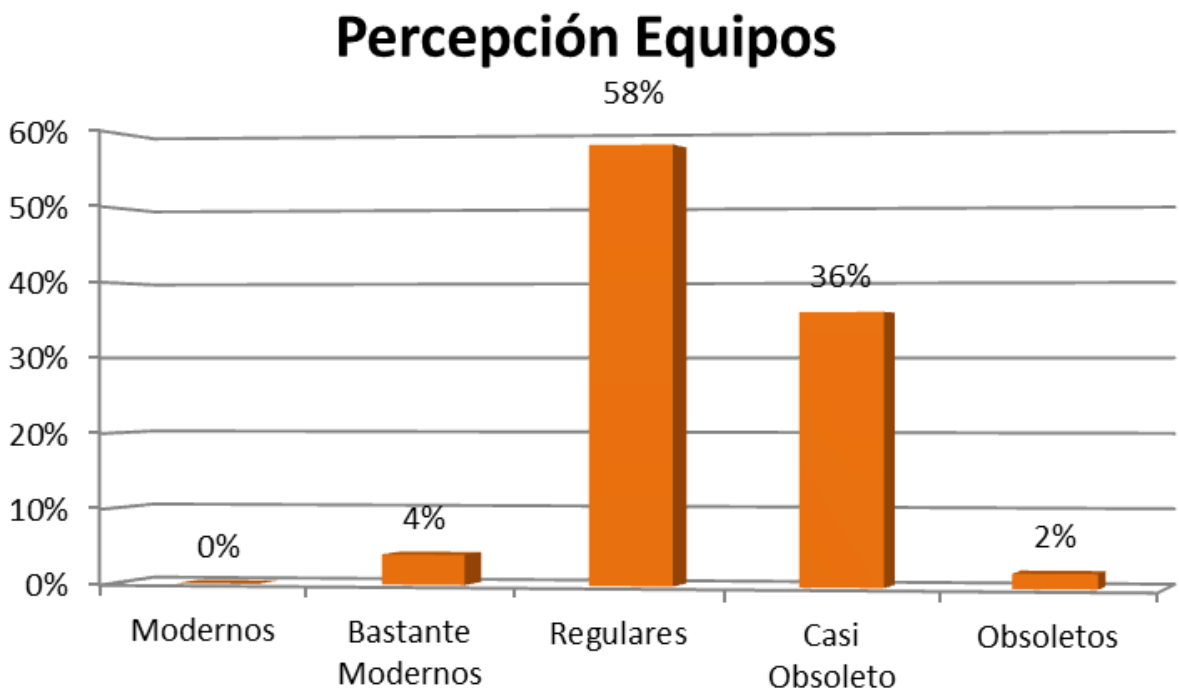

- Nivel de Satisfacción "Equipos"

En el siguiente gráfico se puede observar juntos la apreciación y expectativas por parte de los clientes sobre la apariencia de los Equipos utilizados en el servicio de Obras Particulares. 
Se observa mayor expectativa de que los Equipos utilizados tenían una tendencia de "regulares" a "obsoletos" pero luego la percepción se inclinó hacia equipos "regulares".

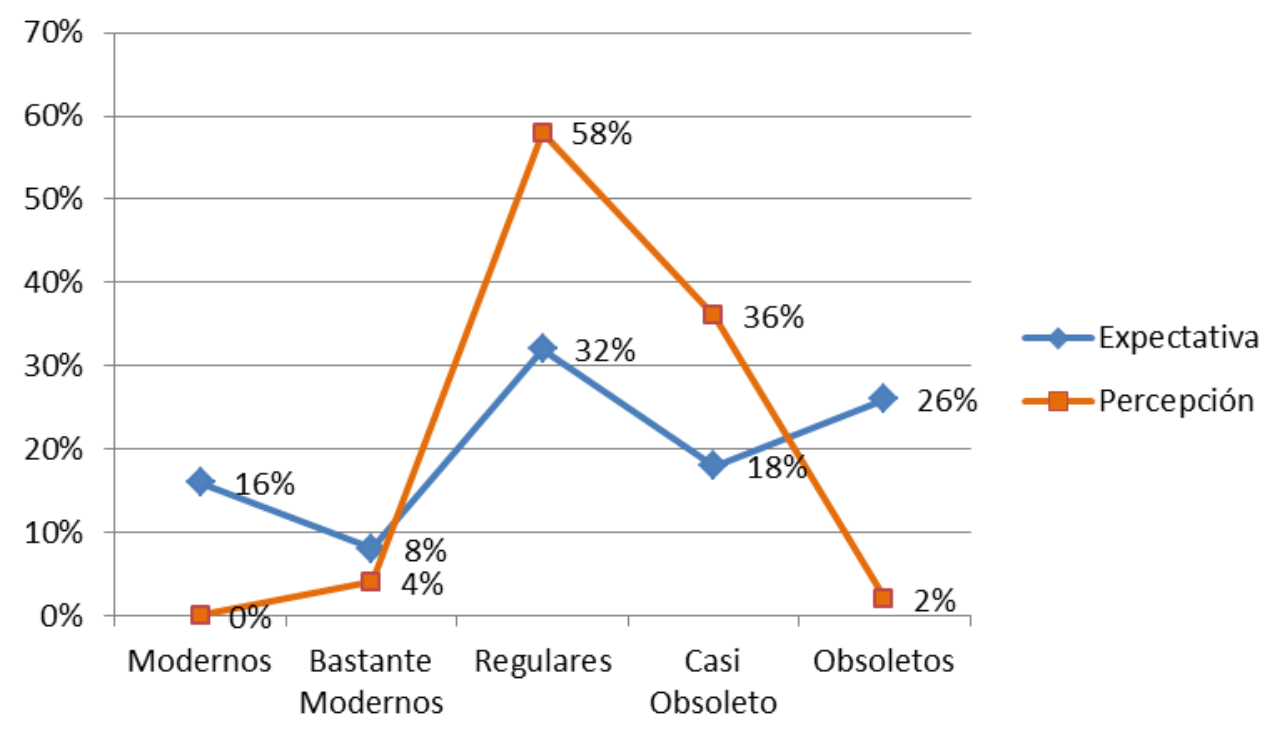

Como resultante, el nivel de satisfacción de los encuestados respecto de los "Equipos" resulta de la siguiente manera:

\section{Brecha expectativa / Percepción Equipos}

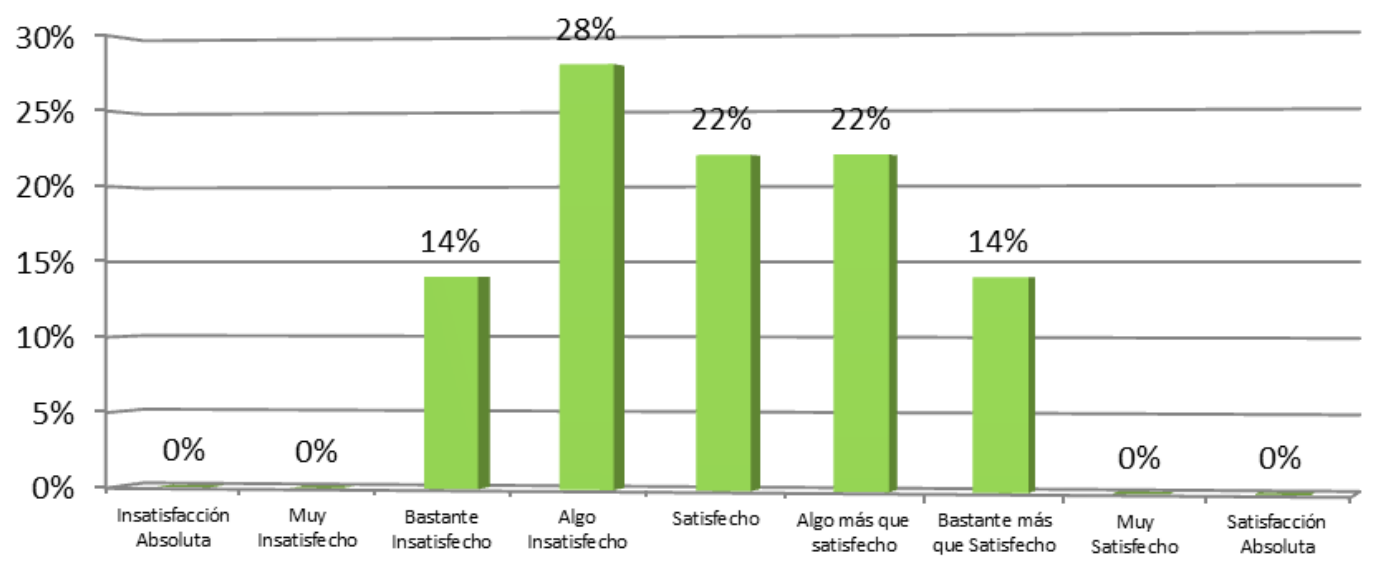

La media aritmética del Nivel de Satisfacción es de -0,33, de "Algo Insatisfecho" con tendencia "Algo más que satisfecho". 


\subsubsection{Instalaciones Físicas}

Este elemento se evalúo bajo la escala siguiente:

\begin{tabular}{c|c}
\hline & Escala \\
\hline 1 & Atractivas \\
\hline 2 & Bastante Atractivas \\
\hline 3 & Agradables \\
\hline 4 & Poco Agradables \\
\hline 5 & Desagradables \\
\hline
\end{tabular}

- Expectativa

Los encuestados esperan que las Instalaciones Físicas de la Dirección de Obras Particulares sean "Agradables" con tendencia a "Desagradables". Media aritmética: 3,38 .

\section{Expectativa Instalaciones Físicas}

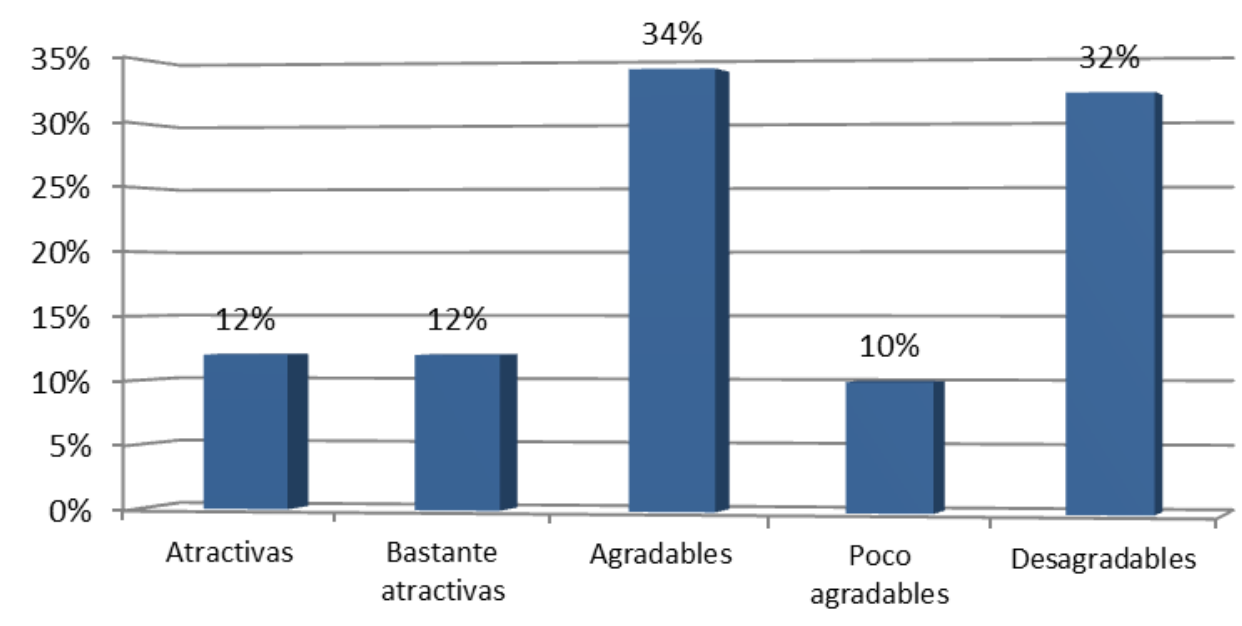

- Percepción

Los encuestados perciben que las Instalaciones Físicas de la Dirección de Obras Particulares son "Agradables" con tendencia a "Poco Agradables". Media aritmética: 3,24 


\section{Percepción Instalaciones Físicas}

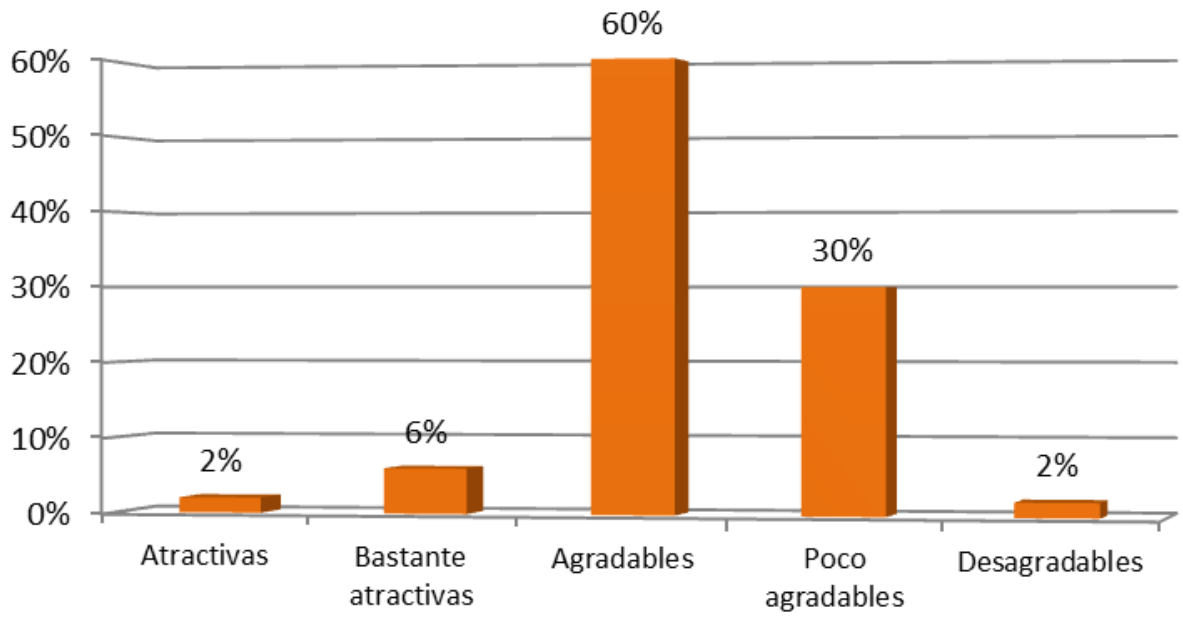

- Nivel de Satisfacción "Instalaciones Físicas"

En el siguiente gráfico se puede observar juntos la apreciación y expectativas por parte de los clientes sobre las Instalaciones Físicas de la dirección de Obras Particulares.

Se observa mayor expectativa de que las Instalaciones Físicas sean "Agradables con tendencia a desagradables", siendo la percepción mayormente "Agradables".

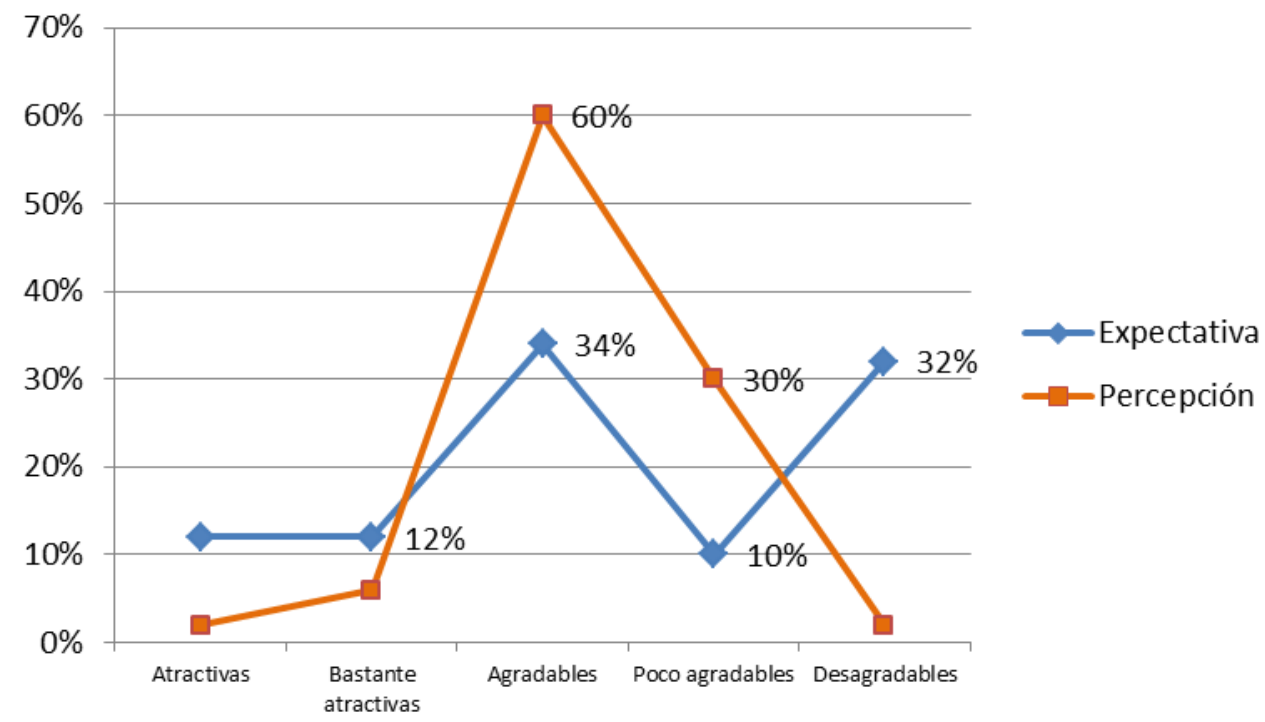

Como resultante, el nivel de satisfacción de los encuestados respecto de la "Instalaciones Físicas" resulta de la siguiente manera: 
Brecha Expectativa / Percepción Instalaciones Físicas

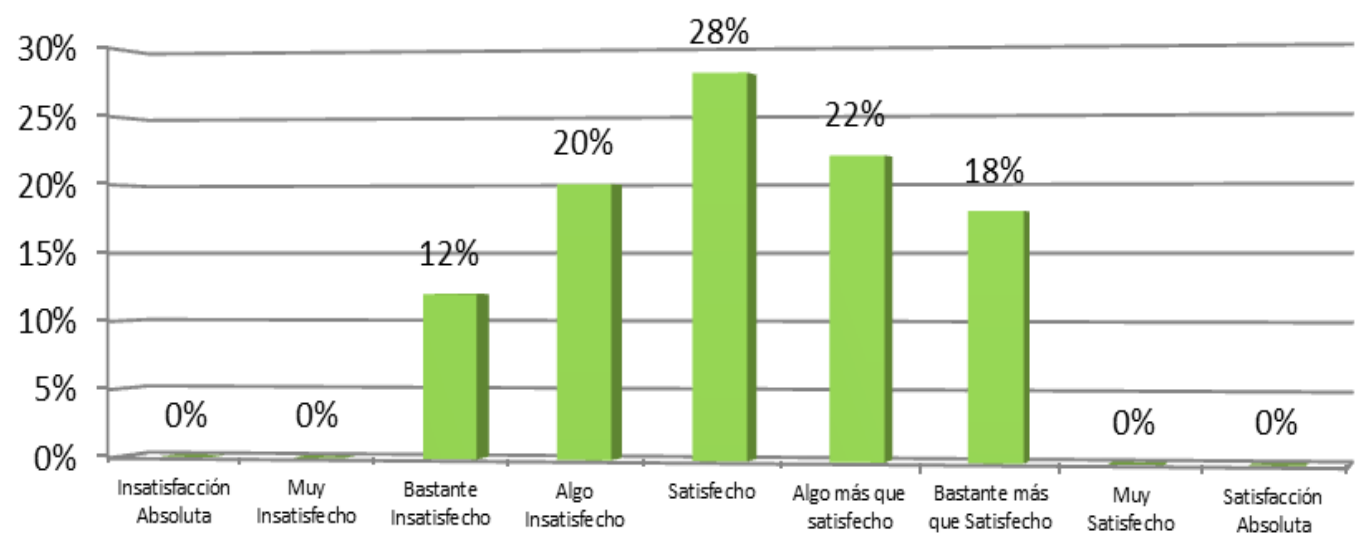

La media aritmética del Nivel de Satisfacción es de 0,77 "Satisfecho" a "Algo más que satisfecho"

\subsubsection{Apariencia Física de los Empleados}

Este elemento se evalúo bajo la escala siguiente:

\begin{tabular}{c|c}
\hline & Escala \\
\hline 1 & Pulcro \\
\hline 2 & Correcto \\
\hline 3 & Normal \\
\hline 4 & Regular \\
\hline 5 & Desaseada \\
\hline
\end{tabular}

Expectativa

Los encuestados esperan que la Apariencia Física de los Empleados del servicio de Obras Particulares sea "Correcta" con tendencia a "Normal". Media aritmética: 2,48. 


\section{Expectativa Apariencia Física}

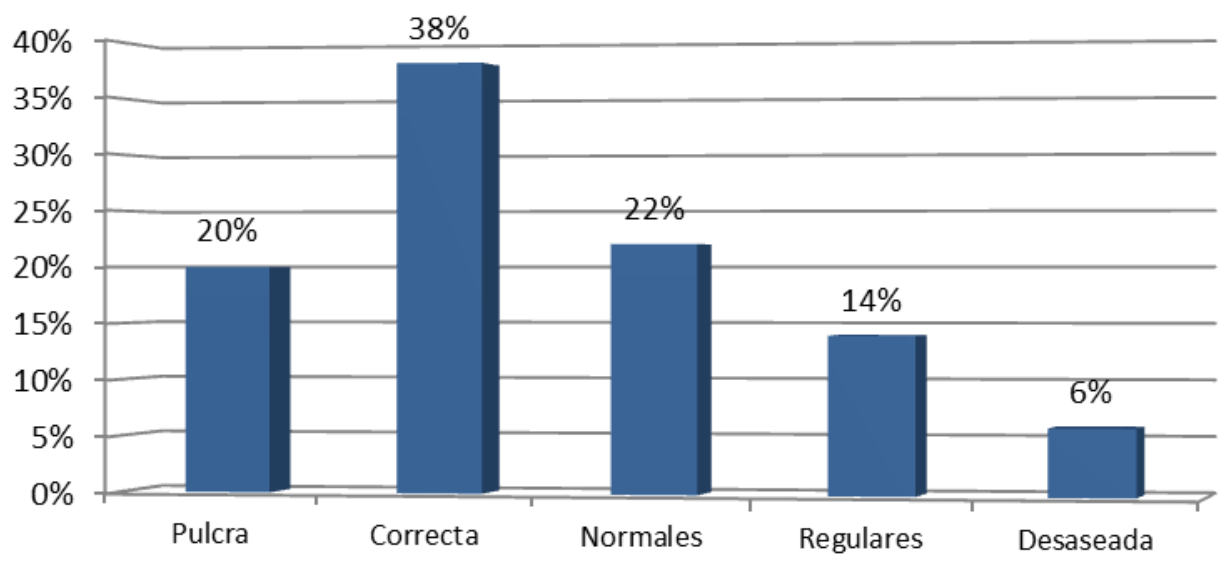

- Percepción

Los encuestados perciben que la Apariencia Física de los Empleados del servicio de Obras Particulares es "Correcta" con tendencia a "Pulcra". Media aritmética: 1,84.

\section{Percepción Apariencia Física}

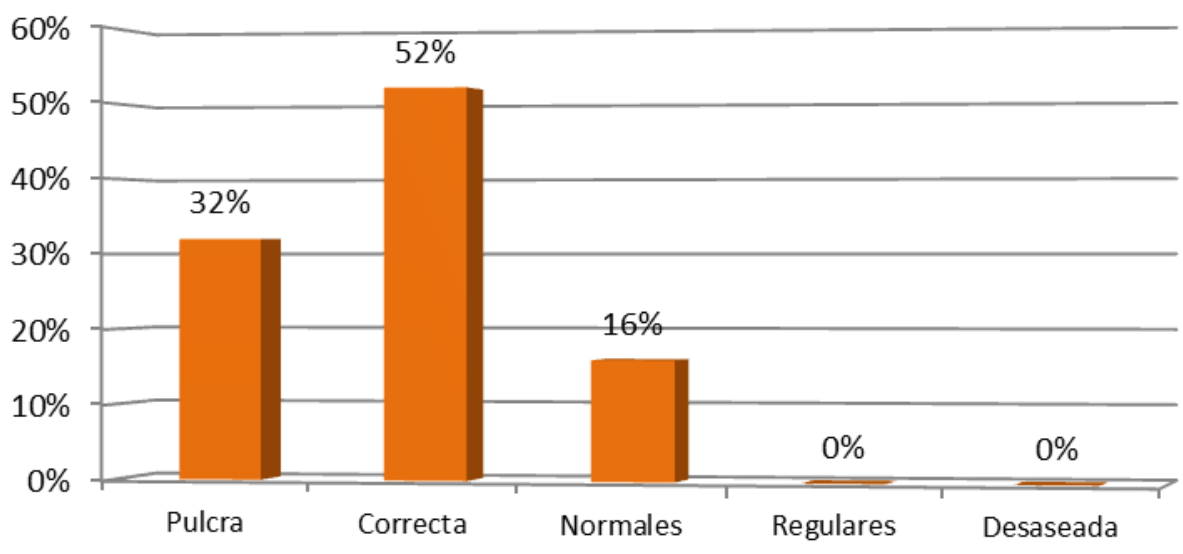

- Nivel de Satisfacción "Apariencia Física de los Empleados"

En el siguiente gráfico se puede observar juntos la apreciación y expectativas por parte de los clientes sobre la Apariencia Física de los Empleados del servicio de Obras Particulares. 
Se observa mayor expectativa de que la Apariencia Física de las Empleados del servicio sea "Correcta", siendo la percepción de "Correcta" en un mayor porcentaje.

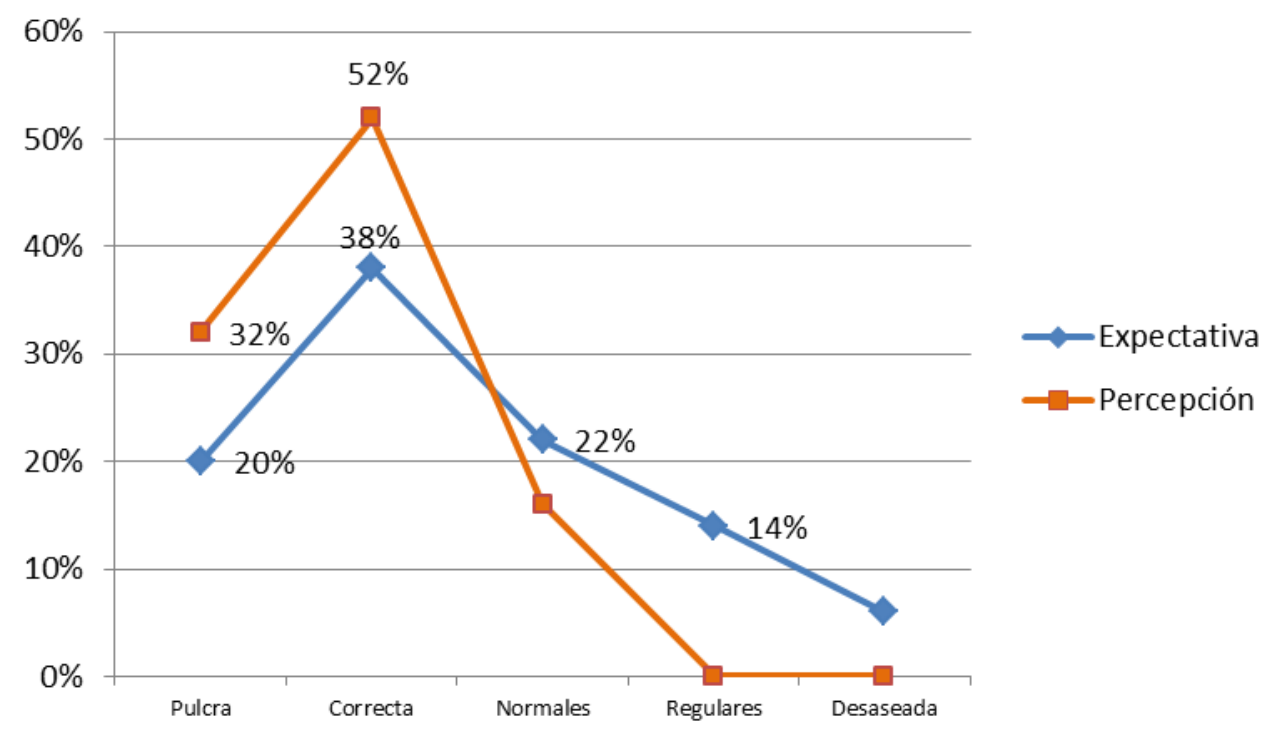

Como resultante, el nivel de satisfacción de los encuestados respecto de la "Apariencia Física de los Empleados" resulta de la siguiente manera:

\section{Brecha Expectativa / Percepción Apariencia Física}

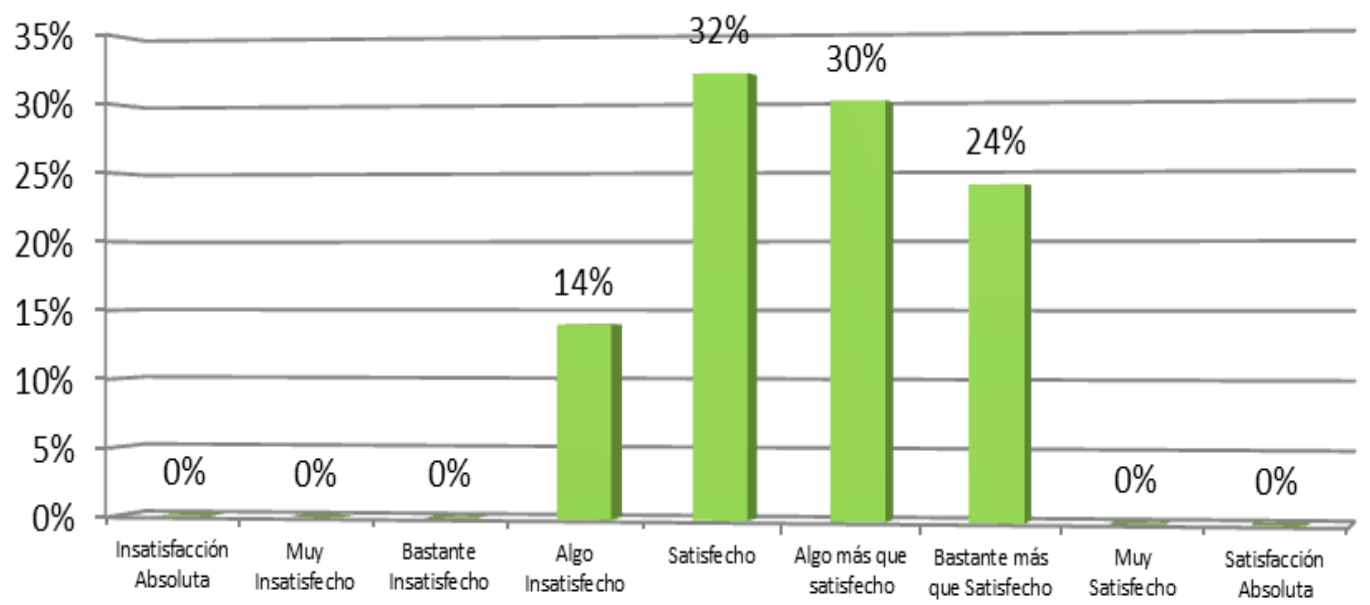

La media aritmética del Nivel de Satisfacción es de 3,55 entre "Satisfecho" y "Bastante más que Satisfecho". 


\subsubsection{Apariencia Visual de los Elementos de Comunicación}

Este elemento se evalúo bajo la escala siguiente:

\begin{tabular}{c|c}
\hline & Escala \\
\hline 1 & Pulcro \\
\hline 2 & Correcto \\
\hline 3 & Normal \\
\hline 4 & Regular \\
\hline 5 & Desaseada \\
\hline
\end{tabular}

- Expectativa

Los encuestados esperan que la Apariencia Visual de los Elementos de Comunicación del servicio Obras Particulares sea "Desaseada" con tendencia a "Correcta".

Media aritmética: 3,58.

\section{Expectativa Apariencia Visual}

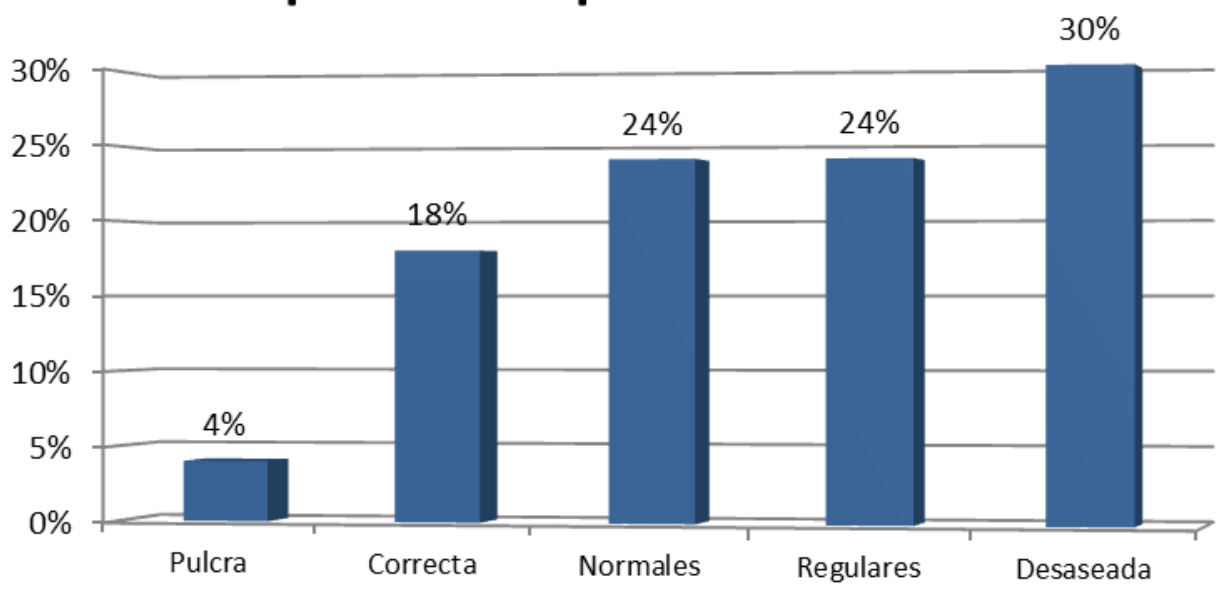

- Percepción

La percepción de los encuestados respecto de la Apariencia Visual de los Elementos de Comunicación del servicio del Servicio de Obras Particulares es "Normal" con tendencia a "Regulares".

Media aritmética: 3,46 


\section{Percepción Apariencia Visual}

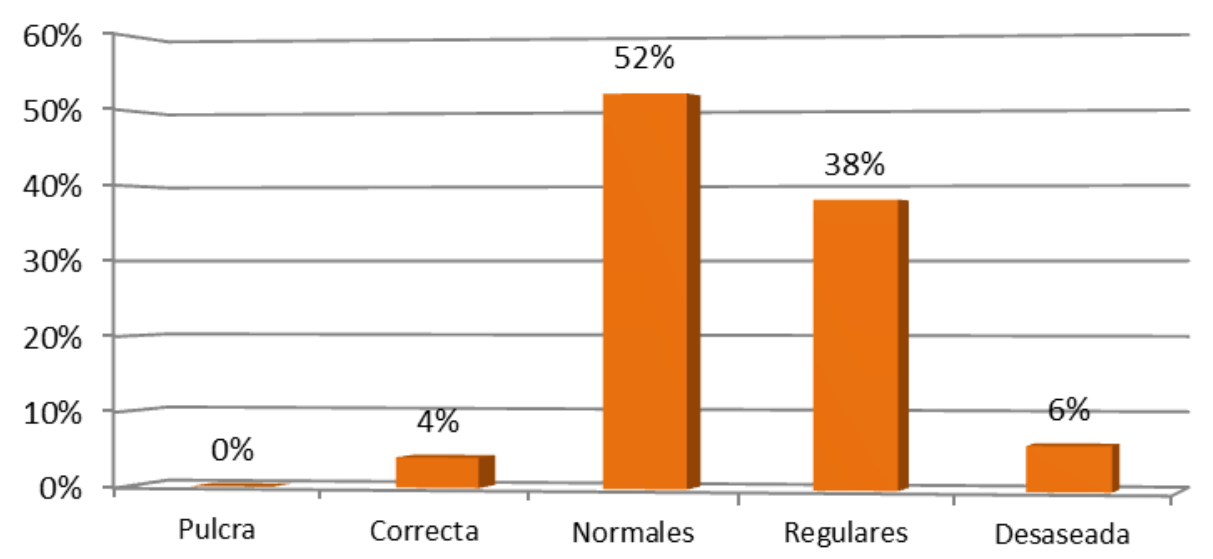

- Nivel de Satisfacción "Apariencia Visual de los Elementos de Comunicación"

En el siguiente gráfico se puede observar juntos la apreciación y expectativas por parte de los clientes sobre la Apariencia Visual de los Elementos de Comunicación del servicio de Obras Particulares.

Se observa que la mayor expectativa sobre la Apariencia Visual de los Elementos de Comunicación del servicio sean "Desaseada" a "Normales", siendo la percepción de "Normales".

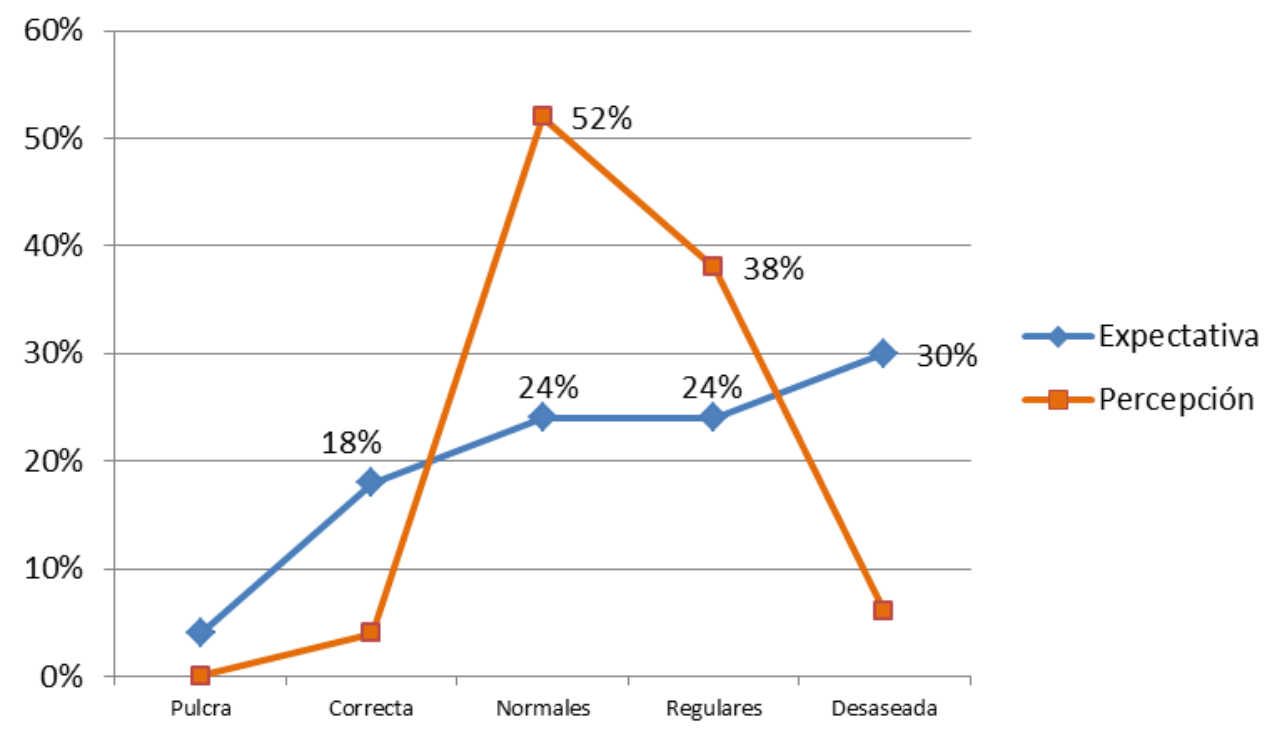

Como resultante, el nivel de satisfacción de los encuestados respecto de la "Apariencia Visual de los Elementos de Comunicación" resulta de la siguiente manera: 


\section{Brecha Expectativa / Percepción Apariencia Visual}

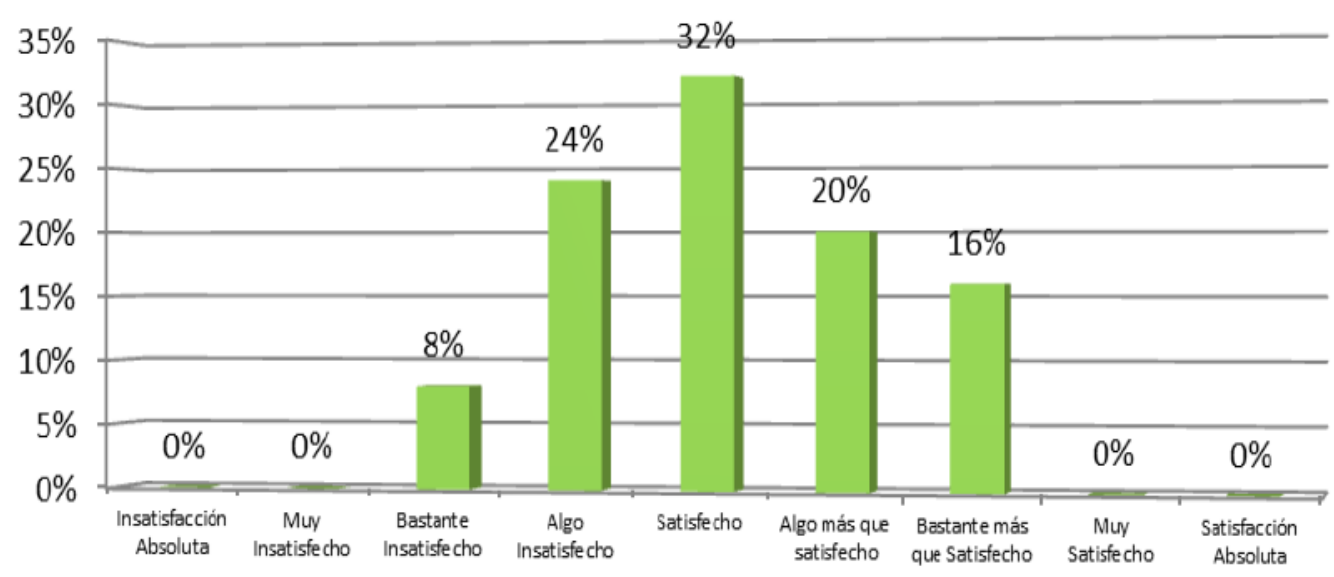

La media aritmética del Nivel de Satisfacción es de 0,66 entre "Satisfecho" y "Algo Insatisfecho".

\subsubsection{Total datos Dimensión I "Elementos Tangibles"}

\begin{tabular}{l|c}
\hline \multicolumn{2}{c}{ Total Datos Dimensión I } \\
\hline Percepción & 2,975 \\
\hline Expectativa & 3,185 \\
\hline Nivel satisfacción & $\mathbf{0 , 2 1}$ \\
\hline Diferencia E-P & $\mathbf{0 , 2 1}$ \\
\hline
\end{tabular}

- Expectativa Vs. Percepción Acumulada Dimensión I

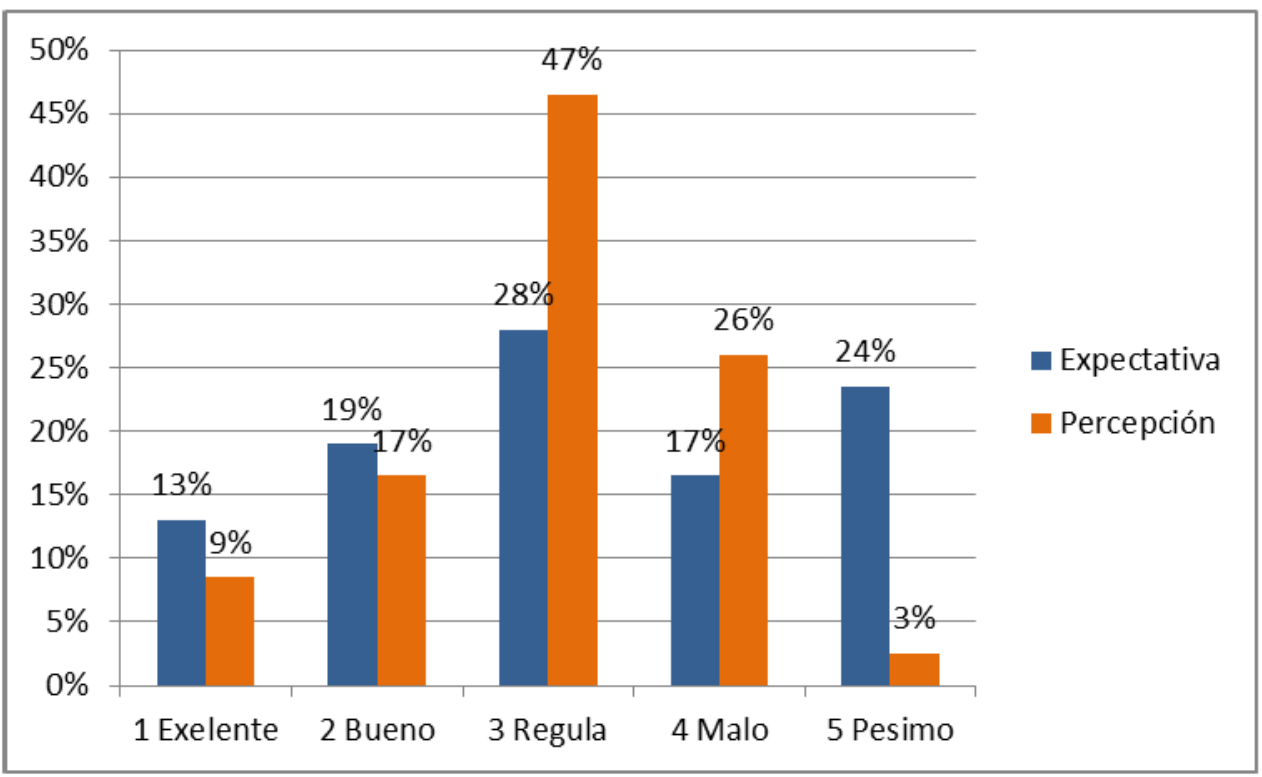


- Total Brecha Expectativa - Percepción Dimensión I

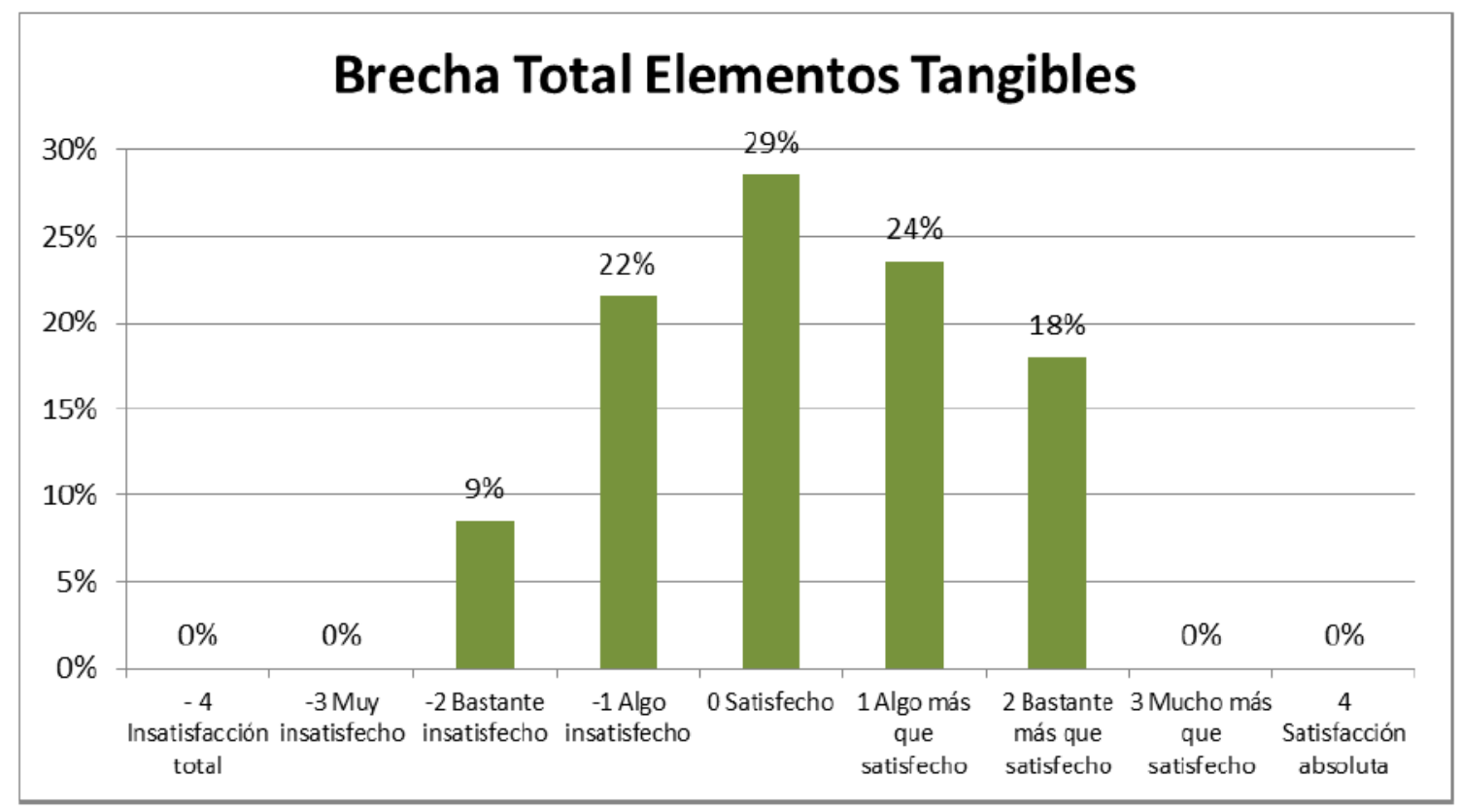

\subsection{Análisis Dimensión II: Confiabilidad}

A continuación se exponen los resultados obtenidos en la Dirección de Obras Particulares respecto de la habilidad para ejecutar el servicio prometido de forma confiable y cuidadosa; Cumplimiento de los Empleados de lo Prometido, Interés de los Empleados en Solucionar Problemas, Eficacia del Servicio, Tiempo de Cumplimiento del Servicio, y, Eficiencia del Servicio.

\subsubsection{Cumplimiento de los Empleados}

Este elemento se evaluó bajo la escala siguiente:

\begin{tabular}{c|c}
\cline { 2 - 2 } & Escala \\
\hline 1 & Siempre Cumplen \\
\hline 2 & Generalmente Cumplen \\
\hline 3 & Normalmente Cumplen \\
\hline 4 & Raramente Cumplen \\
\hline 5 & Nunca Cumplen \\
\hline
\end{tabular}

- Expectativa

Los encuestados esperan del Cumplimiento de los Empleados de lo Prometido del servicio de Obras Particulares que "Siempre Cumplen" con tendencia a "Normalmente Cumplen". 
Media aritmética: 2,44.

\section{Expectativa Empleados Cumplen}

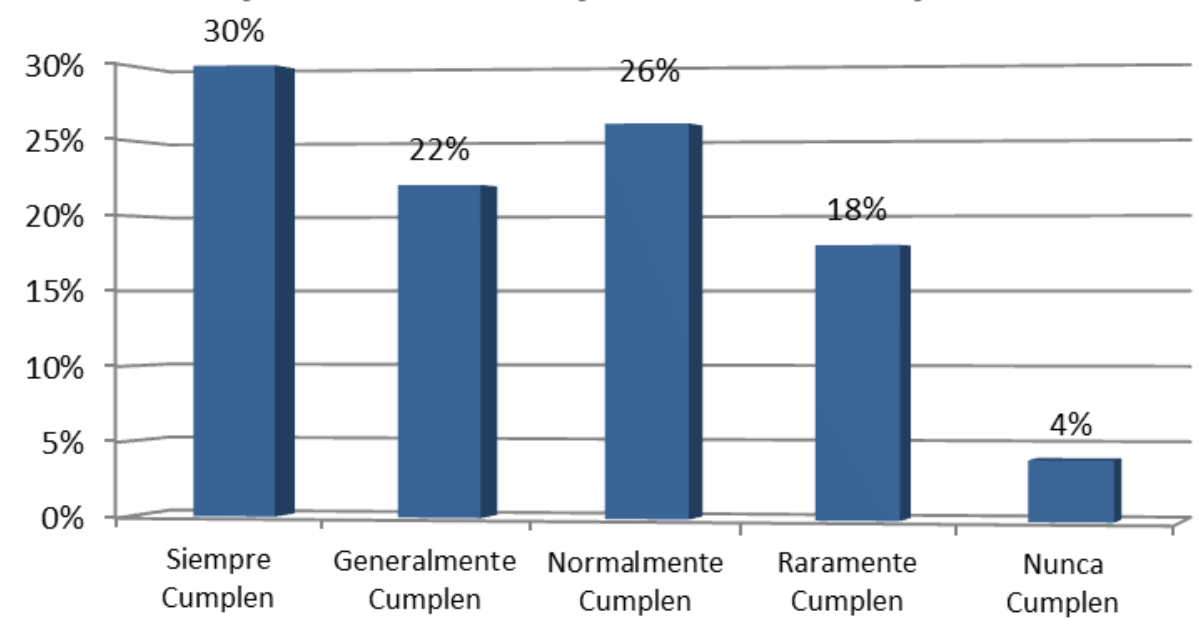

- Percepción

Los encuestados perciben que el Cumplimiento de los Empleados de lo Prometido del servicio de Obras Particulares, es "Generalmente Cumplen" con tendencia a "Siempre Cumplen".

Media aritmética: 1,88.

\section{Percepción Empleados Cumplen}

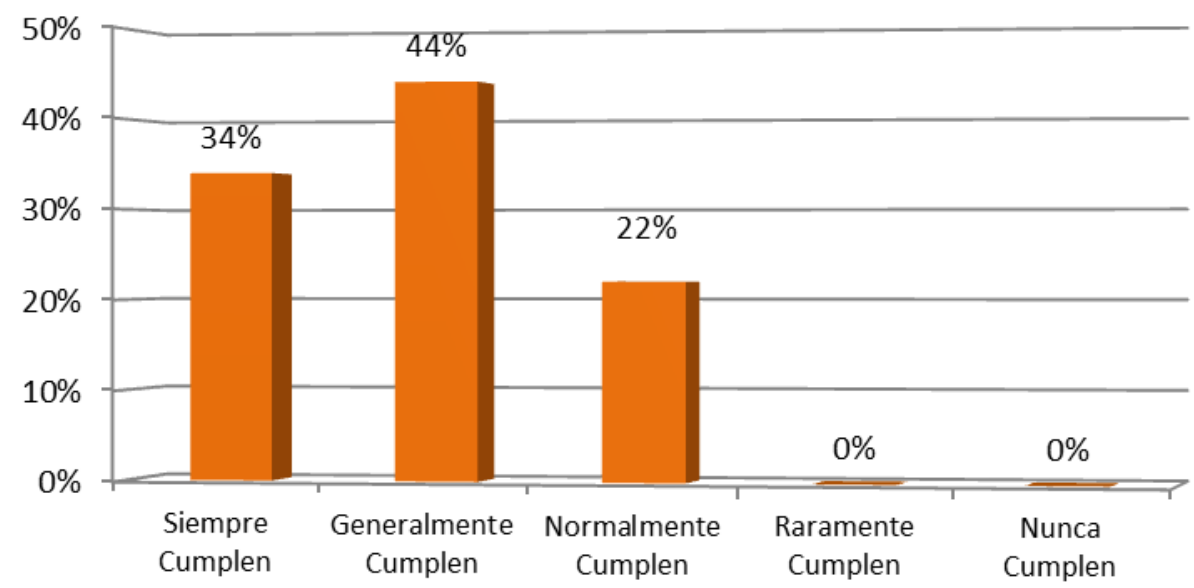

- Nivel de Satisfacción "Cumplimiento de los Empleados de lo Prometido"

En el siguiente gráfico se puede observar juntos la apreciación y expectativas por parte de los clientes sobre Cumplimiento de los Empleados de lo Prometido en la dirección de Obras Particulares. 
Se observa mayor expectativa de que el Cumplimiento de los Empleados de lo Prometido sea "Siempre Cumplen", siendo la percepción de "Generalmente cumplen" a "Siempre Cumplen" en un leve porcentaje por encima de la expectativa.

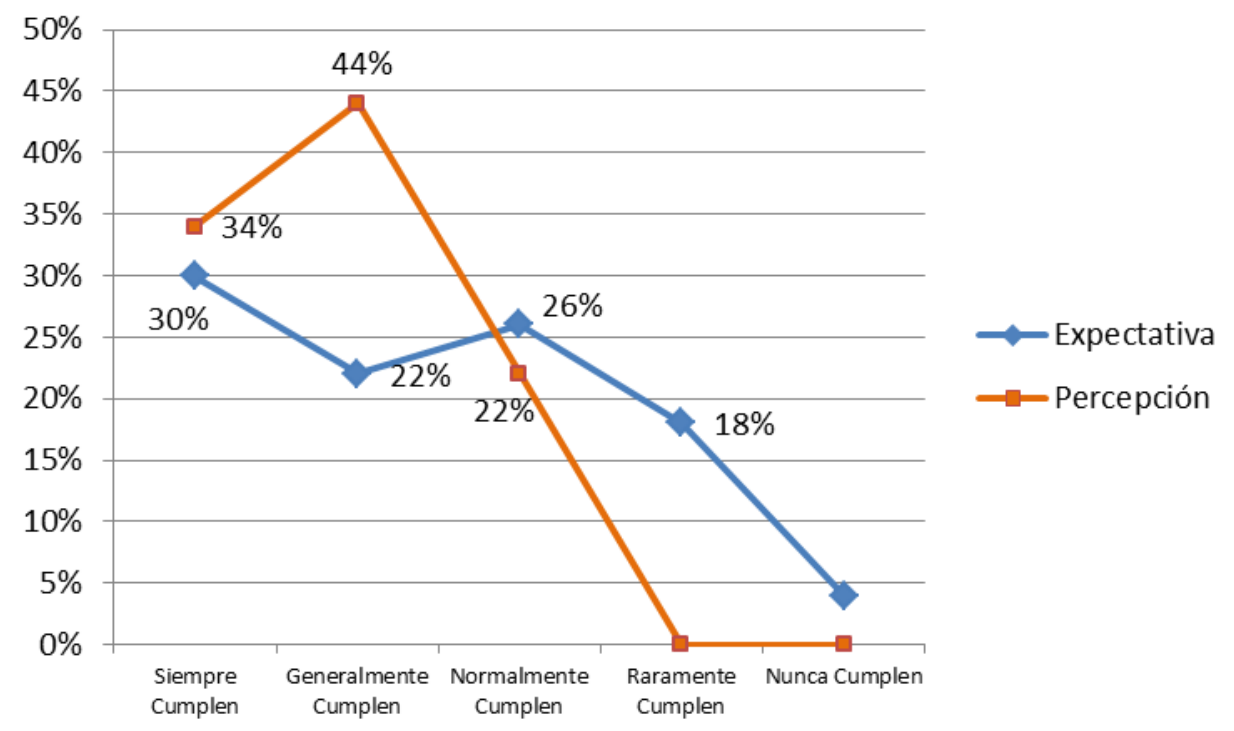

Como resultante, el nivel de satisfacción de los encuestados respecto de los "Cumplimiento de los Empleados de lo Prometido" resulta de la siguiente manera:

\section{Brecha expectativa / Percepción Empleados Cumplen}

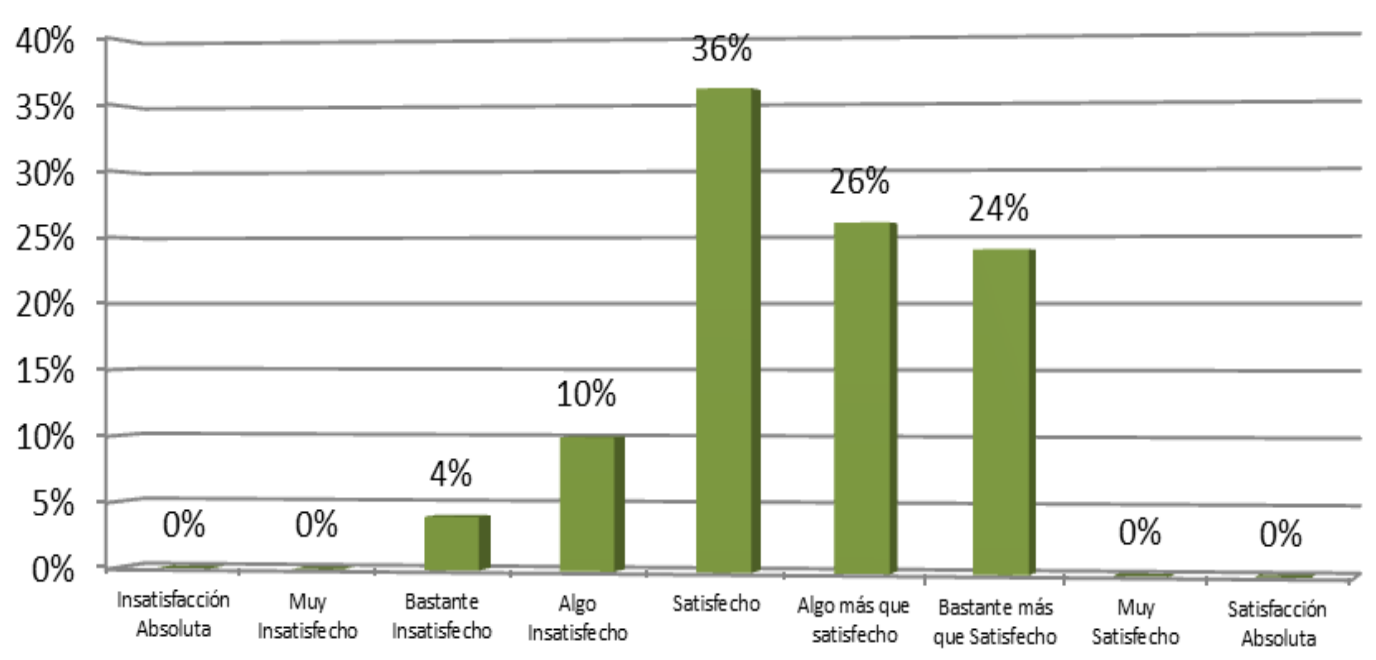

La media aritmética del Nivel de Satisfacción es de 3,11, de "Satisfecho" a "Bastante más que Satisfecho". 


\subsubsection{Interés de los Empleados}

Este elemento se evaluó bajo la escala siguiente:

\begin{tabular}{l|c}
\hline & Escala \\
\hline 1 & Total Interés \\
\hline 2 & Buen Interés \\
\hline 3 & Tienen Interés \\
\hline 4 & Algo de Interés \\
\hline 5 & Completo Desinterés \\
\hline
\end{tabular}

- Expectativa

Los encuestados esperan del Interés de los Empleados en Solucionar los Problemas del Cliente del servicio de Obras Particulares que sea "Buen Interés" con tendencia a "Tienen Interés".

Media aritmética: 2,62.

\section{Expectativa Interés de empleados}

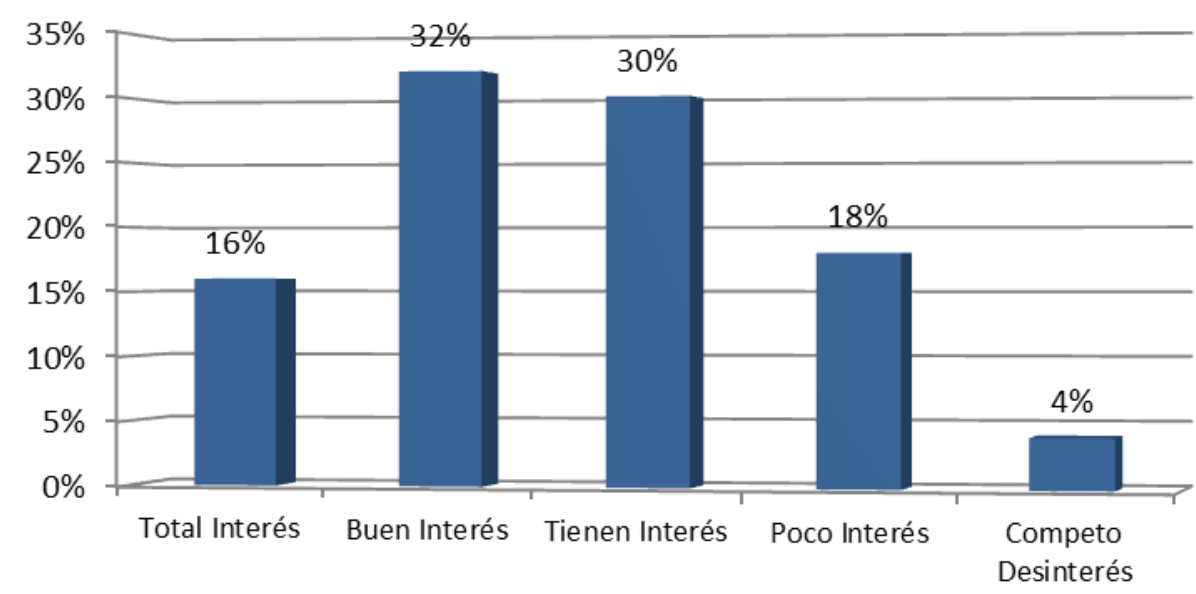

- Percepción

Los encuestados perciben que el Interés de los Empleados en Solucionar los Problemas del Cliente en el servicio de Obras Particulares, es "Buen Interés" con tendencia a "Tienen Interés".

Media aritmética: 2,36. 


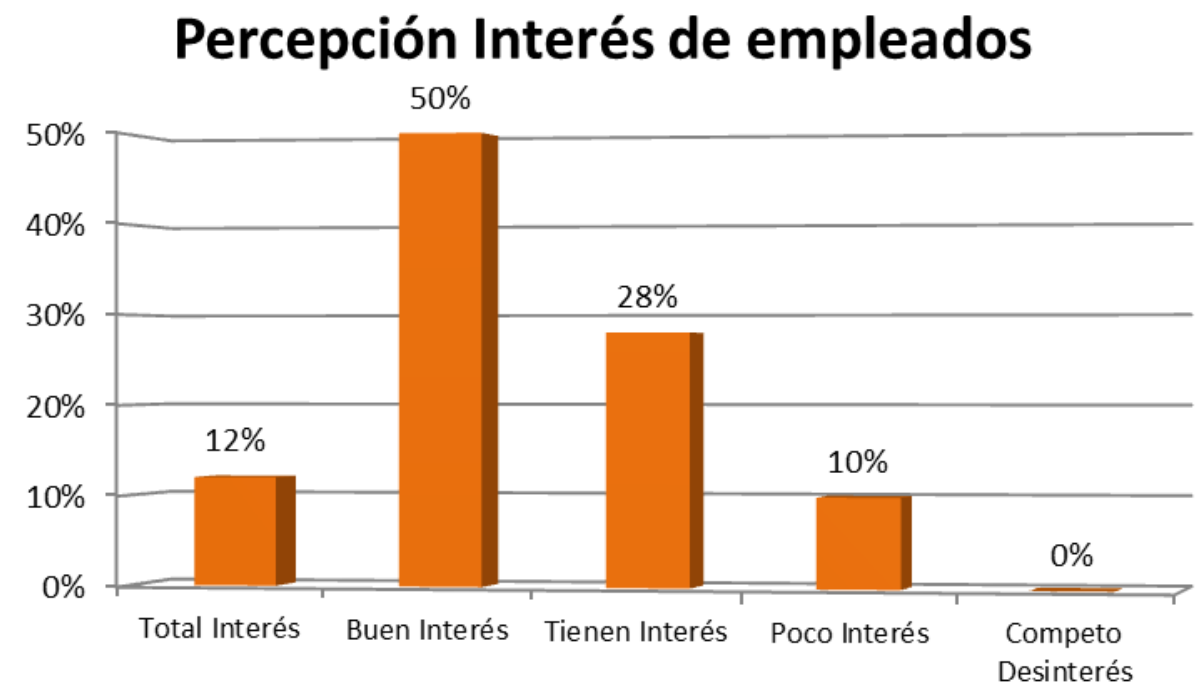

- Nivel de Satisfacción "Interés de los Empleados en Solucionar los Problemas del Cliente"

En el siguiente gráfico se puede observar juntos la apreciación y expectativas por parte de los clientes sobre Interés de los Empleados en Solucionar los Problemas del Cliente.

Se observa mayor expectativa de que el Interés de los Empleados en Solucionar los Problemas del Cliente sea "Buen Interés", mientras la Perspectiva fue "Buen Interés" en un porcentaje mucho mayor.

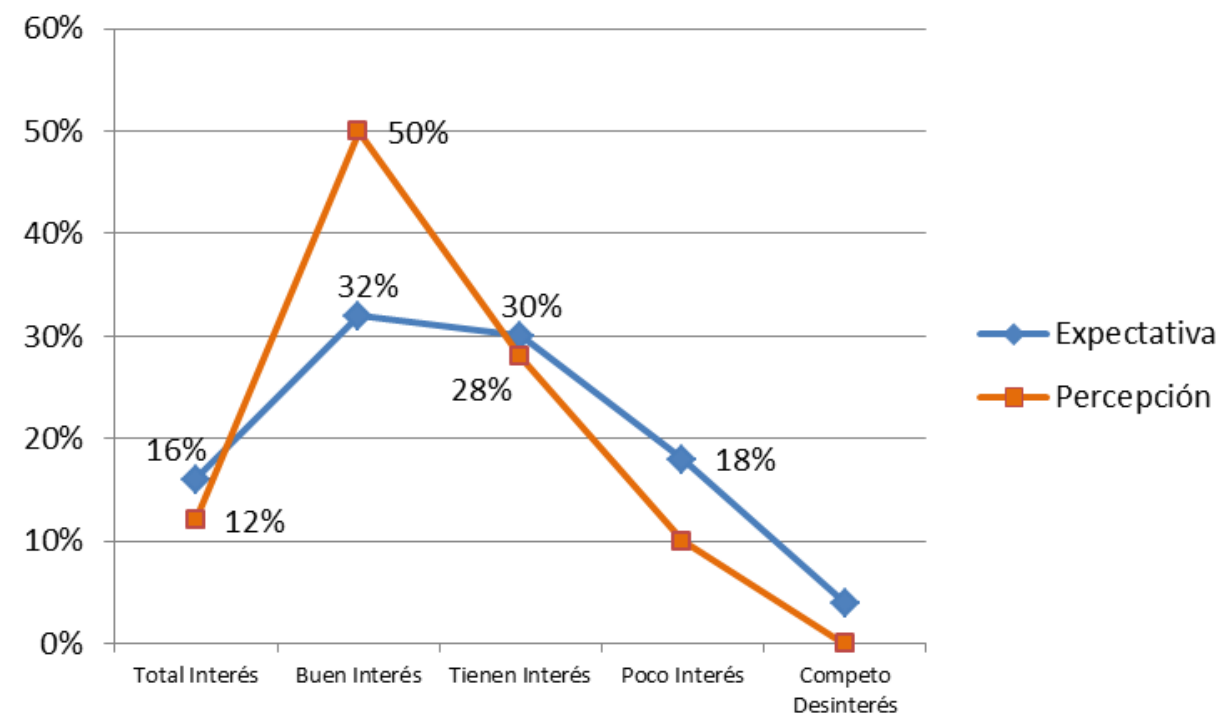


Como resultante, el nivel de satisfacción de los encuestados respecto del “Interés de los Empleados en Solucionar los Problemas del Cliente" resulta de la siguiente manera:

\section{Brecha Expectativa / Percepción Interés Empleados}

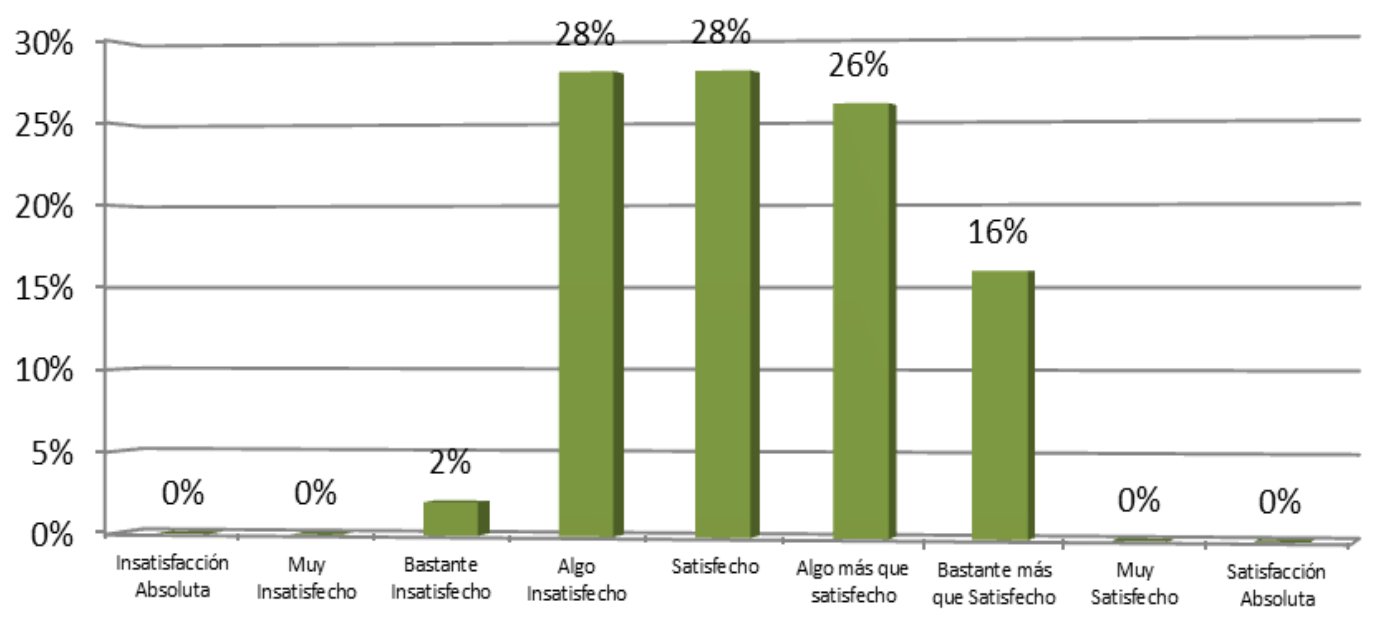

La media aritmética del Nivel de Satisfacción es de 1,44, de "Algo Insatisfecho" y "Satisfecho" con tendencia a "Algo más que satisfecho".

\subsubsection{Eficacia del Servicio}

Este elemento se evaluó bajo la escala siguiente:

\begin{tabular}{c|c}
\hline & Escala \\
\hline 1 & Realiza el trabajo bien 1ra vez \\
\hline 2 & Rara vez se equivocan \\
\hline 3 & Normalmente lo hacen bien \\
\hline 4 & Algunas veces lo hacen bien \\
\hline 5 & Nunca lo hacen bien \\
\hline
\end{tabular}

- Expectativa

Los encuestados esperan que la Eficacia del servicio de Obras Particulares sea "Rara vez se equivocan" con tendencia a "Normalmente lo hacen Bien". Media aritmética: 2,64 . 


\section{Expectativa Eficacia del servicio municipal}

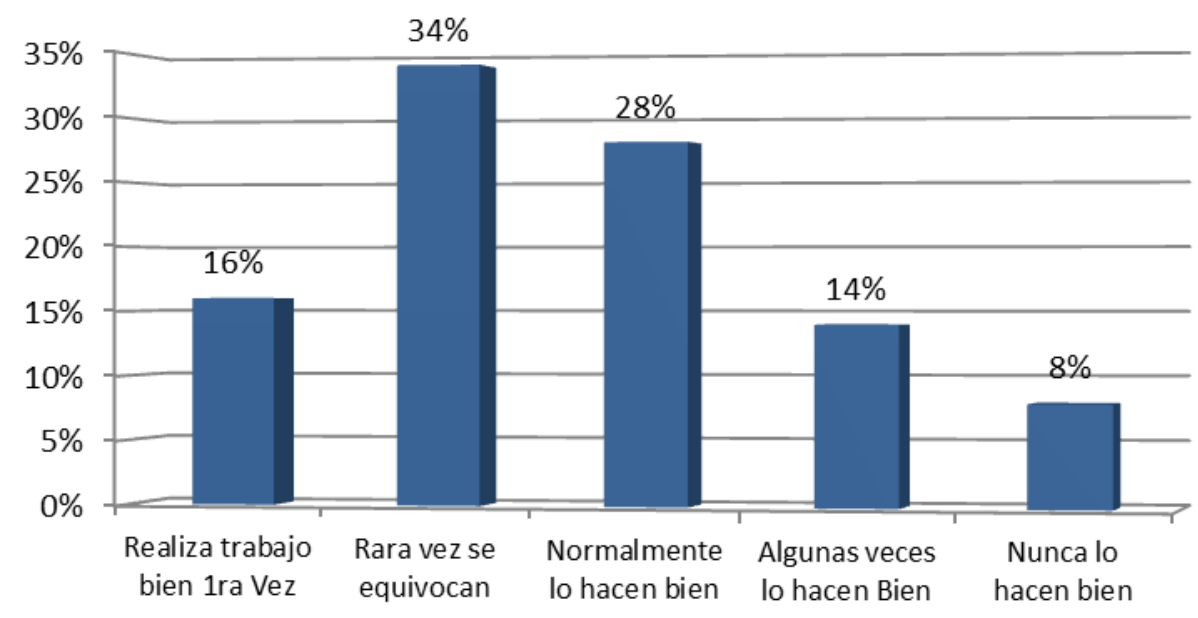

- Percepción

Los encuestados perciben que la Eficacia del servicio de Obras Particulares es mayoritariamente "Rara vez se equivocan".

Media aritmética: 2,04.

\section{Percepción Eficacia del servicio municipal}

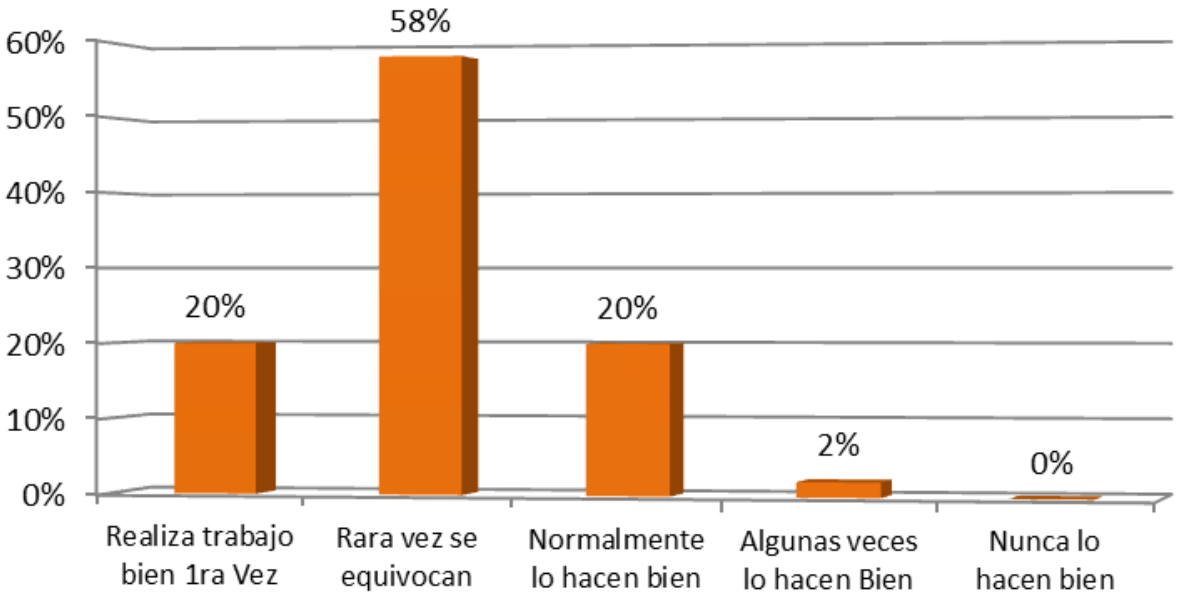

- Nivel de Satisfacción "Eficacia"

En el siguiente gráfico se puede observar juntos la apreciación y expectativas por parte de los clientes sobre Eficacia del servicio.

La mayor Expectativa de los encuestados de que la Eficacia del servicio es "Rara vez se equivocan", encontrándose con una precepción mucho más 
favorable con un mayor porcentaje a la expectativa que tenían en "Rara Vez se equivocan"

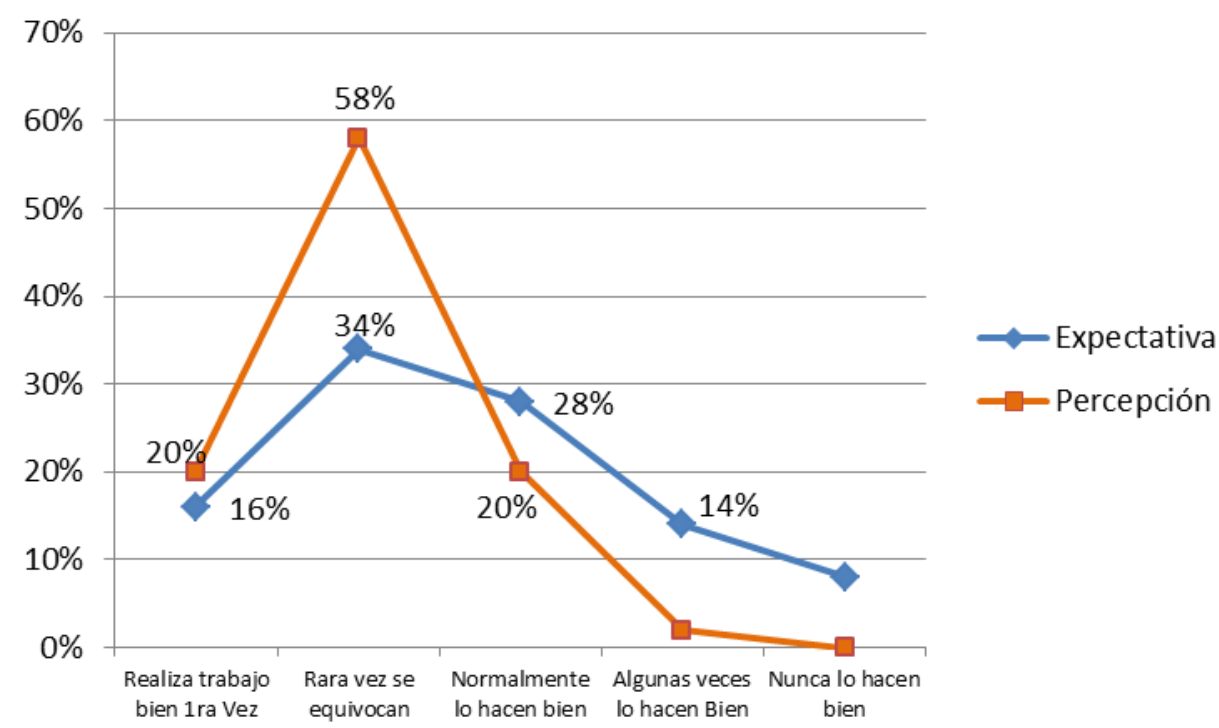

Como resultante, el nivel de satisfacción de los encuestados respecto de la "Eficacia" resulta de la siguiente manera:

\section{Brecha Expectativa / Percepción Eficacia}

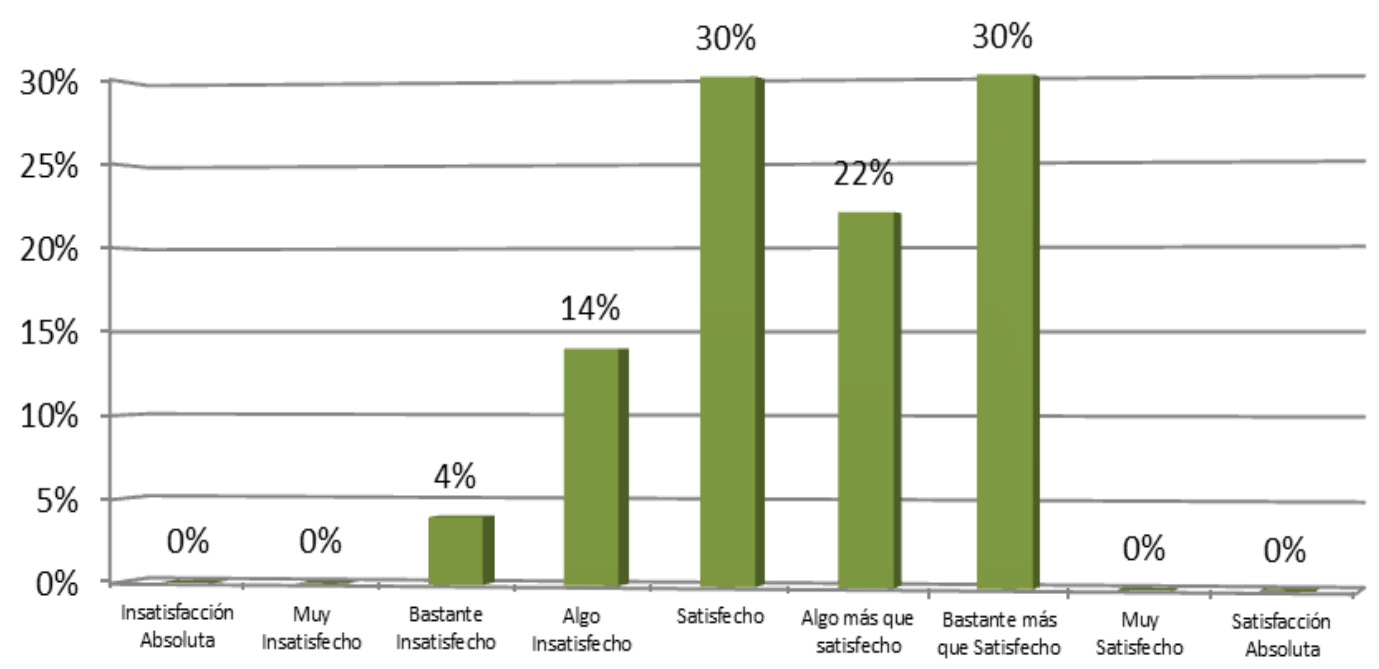

La media aritmética del Nivel de Satisfacción es de 3,33, de "Satisfecho" a "Bastante más que satisfecho". 


\subsubsection{Tiempo de Cumplimiento del Trabajo}

Este elemento se evaluó bajo la escala siguiente:

\begin{tabular}{c|c}
\hline & Escala \\
\hline 1 & Siempre a Tiempo \\
\hline 2 & Generalmente a Tiempo \\
\hline 3 & Normalmente a Tiempo \\
\hline 4 & Pocas veces a Tiempo \\
\hline 5 & Nunca a Tiempo \\
\hline
\end{tabular}

- Expectativa del Servicio

Los encuestados creen y tiene la expectativa que el Tiempo de Cumplimiento del Trabajo del servicio de la Dirección de Obras Particulares sea "Pocas veces a tiempo" un alto porcentaje espera que sea "Siempre a tiempo" mientas que otro alto porcentaje cree que "nunca será a tiempo"

Media aritmética: 3,1 .

\section{Expectativa Tiempo de cumplimiento}

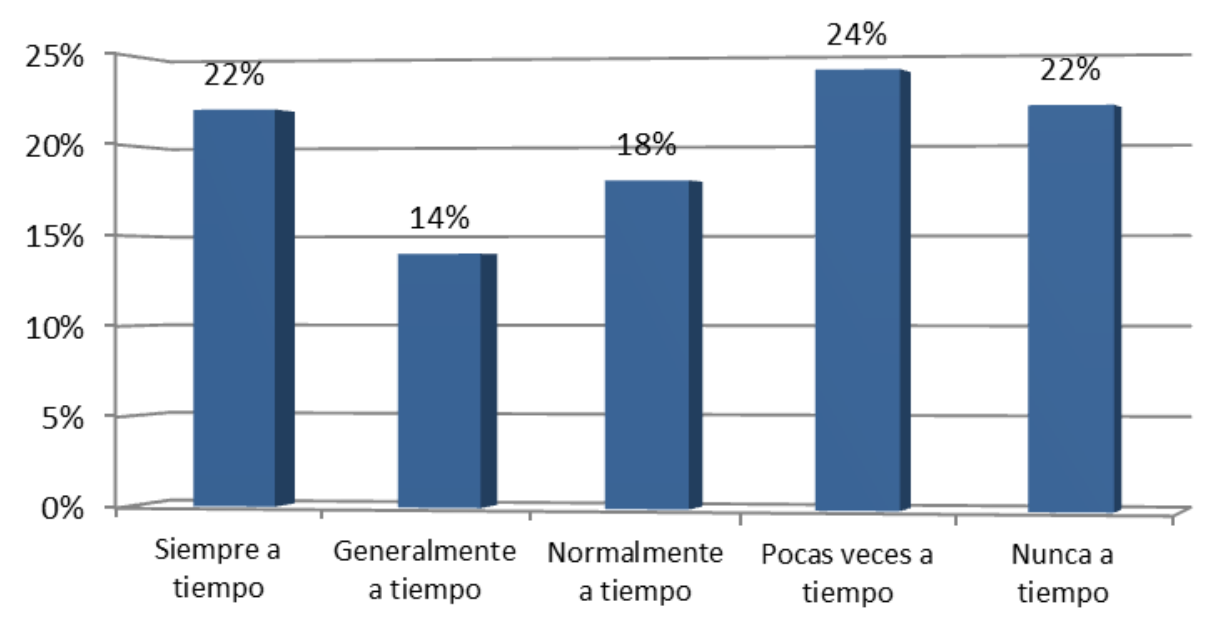

- Percepción

Los encuestados perciben mayoritariamente que el Tiempo de Cumplimiento del Trabajo es "Normalmente a Tiempo"

Media aritmética: 2,82. 


\section{Percepción Tiempo de cumplimiento}

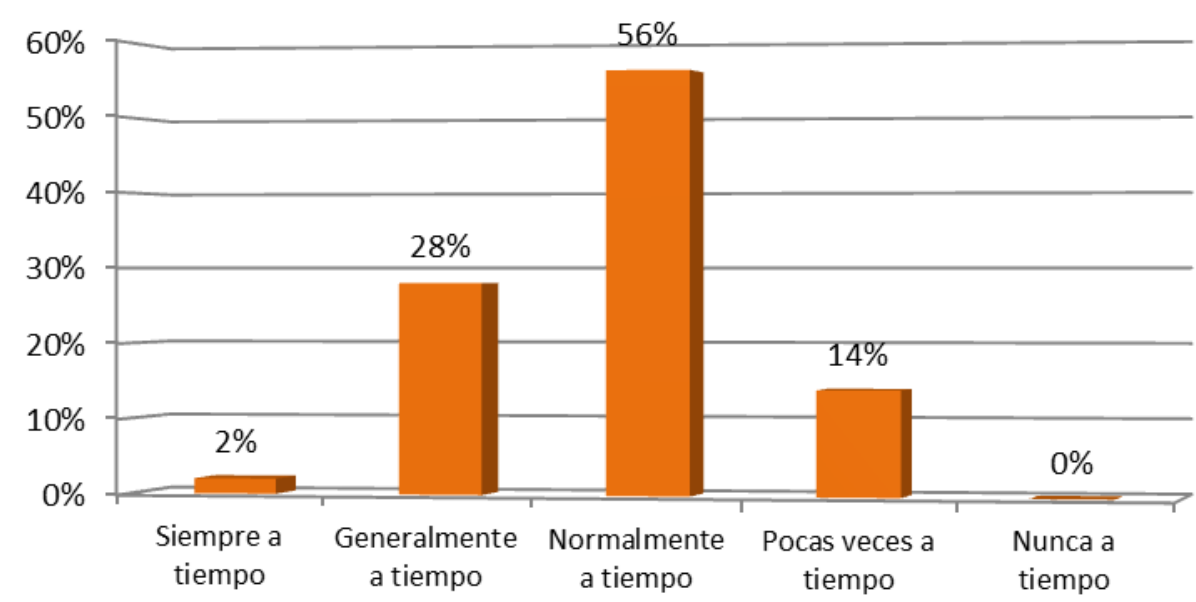

- Nivel de Satisfacción "Tiempo de Cumplimiento del Trabajo"

En el siguiente gráfico se puede observar juntos la apreciación y expectativas por parte de los clientes sobre Tiempo de Cumplimiento del Trabajo del servicio.

Se observa una mayor percepción de que el Tiempo de Cumplimiento del Trabajo del servicio sea "Normalmente a Tiempo".

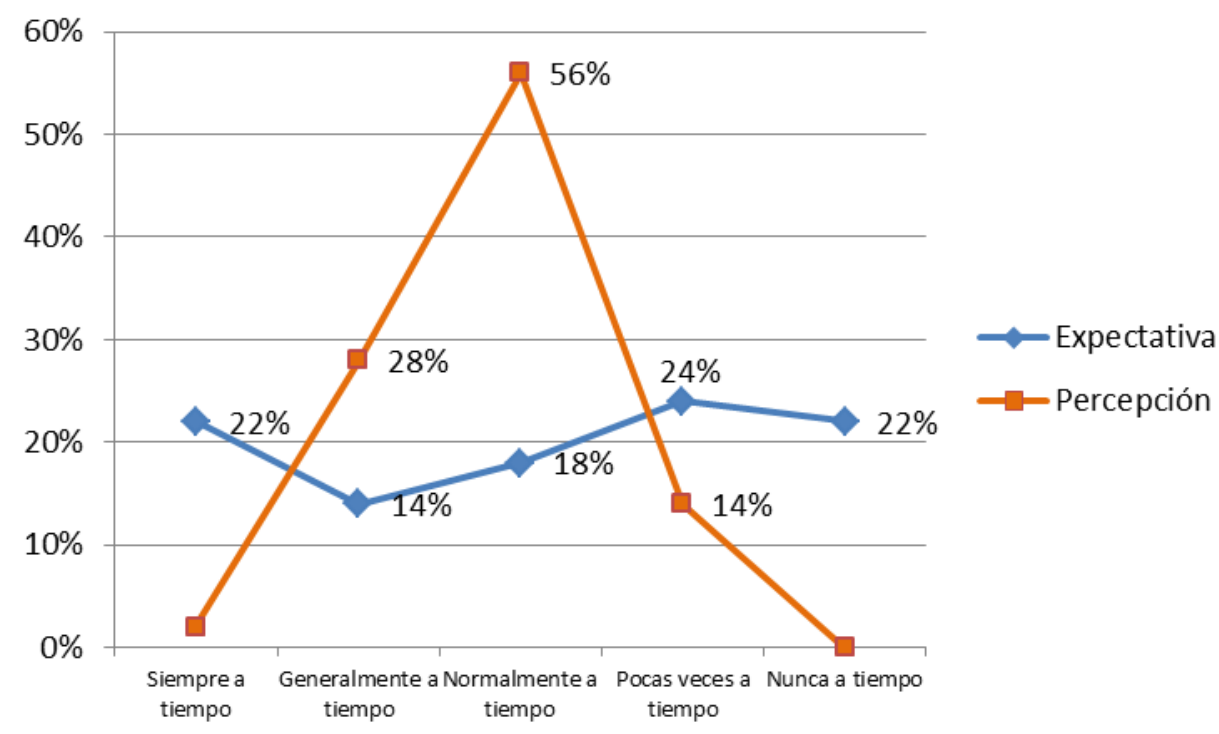

Como resultante, el nivel de satisfacción de los encuestados respecto del "Tiempo de Cumplimiento del Trabajo" resulta de la siguiente manera: 


\section{Brecha Expectativa / Percepción Tiempo}

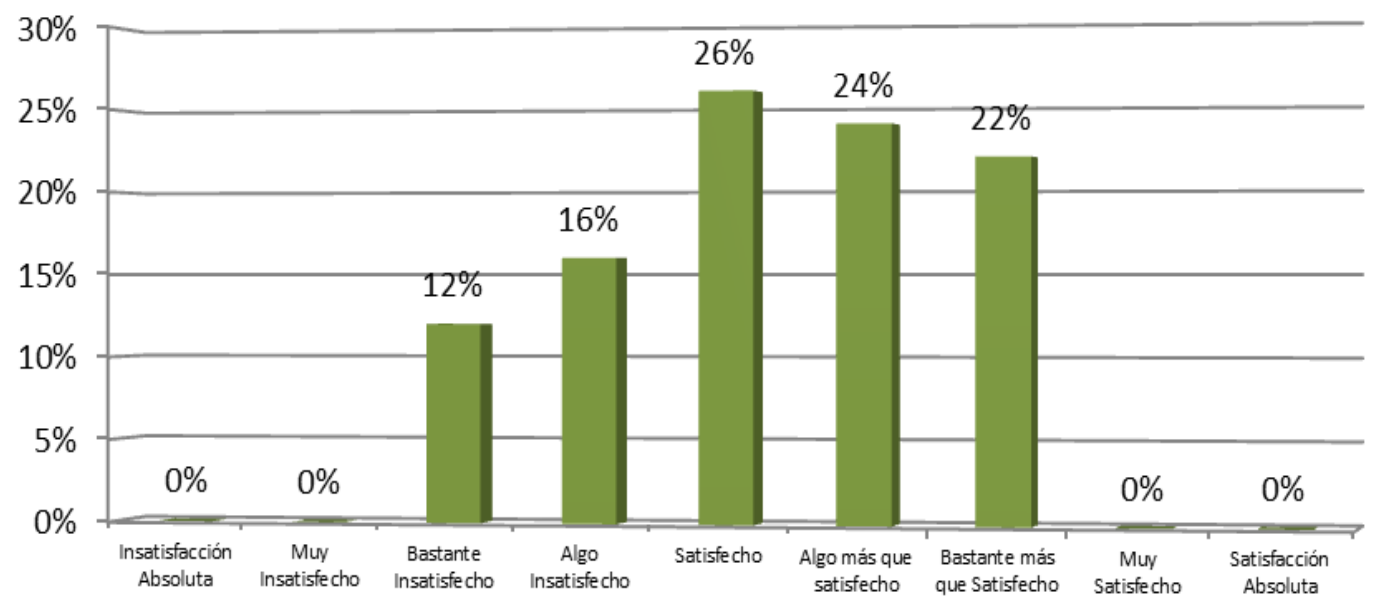

La media aritmética del Nivel de Satisfacción es de 1,55 de "Satisfecho" a "Algo más que Insatisfecho".

\subsubsection{Eficiencia del servicio}

Este elemento se evaluó bajo la escala siguiente:

\begin{tabular}{c|c}
\hline & Escala \\
\hline 1 & Exento de Errores \\
\hline 2 & Muy Eficiente \\
\hline 3 & Eficiente \\
\hline 4 & Deficiente \\
\hline 5 & Con serias deficiencias \\
\hline
\end{tabular}

- Expectativa

Los encuestados esperan que la Eficiencia del servicio de Obras Particulares sea "Muy Eficiente" con tendencia a "Eficiente".

Media aritmética: 2,46. 


\section{Expectativa Eficiencia del Servicio Municipal}

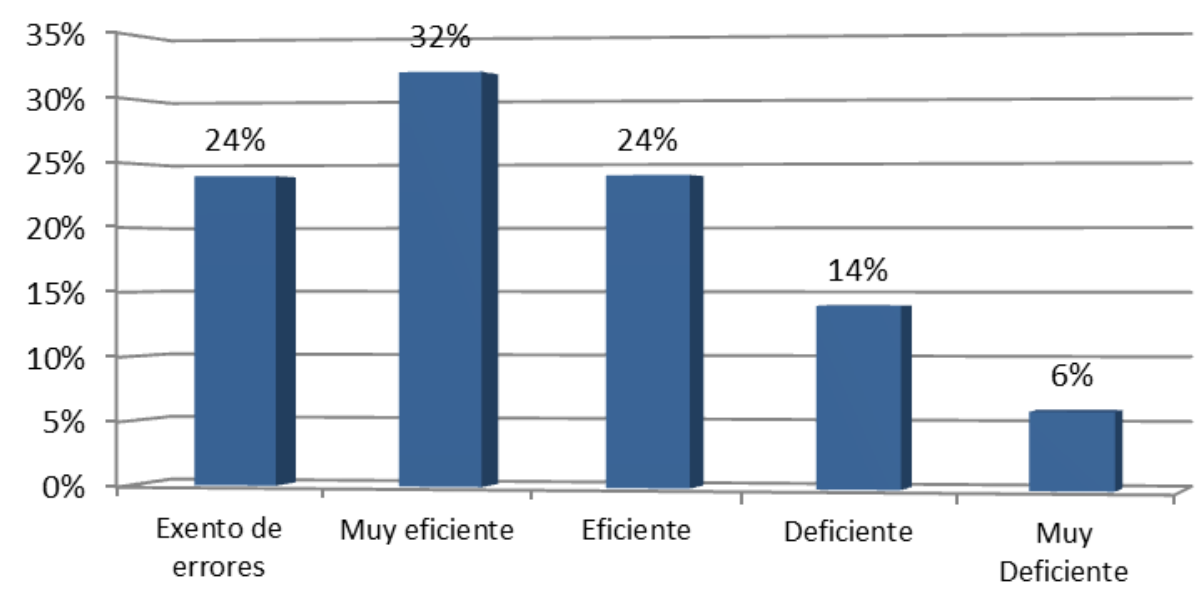

- Percepción

Los encuestados perciben que la Eficiencia del Trabajo es "Muy Eficiente" con tendencia a "Eficiente":

Media aritmética: 2,14.

\section{Percepción Eficiencia del servicio Municipal}

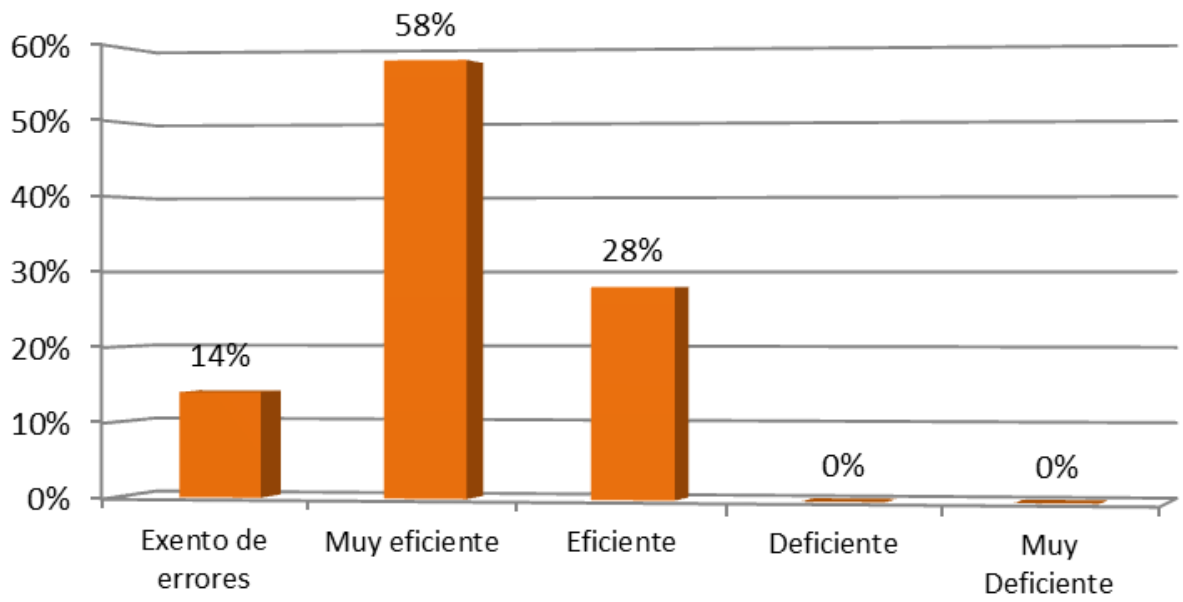

- Nivel de Satisfacción "Eficiencia"

En el siguiente gráfico se puede observar juntos la apreciación y expectativas por parte de los clientes sobre la Eficiencia del Trabajo del servicio.

Se observa menor expectativa de que la Eficiencia sea "Muy Eficiente" a "Eficiente". 


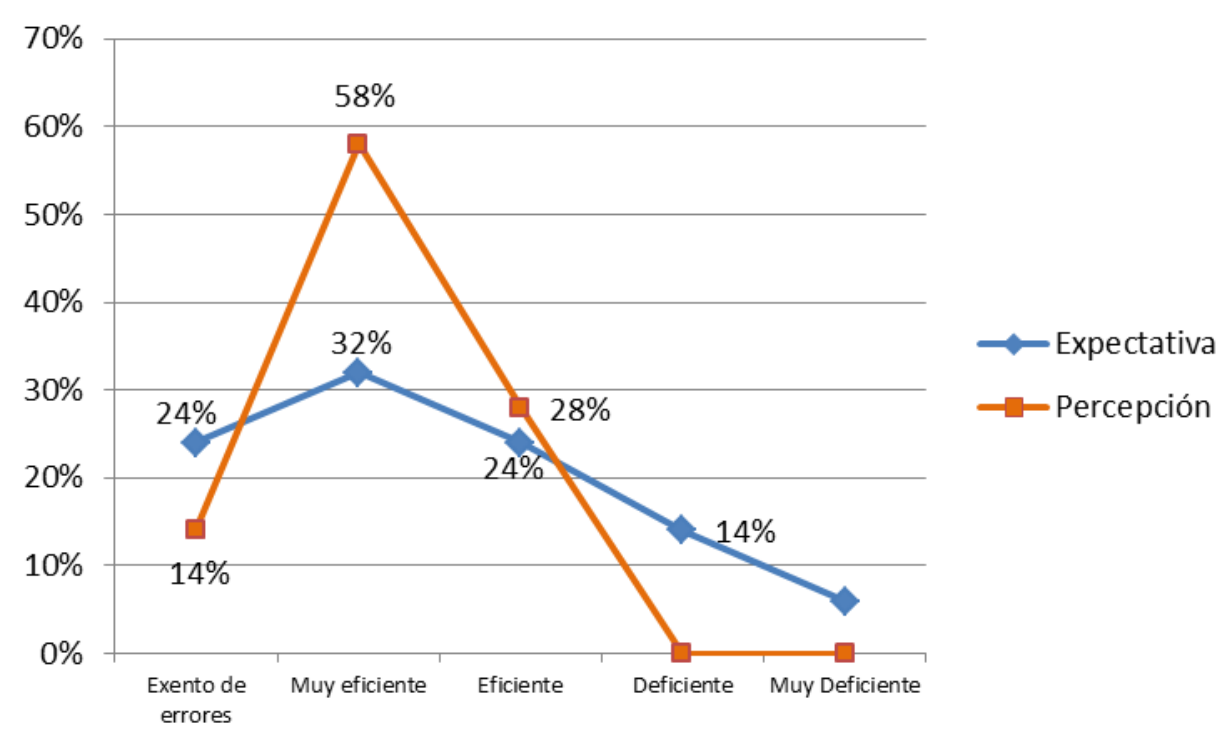

Como resultante, el nivel de satisfacción de los encuestados respecto de la "Eficiencia" resulta de la siguiente manera:

\section{Brecha Expectativa / Percepción Eficiencia}

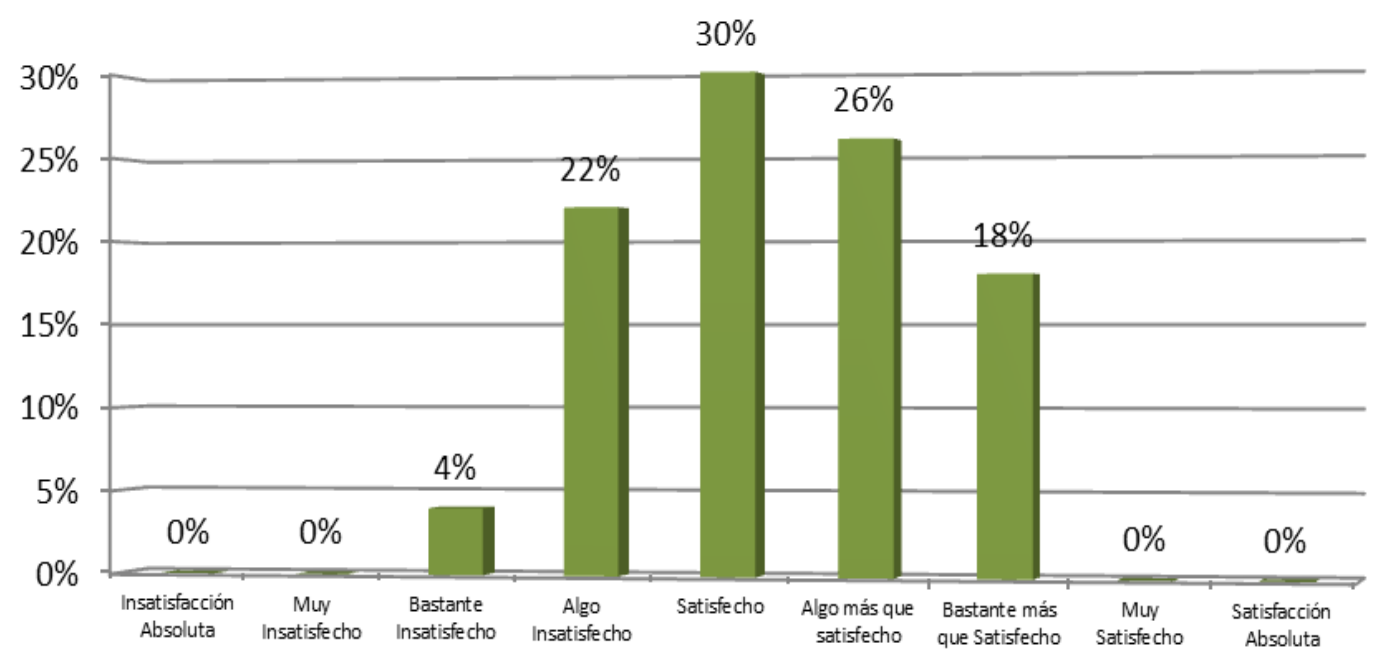

La media aritmética del Nivel de Satisfacción es de 1,77, de "Satisfecho" a "Algo más Satisfecho".

\subsubsection{Total datos Dimensión II "Confiabilidad"}

Total Datos Dimensión II

\begin{tabular}{l|l}
\hline Percepción & 2,248 \\
\hline Expectativa & 2,652 \\
\hline Nivel satisfacción & $\mathbf{0 , 4 0 4}$ \\
\hline Diferencia & $\mathbf{0 , 4 0 4}$ \\
\hline
\end{tabular}


- Expectativa Vs. Percepción Acumulada Dimensión II

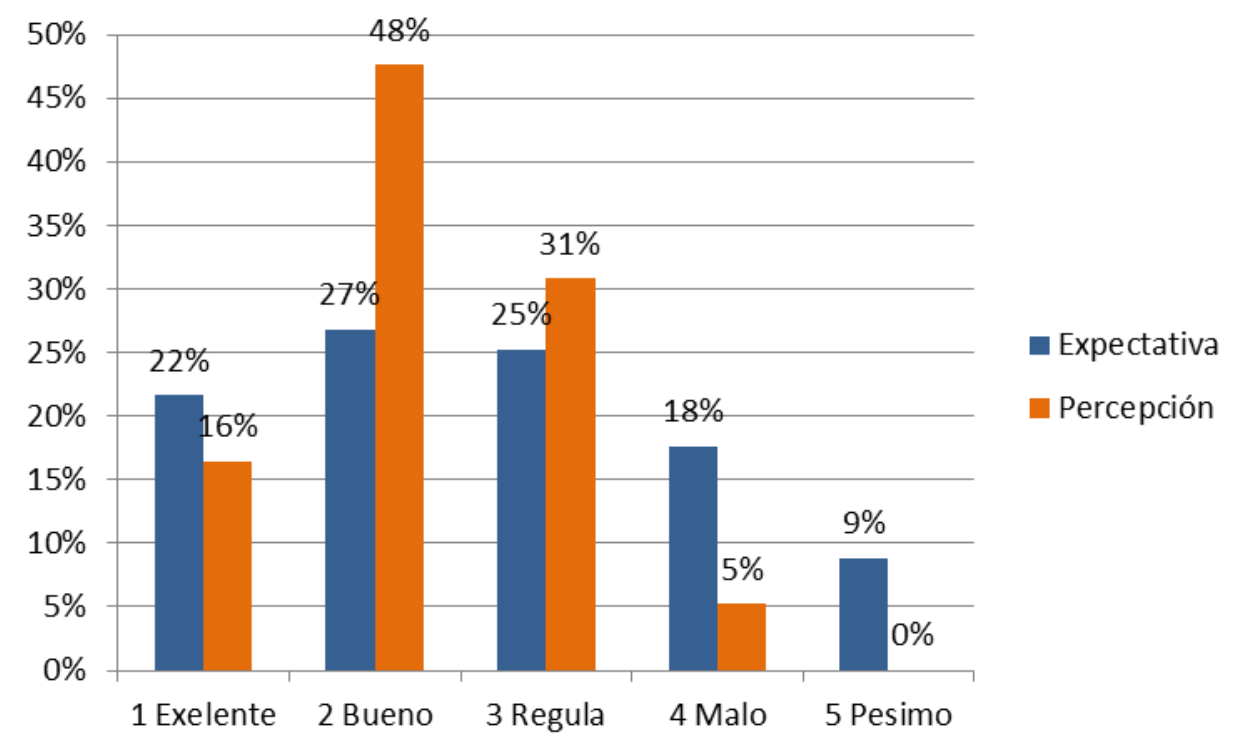

- Total Brecha Expectativa - Percepción Dimensión II

\section{Brecha Total Confiabilidad}

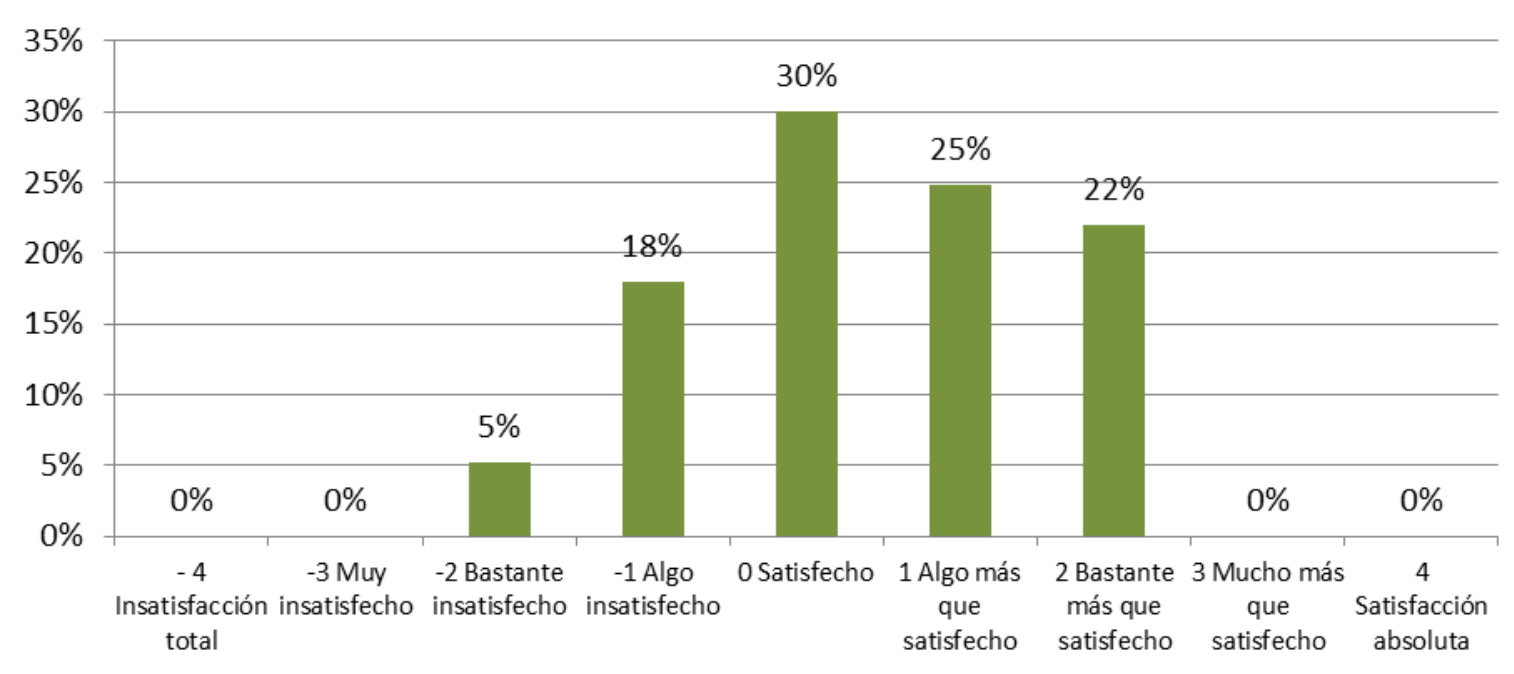

\subsection{Análisis Dimensión III: Capacidad de Respuesta}

A continuación se exponen los resultados obtenidos en la Dirección de Obras Particulares respecto de la disposición y voluntad de los empleados para ayudar al cliente y proporcionar el servicio; Comunicación con los Empleados, Velocidad, Disponibilidad de Atención y Disponibilidad de Atención Inmediata frente a otras Actividades. 


\subsubsection{Comunicación con los Empleados}

Este elemento se evaluó bajo la escala siguiente:

\begin{tabular}{c|c}
\hline & Escala \\
\hline 1 & Excelente \\
\hline 2 & Muy Bueno \\
\hline 3 & Bueno \\
\hline 4 & Regular \\
\hline 5 & Pésimo \\
\hline
\end{tabular}

- Expectativa

Los encuestados esperan que la Comunicación con los Empleados del servicio de Obras Particulares que sea "Muy Buena".

Media aritmética: 2,46 .

\section{Expectativa Nivel de Comunicación}

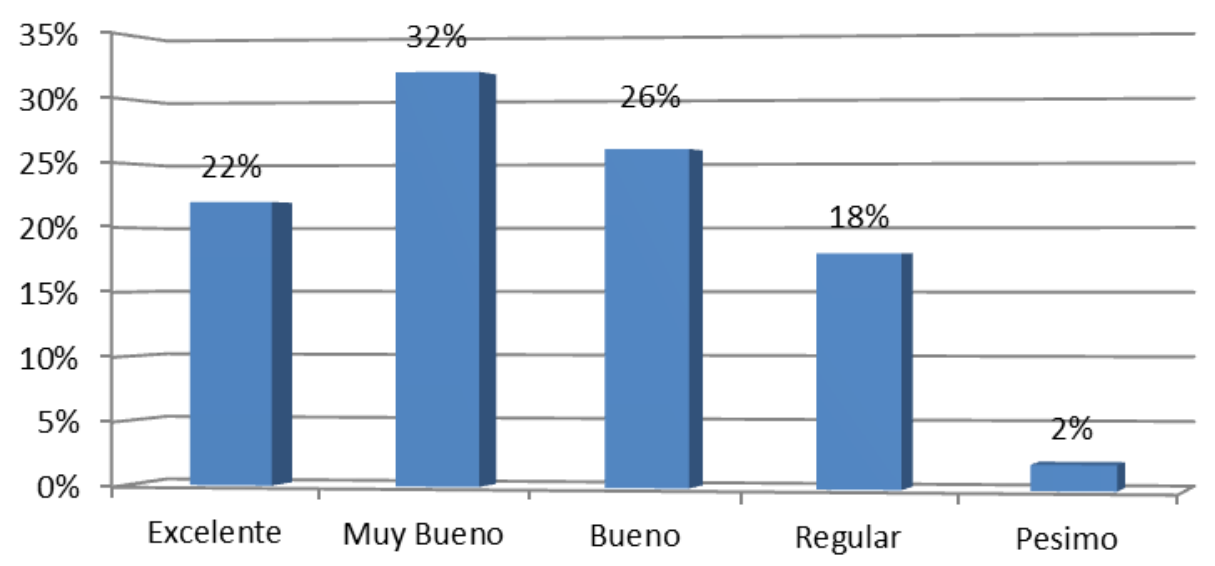

- Percepción

Los encuestados perciben que la Comunicación con los Empleados del servicio de Obras Particulares, es "Muy buena" con tendencia a "Excelente". Media aritmética: 2,68 . 


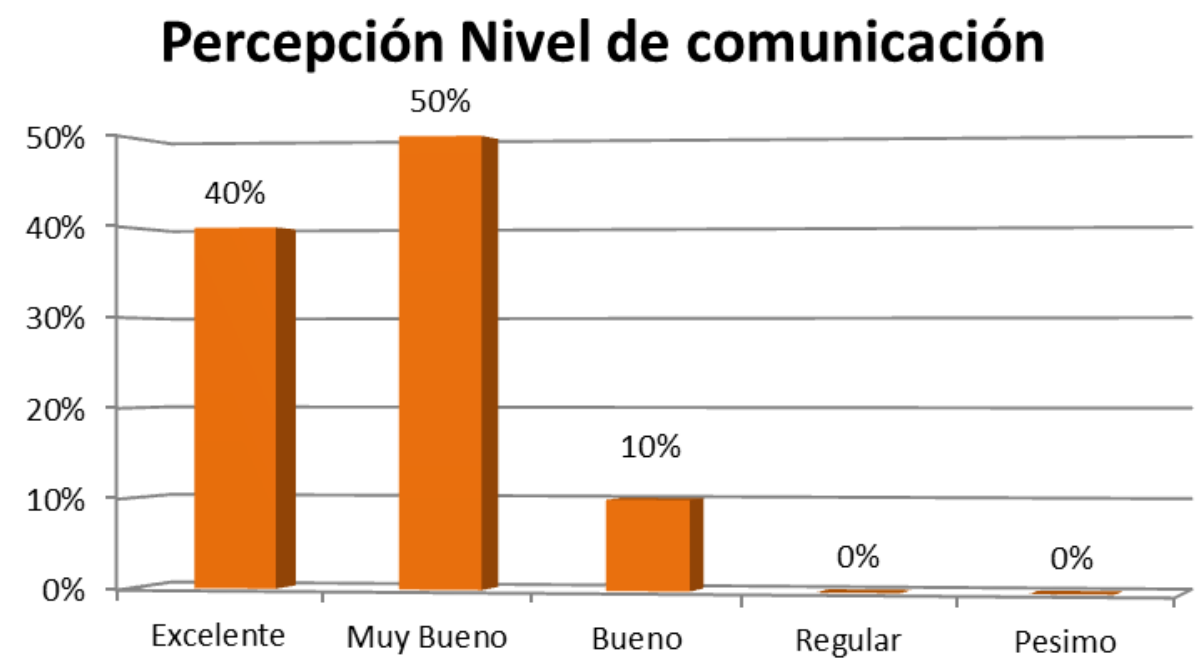

- Nivel de Satisfacción "Comunicación con los Empleados"

En el siguiente gráfico se puede observar juntos la apreciación y expectativas por parte de los clientes sobre la Comunicación con los Empleados.

Se observa menor expectativa de que la Comunicación con los Empleados sea "Muy Buena" a "Excelente", siendo mayor la percepción "Excelente" a "Muy buena".

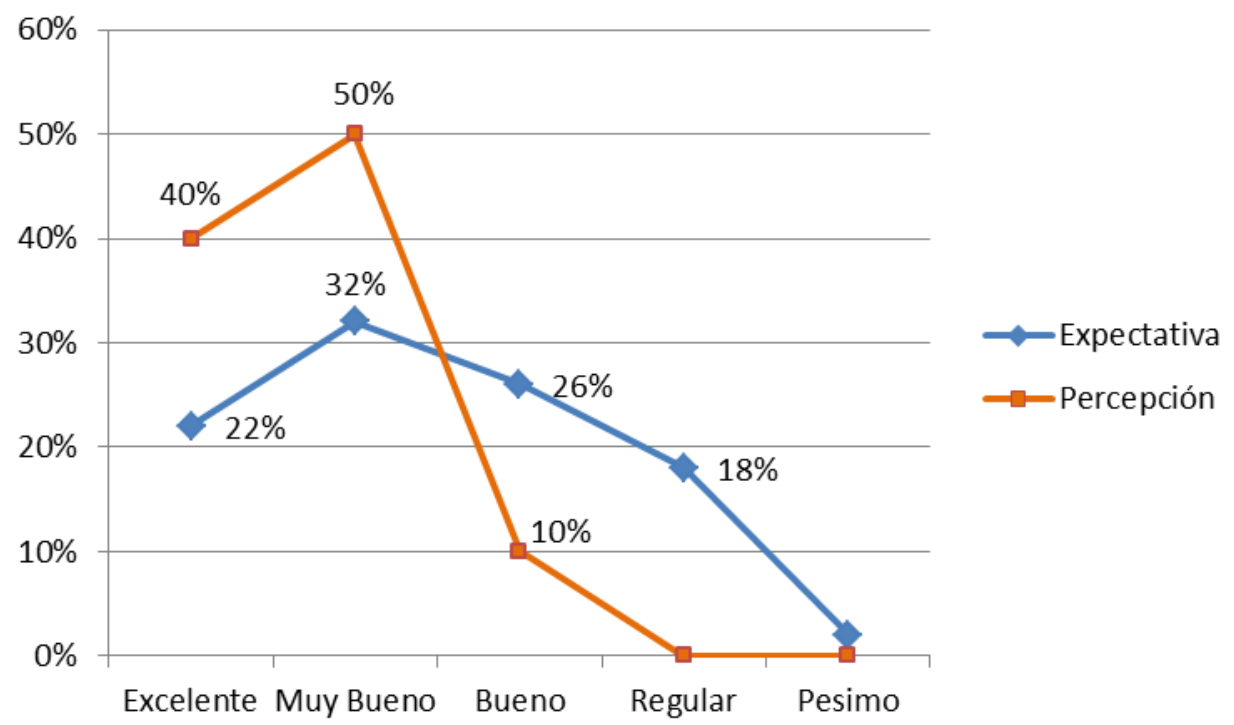

Como resultante, el nivel de satisfacción de los encuestados respecto de los "Comunicación con los Empleados" resulta de la siguiente manera: 


\section{Brecha expectativa / Percepción Nivel de Comunicación}

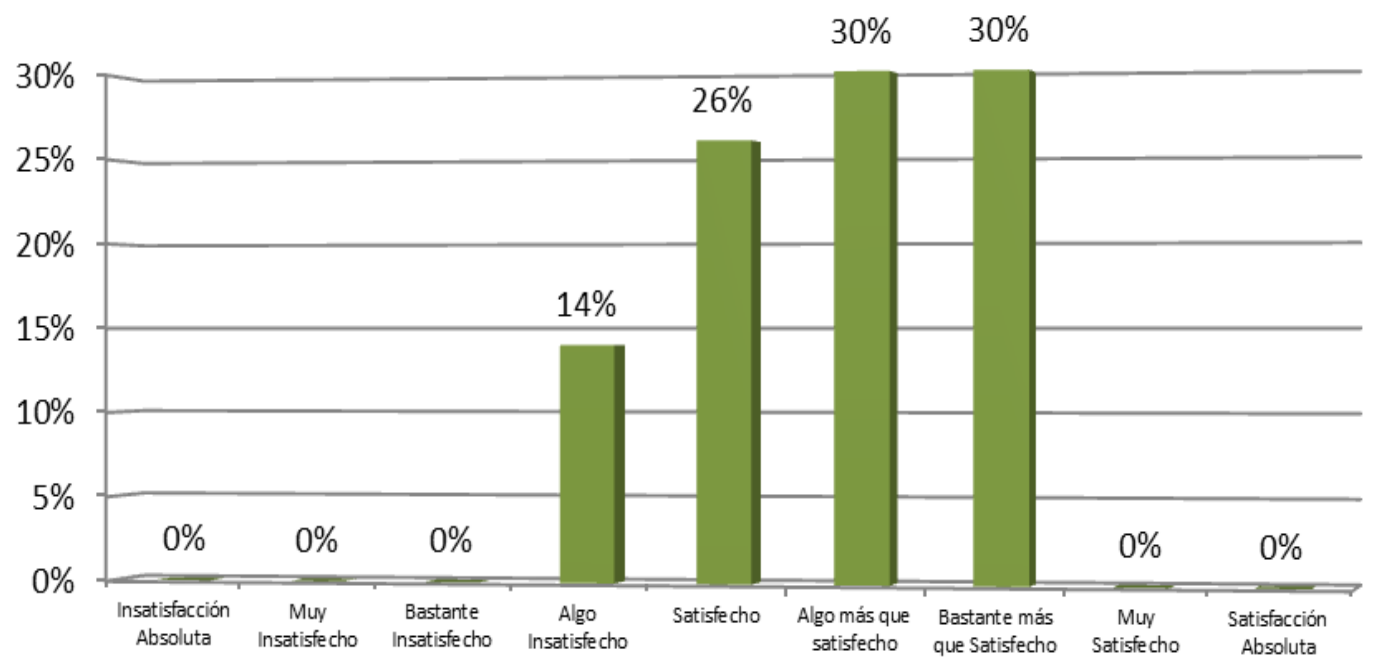

La media aritmética del Nivel de Satisfacción es de 4,22, de "Algo más que satisfecho" y "Bastante más que satisfecho".

\subsubsection{Velocidad del servicio}

Este elemento se evaluó bajo la escala siguiente:

\begin{tabular}{c|c}
\hline & Escala \\
\hline 1 & Muy Rápido \\
\hline 2 & Rápido \\
\hline 3 & Normal \\
\hline 4 & Lenta \\
\hline 5 & Muy Lento \\
\hline
\end{tabular}

- Expectativa

Los encuestados esperan de la Velocidad del servicio de Obras Particulares que sea "Muy Rápido" con tendencia a "Rápido".

Media aritmética: 2,72 


\section{Expectativa Velocidad del Servicio}

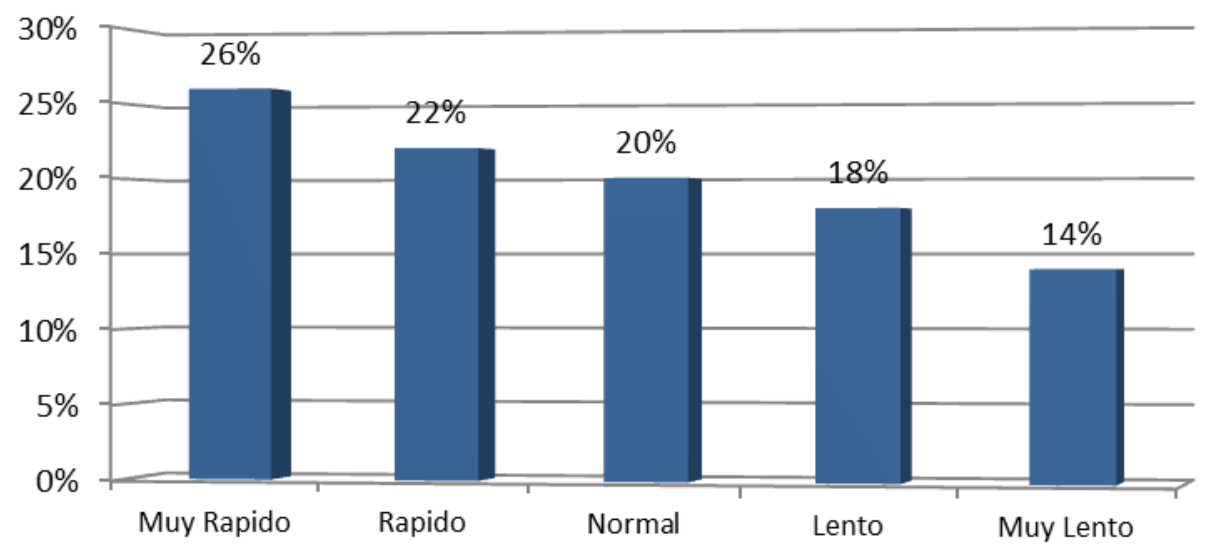

- Percepción

Los encuestados perciben que la Velocidad del servicio de Obras Particulares es "Rápido" con tendencia a "Normal":

Media aritmética: 2,66.

\section{Percepción Velocidad del Servicio}

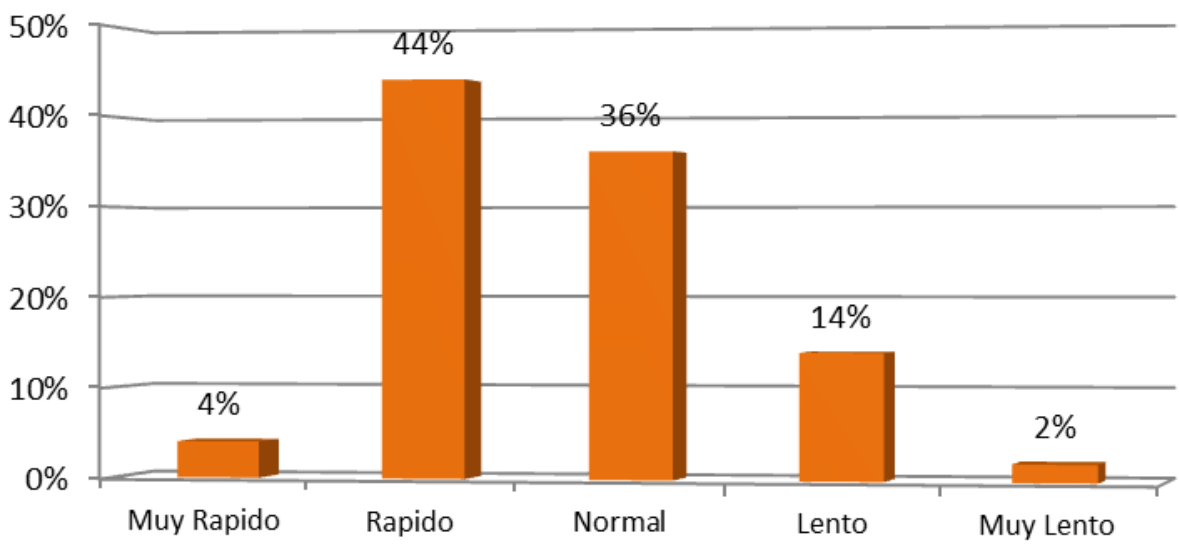

- Nivel de Satisfacción "Velocidad"

En el siguiente gráfico se puede observar juntos la apreciación y expectativas por parte de los clientes sobre la Velocidad del servicio.

Se observa una mayor Percepción de que la Velocidad del servicio sea "Rápida". 


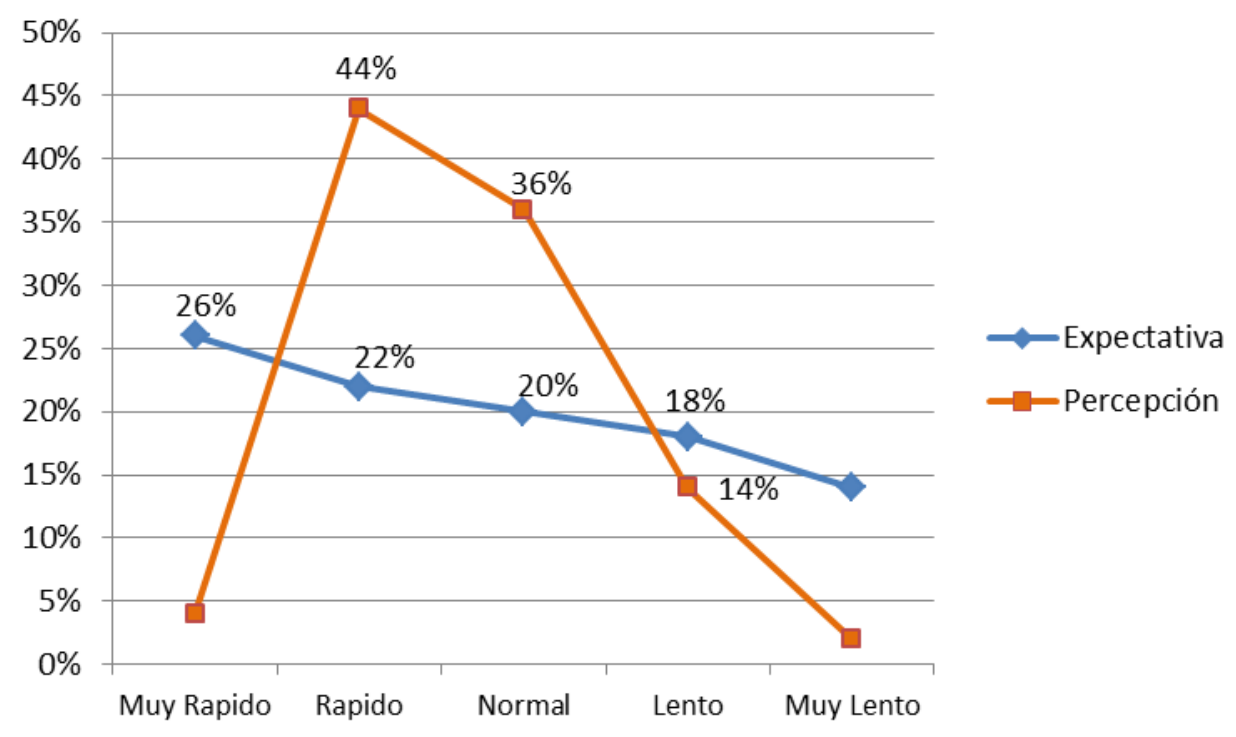

Como resultante, el nivel de satisfacción de los encuestados respecto de la "Velocidad" del servicio resulta de la siguiente manera:

\section{Brecha Expectativa / Percepción Velocidad del Servicio}

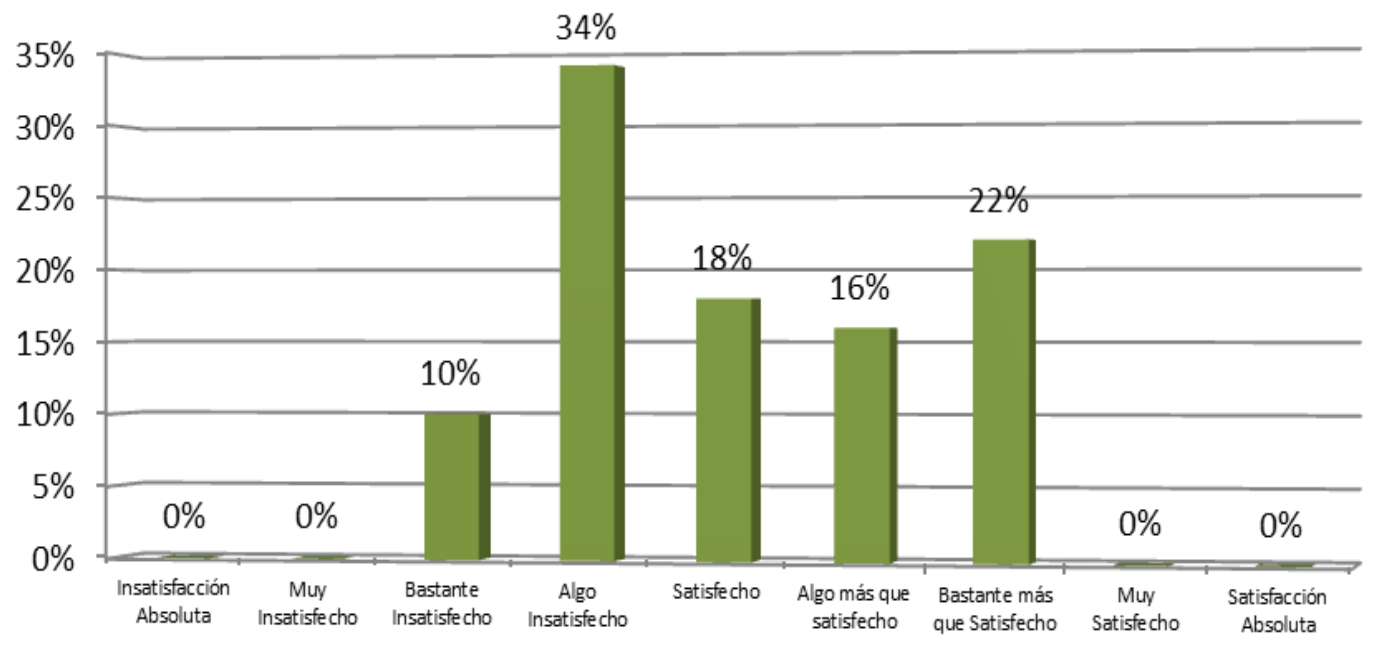

La media aritmética del Nivel de Satisfacción es de 0,33, de "Algo Insatisfecho" a "bastante Satisfecho".

\subsubsection{Disponibilidad del Servicio}

Este elemento se evaluó bajo la escala siguiente: 


\begin{tabular}{c|c}
\hline & Escala \\
\hline 1 & Siempre Disponible \\
\hline 2 & Generalmente Disponible \\
\hline 3 & Normalmente Disponible \\
\hline 4 & Poco Disponible \\
\hline 5 & Nunca Disponible \\
\hline
\end{tabular}

- Expectativa

Los encuestados esperan de la Disponibilidad del servicio de Obras Particulares que sea "Siempre Disponible" con tendencia a "Normalmente Disponible".

Media aritmética: 2,52 .

\section{Expectativa Disponibilidad de atención}

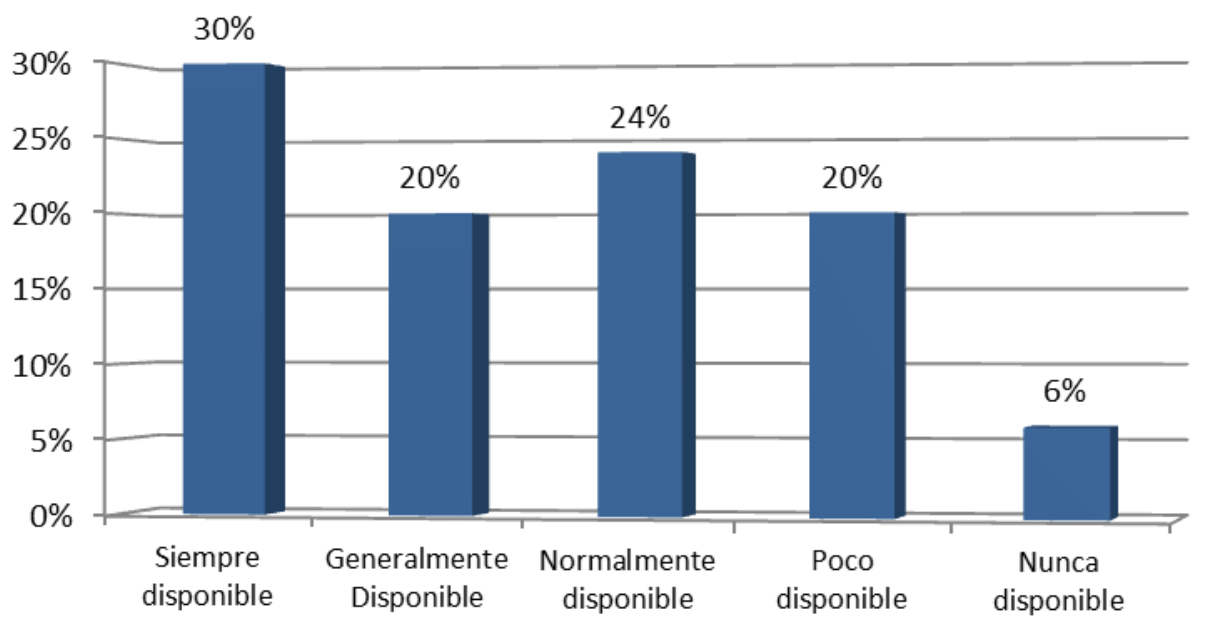

- Percepción

Los encuestados perciben que la Disponibilidad del servicio de Obras Particulares es "Generalmente Disponible" con tendencia a "Normalmente Disponible".

Media aritmética: 2,18 . 


\section{Percepción Disponibilidad de atención}

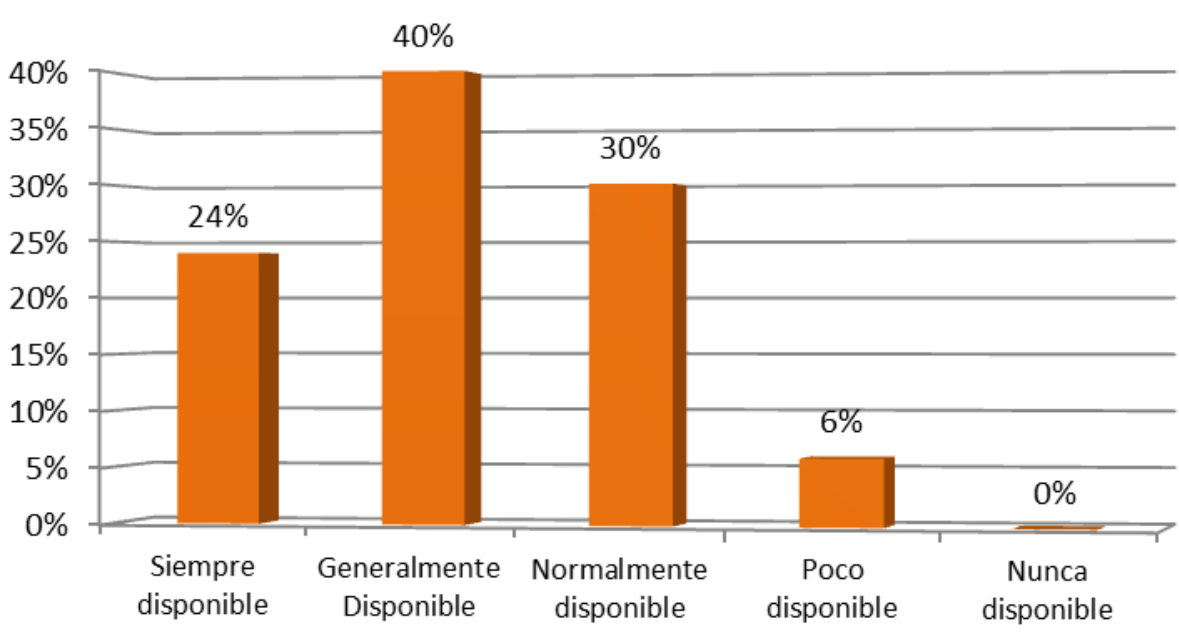

- Nivel de Satisfacción "Disponibilidad de Atención"

En el siguiente gráfico se puede observar juntos la apreciación y expectativas por parte de los clientes sobre la Disponibilidad del servicio.

Se observa mayor percepción de que la Disponibilidad del servicio sea "Generalmente Disponible" a "Normalmente Disponible", mientras se observa menor expectativa para "Generalmente Disponible".

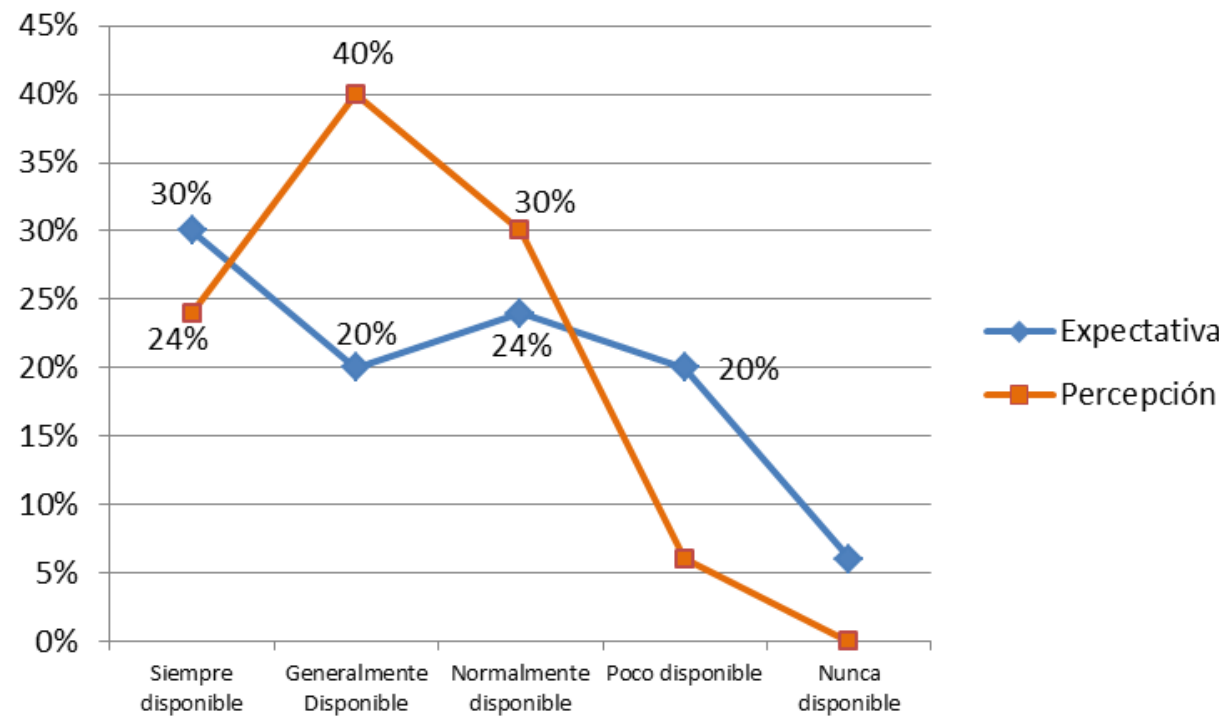

Como resultante, el nivel de satisfacción de los encuestados respecto de la "Disponibilidad del servicio" resulta de la siguiente manera: 


\section{Brecha Expectativa / Percepción Disponibilidad}

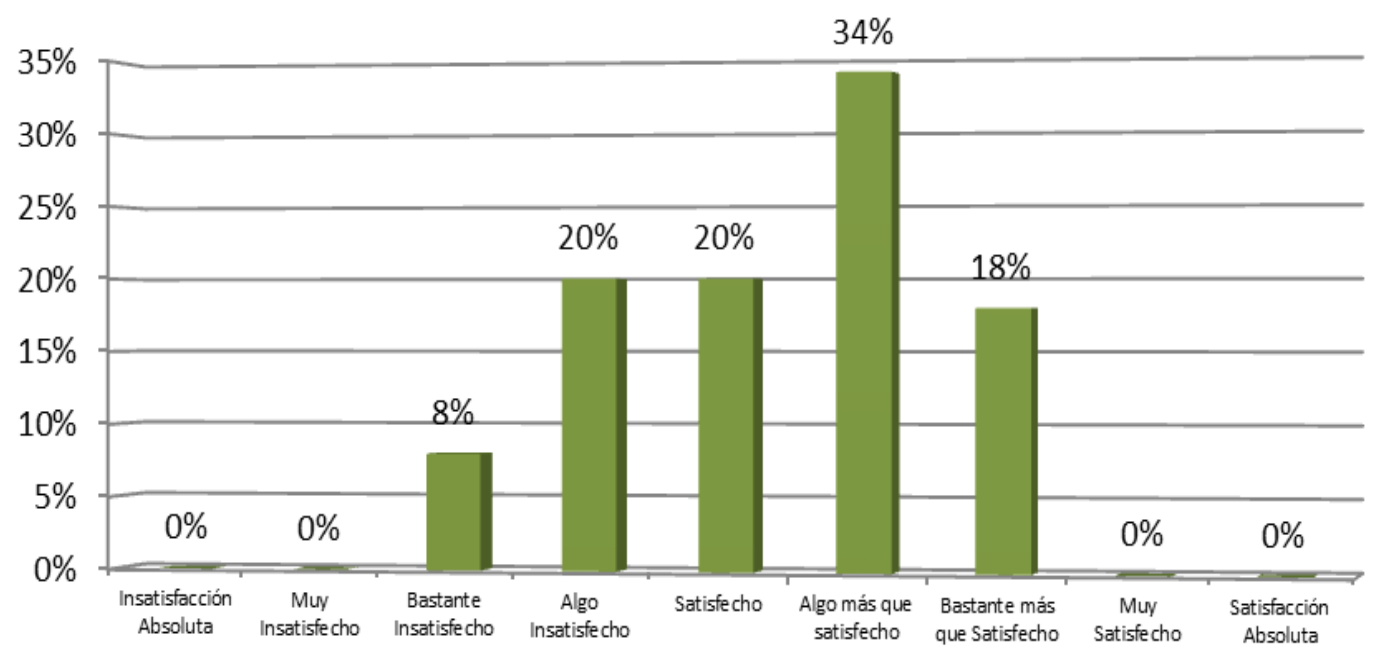

La media aritmética del Nivel de Satisfacción es de 1,88, de "Algo más que satisfecho" a "Satisfecho".

\subsubsection{Disponibilidad de Atención Inmediata frente a otras Actividades}

Este elemento se evaluó bajo la escala siguiente:

\begin{tabular}{c|c}
\hline & Escala \\
\hline 1 & Siempre Disponible \\
\hline 2 & Generalmente Disponible \\
\hline 3 & Normalmente Disponible \\
\hline 4 & Poco Disponible \\
\hline 5 & Nunca Disponible \\
\hline
\end{tabular}

- Expectativa

Los encuestados esperan de la Disponibilidad de Atención Inmediata frente a otras Actividades del servicio de Obras Particulares que sea "Nunca Disponible" con tendencia a "Poco Disponible".

Media aritmética: 3,72 . 


\section{Expectativa Atención Inmediata}

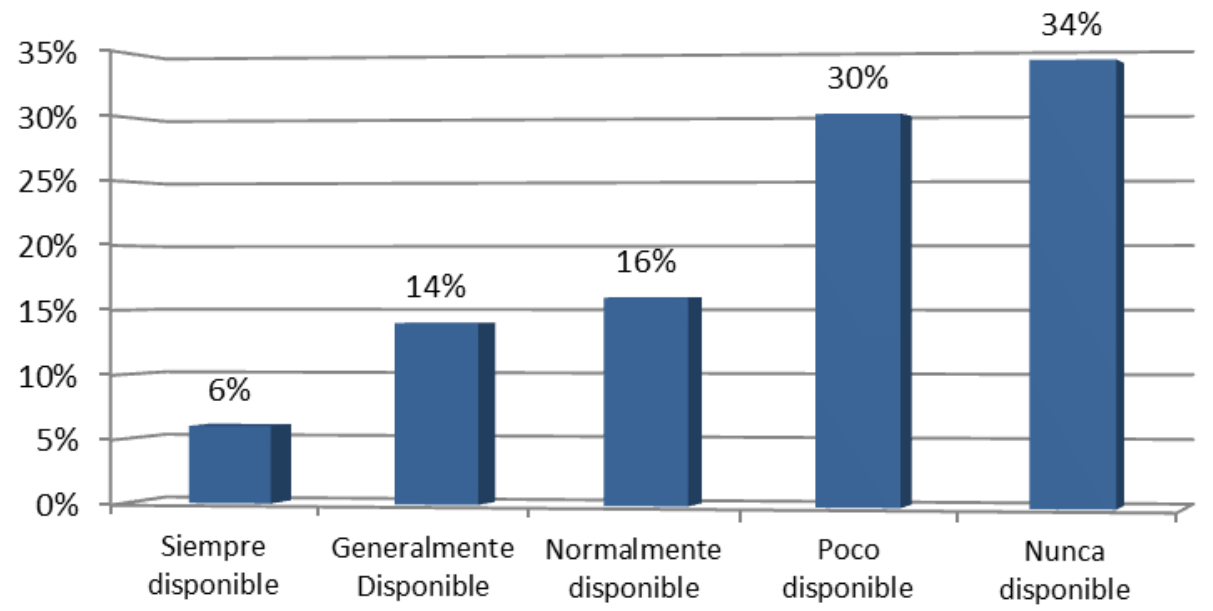

- Percepción

Los encuestados perciben que la Disponibilidad de Atención Inmediata frente a otras Actividades del servicio de Obras Particulares es "Normalmente Disponible" con tendencia "General Disponible".

Media aritmética: 2,98.

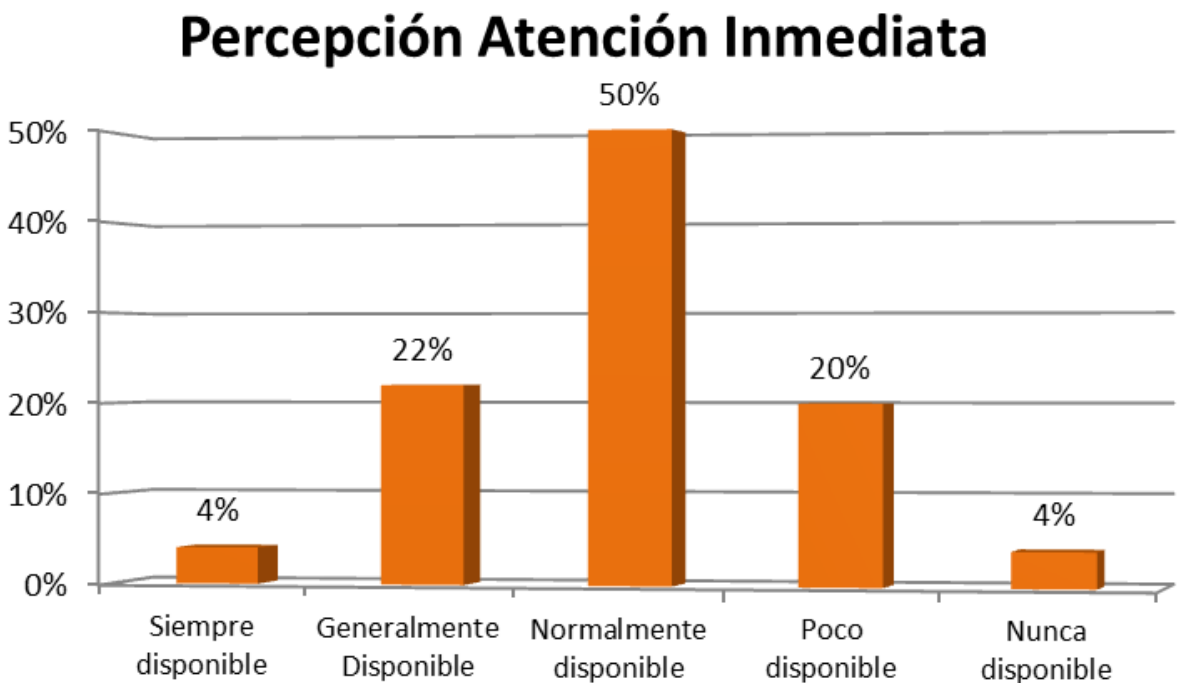

- Nivel de Satisfacción "Disponibilidad de Atención Inmediata frente a otras Actividades"

En el siguiente gráfico se puede observar juntos la apreciación y expectativas por parte de los clientes sobre la Disponibilidad de Atención Inmediata frente a otras Actividades del servicio. 
Se observa mayor expectativa de que la Disponibilidad de Atención Inmediata frente a otras Actividades del servicio sea "Nunca Disponible", mientras se observa mayor percepción "Normalmente Disponible".

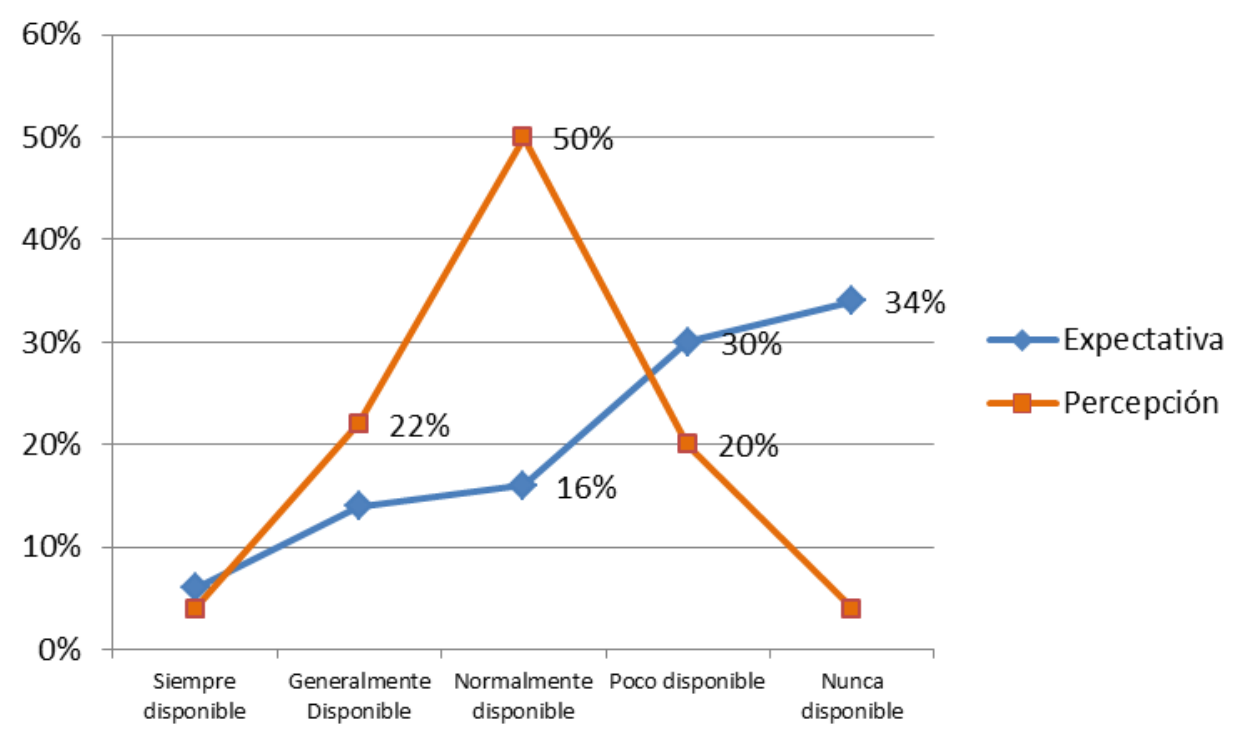

Como resultante, el nivel de satisfacción de los encuestados respecto de la "Disponibilidad de Atención Inmediata frente a otras Actividades" del servicio resulta de la siguiente manera:

\section{Brecha Expectativa / Percepción Atención Inmediata}

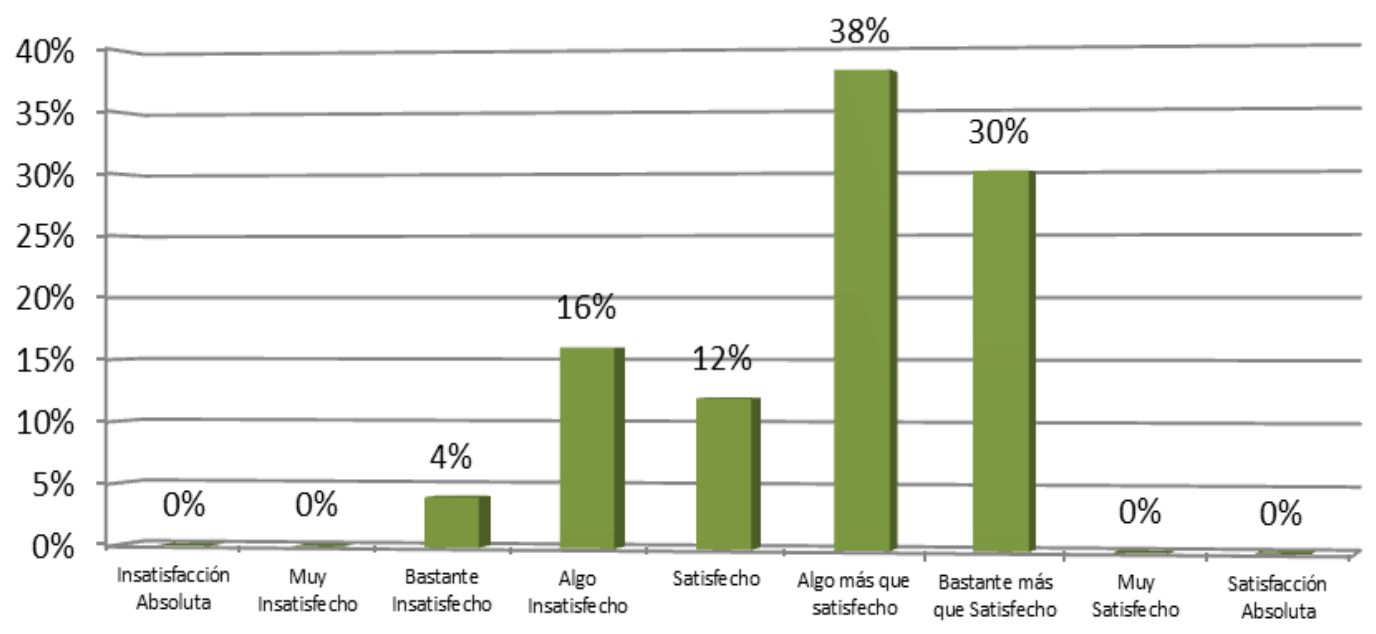

La media aritmética del Nivel de Satisfacción es de 4,11, de "Algo más que satisfecho" a "Bastante más que Satisfecho". 


\subsubsection{Total datos Dimensión III "Capacidad de Respuesta"}

\begin{tabular}{l|c}
\hline \multicolumn{2}{c}{ Total Datos Dimensión III } \\
\hline Percepción & 2,38 \\
\hline Expectativa & 2,855 \\
\hline Nivel satisfacción & $\mathbf{0 , 4 7 5}$ \\
\hline Diferencia E-P & $\mathbf{0 , 4 7 5}$ \\
\hline
\end{tabular}

- Expectativa Vs. Percepción Total Dimensión III

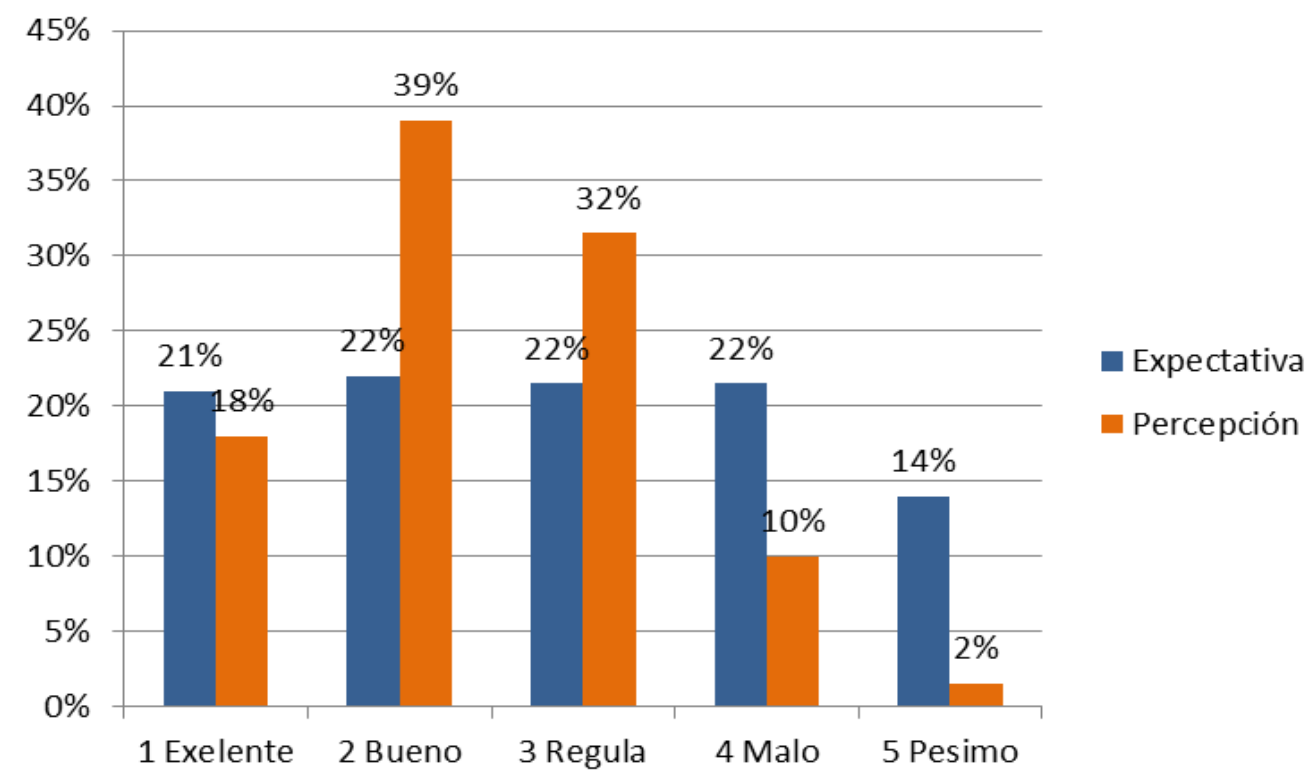

- Brecha Expectativa Vs. Percepción Dimensión III

\section{Brecha Total Capacidad de Respuesta}

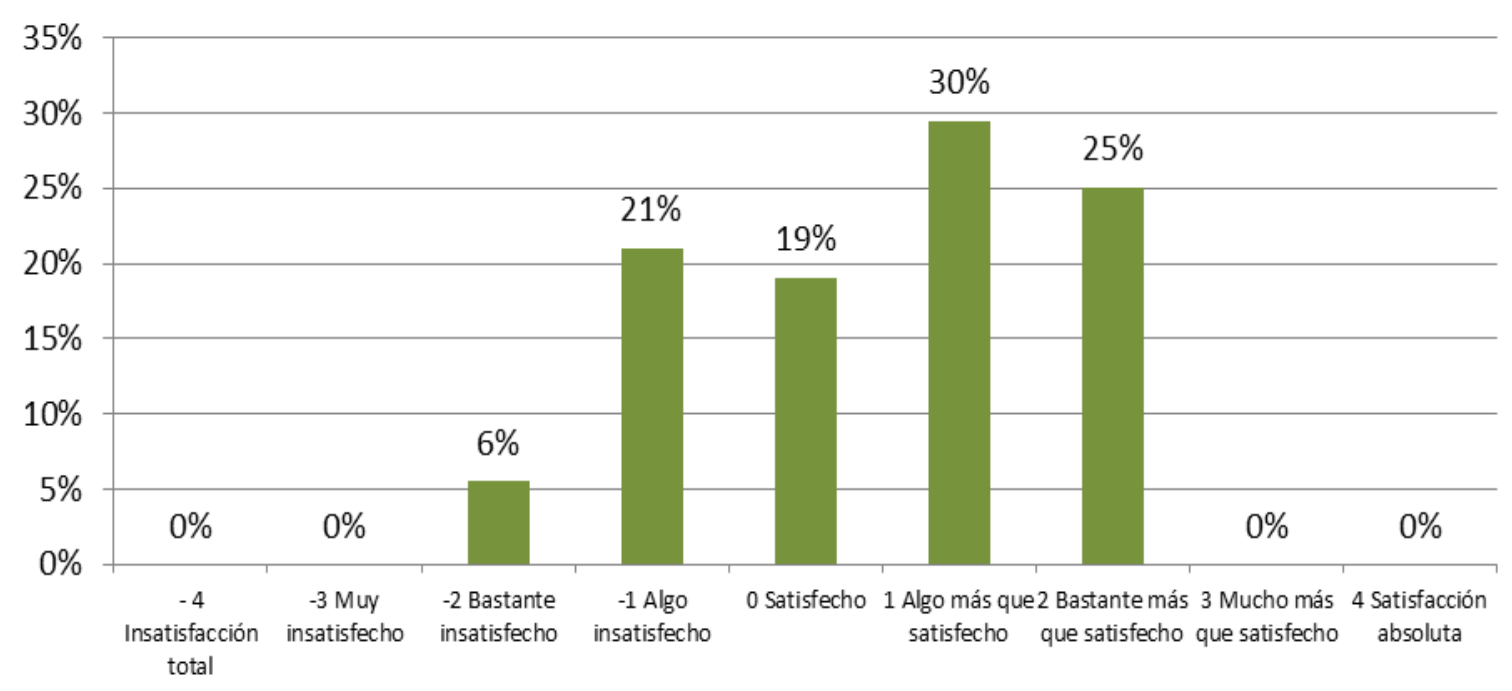




\subsection{Análisis Dimensión IV: Seguridad}

A continuación se exponen los resultados obtenidos en el Servicio de Obras Particulares respecto de la conocimiento y atención mostrados por los empleados y sus habilidades para inspirar credibilidad y confianza; Confianza que brinda el Comportamiento de los Empleados, Seguridad en las transacciones, Amabilidad de los Empleados y Conocimiento de los Empleados.

\subsubsection{Confianza en el Comportamiento de los Empleados}

Este elemento se evaluó bajo la escala siguiente:

\begin{tabular}{c|c}
\hline & Escala \\
\hline 1 & Completa Confianza \\
\hline 2 & Muy Confiable \\
\hline 3 & Confiable \\
\hline 4 & Poco Confiable \\
\hline 5 & Absoluta Desconfianza \\
\hline
\end{tabular}

- Expectativa

Los encuestados esperan que la Confianza en el Comportamiento de los Empleados del servicio de Obras Particulares sea "Muy Confiable" con tendencia a "Completa Confianza":

Media aritmética: 2,50.

\section{Expectativa Confianza}

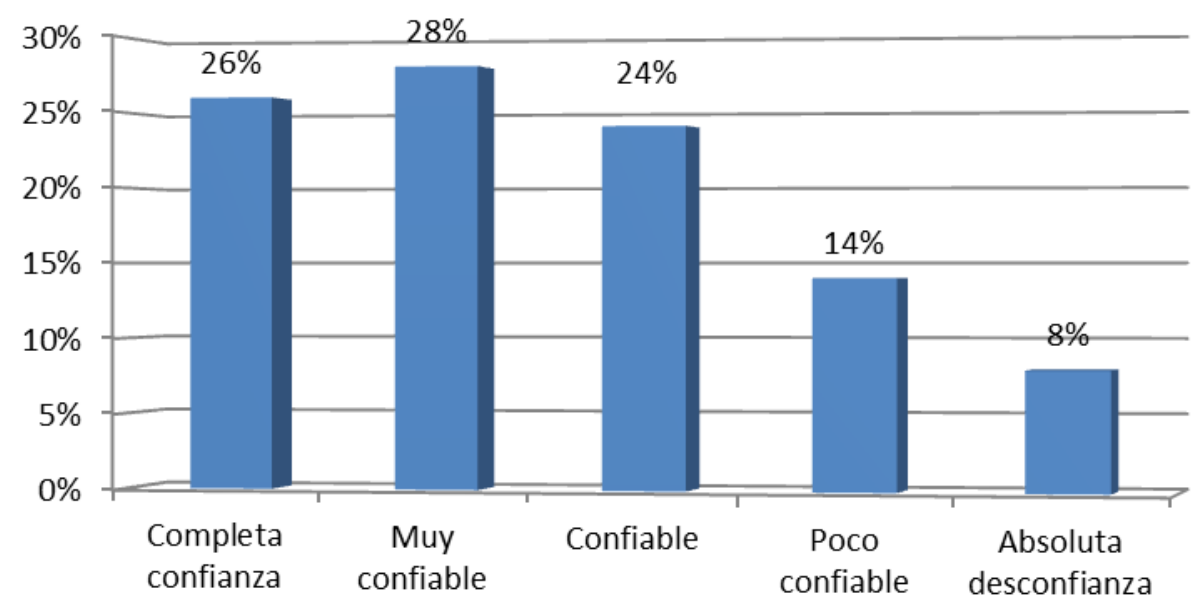




\section{- Percepción}

Los encuestados perciben que la Confianza en el Comportamiento de los Empleados del servicio de Obras Particulares es "Muy Confiable" con tendencia a "Completa Confianza".

Media aritmética: 2,02.

\section{Percepción Confianza}

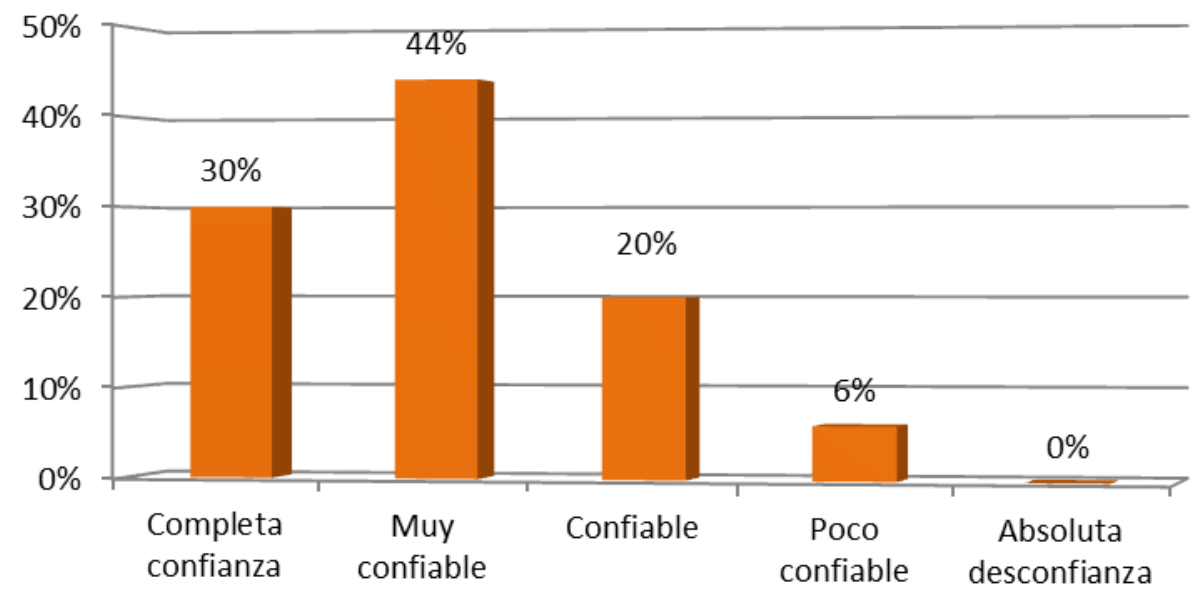

- Nivel de Satisfacción "Confianza en el Comportamiento de los Empleados"

En el siguiente gráfico se puede observar juntos la apreciación y expectativas por parte de los clientes sobre Confianza en el Comportamiento de los Empleados.

La mayor expectativa de los encuestados acerca de la Confianza en el Comportamiento de los Empleados es que sea "Muy Confiable" con un $28 \%$, Después de obtener el servicio, se observa una mayor percepción en el mismo punto del $44 \%$ en "Muy confiable". 


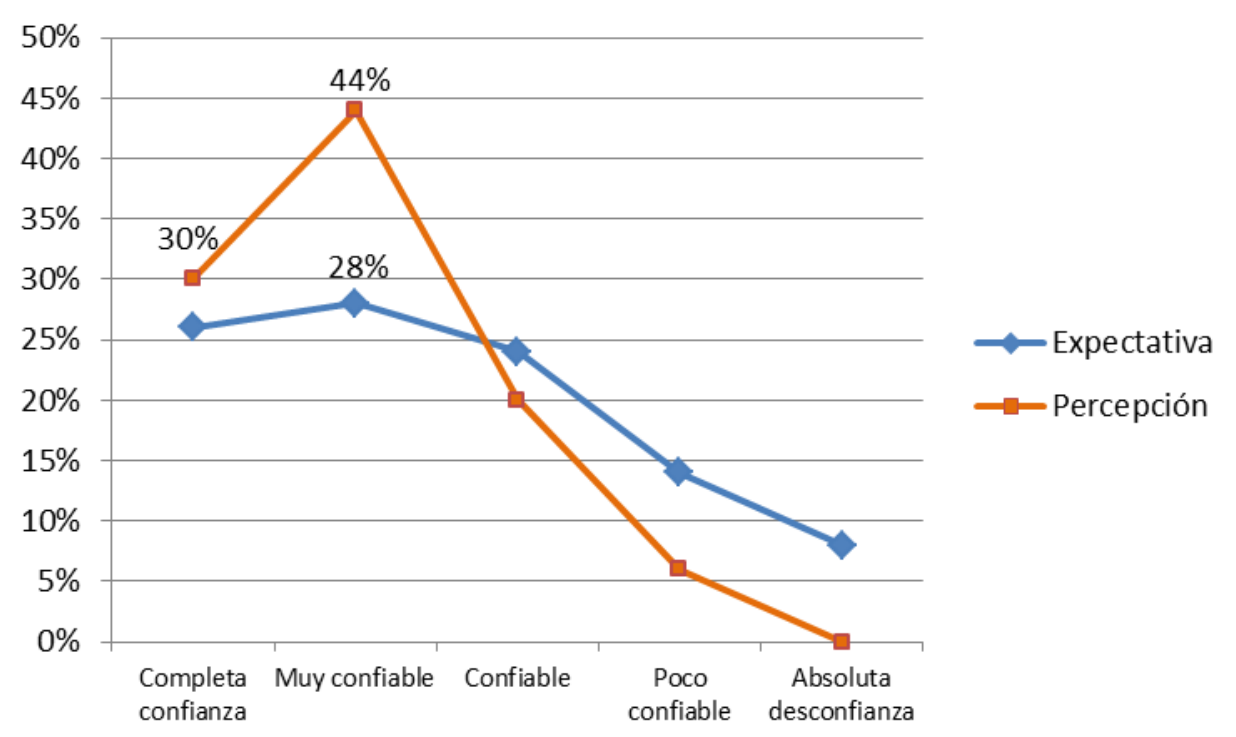

Como resultante, el nivel de satisfacción de los encuestados respecto de los "Confianza en el Comportamiento de los Empleados" resulta de la siguiente manera:

\section{Brecha expectativa / Percepción Confianza}

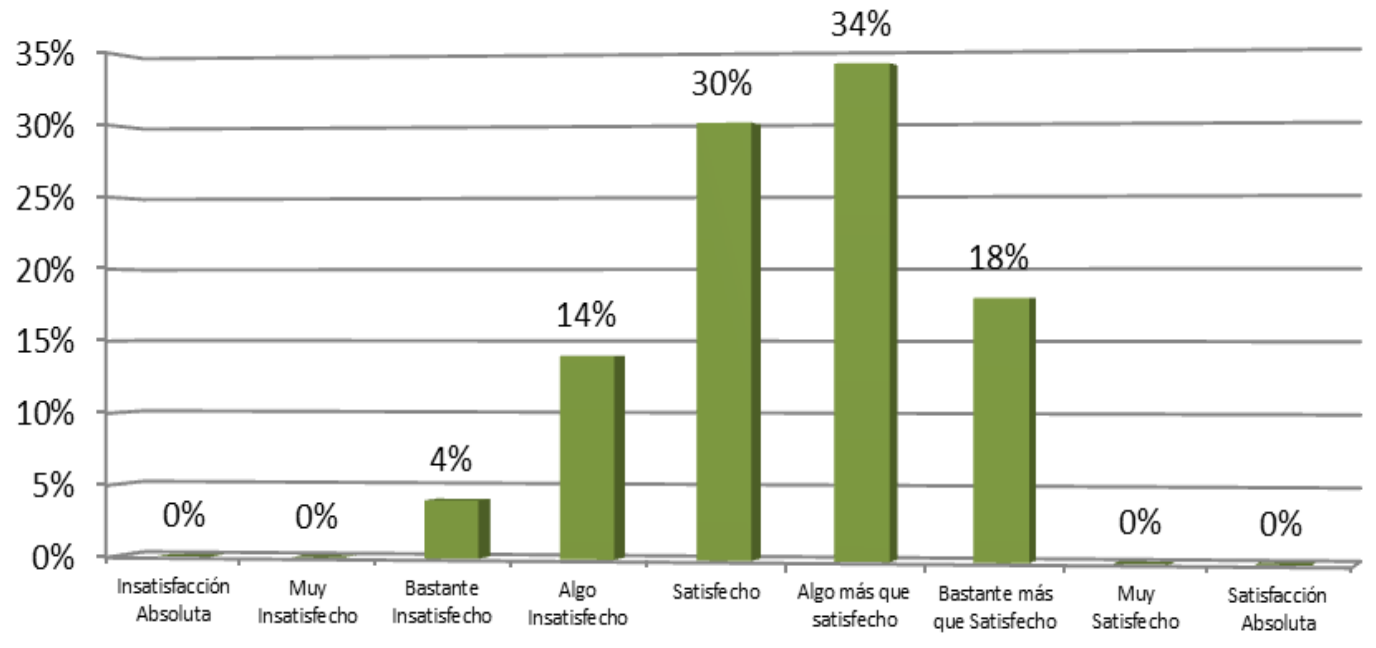

La media aritmética del Nivel de Satisfacción es de 2,66; obteniendo como principal aspecto por parte de las personas encuestadas "Algo más que Satisfecho" con el $34 \%$.

\subsubsection{Seguridad en las Transacciones}

Este elemento se evaluó bajo la escala siguiente: 


\begin{tabular}{c|c}
\hline & Escala \\
\hline 1 & Muy Seguro \\
\hline 2 & Altamente Seguro \\
\hline 3 & Seguro \\
\hline 4 & Inseguro \\
\hline 5 & Muy Inseguro \\
\hline
\end{tabular}

- Expectativa

Los encuestados esperan que la Seguridad en las Transacciones del servicio de Obras Particulares sea "Seguro".

Media aritmética: 2,46 .

\section{Expectativa Seguridad en las transacciones con el servicio}

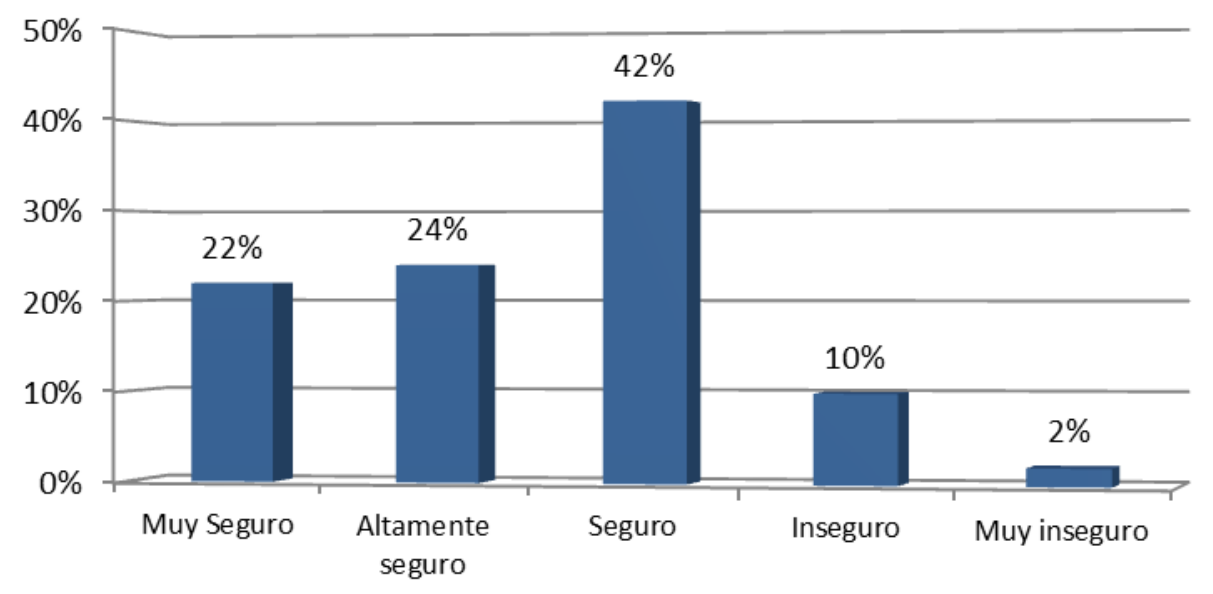

- Percepción

Los encuestados perciben que la Seguridad en las Transacciones del servicio de Obras Particulares es "Altamente Seguro" con tendencia a "Muy Seguro": Media aritmética: 1,92. 


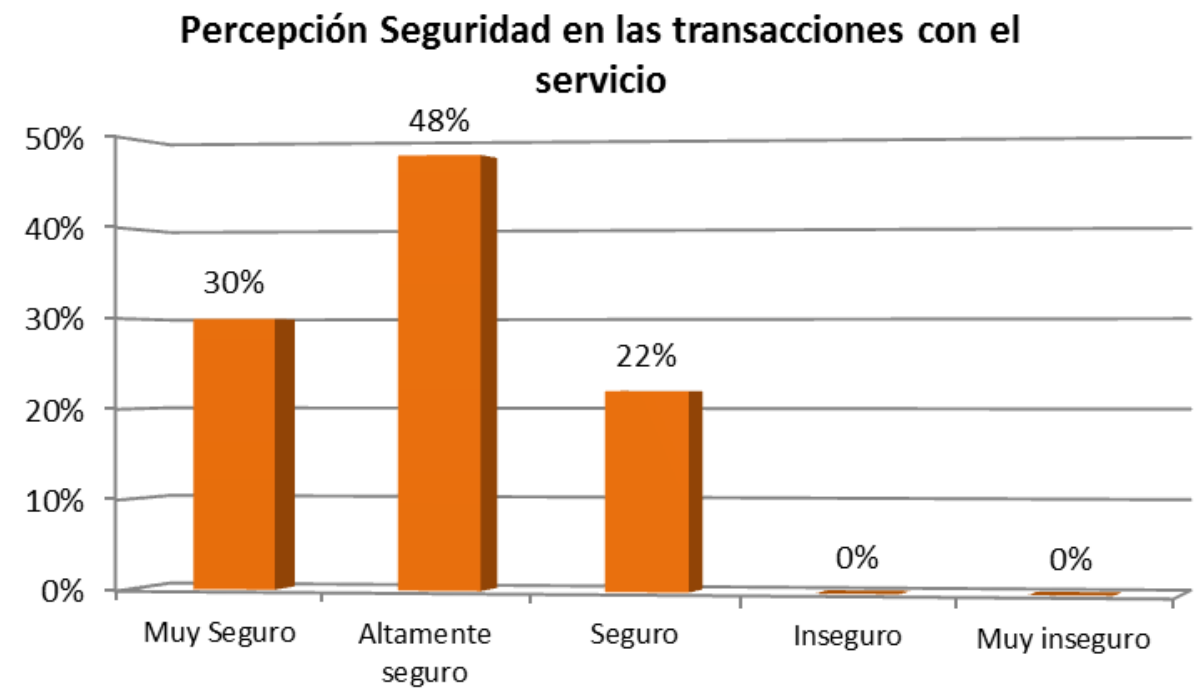

- Nivel de Satisfacción "Seguridad en las Transacciones"

En el siguiente gráfico se puede observar juntos la apreciación y expectativas por parte de los clientes sobre Seguridad en las Transacciones.

La mayor expectativa de los encuestados acerca de la seguridad en las transacciones es que sea "Seguro" con un 42\%, Después de obtener el servicio, se observa una mayor percepción en la seguridad pasando de "Seguridad" a "Altamente seguro" con un porcentaje del $48 \%$ y con tendencia a "Muy Seguro".

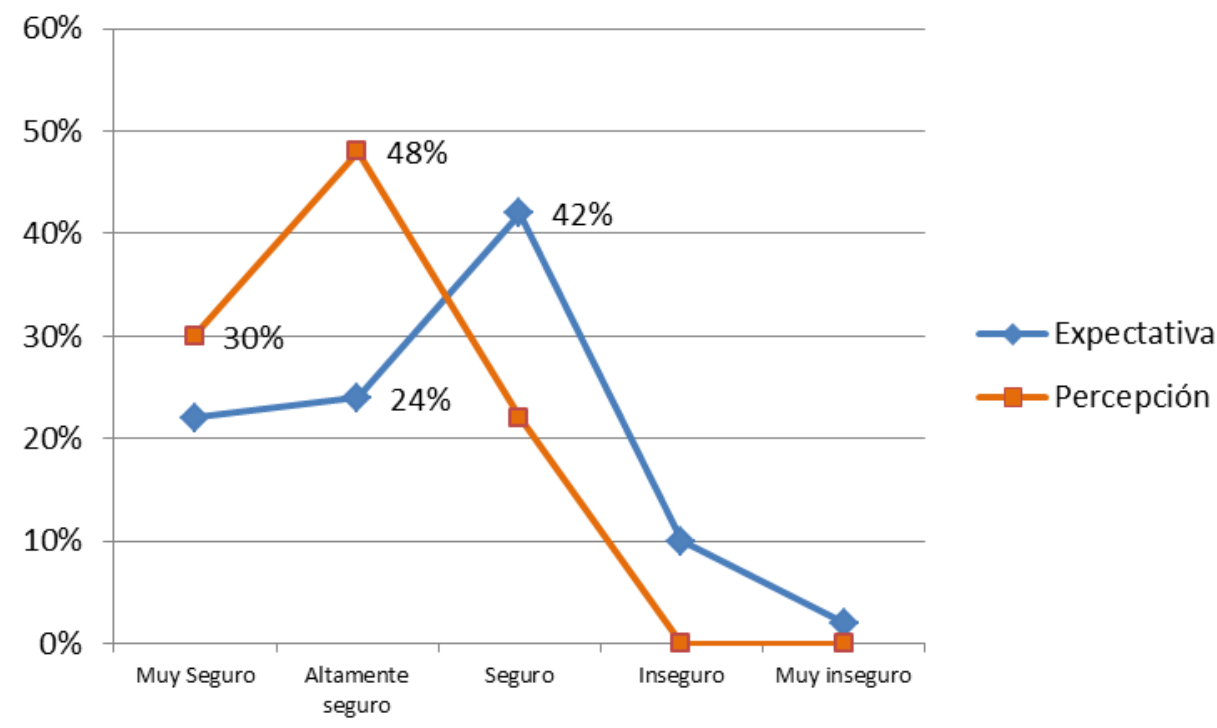


Como resultante, el nivel de satisfacción de los encuestados respecto de los "Confianza en el Comportamiento de los Empleados" resulta de la siguiente manera:

\section{Brecha Expectativa / Percepción Seguridad}

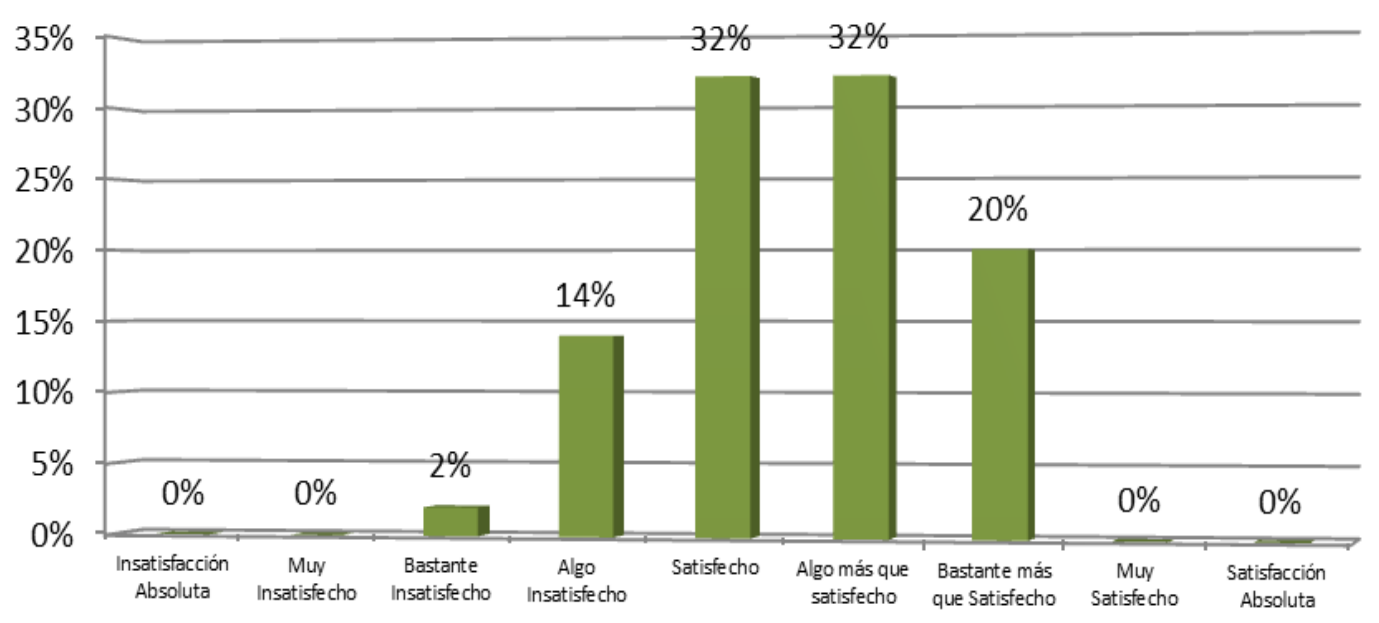

La media aritmética del Nivel de Satisfacción es de 3,00; obteniendo como principal aspecto por parte de las personas encuestadas "Satisfecho" y "Algo más que Satisfecho" con el servicio manteniendo ambos aspectos en el $32 \%$.

\subsubsection{Amabilidad}

Este elemento se evaluó bajo la escala siguiente:

\begin{tabular}{l|c}
\hline & Escala \\
\hline 1 & Muy Amable \\
\hline 2 & Amable \\
\hline 3 & Aceptable \\
\hline 4 & Descortés \\
\hline 5 & Muy Descortés \\
\hline
\end{tabular}

\section{- Expectativa}

Los encuestados esperan que la Amabilidad en el servicio de Obras Particulares sea "Aceptable" con tendencia a "Amable".

Media aritmética: 2,48. 


\section{Expectativa Amabilidad de los empleados}

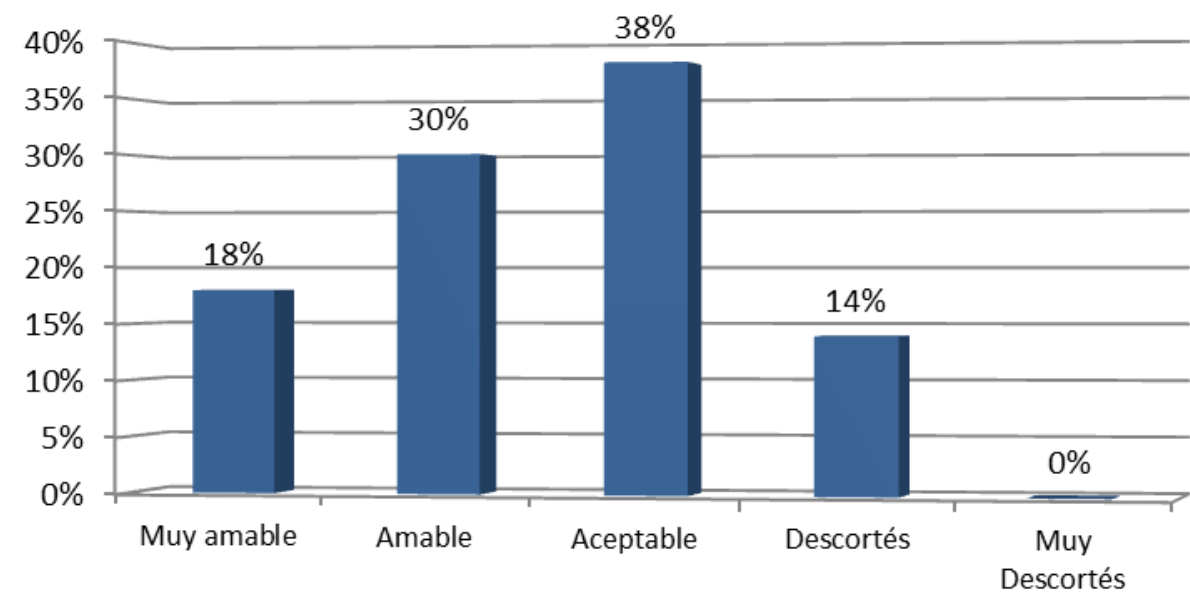

- Percepción

Los encuestados perciben que la Amabilidad en el servicio de Obras Particulares es "Muy Amable".

Media aritmética: 2,7 .

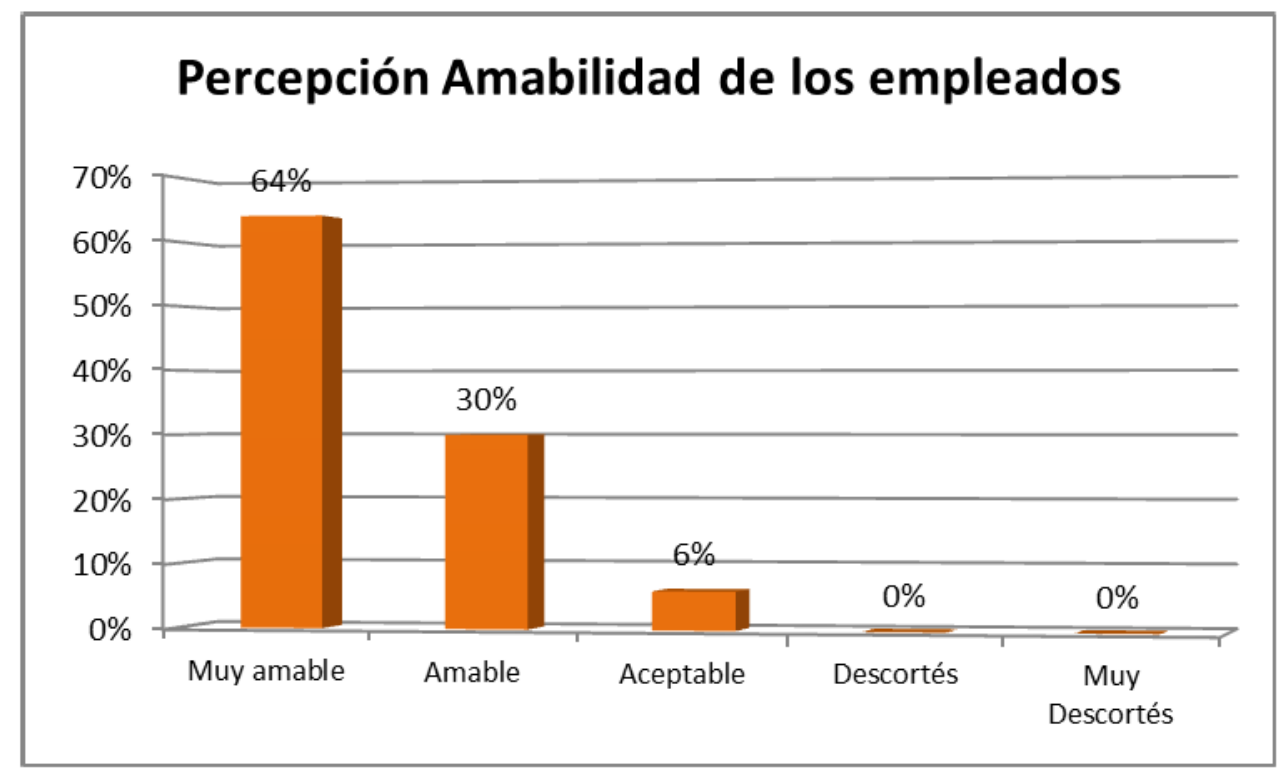

- Nivel de Satisfacción "Amabilidad"

En el siguiente gráfico se puede observar juntos la apreciación y expectativas por parte de los clientes sobre la Amabilidad en el servicio.

La mayor expectativa de los encuestados acerca de la Amabilidad del Servicio es que sea "Aceptable" con un $38 \%$, Después de obtener el servicio, se 
observa una mayor percepción en la Amabilidad del servicio pasando de "Aceptable" a "Muy amable" con un porcentaje del 64\%.

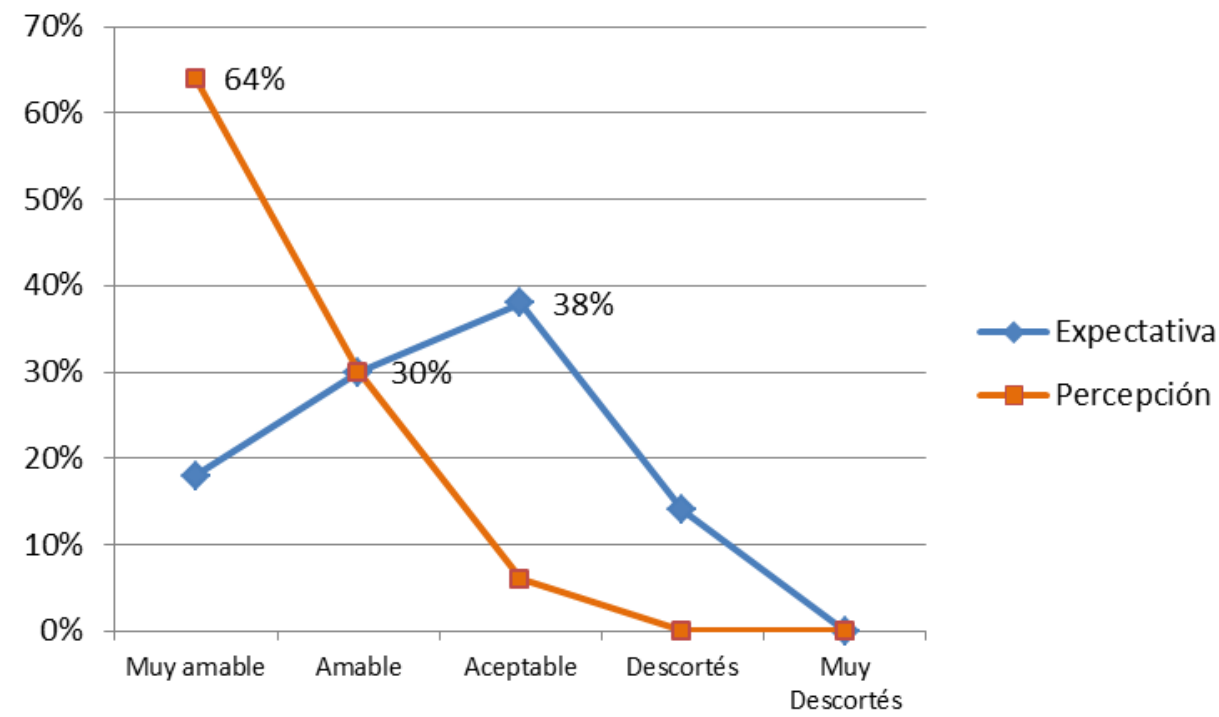

Como resultante, el nivel de satisfacción de los encuestados respecto de los "Amabilidad" resulta de la siguiente manera:

\section{Brecha Expectativa / Percepción Amabilidad}

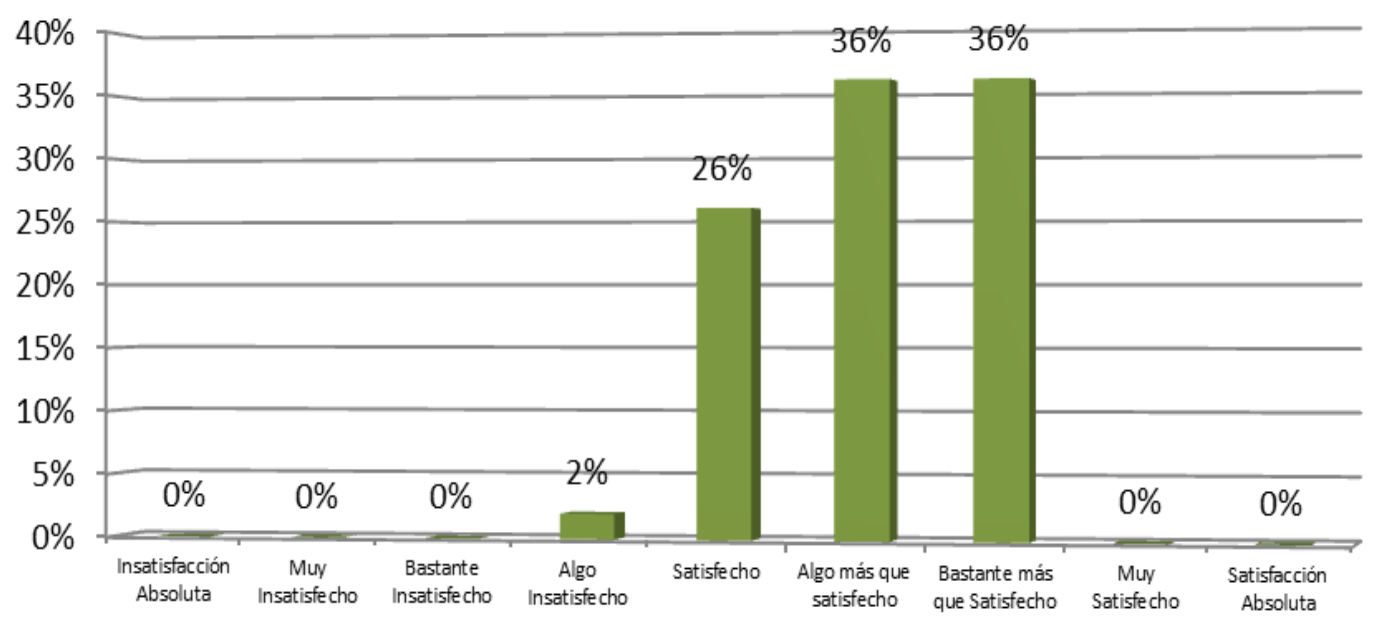

La media aritmética del Nivel de Satisfacción es de 5,88; obteniendo como principal aspecto por parte de las personas encuestadas "Bastante Satisfecho" y "Algo más que Satisfecho" con el servicio manteniendo ambos aspectos en el $36 \%$. 


\subsubsection{Conocimiento de los Empleados}

Este elemento se evaluó bajo la escala siguiente:

\begin{tabular}{c|c}
\hline & Escala \\
\hline 1 & Totalmente Conocedor \\
\hline 2 & Muy Conocedor \\
\hline 3 & Conocedor \\
\hline 4 & Poco Conocedor \\
\hline 5 & Absolutamente Ignorante \\
\hline
\end{tabular}

- Expectativa

Los encuestados esperan que el Conocimiento de los Empleados del servicio de Obras Particulares sea "Conocedor" con tendencia a "Totalmente Conocedor":

Media aritmética: 2,26 .

\section{Expectativa Conocimiento}

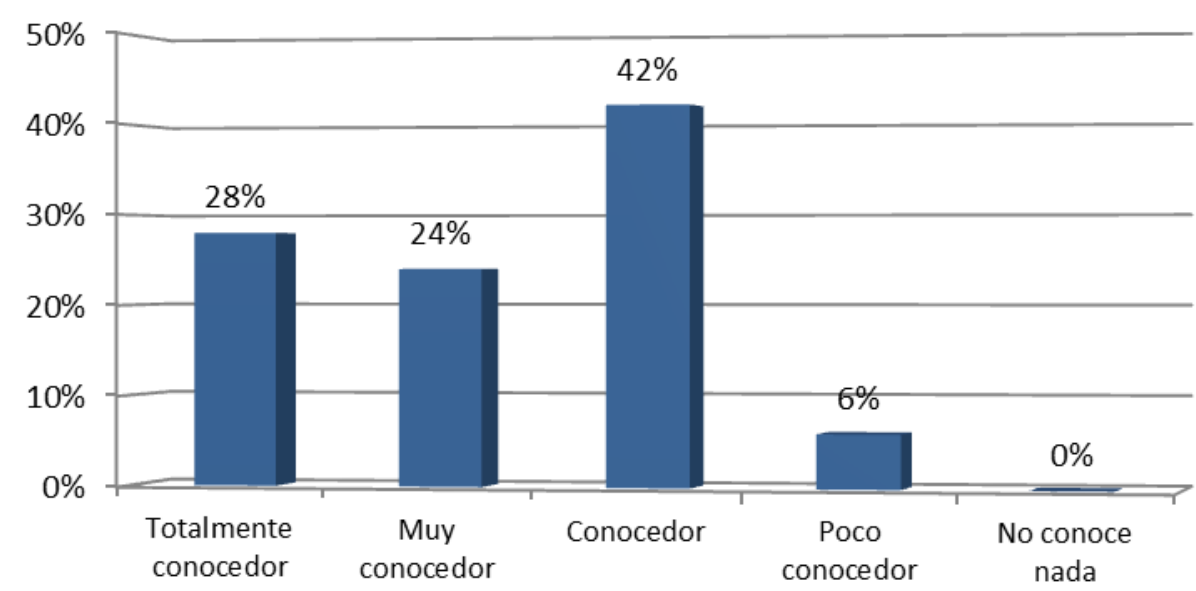

- Percepción

Los encuestados perciben que el Conocimiento de los Empleados en el servicio de Obras Publicas es "Totalmente Conocedor" con tendencia a "Muy Conocedor":

Media aritmética: 1,32. 


\section{Percepción Conocimiento}

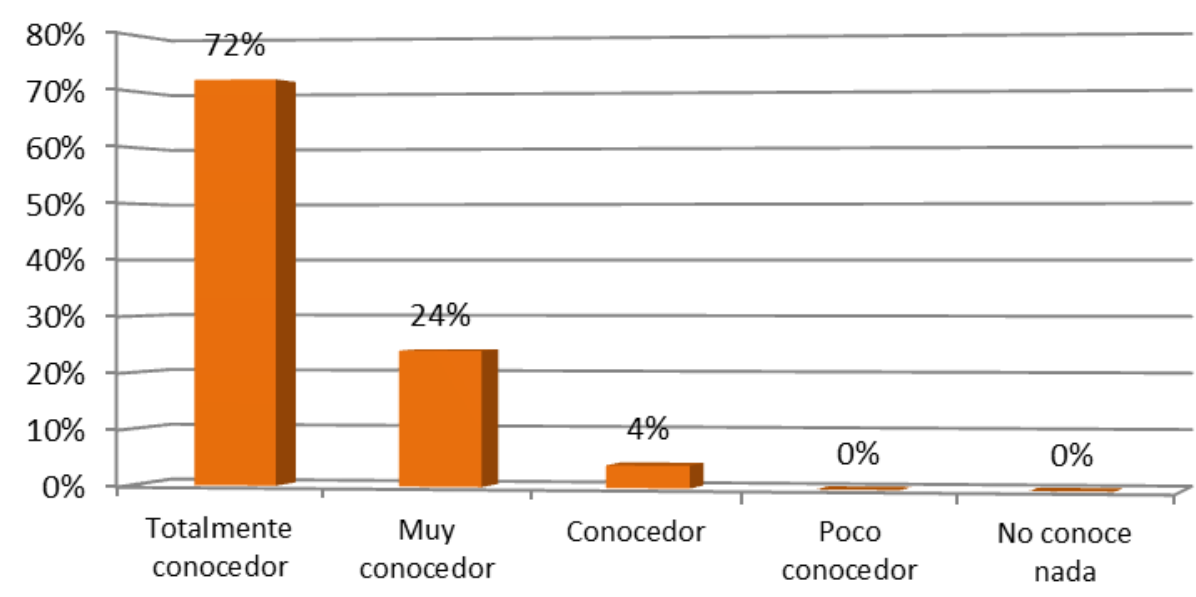

- Nivel de Satisfacción "Conocimiento de los Empleados"

En el siguiente gráfico se puede observar juntos la apreciación y expectativas por parte de los clientes sobre el Conocimiento de los Empleados en el servicio.

La mayor expectativa de los encuestados acerca del conocimiento de los empleados del Servicio es que sea "Conocedor" con un $42 \%$, Después de obtener el servicio, se observa una mayor percepción en el conocimiento de los empleados del servicio pasando de "conocedor" a "Totalmente Conocedor" con un porcentaje del $72 \%$.

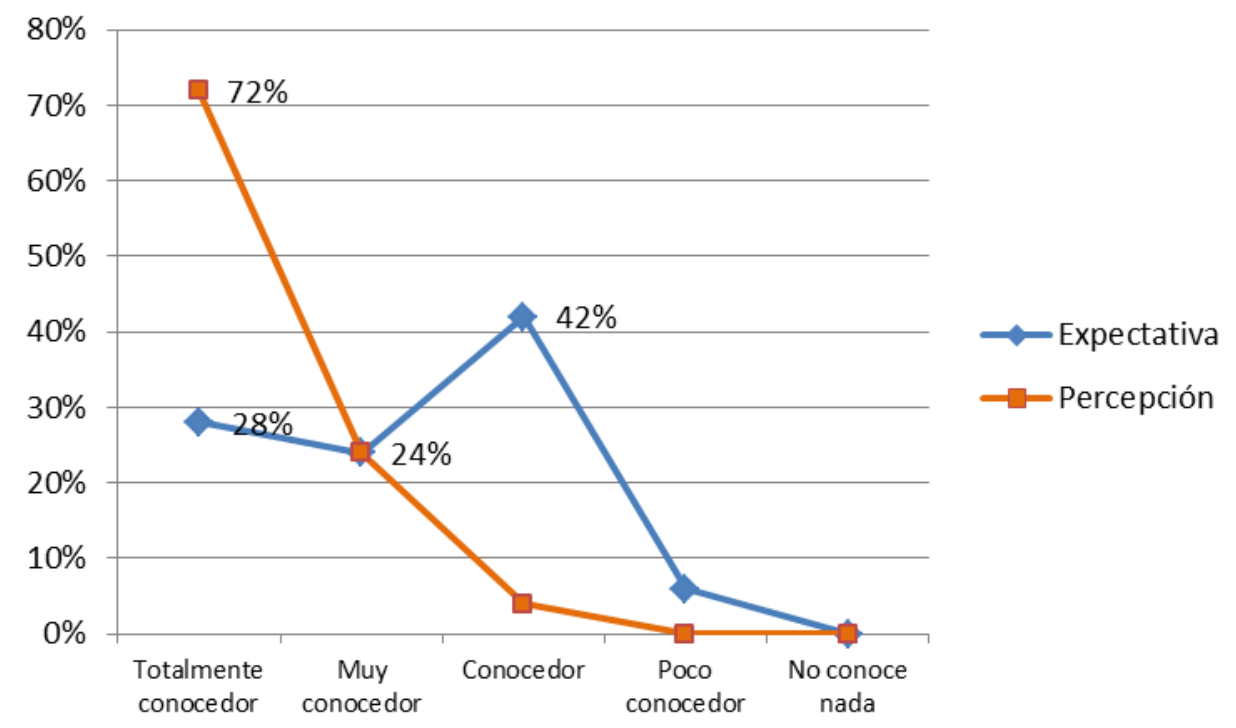


Como resultante, el nivel de satisfacción de los encuestados respecto del "Conocimiento de los Empleados" resulta de la siguiente manera:

\section{Brecha Expectativa / Percepción Conocimiento}

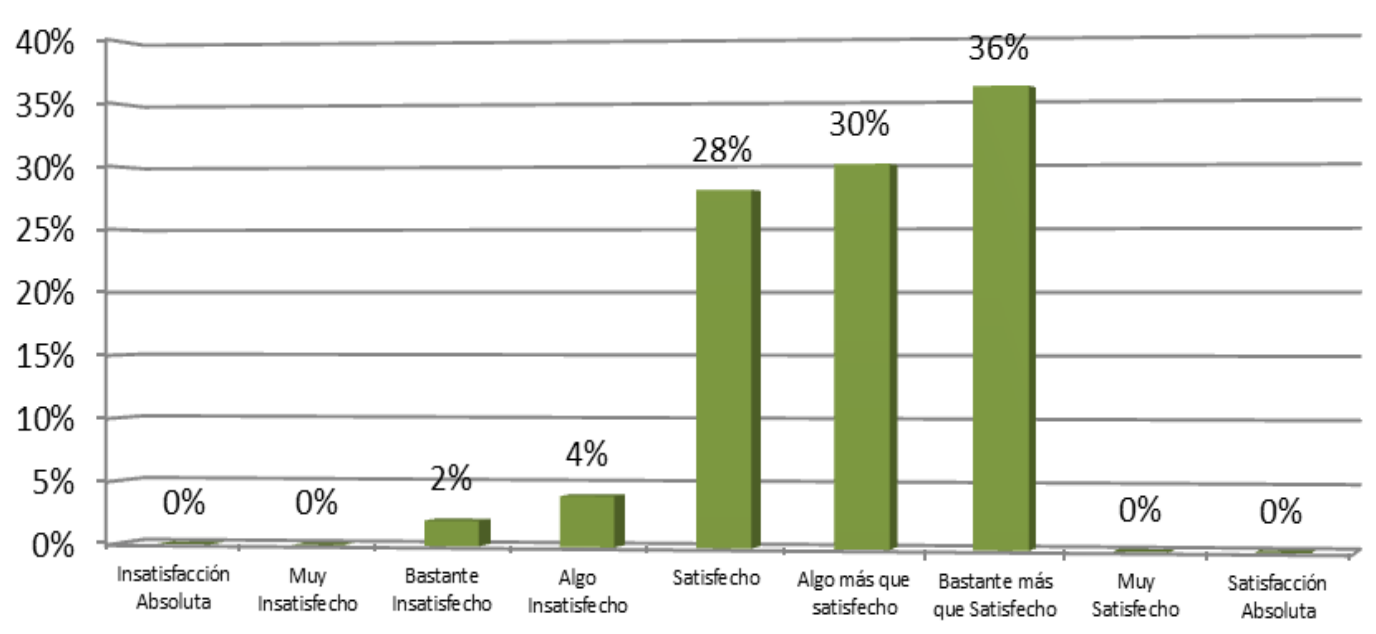

La media aritmética del Nivel de Satisfacción es de 5,22; obteniendo como principal aspecto por parte de las personas encuestadas "Bastante más que Satisfecho" con el servicio manteniendo con un porcentaje el 36\%.

\subsubsection{Total datos Dimensión IV "Seguridad"}

\begin{tabular}{l|c}
\hline \multicolumn{2}{c}{ Total Datos Dimensión IV } \\
\hline Percepción & 1,67 \\
\hline Expectativa & 2,425 \\
\hline Nivel satisfacción & $\mathbf{0 , 7 5 5}$ \\
\hline Diferencia E-P & $\mathbf{0 , 7 5 5}$ \\
\hline
\end{tabular}

- Expectativa Vs. Percepción Acumulada Dimensión IV 


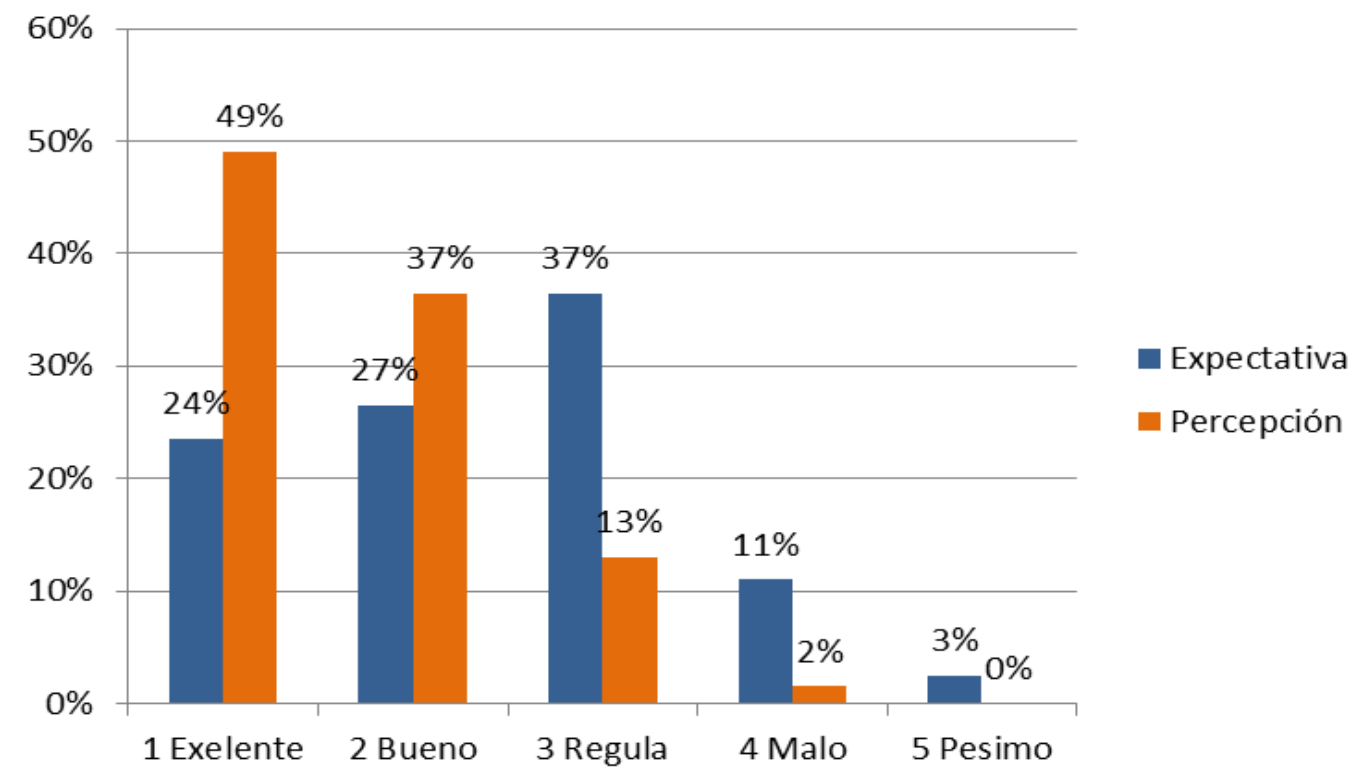

- Brecha Expectativa - Percepción Total Dimensión

\section{Brecha Total Seguridad}

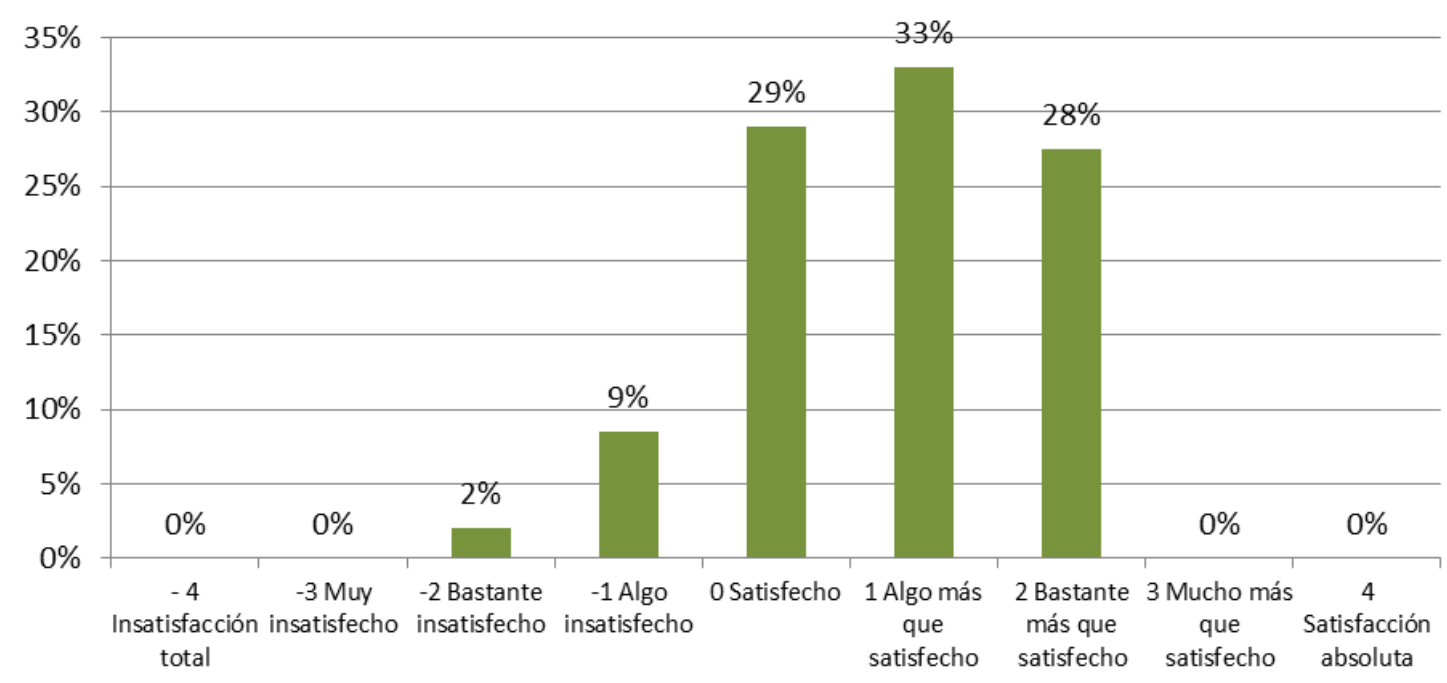

\subsection{Análisis Dimensión V: Empatía}

A continuación se exponen los resultados obtenidos en el Servicio de Obras Particulares respecto de la atención individualizada que ofrece la organización a los clientes; Individualización de la Atención, Conveniencia de los Horarios, Personalización del Servicio, Preocupación por los Intereses de los Clientes y Compresión de las Necesidades de los Clientes. 


\subsubsection{Individualización de la Atención}

Este elemento se evaluó bajo la escala siguiente:

\begin{tabular}{c|c}
\hline & Escala \\
\hline 1 & Individualizada \\
\hline 2 & Bastante Individualizada \\
\hline 3 & Atenta \\
\hline 4 & Despersonalizada \\
\hline 5 & Colectiva \\
\hline
\end{tabular}

- Expectativa

Los encuestados esperan que la Individualización de la Atención del servicio de Obras Particulares sea "Atenta" con tendencia a "Bastante Individualizada". Media aritmética: 2,48 .

\section{Expectativa Individualización}

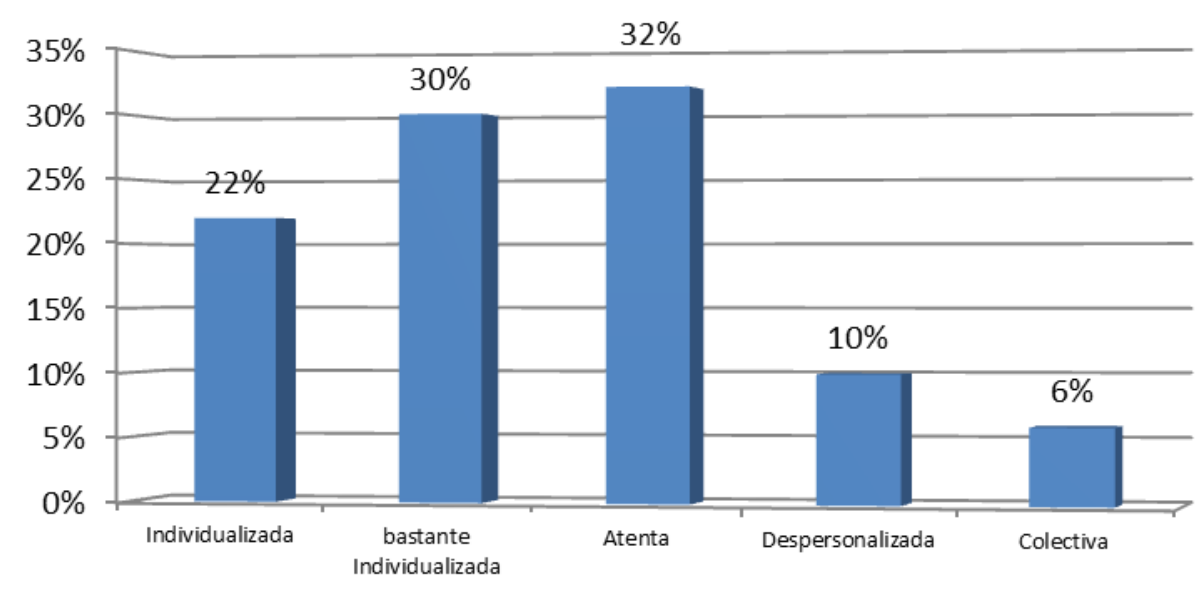

- Percepción

Los encuestados perciben que la Individualización de la Atención de los Empleados del servicio de Obras Particulares "Bastante Individualizada". Media aritmética: 2,10 . 


\section{Percepción Individualización}

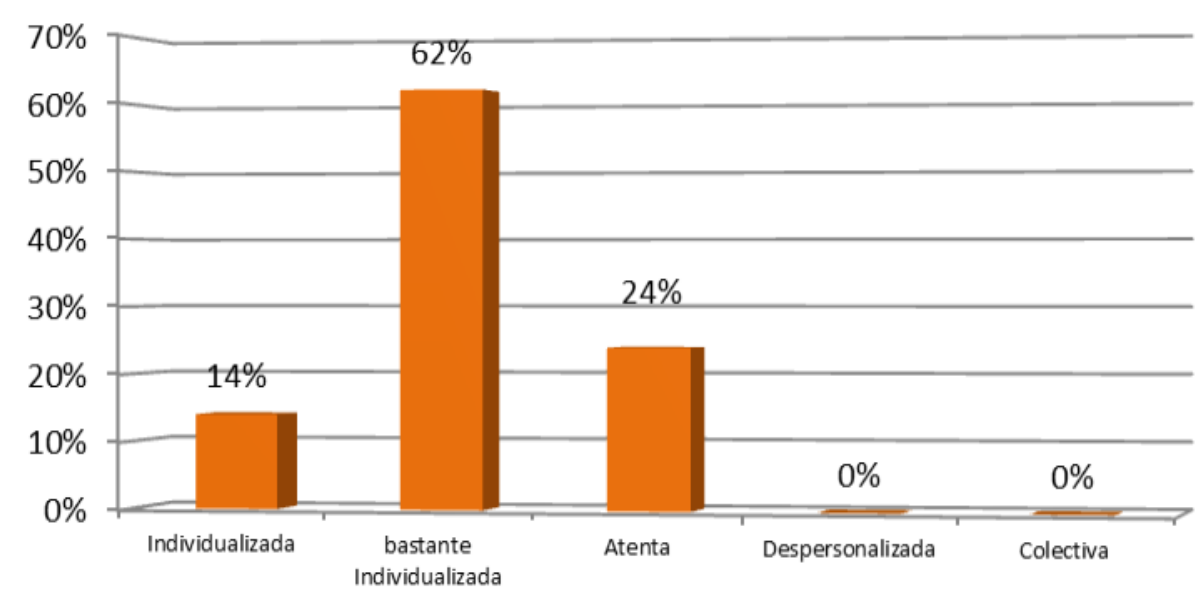

- Nivel de Satisfacción "Individualización de la Atención"

En el siguiente gráfico se puede observar juntos la apreciación y expectativas por parte de los clientes sobre la Individualización de la Atención de los Empleados.

La mayor expectativa de los encuestados acerca de la Individualización de la Atención de los Empleados del Servicio es que sea "Atenta" con un $32 \%$ con tendencia a "Bastante Individualizada" con un 30\%, Después de obtener el servicio, se observa una mayor percepción en la Individualización de la atención de los empleados del servicio pasando de "Atenta" a "Bastante Individualizada" con un porcentaje del $62 \%$.

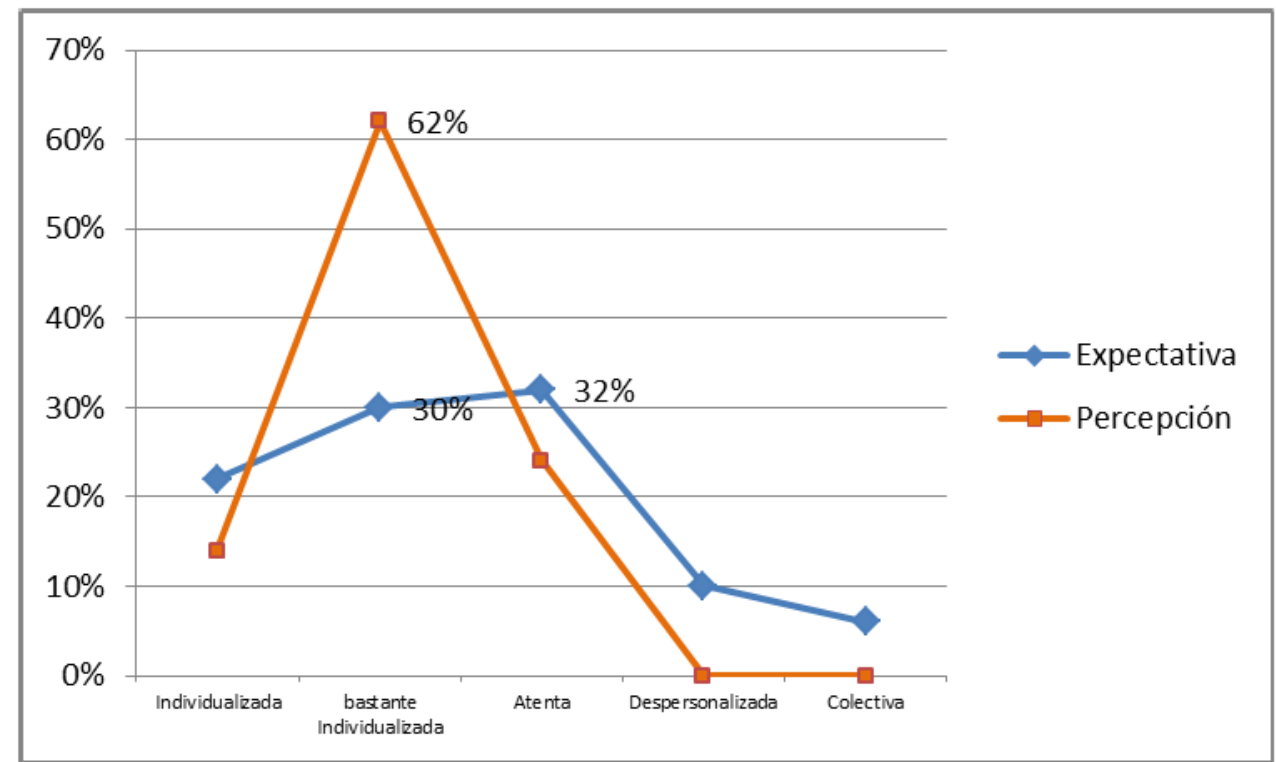


Como resultante, el nivel de satisfacción de los encuestados respecto de la "Individualización de la Atención" resulta de la siguiente manera:

\section{Brecha expectativa / Percepción Individualización}

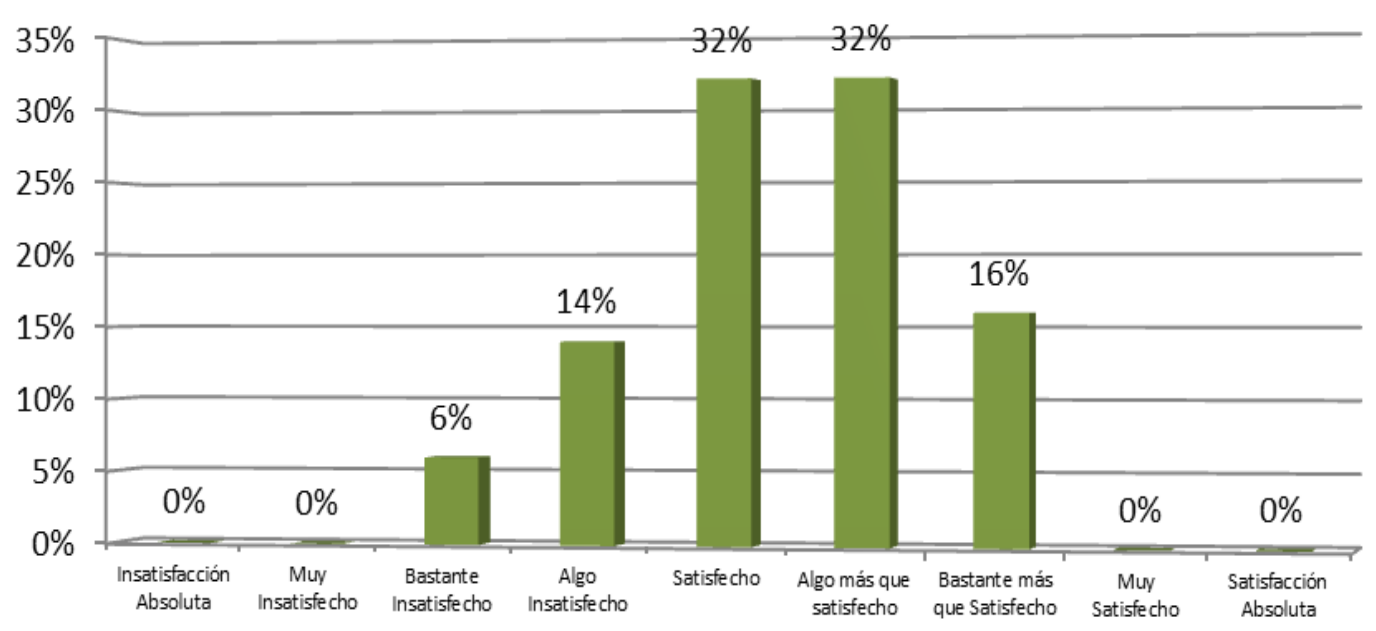

La media aritmética del Nivel de Satisfacción es de 2,11; obteniendo como principal aspecto por parte de las personas encuestadas "Satisfecho" y "Algo más que Satisfecho" con el servicio manteniendo con un porcentaje igual al $32 \%$.

\subsubsection{Conveniencia de los Horarios}

Este elemento se evaluó bajo la escala siguiente:

\begin{tabular}{c|c}
\hline & Escala \\
\hline 1 & Muy Convenientes \\
\hline 2 & Bastante Convenientes \\
\hline 3 & Convenientes \\
\hline 4 & Poco Convenientes \\
\hline 5 & Muy Convenientes \\
\hline
\end{tabular}

- Expectativa 
Los encuestados esperan de la Conveniencia de los Horarios del servicio de Obras Particulares sea "Convenientes".

Media aritmética: 2,90.

\section{Expectativa Horarios de trabajo}

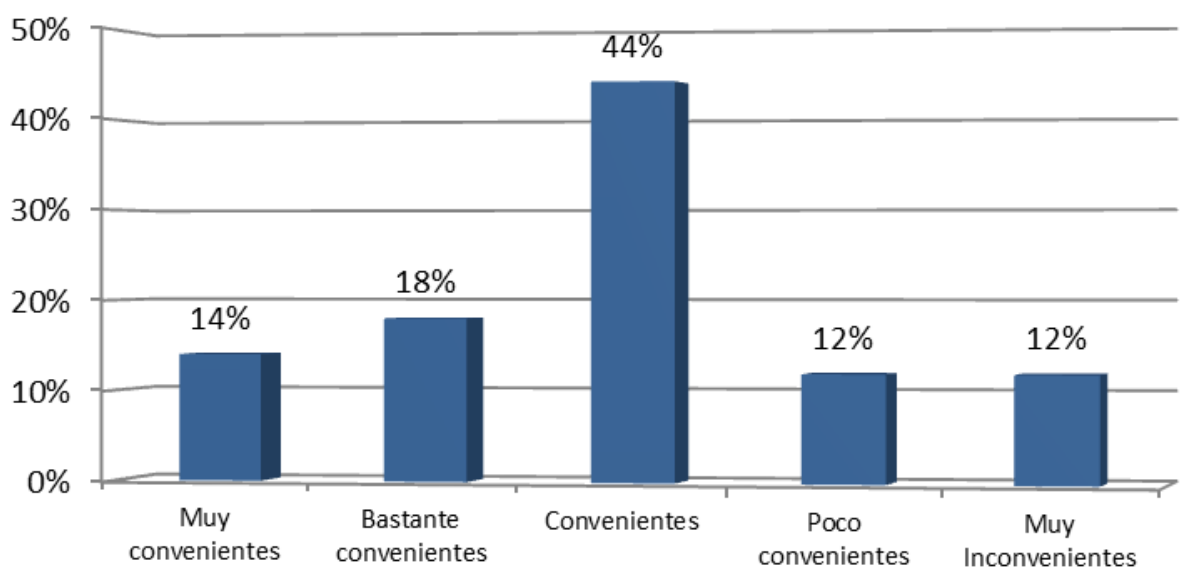

- Percepción

Los encuestados perciben que la Conveniencia de los Horarios del servicio de Obras Particulares es "Bastante Convenientes" con tendencia a "Convenientes".

Media aritmética: 2,42

\section{Percepción Horarios de trabajo}

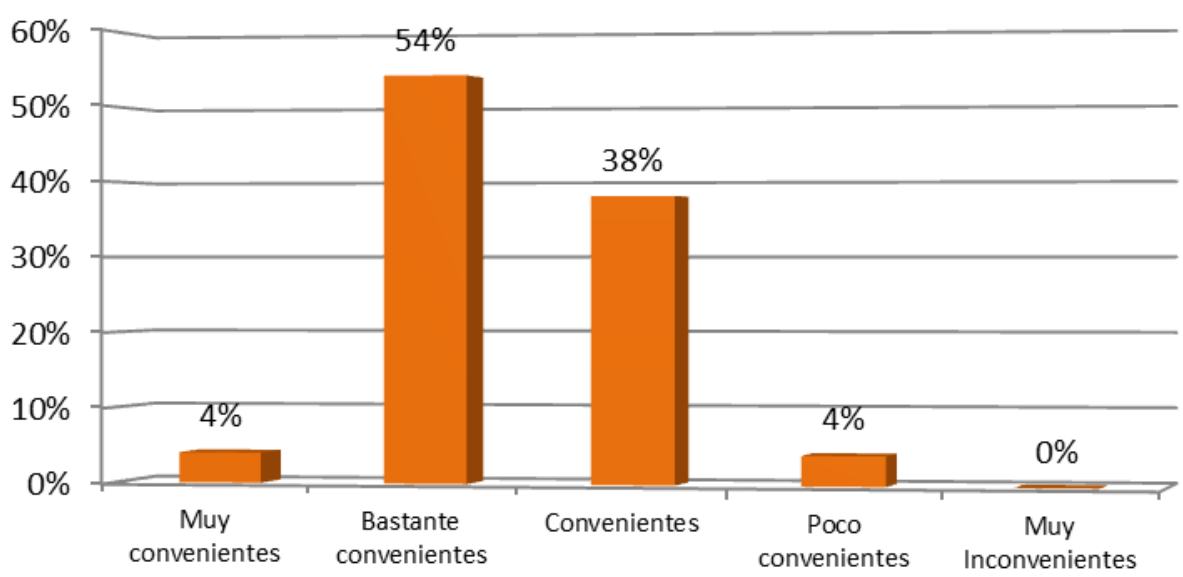

- Nivel de Satisfacción "Conveniencia de los Horarios" 
En el siguiente gráfico se puede observar juntos la apreciación y expectativas por parte de los clientes sobre la Conveniencia de los Horarios.

La mayor expectativa de los encuestados acerca de la Conveniencia de los Horarios de los Empleados del Servicio es "Convenientes" con un 44\%, Después de obtener el servicio, se observa una mayor percepción en la conveniencia de los Horarios de los empleados del servicio pasando de "convenientes" a "Bastante Convenientes" con un porcentaje del $54 \%$.

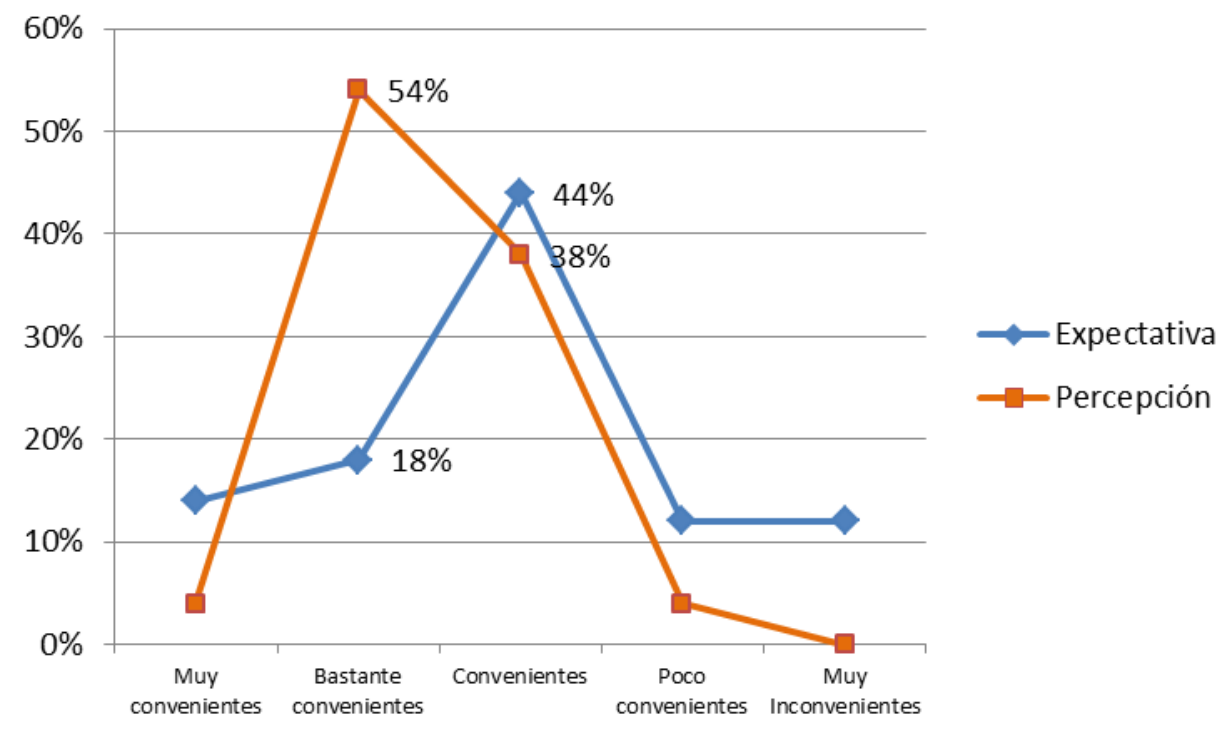

Como resultante, el nivel de satisfacción de los encuestados respecto de la "Conveniencia de los Horarios" resulta de la siguiente manera:

\section{Brecha Expectativa / Percepción Horarios}

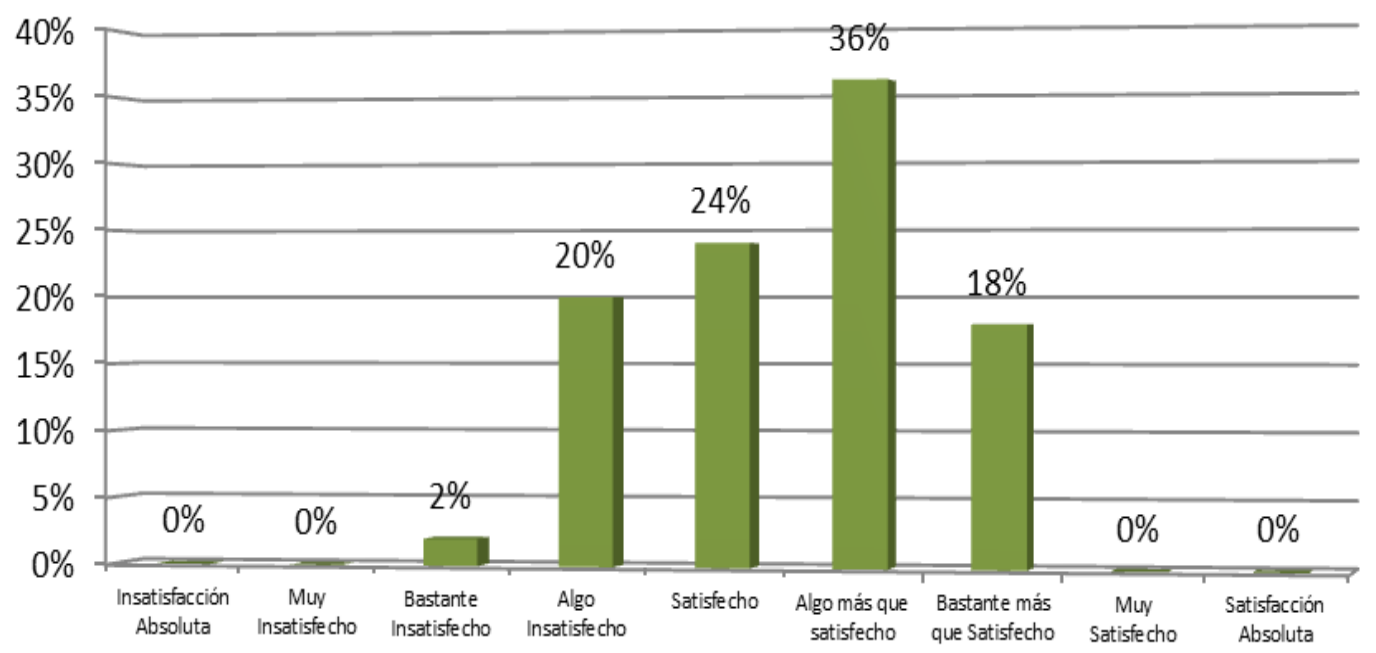


La media aritmética del Nivel de Satisfacción es de 2,66; obteniendo como principal aspecto por parte de las personas encuestadas "Algo más que Satisfecho" con el servicio manteniendo con un porcentaje del $36 \%$.

\subsubsection{Personalización de la Atención}

Este elemento se evaluó bajo la escala siguiente:

\begin{tabular}{c|c}
\hline & Escala \\
\hline 1 & Personalizada \\
\hline 2 & Algo Personalizada \\
\hline 3 & Algo Despersonalizada \\
\hline 4 & Despersonalizada \\
\hline 5 & Común \\
\hline
\end{tabular}

\section{- Expectativa}

Los encuestados esperan de la Personalización de la Atención del Servicio de Obras Particulares "Despersonalizada" aunque no muy separado de los demás elementos como "Personalizada o Muy Despersonalizada".

Media aritmética: 2,56.

\section{Expectativa Personalización del Servicio}

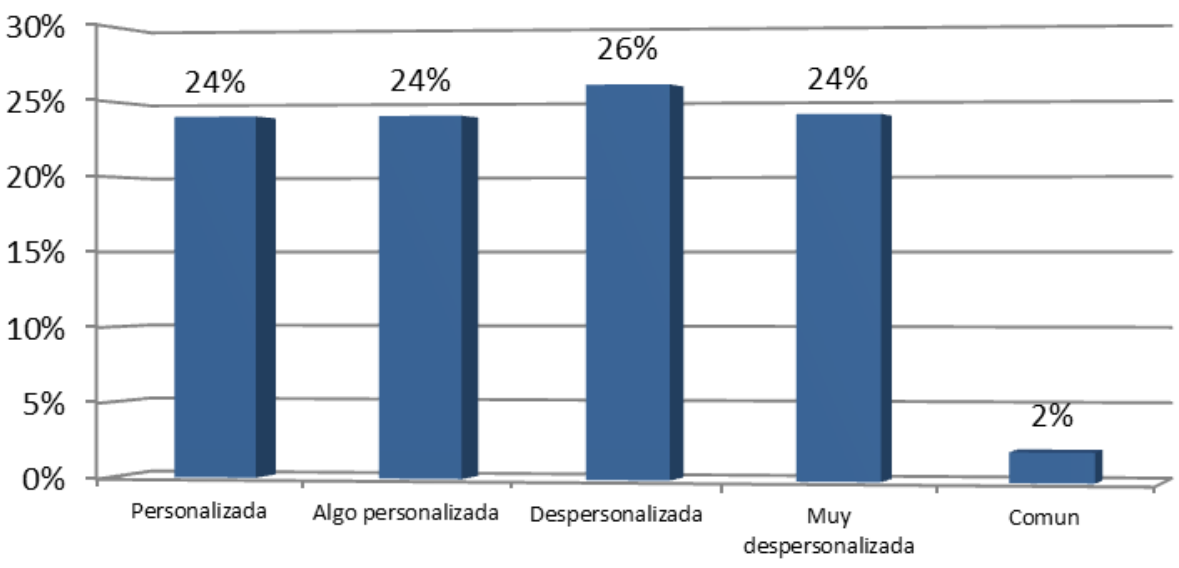

- Percepción

Los encuestados perciben que la Personalización de la Atención del servicio de Obras Particulares es "Algo Personalizada" con tendencia a "Despersonalizada". 
Media aritmética: 2,26.

\section{Percepción Personalización del Servicio}

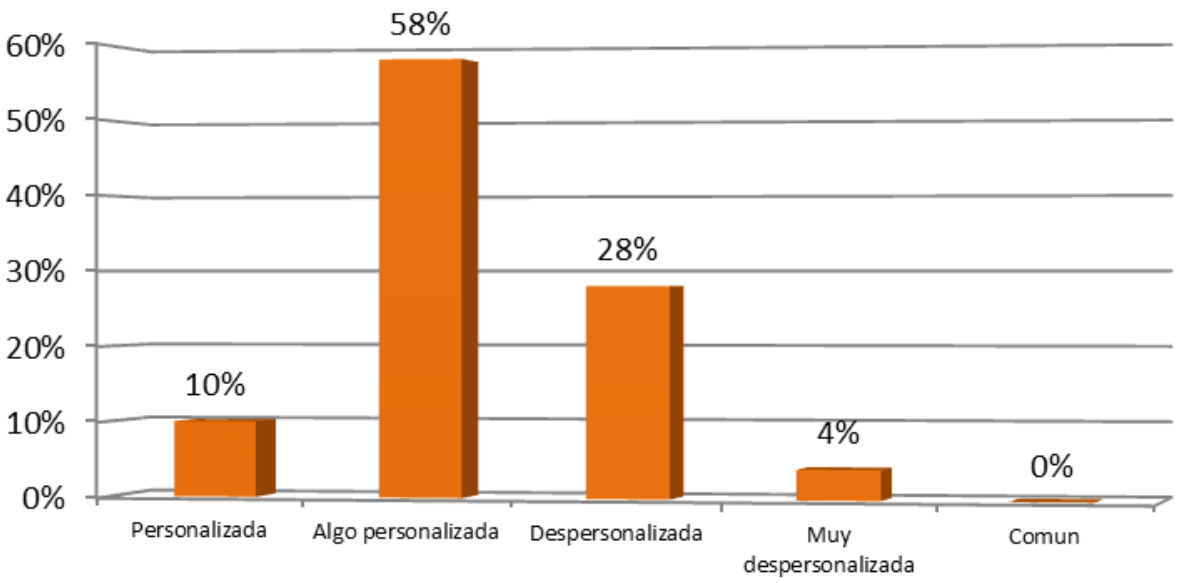

- Nivel de Satisfacción "Personalización de la Atención"

En el siguiente gráfico se puede observar juntos la apreciación y expectativas por parte de los clientes sobre la Personalización de la Atención.

La mayor expectativa de los encuestados acerca de la Personalización de la Atención de los Empleados del Servicio es "Despersonalizada" con un 28\%, Después de obtener el servicio, se observa una mayor percepción en la Personalización de la Atención de los empleados del servicio pasando de “Despersonalizada" a "Algo Personalizada" con un porcentaje del 58\%.

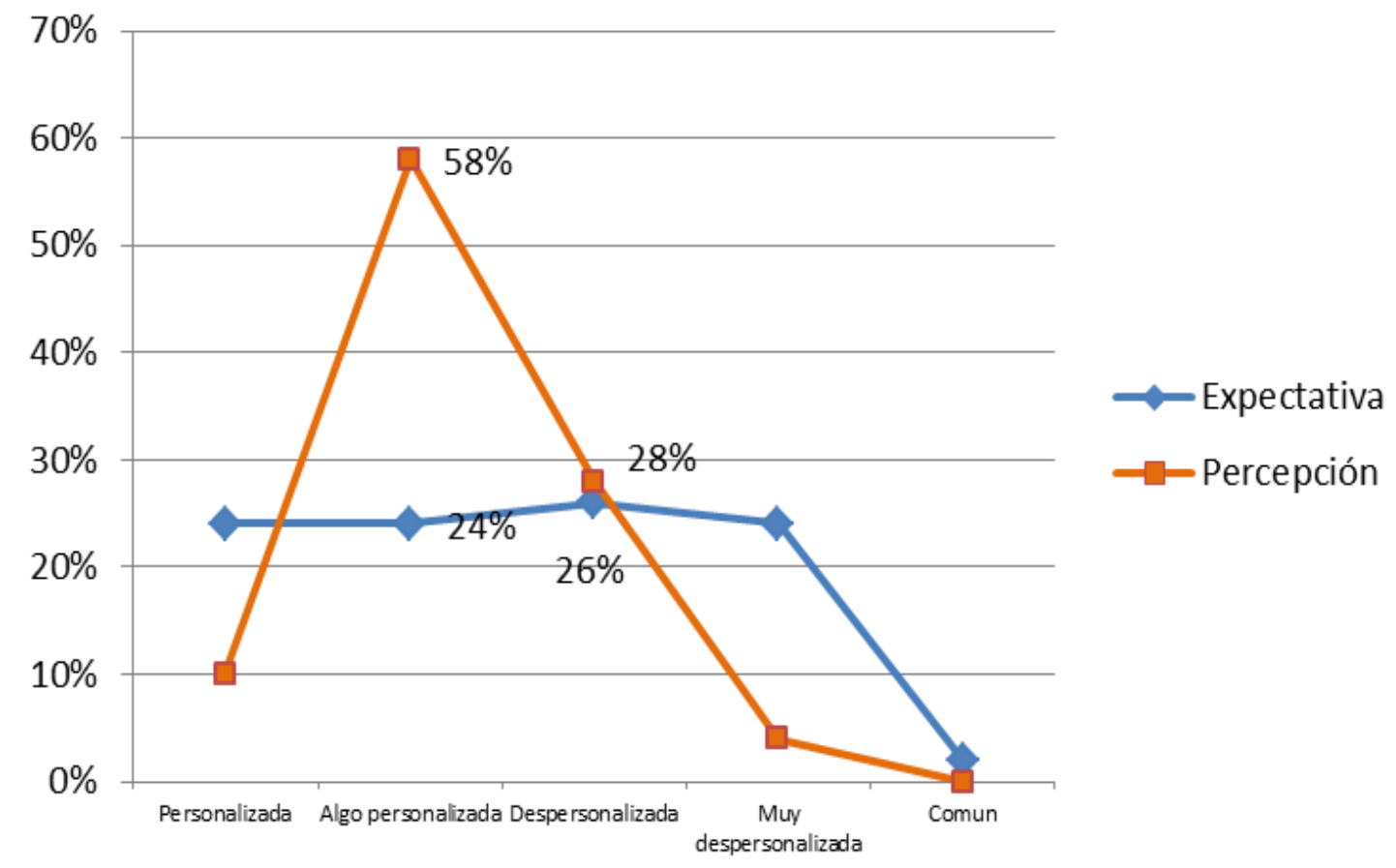


Como resultante, el nivel de satisfacción de los encuestados respecto de la "Personalización de la Atención" resulta de la siguiente manera:

\section{Brecha Expectativa / Percepción Personalización}

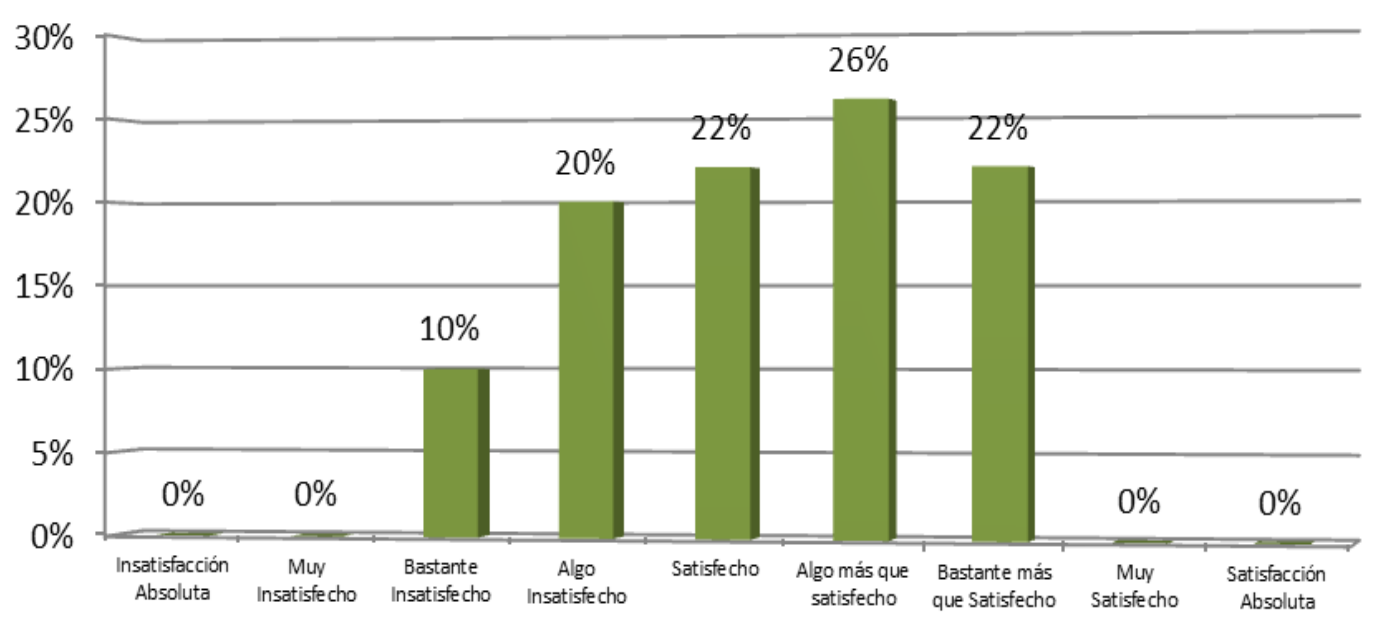

La media aritmética del Nivel de Satisfacción es de 1,66; obteniendo como principal aspecto por parte de las personas encuestadas "Algo más que Satisfecho" con el servicio, con un porcentaje del $26 \%$.

\subsubsection{Preocupación por los Intereses de los Clientes}

Este elemento se evaluó bajo la escala siguiente:

\begin{tabular}{c|c}
\hline & Escala \\
\hline 1 & Mucha Preocupación \\
\hline 2 & Preocupación \\
\hline 3 & Alguna Preocupación \\
\hline 4 & Poca Preocupación \\
\hline 5 & Despreocupación \\
\hline
\end{tabular}

- Expectativa

Los encuestados esperan de la Preocupación por los Intereses de los Clientes del Servicio de Obras Particulares sea "Mucha Preocupación" con tendencia a "Poca Preocupación":

Media aritmética: 2,46 . 


\section{Expectativa - Preocupación de los empleados} por los intereses del cliente

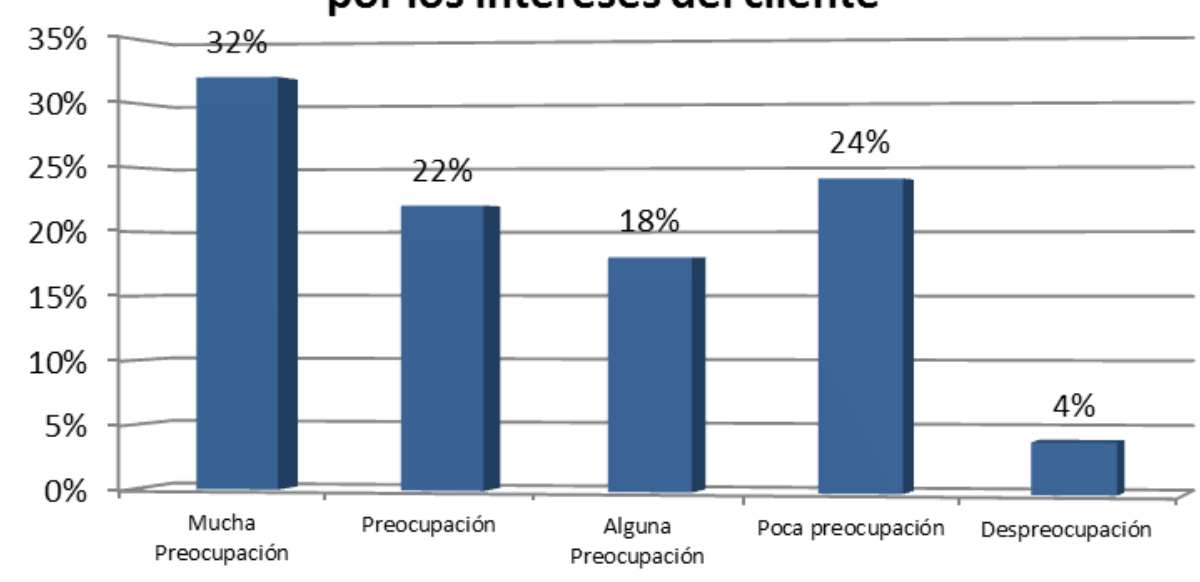

- Percepción

Los encuestados perciben que la Personalización de la Atención del servicio de Obras Particulares es "Preocupación" con tendencia a "Alguna Preocupación". Media aritmética: 2,38.

Percepción - Preocupación de los empleados por los intereses del cliente

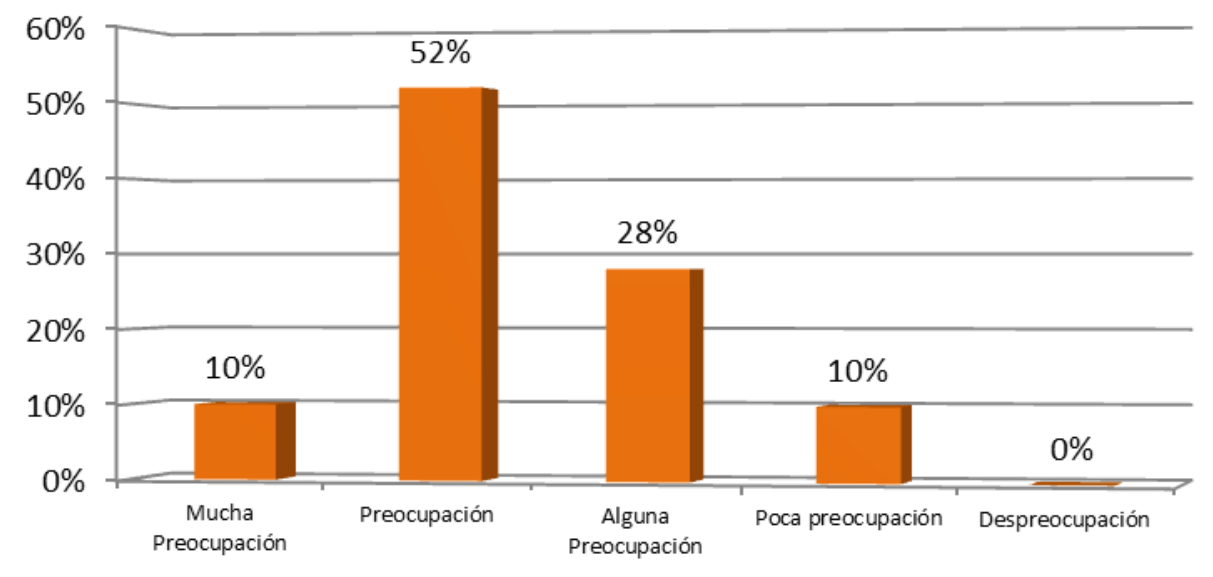

- Nivel de Satisfacción "Preocupación por los Intereses de los Clientes"

En el siguiente gráfico se puede observar juntos la apreciación y expectativas por parte de los clientes sobre la Preocupación por los Intereses de los Clientes. 
La mayor expectativa de los encuestados acerca de la Preocupación de los Intereses de los clientes por parte de los Empleados del Servicio es "Mucha Preocupación" con un 32\%; Después de obtener el servicio, se observa una menor percepción en la Preocupación de los Intereses de los clientes por parte de los empleados del servicio pasando de "Mucha Preocupación" a "Preocupación" con un porcentaje del 52\%.

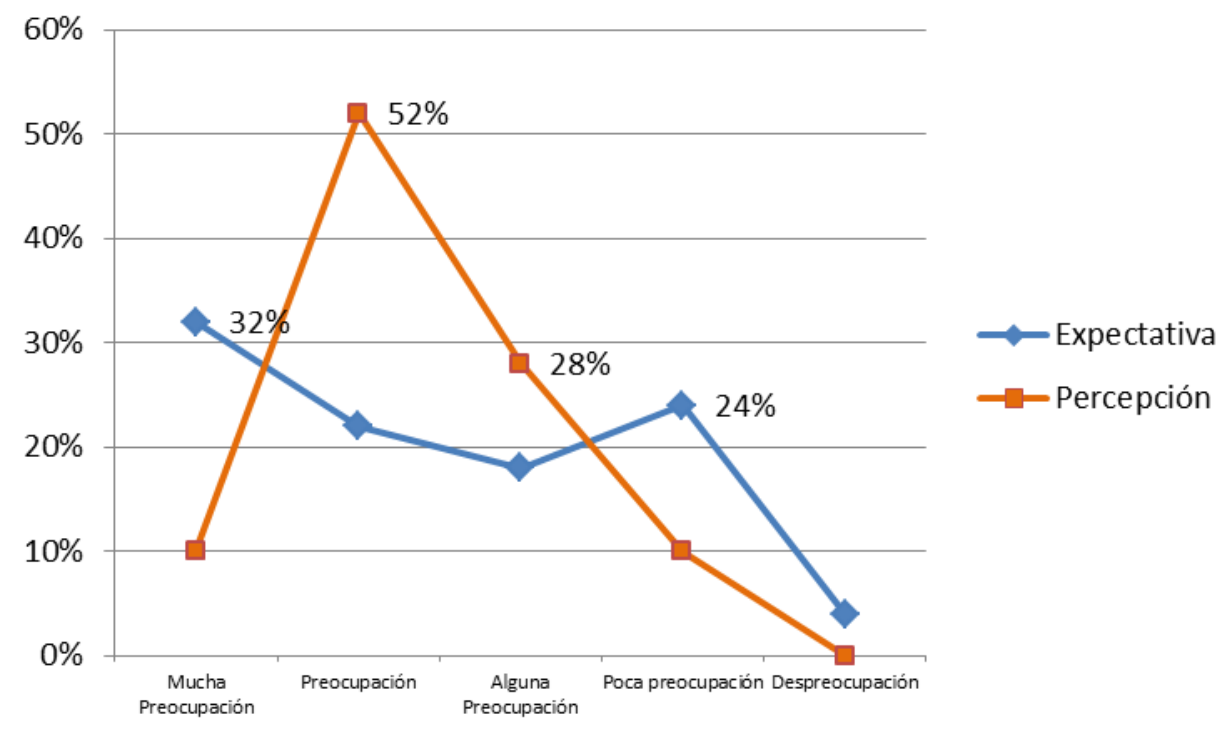

Como resultante, el nivel de satisfacción de los encuestados respecto de la "Preocupación de los Intereses de los clientes" resulta de la siguiente manera:

\section{Brecha Expectativa / Percepción Preocupación}

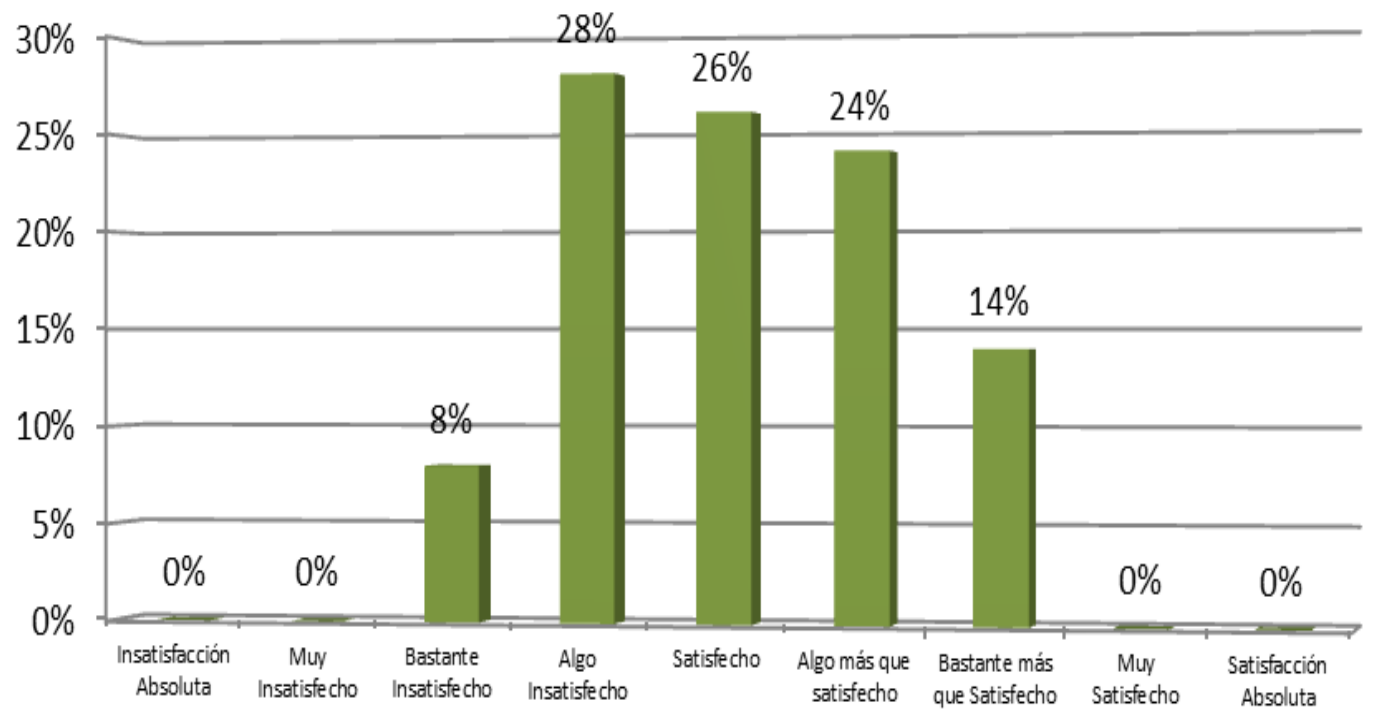


La media aritmética del Nivel de Satisfacción es de 0,44; obteniendo como principal aspecto por parte de las personas encuestadas "Algo Insatisfecho" con tendencia a "Satisfecho" con el servicio, con un porcentaje del $28 \%$ y $26 \%$ respectivamente.

\subsubsection{Comprensión de las necesidades del Cliente}

Este elemento se evaluó bajo la escala siguiente:

\begin{tabular}{c|c}
\hline & Escala \\
\hline 1 & Excelente \\
\hline 2 & Muy Bueno \\
\hline 3 & Bueno \\
\hline 4 & Regular \\
\hline 5 & Pésimo \\
\hline
\end{tabular}

\section{- Expectativa}

Los encuestados esperan que la Comprensión de las Necesidades del Cliente del Servicio de Obras Particulares sea "Buena" con tendencia a "Muy Buena": Media aritmética: 2,30.

\section{Expectativa - Comprende las Necesidades del cliente}

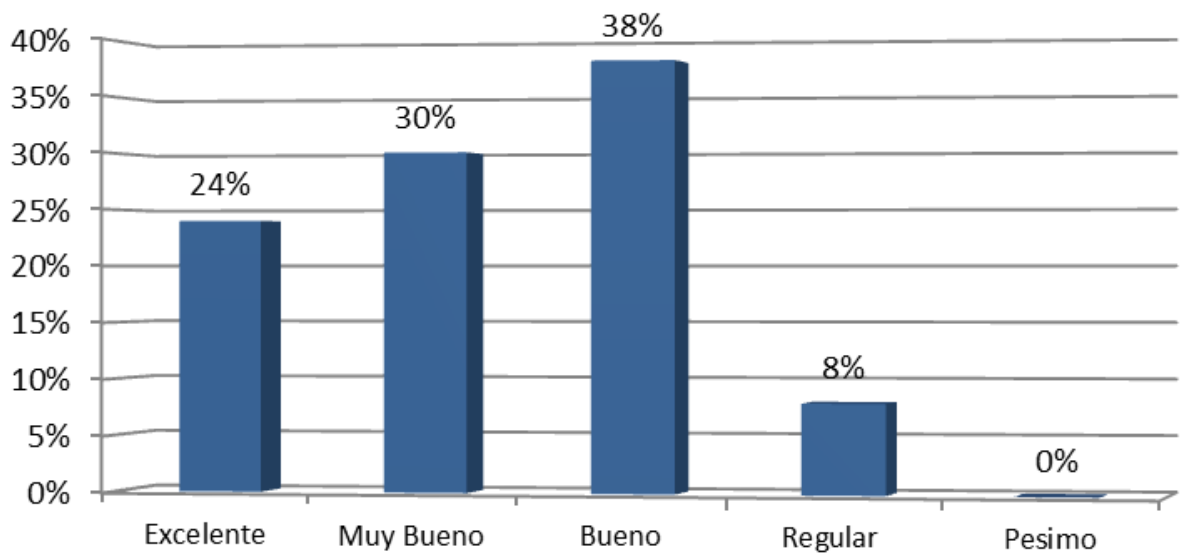

- Percepción

Los encuestados perciben que la Preocupación por los Intereses de los Clientes del servicio de Obras Particulares es "Excelente". 
Media aritmética: 1,36.

Percepción - Comprende las Necesidades del cliente

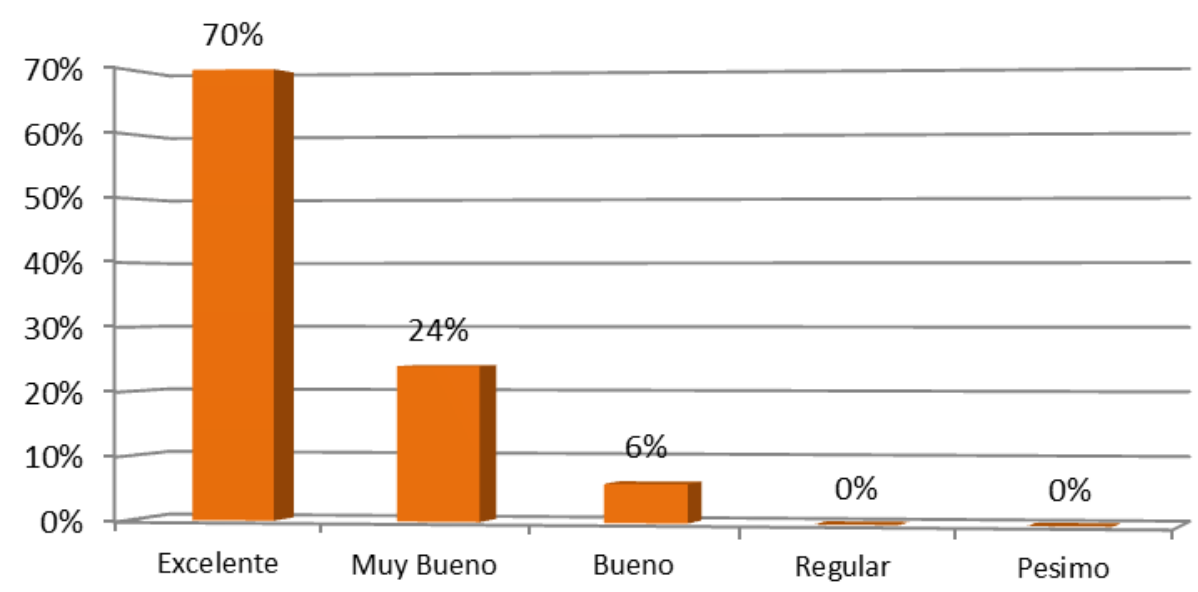

- Nivel de Satisfacción "Comprensión de las Necesidades de los Clientes"

En el siguiente gráfico se puede observar juntos las expectativas y percepción por parte de los clientes sobre la comprensión de las necesidades de los Clientes.

La mayor expectativa de los encuestados acerca de la Comprensión de las necesidades de los clientes por parte de los Empleados del Servicio es "Buena" con un 38\%; después de obtener el servicio, se observa una mayor percepción en la Comprensión de las necesidades de los clientes por parte de los empleados del servicio pasando de "Bueno" a "Excelente" con un porcentaje del $70 \%$.

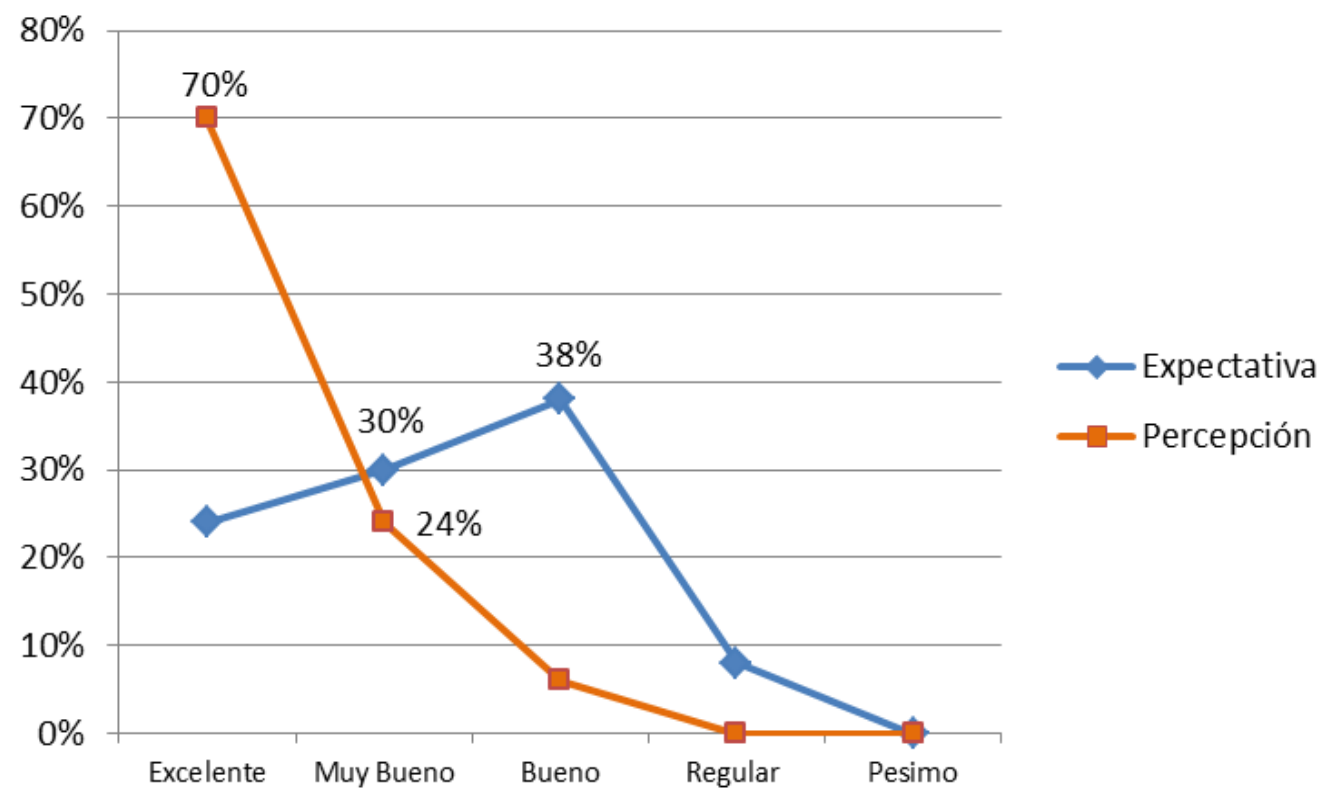


Como resultante, el nivel de satisfacción de los encuestados respecto de la "Preocupación por los Intereses de los Clientes" resulta de la siguiente manera:

\section{Brecha Expectativa / Percepción Comprende Necesidades}

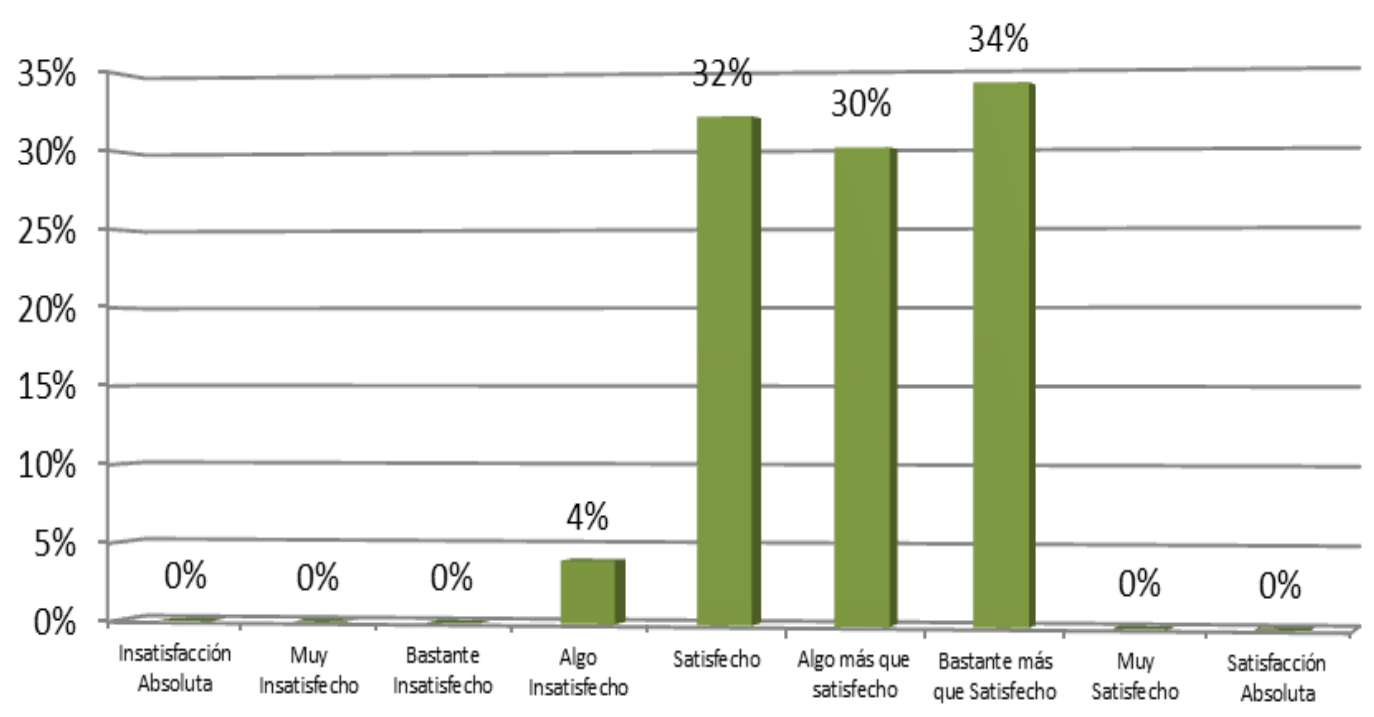

La media aritmética del Nivel de Satisfacción es de 5,22; obteniendo como principal aspecto por parte de las personas encuestadas "Bastante más que Satisfecho" con tendencia a "Satisfecho" con el servicio, con un porcentaje del $34 \%$ y $32 \%$ respectivamente.

\subsubsection{Total datos Dimensión V "Empatía"}

\begin{tabular}{|l|c|}
\hline \multicolumn{2}{|c|}{ Total Datos Dimensión V } \\
\hline Percepción & 2,104 \\
\hline Expectativa & 2,54 \\
\hline Nivel satisfacción & $\mathbf{0 , 4 3 6}$ \\
\hline Diferencia E-P & $\mathbf{0 , 4 3 6}$ \\
\hline
\end{tabular}

- Expectativa Vs. Percepción Acumulada Dimensión V 


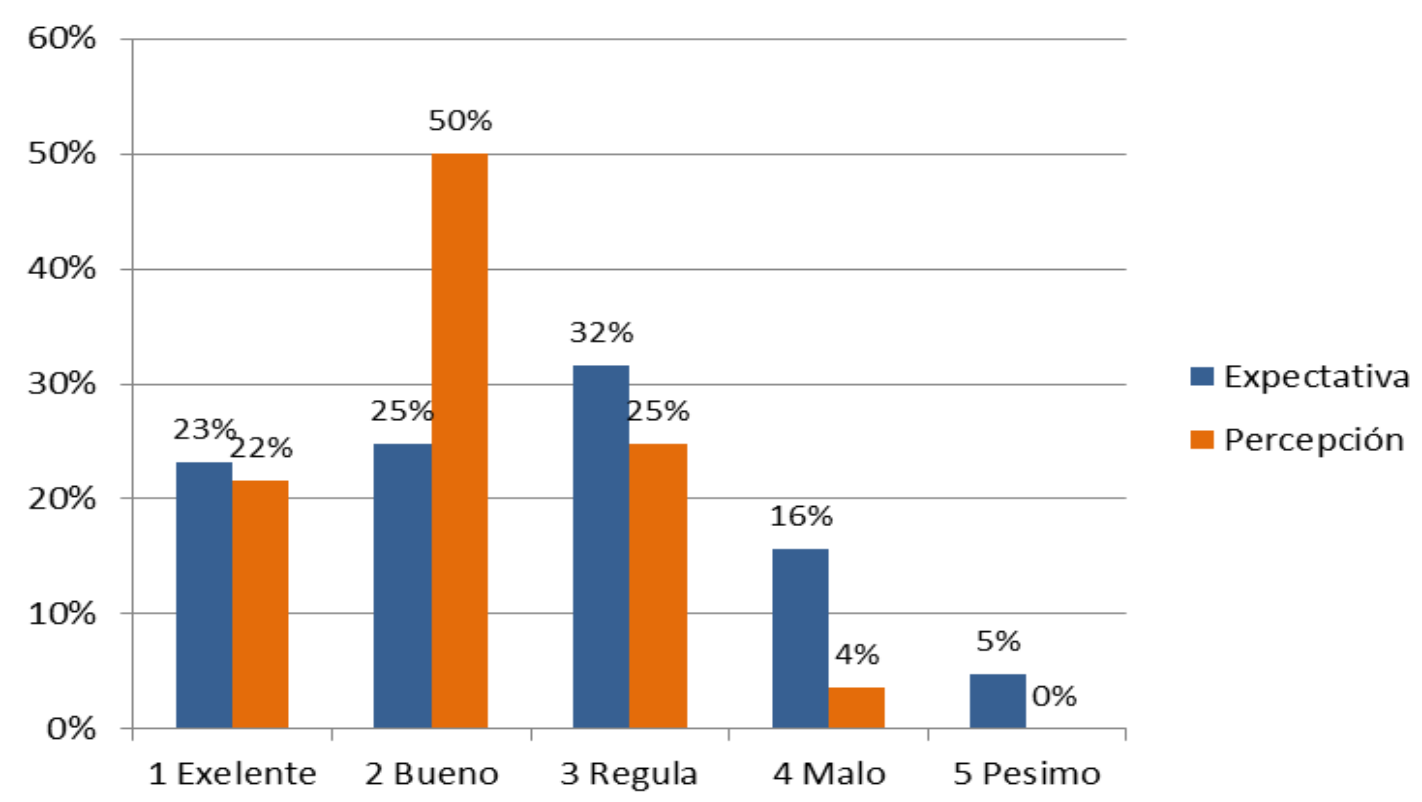

- Brecha Total Expectativa - Percepción Dimensión V

\section{Brecha Total Empatia}

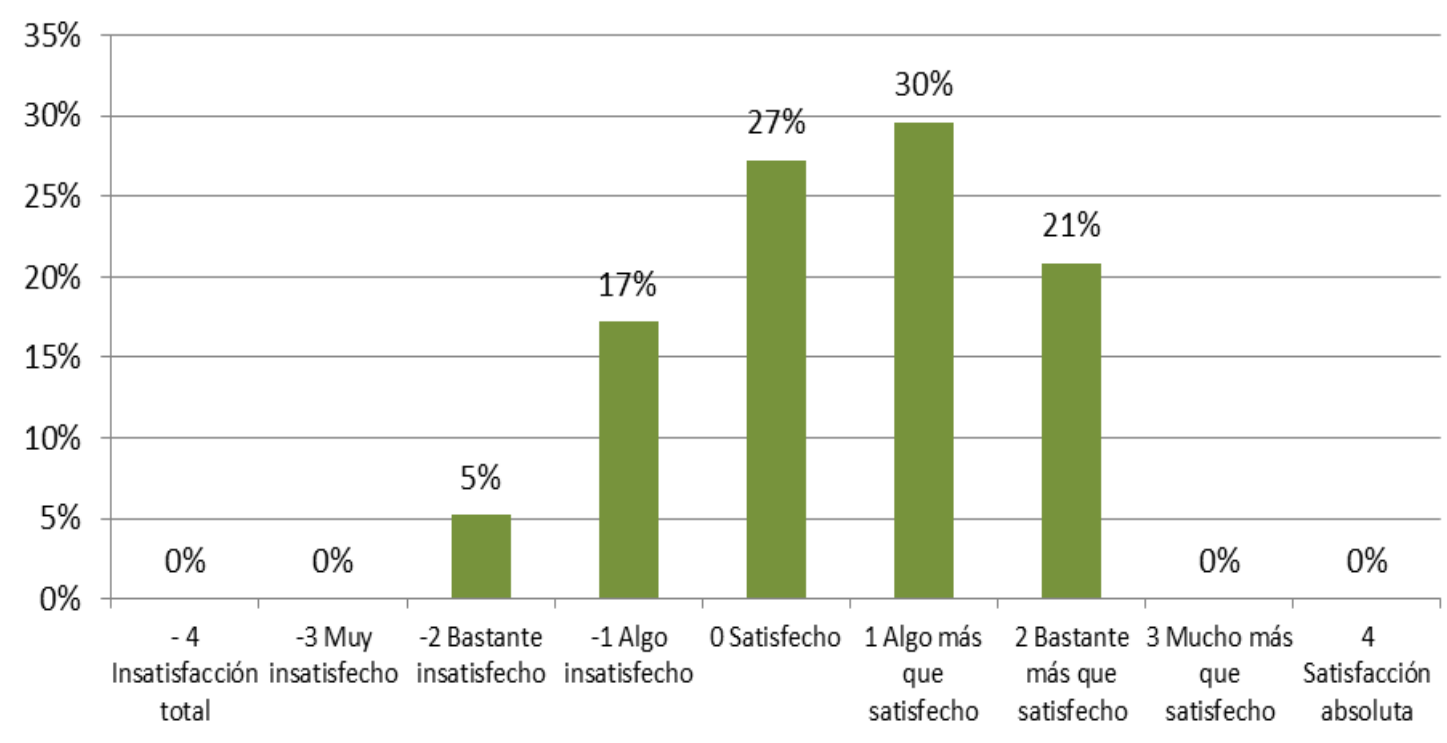

7.7 Importancia de cada Dimensión según los usuarios del servicio de Obras Particulares de la municipalidad de Ensenada.

Los usuarios del servicio de Obras Particulares ordenaron las distintas dimensiones según la importancia que consideran para cada una. 
Como resultante, la dimensión más importante para los usuarios es Capacidad de Respuesta, seguido por la Confiabilidad. Con mayor diferencia, la dimensión Seguridad y Empatía en tercer y cuarto puesto respectivamente. Por último, la dimensión de Elementos Tangibles es la que los usuarios consideran menos importante a la hora de tomar el servicio.

Para definir la dimensión más importante para los usuarios del Servicio de Obras Particulares de la Municipalidad de Ensenada a la hora de tomar el servicio, se realizaron las siguientes tablas confirman que la Capacidad de Respuesta, Con una frecuencia de 29 usuarios, un peso del $58 \%$ y un promedio de 1,72, en una escala de 1 - más importante- a 5 -menos importante-.

\section{Grado de Importancia de las Dimensiones Según los Usuarios}

\begin{tabular}{|c|c|c|c|c|c|}
\hline \multirow[b]{2}{*}{$\begin{array}{l}\text { 罚 } \\
\stackrel{\underline{Q}}{Q}\end{array}$} & \multicolumn{5}{|c|}{ Dimensiones } \\
\hline & $\begin{array}{c}\text { Elementos } \\
\text { Tangibles }\end{array}$ & Confiabilidad & $\begin{array}{l}\text { Capacidad de } \\
\text { Respuesta }\end{array}$ & Seguridad & Empatía \\
\hline 1 & 0 & 15 & 29 & 6 & 0 \\
\hline 2 & 0 & 22 & 8 & 16 & 4 \\
\hline 3 & 5 & 8 & 11 & 19 & 7 \\
\hline 4 & 11 & 4 & 2 & 7 & 26 \\
\hline 5 & 34 & 1 & 0 & 2 & 13 \\
\hline Total Encuestas & 250 & 50 & 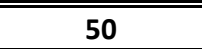 & 250 & 250 \\
\hline Promedio & 4,58 & 2,08 & 1,72 & 2,66 & 3,96 \\
\hline
\end{tabular}

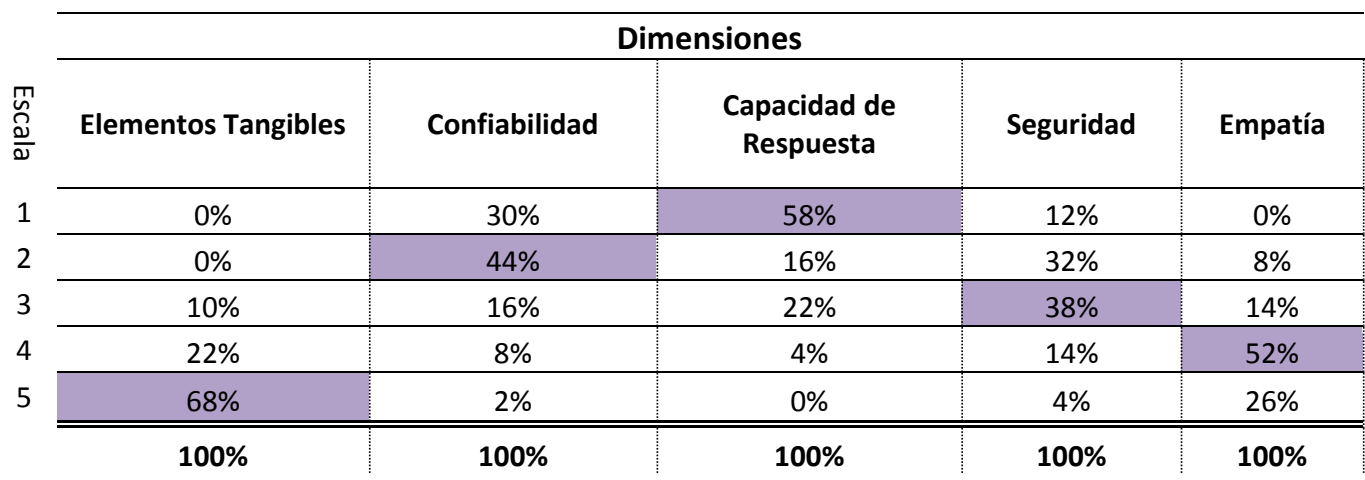

\begin{tabular}{l|c|c|c|c}
\hline \multicolumn{1}{c|}{ Dimensión } & Importancia & Promedio & Frecuencia & Ponderación \\
\hline Capacidad de respuesta & 19 & 1,72 & 29 & 3,28 \\
\hline Confiabilidad & 20 & 2,08 & 15 & 2,92 \\
\hline Seguridad & 30 & 2,66 & 6 & 2,34 \\
\hline Empatía & 40 & 3,96 & 0 & 1,04 \\
\hline Elementos tangibles & 50 & 4,58 & 0 & 0,42 \\
\hline \hline & & & $\mathbf{5 0}$ &
\end{tabular}


Grado de Importamcia de las Dimensiones

(promedio)

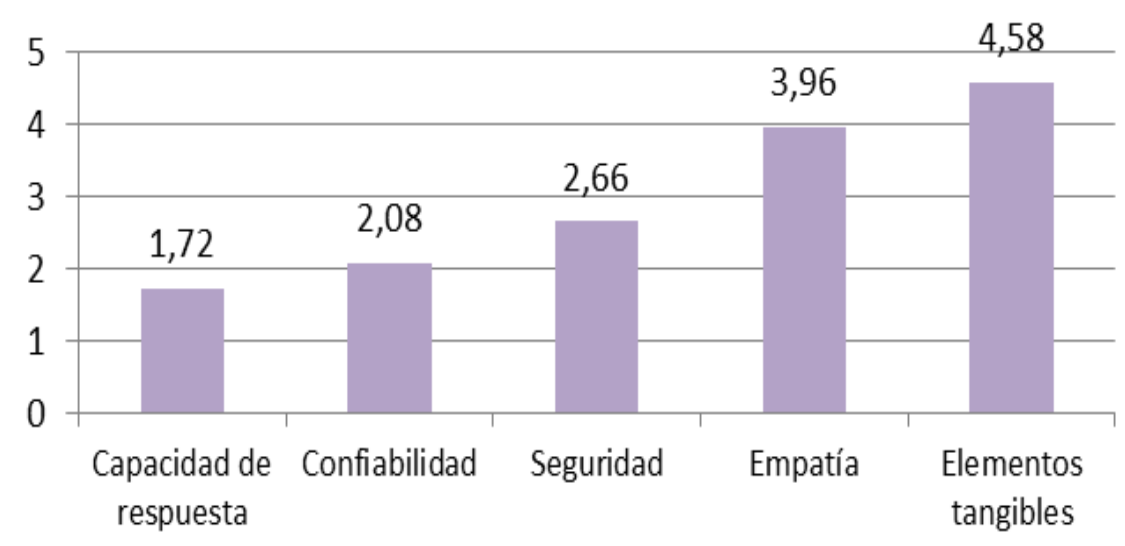

Grado de Importancia de las Dimensiones

(Frecuencia)

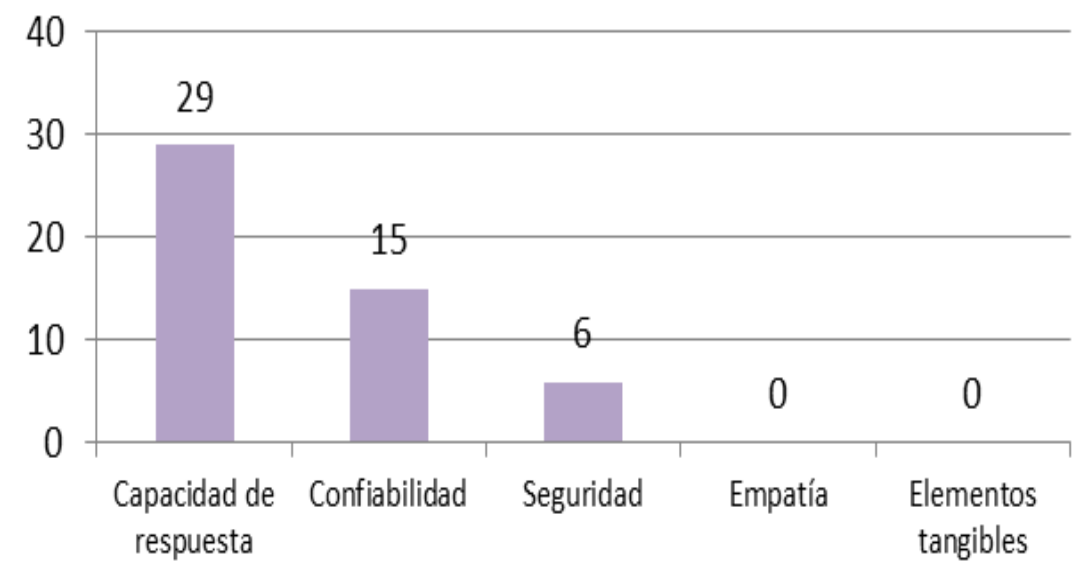

\subsection{Calificación Global de los usuarios del servicio de Obras Particulares}

De acuerdo a la siguiente escala, se calificara la expectativa y percepción de los usuarios del servicio de Obras Particulares.

\begin{tabular}{lc}
\hline & Escala \\
\hline 1 & Excelente \\
\hline 2 & Bueno \\
\hline 3 & Regular \\
\hline 4 & Malo \\
\hline 5 & Pésimo \\
\hline
\end{tabular}


La Calificación Global de la Expectativa de los usuarios de la Dirección de Obras Particulares de la Municipalidad de Ensenada según la frecuencia tiende de "Regular" con un 29\% a "Buena" con un 24\%.

\begin{tabular}{l|c|c}
\hline \multicolumn{1}{c|}{ Calificación } & Frecuencia & Importancia \\
\hline 1 Excelente & 227 & $21 \%$ \\
\hline 2 Bueno & 264 & $24 \%$ \\
\hline 3 Regular & 314 & $29 \%$ \\
\hline 4 Malo & 181 & $16 \%$ \\
\hline 5 Pésimo & 114 & $10 \%$ \\
\hline \hline & 1100 & $100 \%$ \\
\hline
\end{tabular}

\section{Calificación Global expectativa}

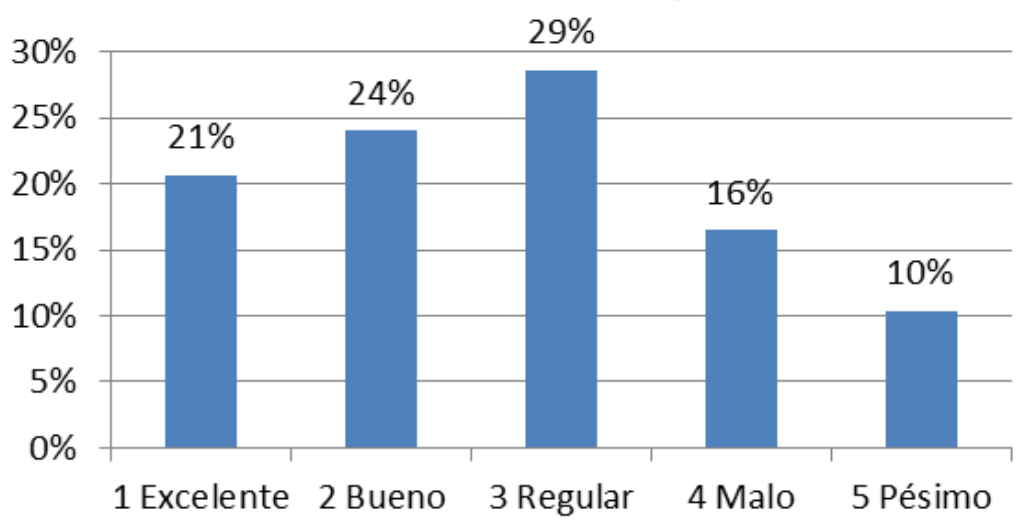

La Calificación Global de la Percepción de los usuarios de la Dirección de Obras Particulares de la Municipalidad de Ensenada según la frecuencia tiende de "Bueno" con un 39\% a "Regular" con un $29 \%$.

\begin{tabular}{l|c|c}
\hline \multicolumn{1}{c|}{ Calificación } & Frecuencia & Importancia \\
\hline 1 Excelente & 246 & $22 \%$ \\
\hline 2 Bueno & 428 & $39 \%$ \\
\hline 3 Regular & 321 & $29 \%$ \\
\hline 4 Malo & 97 & $9 \%$ \\
\hline 5 Pésimo & 8 & $1 \%$ \\
\hline \hline
\end{tabular}




\section{Calificación Global Percepción}
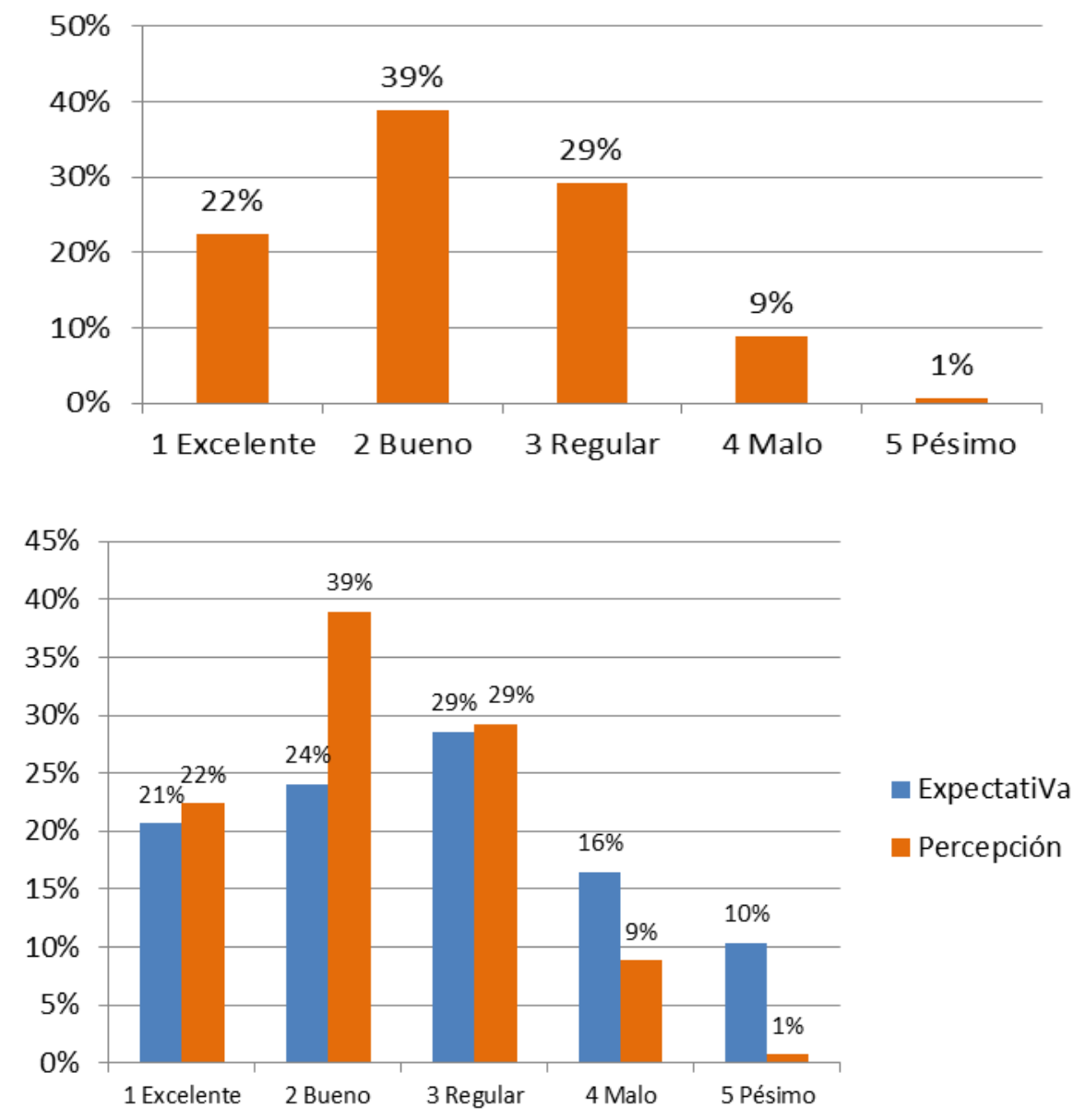

- Total Brecha obtenida entre la expectativa y la Percepción de los usuarios

Por diferencia total entre la Expectativa y la Percepción que tienen los usuarios del servicio de la Dirección de Obras Particulares de la Municipalidad de Ensenada, se obtiene la brecha según determina su tabla de frecuencia tiende de "Algo más que Satisfecho" con un $28 \%$ a "Satisfecho" con un $27 \%$

\begin{tabular}{l|c|c}
\multicolumn{1}{c|}{ Calificación } & Frecuencia & Importancia \\
\hline-4 Insatisfacción total & 0 & $0 \%$ \\
\hline-3 Muy insatisfecho & 0 & $0 \%$ \\
\hline-2 Bastante insatisfecho & 58 & $5 \%$ \\
\hline-1 Algo insatisfecho & 190 & $17 \%$ \\
\hline 0 Satisfecho & 296 & $27 \%$ \\
\hline 1 Algo más que satisfecho & 308 & $28 \%$ \\
\hline 2 Bastante más que satisfecho & 248 & $23 \%$ \\
\hline 3 Mucho más que satisfecho & 0 & $0 \%$ \\
\hline 4 Satisfacción absoluta & 0 & $0 \%$ \\
\hline \hline Total & $\mathbf{1 1 0 0}$ & $\mathbf{1 0 0 \%}$
\end{tabular}




\section{Calificación Glogal Brecha (Expectativa - Percepción)}

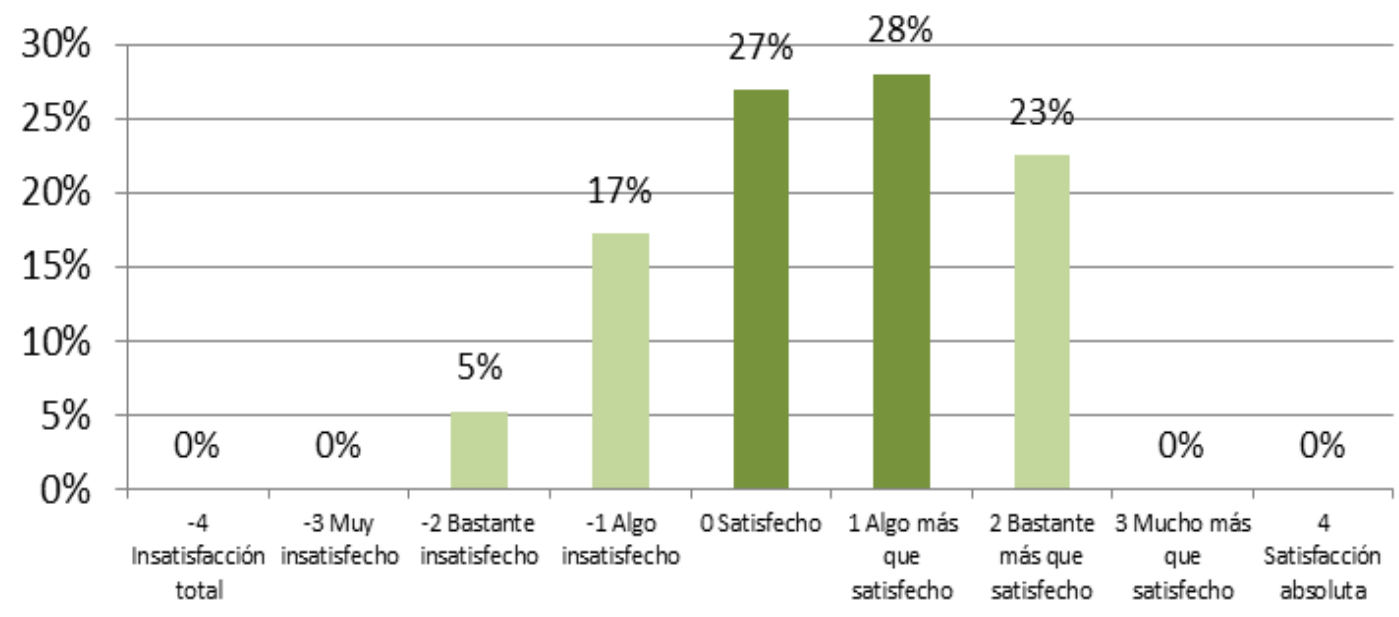

Para determinar el nivel exacto de satisfacción de los usuarios de la Municipalidad de Ensenada, Tomamos los datos obtenidos para la Expectativa en las 5 dimensiones analizadas y de igual forma para la Percepción. De la diferencia de estos valores obtenemos el nivel de satisfacción de cada dimensión y posteriormente se obtiene el nivel de satisfacción general del servicio de la Dirección de Obras Particulares sacando la diferencia entre Expectativa y Percepción de los totales de las dimensiones como lo vemos en la siguiente tabla.

\begin{tabular}{l|c|c|c|c|c}
\hline \multicolumn{1}{c|}{ Dimensión } & Expectativa & Percepción & $\begin{array}{c}\text { Nivel de } \\
\text { Satisfacción }\end{array}$ & Ponderación & $\begin{array}{c}\text { Nivel de } \\
\text { Satisfacción } \\
\text { Ponderado }\end{array}$ \\
\hline I. Elementos Tangibles & 3,185 & 2,975 & 0,210 & 2,025 & 0,689 \\
\hline II. Confiabilidad & 2,652 & 2,248 & 0,404 & 2,752 & 1,180 \\
\hline III. Capacidad de Respuesta & 2,855 & 2,380 & 0,475 & 2,62 & 1,112 \\
\hline IV. Seguridad & 2,425 & 1,670 & 0,755 & 3,33 & 0,785 \\
\hline V. Empatía & 2,540 & 2,104 & 0,436 & 2,896 & 0,183 \\
\hline \hline TOTAL & $\mathbf{2 , 7 3 1}$ & $\mathbf{2 , 2 7 5 4}$ & $\mathbf{0 , 4 5 6}$ & & $\mathbf{0 , 7 9 0}$ \\
\hline
\end{tabular}

\begin{tabular}{l|c|c}
\hline \multicolumn{1}{c|}{ Dimensión } & $\begin{array}{c}\text { Nivel de } \\
\text { Satisfacción }\end{array}$ & Importancia \\
\hline I. Elementos Tangibles & 0,689 & 50 \\
\hline II. Confiabilidad & 1,180 & $2 ㅇ$ \\
\hline III. Capacidad de Respuesta & 1,112 & 19 \\
\hline IV. Seguridad & 0,785 & 3o \\
\hline V. Empatía & 0,183 & 4은 \\
\hline \hline TOTAL & $\mathbf{0 , 7 9 0}$ & \\
\hline
\end{tabular}


Finalmente obtenemos el Nivel de Satisfacción Ponderado total de la Dirección de Obras Particulares de la Municipalidad de Ensenada con un valor de 0,790. El valor final se encuentra ubicado entre 1 y 0 lo que nos dice que la satisfacción de los usuarios se encuentre entre "Algo más que satisfechos" y "Satisfechos" Según la tabla que veremos a continuación.

\begin{tabular}{l:l} 
& \multicolumn{1}{|c}{ Escala de Satisfacción } \\
\hline-4 & Insatisfacción total \\
\hline-3 & Muy insatisfecho \\
\hline-2 & Bastante insatisfecho \\
\hline-1 & Algo insatisfecho \\
\hline 0 & Satisfecho \\
\hline 1 & Algo más que satisfecho \\
\hline 2 & Bastante más que satisfecho \\
\hline 3 & Mucho más que satisfecho \\
\hline 4 & Satisfacción absoluta
\end{tabular}




\section{Comparación de las dimensiones entre los resultados obtenidos en la Municipalidad de Ensenada y la Plata}

En el siguiente cuadro vamos a realizar una comparación detallada de los resultados obtenidos en la Municipalidad de Ensenada y la Municipalidad de La Plata en lo que se refiera a la Dirección de Obras particulares de cada una de las dimensiones que se plantearon. Esta comparación se hace con el fin de tener una marco de comparación y así poder tener una mayor perspectiva de la calidad del servicio prestado en la Dirección de Obras Particulares del la Municipalidad de ensenada.

\subsection{Cuadro comparativo Detallado por dimensiones}

\subsubsection{Comparación del análisis descriptivo de la muestra}

\begin{tabular}{|c|c|}
\hline \multicolumn{2}{|l|}{ Distribución por genero } \\
\hline Ensenada & La Plata \\
\hline $\begin{array}{l}\text { Hombres : } 88 \% \\
\text { Mujeres: } 12 \%\end{array}$ & $\begin{array}{l}\text { Hombres: } 50 \% \\
\text { Mujeres: } 50 \%\end{array}$ \\
\hline \multicolumn{2}{|c|}{$\begin{array}{l}\text { Análisis: Se nota una marcada diferencia en la Municipalidad de Ensenada hacia el } \\
\text { género Masculino en el uso del servicio. }\end{array}$} \\
\hline \multicolumn{2}{|l|}{ Edad de los encuestados } \\
\hline Ensenada & La Plata \\
\hline $\begin{array}{l}\text { De } 20 \text { a } 30 \text { años: } 4 \text { personas } 8 \% \\
\text { De } 30 \text { a } 40 \text { años: } 17 \text { personas } 34 \% \\
\text { De } 40 \text { a } 50 \text { años: } 15 \text { Personas } 30 \% \\
\text { De } 50 \text { a } 60 \text { años: } 14 \text { personas } 28 \% \\
\text { Más de } 60 \text { años: } 0 \text { personas } 0 \%\end{array}$ & $\begin{array}{l}\text { Hasta } 20 \text { años: } 5 \text { Personas } 10,00 \% \\
\text { De } 20 \text { Y } 30 \text { años: } 8 \text { Personas } 16,00 \% \\
\text { De } 30 \text { y } 40 \text { años: } 18 \text { Personas } 36,00 \% \\
\text { De } 40 \text { y } 50 \text { años: } 9 \text { Personas } 18,00 \% \\
\text { De } 50 \text { y } 60 \text { años: } 9 \text { Personas } 18,00 \% \\
\text { Más de } 60 \text { años: } 1 \text { Persona } 2,00 \%\end{array}$ \\
\hline \multicolumn{2}{|c|}{$\begin{array}{l}\text { Análisis: Se puede observar que el } 64 \% \text { de los usuarios cuyo rango etario está } \\
\text { comprendido entre los } 30 \text { y } 50 \text { años utilizan el servicio de obras particulares de la } \\
\text { Municipalidad de Ensenada, siendo la franja de } 30-40 \text { años la más predominante. En } \\
\text { la Municipalidad de la Ciudad de La Plata en cambio el } 54 \% \text { de los usuarios se } \\
\text { encuentra dentro del rango etario } 30-50 \text { años, siendo el más predominante el rango } \\
\text { de } 30-40 \text { con un } 36 \% \text { de uso }\end{array}$} \\
\hline
\end{tabular}




\section{Frecuencia de utilización del servicio de obras particulares.}

\begin{tabular}{|ll|lc|}
\hline \multicolumn{2}{|c|}{ Ensenada } & \multicolumn{2}{c|}{ La Plata } \\
\hline A diario: & $4 \%$ & A diario: & $16 \%$ \\
Varias veces a la semana: & $46 \%$ & Varias veces a la semana: & $30 \%$ \\
Una vez al mes: & $30 \%$ & Una vez al mes: & $20 \%$ \\
Una vez cada seis meses: & $12 \%$ & Una vez cada seis meses: & $16 \%$ \\
Una Vez al año: & $8 \%$ & Una Vez al año: & $8 \%$ \\
Cada Varios años: & $0 \%$ & Cada Varios años: & $10 \%$ \\
\hline
\end{tabular}

Análisis: La tendencia nos muestra en ambos casos que es un servicio mayormente utilizado varias veces a la semana en ambas ciudades seguido de una vez al mes. En este aspecto el comportamiento es muy similar para las dos municipalidades.

\section{Calificación del servicio de obras particulares}

\begin{tabular}{|c|c|}
\hline Ensenada & La Plata \\
\hline Excelente: $4 \%$ & Excelente: $8 \%$ \\
\hline Bueno: $\quad 70 \%$ & Bueno: $\quad 22 \%$ \\
\hline Regular: $\quad 22 \%$ & Regular: \\
\hline Malo: & Malo: \\
\hline Pésimo: & Pésimo: \\
\hline
\end{tabular}

Análisis: Según la tabla anterior podemos ver que en la Municipalidad de Ensenada califica el servicio como Bueno en un $70 \%$ siendo una calificación bastante buena frente a lo que opinan los usuarios de la ciudad de La Plata a la hora de calificar el mismo servicio. Pues podemos ver que el rango de calificaciones alcanza toso los aspectos centrándose en Regular con un $42 \%$. También se puede destacar que en la Ciudad de la Plata algunas personas catalogaron el servicio como Pésimo con un $12 \%$ a diferencia de Ensenada donde este ítem obtuvo porcentaje $0 \%$.

\subsubsection{Comparación Dimensión I: Elementos Tangibles}

Apariencia de las instalaciones físicas, equipos, personal y materiales de comunicación

\begin{tabular}{|c|c|}
\hline \multicolumn{2}{|c|}{ Dimensión I: Elementos Tangibles } \\
\hline Evaluación Equipos & La Plata \\
\hline Ensenada & \\
\hline
\end{tabular}




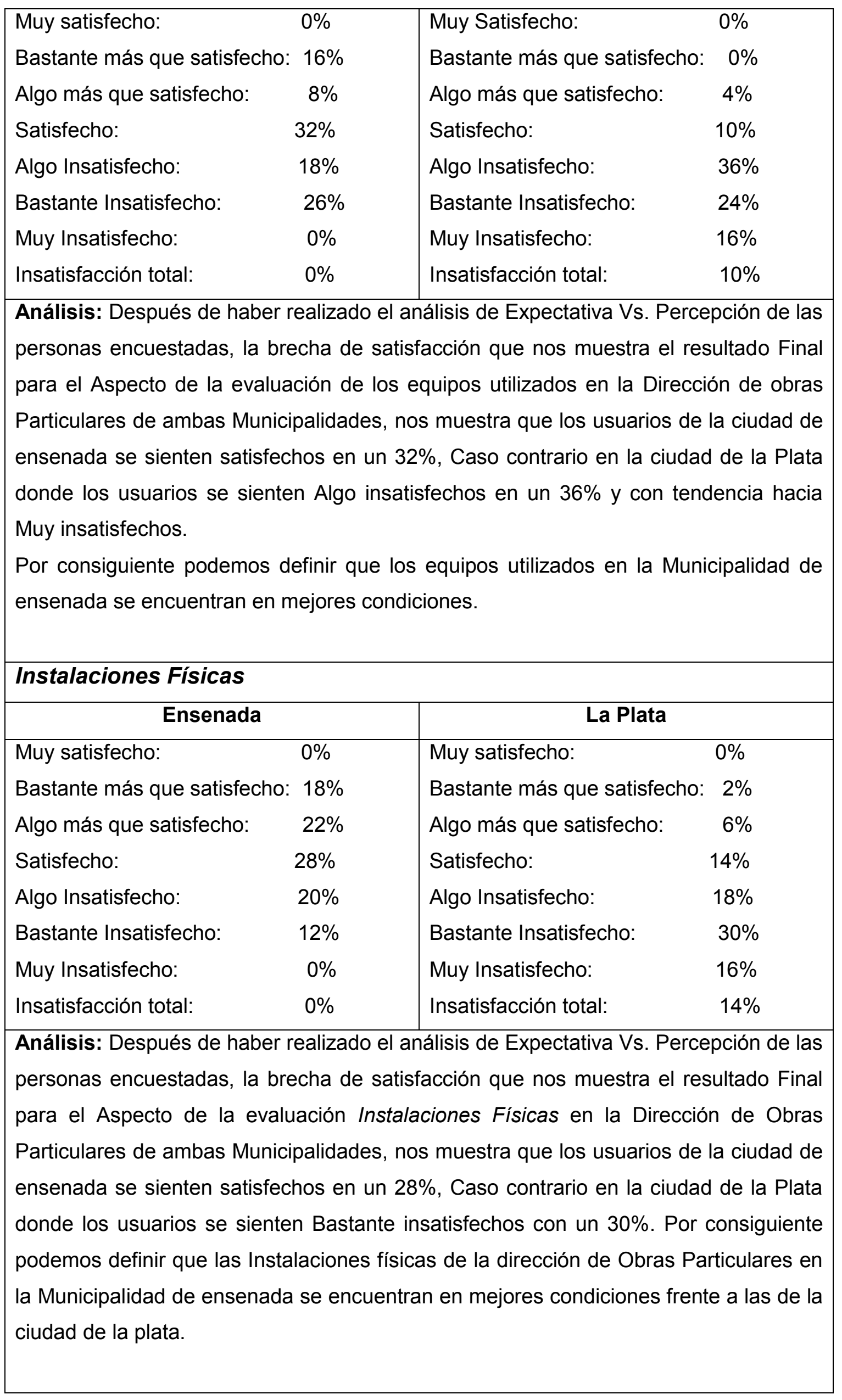




\section{Apariencia Física de los empleados}

\begin{tabular}{|lc|lc|}
\hline \multicolumn{2}{|c|}{ Ensenada } & \multicolumn{2}{c|}{ La Plata } \\
\hline Muy satisfecho: & $0 \%$ & Muy satisfecho: & $0 \%$ \\
Bastante más que satisfecho: & $24 \%$ & Bastante más que satisfecho: & $0 \%$ \\
Algo más que satisfecho: & $30 \%$ & Algo más que satisfecho: & $6 \%$ \\
Satisfecho: & $32 \%$ & Satisfecho: & $80 \%$ \\
Algo Insatisfecho: & $14 \%$ & Algo Insatisfecho: & $10 \%$ \\
Bastante Insatisfecho: & $0 \%$ & Bastante Insatisfecho: & $0 \%$ \\
Muy Insatisfecho: & $0 \%$ & Muy Insatisfecho: & $2 \%$ \\
Insatisfacción total: & $0 \%$ & Insatisfacción total: & $2 \%$
\end{tabular}

Análisis: Después de haber realizado el análisis de Expectativa Vs. Percepción de las personas encuestadas, la brecha de satisfacción que nos muestra el resultado Final para el Aspecto de la evaluación Apariencia Física de los Empleados en la Dirección de Obras Particulares de ambas Municipalidades, nos muestra que los usuarios de la ciudad de ensenada se sienten satisfechos en un $30 \%$ con tendencia a algo más que satisfechos, Mientras en la ciudad de la Plata los usuarios se sienten Mayoritariamente satisfechos con un $80 \%$. Por consiguiente podemos definir que la Apariencia Física de los empleados de la dirección de Obras Particulares en la Municipalidad de la Plata son mejor percibidos frente a los de la ciudad de Ensenada.

\section{Apariencia visual de los elementos materiales de comunicación}

\begin{tabular}{|lc|lc|}
\hline \multicolumn{2}{|c|}{ Ensenada } & \multicolumn{2}{c|}{ La Plata } \\
\hline Muy satisfecho: & $0 \%$ & Muy satisfecho: & $0 \%$ \\
Bastante más que satisfecho: & $16 \%$ & Bastante más que satisfecho: & $4 \%$ \\
Algo más que satisfecho: & $20 \%$ & Algo más que satisfecho: & $6 \%$ \\
Satisfecho: & $32 \%$ & Satisfecho: & $24 \%$ \\
Algo Insatisfecho: & $24 \%$ & Algo Insatisfecho: & $34 \%$ \\
Bastante Insatisfecho: & $8 \%$ & Bastante Insatisfecho: & $14 \%$ \\
Muy Insatisfecho: & $0 \%$ & Muy Insatisfecho: & $16 \%$ \\
Insatisfacción total: & $0 \%$ & Insatisfacción total: & $2 \%$ \\
\hline
\end{tabular}

Análisis: Después de haber realizado el análisis de Expectativa Vs. Percepción de las personas encuestadas, la brecha de satisfacción que nos muestra el resultado Final para el Aspecto de la evaluación Apariencia visual de los elementos materiales de comunicación en la Dirección de Obras Particulares de ambas Municipalidades, nos muestra que los usuarios de la ciudad de ensenada se sienten satisfechos en un $32 \%$ con tendencia a algo insatisfechos, Mientras en la ciudad de la Plata los usuarios se sienten algo insatisfechos con un $34 \%$. Por consiguiente podemos definir que la Apariencia visual de los elementos de comunicación de la dirección de Obras 


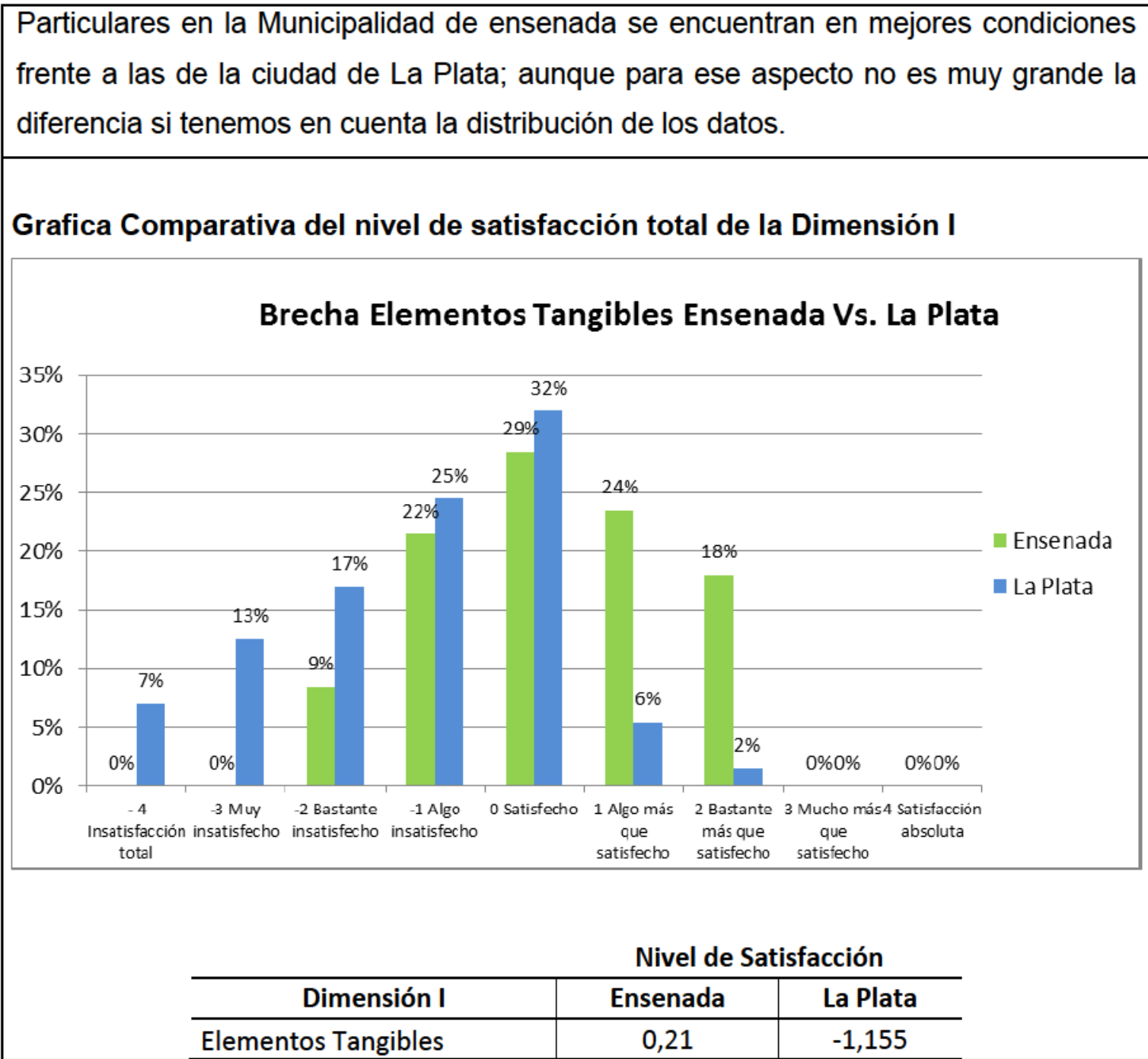

\subsubsection{Comparación Dimensión II: Confiabilidad}

Habilidad para ejecutar el servicio prometido de forma confiable y cuidadosa

\begin{tabular}{|lc|lc|}
\hline \multicolumn{4}{|c|}{ Dimensión II: Confiabilidad } \\
\hline \multicolumn{2}{|c|}{ Cumplimiento de los empleados } & \multicolumn{2}{c|}{ La Plata } \\
\hline \multicolumn{2}{|c|}{ Ensenada } & Muy satisfecho: & $0 \%$ \\
\hline Muy satisfecho: & $0 \%$ & Bastante más que satisfecho: $0 \%$ \\
Bastante más que satisfecho: & $24 \%$ & Algo más que satisfecho: & $10 \%$ \\
Algo más que satisfecho: & $26 \%$ & Satisfecho: & $36 \%$ \\
Satisfecho: & $36 \%$ & Algo Insatisfecho: & $24 \%$ \\
Algo Insatisfecho: & $10 \%$ & Bastante Insatisfecho: & $24 \%$ \\
Bastante Insatisfecho: & $4 \%$ & Muy Insatisfecho: & $6 \%$ \\
Muy Insatisfecho: & $0 \%$ & Insatisfacción total: & $0 \%$ \\
Insatisfacción total: & $0 \%$ & \\
\hline \multicolumn{4}{|c|}{} \\
\hline
\end{tabular}


Análisis: Después de haber realizado el análisis de Expectativa Vs. Percepción de las personas encuestadas, la brecha de satisfacción que nos muestra el resultado Final para el Aspecto de la evaluación sobre el Cumplimiento de los empleados en la Dirección de Obras Particulares de ambas Municipalidades, nos muestra que los usuarios de la ciudad de ensenada se sienten satisfechos en un $36 \%$ con tendencia a Algo más que satisfechos, De igual forma en la ciudad de la Plata donde los usuarios se sienten satisfechos con un $36 \%$ pero con tendencia a Algo Insatisfechos. Por consiguiente podemos definir que los usuarios determinaron que el cumplimiento de los empleados de la dirección de Obras Particulares en ambas municipalidades se encuentra en igualdad de condiciones; con la diferencia que la tendencia de la municipalidad de Ensenada tiende hacia un nivel de satisfacción mayor contrario a lo que pasa en la Municipalidad de la Plata.

Interés de los empleados del servicio municipal por solucionar los problemas del cliente

\begin{tabular}{|lc|lc|}
\hline \multicolumn{2}{|c|}{ Ensenada } & \multicolumn{2}{c}{ La Plata } \\
\hline Muy satisfecho: & $0 \%$ & Muy satisfecho: & $0 \%$ \\
Bastante más que satisfecho: & $16 \%$ & Bastante más que satisfecho: & $0 \%$ \\
Algo más que satisfecho: & $26 \%$ & Algo más que satisfecho: & $2 \%$ \\
Satisfecho: & $28 \%$ & Satisfecho: & $50 \%$ \\
Algo Insatisfecho: & $28 \%$ & Algo Insatisfecho: & $30 \%$ \\
Bastante Insatisfecho: & $2 \%$ & Bastante Insatisfecho: & $14 \%$ \\
Muy Insatisfecho: & $0 \%$ & Muy Insatisfecho: & $2 \%$ \\
Insatisfacción total: & $0 \%$ & Insatisfacción total: & $2 \%$ \\
\hline
\end{tabular}

Análisis: Después de haber realizado el análisis de Expectativa Vs. Percepción de las personas encuestadas, la brecha de satisfacción que nos muestra el resultado final para el Aspecto de la evaluación sobre el Interés de los empleados por solucionar los problemas del cliente en la Dirección de Obras Particulares de ambas Municipalidades, nos muestra que los usuarios de la ciudad de Ensenada se sienten Algo Insatisfechos y satisfechos en un $28 \%$ respectivamente: Mientras que en la ciudad de la Plata se evidencio claramente que los usuarios están Satisfechos con un $50 \%$ pero con tendencia a Algo Insatisfechos. Por consiguiente podemos definir que los usuarios determinaron que el Interés de los empleados por solucionar los problemas del cliente de la Dirección de Obras Particulares es más clara en la ciudad de la Plata pues se ve una marcada diferencia frente a los datos observados en la Municipalidad de Ensenada donde una frecuencia con mayor distribución en la percepción obtenida en este aspecto. 


\section{Eficacia del Servicio Municipal}

\begin{tabular}{|lc|lc}
\hline \multicolumn{2}{|c|}{ Ensenada } & \multicolumn{2}{c}{ La Plata } \\
\hline Muy satisfecho: & $0 \%$ & Muy satisfecho: & $0 \%$ \\
Bastante más que satisfecho: & $30 \%$ & Bastante más que satisfecho: & $0 \%$ \\
Algo más que satisfecho: & $22 \%$ & Algo más que satisfecho: & $4 \%$ \\
Satisfecho: & $30 \%$ & Satisfecho: & $22 \%$ \\
Algo Insatisfecho: & $14 \%$ & Algo Insatisfecho: & $24 \%$ \\
Bastante Insatisfecho: & $4 \%$ & Bastante Insatisfecho: & $28 \%$ \\
Muy Insatisfecho: & $0 \%$ & Muy Insatisfecho: & $12 \%$ \\
Insatisfacción total: & $0 \%$ & Insatisfacción total: & $10 \%$
\end{tabular}

Análisis: Después de haber realizado el análisis de Expectativa Vs. Percepción de las personas encuestadas, la brecha de satisfacción que nos muestra el resultado final para el Aspecto de la evaluación sobre la Eficacia del Servicio Municipal en la Dirección de Obras Particulares de ambas Municipalidades, nos muestra que los usuarios de la ciudad de Ensenada se sienten bastante más que satisfechos en un $30 \%$ e igualmente satisfechos también con un $30 \%$; mientras que en la ciudad de la Plata se evidencio una percepción contraria donde los usuarios están bastante insatisfechos con la eficacia del servicio con un $28 \%$ pero con tendencia a Algo Insatisfechos y satisfecho. Por consiguiente podemos definir que los usuarios determinaron que la Eficacia del Servicio Municipal de la Dirección de Obras Particulares es mucho mejor en la Municipalidad de Ensenada pues se ve una marcada diferencia frente a los datos observados en la ciudad de la Plata donde se ve una frecuencia con una mayor distribución en la percepción obtenida en este aspecto.

\section{Tiempo de cumplimiento del trabajo}

\begin{tabular}{|lc|lc|}
\hline \multicolumn{2}{|c|}{ Ensenada } & \multicolumn{2}{c|}{ La Plata } \\
\hline Muy satisfecho: & $0 \%$ & Muy satisfecho: & $0 \%$ \\
Bastante más que satisfecho: & $22 \%$ & Bastante más que satisfecho: & $0 \%$ \\
Algo más que satisfecho: & $24 \%$ & Algo más que satisfecho: & $2 \%$ \\
Satisfecho: & $26 \%$ & Satisfecho: & $14 \%$ \\
Algo Insatisfecho: & $16 \%$ & Algo Insatisfecho: & $10 \%$ \\
Bastante Insatisfecho: & $12 \%$ & Bastante Insatisfecho: & $26 \%$ \\
Muy Insatisfecho: & $0 \%$ & Muy Insatisfecho: & $24 \%$ \\
Insatisfacción total: & $0 \%$ & Insatisfacción total: & $24 \%$ \\
\hline
\end{tabular}

Análisis: Después de haber realizado el análisis de Expectativa Vs. Percepción de las personas encuestadas, la brecha de satisfacción que nos muestra el resultado final para el Aspecto de la evaluación sobre el Tiempo del cumplimiento del Trabajo en la 
Dirección de Obras Particulares de ambas Municipalidades, nos muestra que los usuarios de la ciudad de Ensenada se sienten satisfechos en un $26 \%$ con tendencia a algo más que satisfechos; mientras que en la ciudad de la Plata se evidencio una percepción contraria donde los usuarios están bastante insatisfechos con el cumplimiento del trabajo con un $26 \%$ y con tendencia a muy Insatisfechos e insatisfacción total. Por consiguiente podemos definir que los usuarios determinaron que el Tiempo del Cumplimiento del Trabajo de la Dirección de Obras Particulares es mucho mejor en la Municipalidad de Ensenada pues se ve una marcada diferencia frente a los datos observados en la ciudad de la Plata donde los usuarios percibieron lo contrario.

\section{Eficiencia del Servicio Municipal}

\begin{tabular}{|lc|lc|}
\hline \multicolumn{2}{|c|}{ Ensenada } & \multicolumn{2}{c}{ La Plata } \\
\hline Muy satisfecho: & $0 \%$ & Muy satisfecho: & $0 \%$ \\
Bastante más que satisfecho: & $18 \%$ & Bastante más que satisfecho: & $0 \%$ \\
Algo más que satisfecho: & $26 \%$ & Algo más que satisfecho: & $0 \%$ \\
Satisfecho: & $30 \%$ & Satisfecho: & $18 \%$ \\
Algo Insatisfecho: & $22 \%$ & Algo Insatisfecho: & $30 \%$ \\
Bastante Insatisfecho: & $4 \%$ & Bastante Insatisfecho: & $38 \%$ \\
Muy Insatisfecho: & $0 \%$ & Muy Insatisfecho: & $10 \%$ \\
Insatisfacción total: & $0 \%$ & Insatisfacción total: & $4 \%$ \\
\hline
\end{tabular}

Análisis: Después de haber realizado el análisis de Expectativa Vs. Percepción de las personas encuestadas, la brecha de satisfacción que nos muestra el resultado final para el Aspecto de la evaluación sobre la Eficiencia del servicio Municipal en la Dirección de Obras Particulares de ambas Municipalidades, nos muestra que los usuarios de la ciudad de Ensenada se sienten satisfechos en un $30 \%$ con tendencia a algo más que satisfechos; mientras que en la ciudad de la Plata se evidencio una percepción contraria donde los usuarios están bastante insatisfechos con el cumplimiento del trabajo con un $38 \%$ pero con tendencia a algo satisfechos. Por consiguiente podemos definir que los usuarios determinaron que la eficiencia del Servicio Municipal de la Dirección de Obras Particulares es mucho mejor en la Municipalidad de Ensenada pues se ve una marcada diferencia frente a los datos observados en la ciudad de la Plata donde los usuarios percibieron lo contrario. 


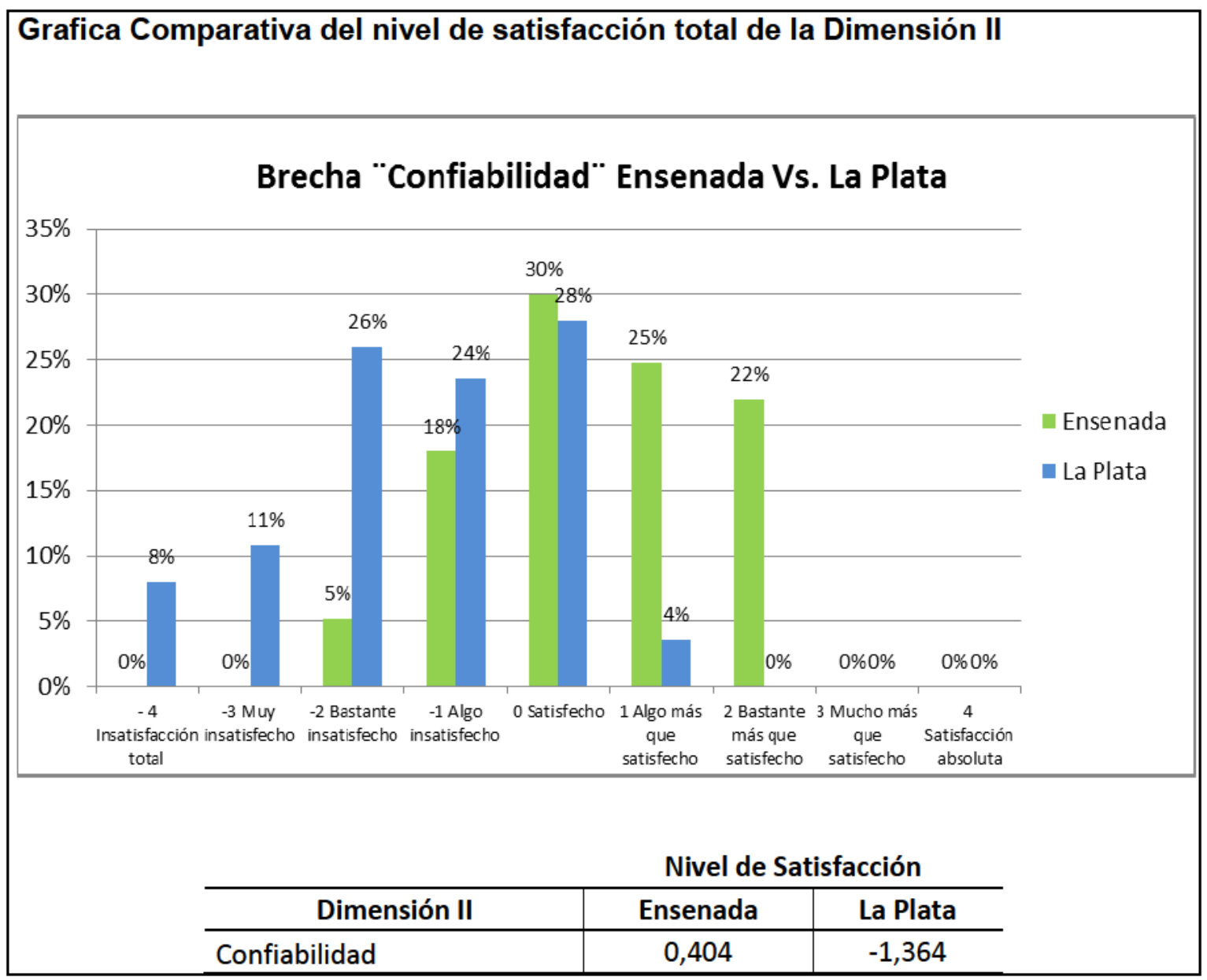

\subsubsection{Comparación Dimensión III: Capacidad de Respuesta}

Disposición de los empleados para ayudar al cliente y proporcionar el servicio.

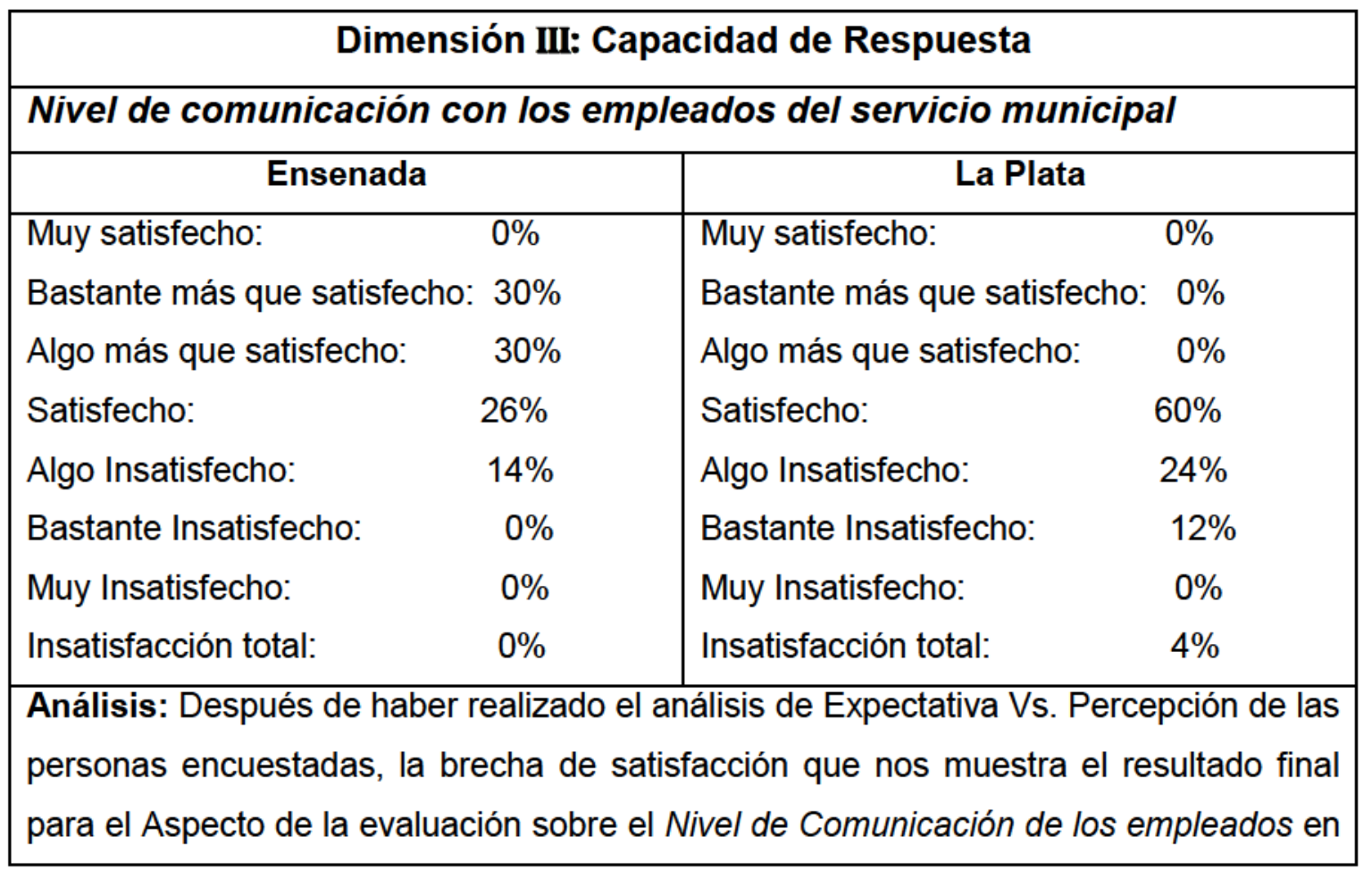


la Dirección de Obras Particulares de ambas Municipalidades, nos muestra que los usuarios de la ciudad de Ensenada se sienten Bastante más que satisfechos y algo más que satisfechos en un $30 \%$ respectivamente; mientras que en la ciudad de la Plata se evidencio una percepción mayoritaria a satisfecho con el $60 \%$ pero con tendencia negativa hacia algo insatisfechos. Por consiguiente podemos definir que los usuarios determinaron que el Nivel de Comunicación de los empleados de la Dirección de Obras Particulares es mucho mejor en la Municipalidad de Ensenada pues se ve una marcada diferencia frente a los datos observados en la ciudad de la Plata.

\section{Velocidad del Servicio}

\begin{tabular}{|ll|lc|}
\hline \multicolumn{2}{|c|}{ Ensenada } & \multicolumn{2}{c}{ La Plata } \\
\hline Muy satisfecho: & $0 \%$ & Muy satisfecho: & $0 \%$ \\
Bastante más que satisfecho: & $22 \%$ & Bastante más que satisfecho: & $0 \%$ \\
Algo más que satisfecho: & $16 \%$ & Algo más que satisfecho: & $0 \%$ \\
Satisfecho: & $18 \%$ & Satisfecho: & $14 \%$ \\
Algo Insatisfecho: & $34 \%$ & Algo Insatisfecho: & $16 \%$ \\
Bastante Insatisfecho: & $10 \%$ & Bastante Insatisfecho: & $30 \%$ \\
Muy Insatisfecho: & $0 \%$ & Muy Insatisfecho: & $22 \%$ \\
Insatisfacción total: & $0 \%$ & Insatisfacción total: & $18 \%$
\end{tabular}

Análisis: Después de haber realizado el análisis de Expectativa Vs. Percepción de las personas encuestadas, la brecha de satisfacción que nos muestra el resultado final para el Aspecto de la evaluación sobre la Velocidad del Servicio en la Dirección de Obras Particulares de ambas Municipalidades, nos muestra que los usuarios de la ciudad de Ensenada se sienten Algo insatisfechos con el 34\% pero con una tendencia positiva a bastante más que satisfechos; mientras que en la ciudad de la Plata se evidencio una percepción de los usuarios de Bastante Insatisfecho con el $30 \%$ pero con tendencia negativa hacia muy insatisfechos. Por consiguiente podemos definir que los usuarios determinaron que la Velocidad del servicio de la Dirección de Obras Particulares es mucho mejor en la Municipalidad de Ensenada pues se ve una marcada diferencia frente a los datos observados en la ciudad de la Plata.

\section{Disponibilidad del Servicio}

\begin{tabular}{|lc|lc|}
\hline \multicolumn{2}{|c|}{ Ensenada } & \multicolumn{2}{c|}{ La Plata } \\
\hline Muy satisfecho: & $0 \%$ & Muy satisfecho: & $0 \%$ \\
Bastante más que satisfecho: & $18 \%$ & Bastante más que satisfecho: & $0 \%$ \\
Algo más que satisfecho: & $34 \%$ & Algo más que satisfecho: & $2 \%$ \\
Satisfecho: & $20 \%$ & Satisfecho: & $42 \%$ \\
Algo Insatisfecho: & $20 \%$ & Algo Insatisfecho: & $28 \%$ \\
\hline
\end{tabular}




\begin{tabular}{|ll|ll|}
\hline Bastante Insatisfecho: & $8 \%$ & Bastante Insatisfecho: & $22 \%$ \\
Muy Insatisfecho: & $0 \%$ & Muy Insatisfecho: & $2 \%$ \\
Insatisfacción total: & $0 \%$ & Insatisfacción total: & $4 \%$ \\
\hline
\end{tabular}

Análisis: Después de haber realizado el análisis de Expectativa Vs. Percepción de las personas encuestadas, la brecha de satisfacción que nos muestra el resultado final para el Aspecto de la evaluación sobre la Disponibilidad del Servicio en la Dirección de Obras Particulares de ambas Municipalidades, nos muestra que los usuarios de la ciudad de Ensenada se sienten Algo más que satisfechos con el $34 \%$ pero con una tendencia negativa a algo insatisfechos; mientras que en la ciudad de la Plata se evidencio una percepción casi similar de los usuarios que mayoritariamente se sienten satisfechos con el $42 \%$ pero con tendencia negativa hacia algo insatisfechos. Por consiguiente podemos definir que los usuarios determinaron que la Disponibilidad del Servicio de la Dirección de Obras Particulares es mucho más equilibrada en la Municipalidad de Ensenada, mientras que en la ciudad de la Plata aunque vemos un alto porcentaje y los usuarios se sienten satisfechos la tendencia nos dice que este aspecto es mejor en la Municipalidad de Ensenada.

\section{Disponibilidad de atención inmediata frente a otras actividades}

\begin{tabular}{|lc|lc|}
\hline \multicolumn{2}{|c|}{ Ensenada } & \multicolumn{2}{c}{ La Plata } \\
\hline Muy satisfecho: & $0 \%$ & Muy satisfecho: & $4 \%$ \\
Bastante más que satisfecho: & $30 \%$ & Bastante más que satisfecho: & $4 \%$ \\
Algo más que satisfecho: & $38 \%$ & Algo más que satisfecho: & $0 \%$ \\
Satisfecho: & $12 \%$ & Satisfecho: & $50 \%$ \\
Algo Insatisfecho: & $16 \%$ & Algo Insatisfecho: & $18 \%$ \\
Bastante Insatisfecho: & $4 \%$ & Bastante Insatisfecho: & $12 \%$ \\
Muy Insatisfecho: & $0 \%$ & Muy Insatisfecho: & $8 \%$ \\
Insatisfacción total: & $0 \%$ & Insatisfacción total: & $4 \%$ \\
\hline
\end{tabular}

Análisis: Después de haber realizado el análisis de Expectativa Vs. Percepción de las personas encuestadas, la brecha de satisfacción que nos muestra el resultado final para el Aspecto de la evaluación sobre la Disponibilidad de Atención Inmediata Frente a Otras Actividades en la Dirección de Obras Particulares de ambas Municipalidades, nos muestra que los usuarios de la ciudad de Ensenada se sienten Algo más que satisfechos con el $38 \%$ y con una tendencia positiva a bastante mas que satisfechos; mientras que en la ciudad de la Plata se evidencio una percepción de los usuarios que mayoritariamente se sienten satisfechos con el $50 \%$ pero con tendencia negativa hacia algo insatisfechos. Por consiguiente podemos definir que los usuarios 


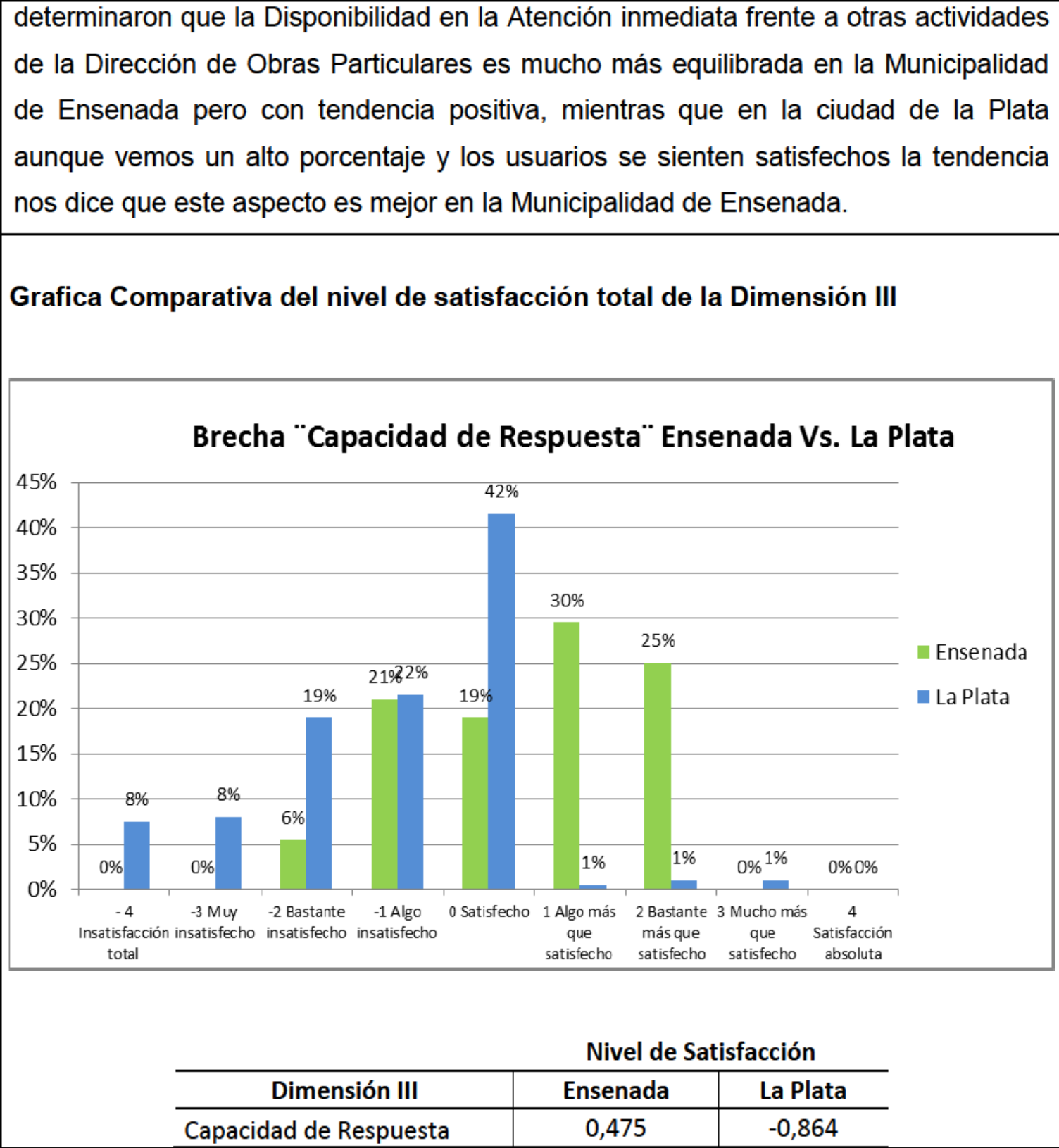

\subsubsection{Dimensión IV: Seguridad}

Conocimiento y atención mostrados por los empleados y sus habilidades para inspirar credibilidad y confianza.

\begin{tabular}{|ll|ll|}
\hline \multicolumn{3}{|c|}{ Dimensión IV: Seguridad } \\
\hline \multicolumn{2}{|c|}{ Nivel de confianza que brinda el comportamiento de los empleados } \\
\hline \multicolumn{2}{|c|}{ Ensenada } & \multicolumn{1}{c|}{ La Plata } \\
\hline Muy satisfecho: & $0 \%$ & Muy satisfecho: & $0 \%$ \\
Bastante más que satisfecho: & $18 \%$ & Bastante más que satisfecho: $0 \%$ \\
Algo más que satisfecho: & $34 \%$ & Algo más que satisfecho: $\quad 2 \%$ \\
\hline
\end{tabular}




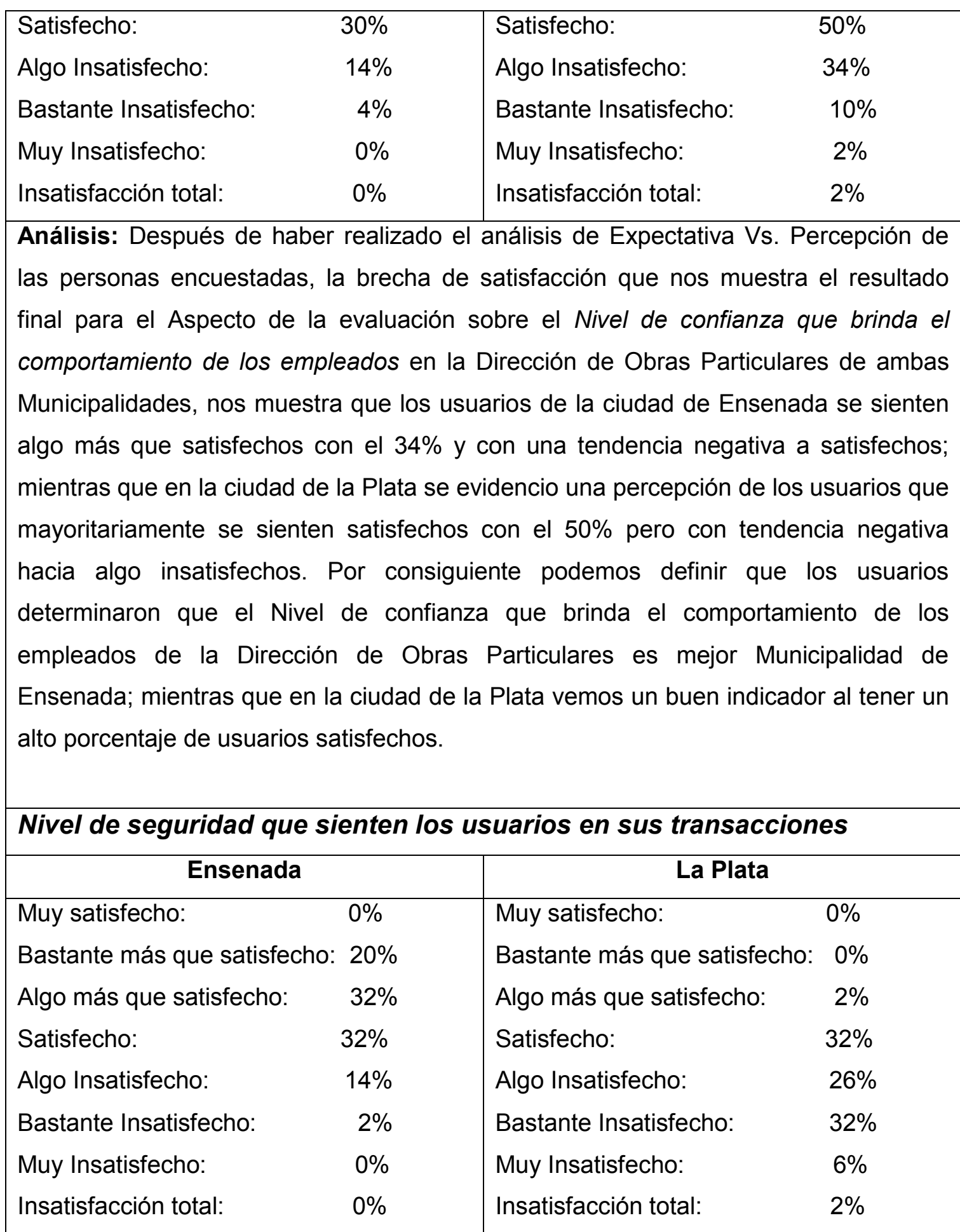

Análisis: Después de haber realizado el análisis de Expectativa Vs. Percepción de las personas encuestadas, la brecha de satisfacción que nos muestra el resultado final para el Aspecto de la evaluación sobre el Nivel de seguridad que sienten los usuarios en sus transacciones en la Dirección de Obras Particulares de ambas Municipalidades, nos muestra que los usuarios de la ciudad de Ensenada se sienten algo más que satisfechos y satisfechos respectivamente con el $32 \%$; mientras que en la ciudad de la Plata se evidencio una percepción de los usuarios que Fraccionada entre Satisfechos y bastante insatisfechos con un $32 \%$ respectivamente. Por consiguiente podemos definir que los usuarios determinaron que el Nivel de 
seguridad que sienten los usuarios en sus transacciones de la Dirección de Obras Particulares es mejor Municipalidad de Ensenada; mientas que en la ciudad de la Plata vemos un buen indicador con tendencia negativa al tener también un alto porcentaje en usuarios bastante insatisfechos.

\section{Nivel de amabilidad de los empleados}

\begin{tabular}{|lc|lc|}
\hline \multicolumn{2}{|c|}{ Ensenada } & \multicolumn{2}{c}{ La Plata } \\
\hline Muy satisfecho: & $0 \%$ & Muy satisfecho: & $0 \%$ \\
Bastante más que satisfecho: & $36 \%$ & Bastante más que satisfecho: & $2 \%$ \\
Algo más que satisfecho: & $36 \%$ & Algo más que satisfecho: & $12 \%$ \\
Satisfecho: & $26 \%$ & Satisfecho: & $56 \%$ \\
Algo Insatisfecho: & $2 \%$ & Algo Insatisfecho: & $16 \%$ \\
Bastante Insatisfecho: & $0 \%$ & Bastante Insatisfecho: & $12 \%$ \\
Muy Insatisfecho: & $0 \%$ & Muy Insatisfecho: & $2 \%$ \\
Insatisfacción total: & $0 \%$ & Insatisfacción total: & $0 \%$ \\
\hline
\end{tabular}

Análisis: Después de haber realizado el análisis de Expectativa Vs. Percepción de las personas encuestadas, la brecha de satisfacción que nos muestra el resultado final para el Aspecto de la evaluación sobre el Nivel de amabilidad de los empleados en la Dirección de Obras Particulares de ambas Municipalidades, nos muestra que los usuarios de la ciudad de Ensenada se sienten Bastante más que satisfechos y algo mas que satisfechos en un $36 \%$ respectivamente determinado un alto nivel de satisfacción; mientras que en la ciudad de la Plata se evidencio una percepción de los usuarios que mayoritariamente se sienten satisfechos con el $56 \%$ pero con tendencia negativa hacia algo insatisfechos. Por consiguiente podemos definir que los usuarios determinaron que el Nivel de amabilidad de los empleados de la Dirección de Obras Particulares es mejor percibido en la Municipalidad de Ensenada; mientras que en la ciudad de la Plata vemos un buen indicador al tener un alto porcentaje de usuarios satisfechos.

Grado de conocimiento que tienen los empleados para resolver las inquietudes de los usuarios.

\begin{tabular}{|ll|lr|}
\hline \multicolumn{2}{|c|}{ Ensenada } & \multicolumn{2}{c|}{ La Plata } \\
\hline Muy satisfecho: & $0 \%$ & Muy satisfecho: & $0 \%$ \\
Bastante más que satisfecho: & $30 \%$ & Bastante más que satisfecho: & $0 \%$ \\
Algo más que satisfecho: & $38 \%$ & Algo más que satisfecho: & $2 \%$ \\
Satisfecho: & $12 \%$ & Satisfecho: & $34 \%$ \\
Algo Insatisfecho: & $16 \%$ & Algo Insatisfecho: & $36 \%$ \\
\hline
\end{tabular}




\begin{tabular}{|ll|ll|}
\hline Bastante Insatisfecho: & $4 \%$ & Bastante Insatisfecho: & $24 \%$ \\
Muy Insatisfecho: & $0 \%$ & Muy Insatisfecho: & $4 \%$ \\
Insatisfacción total: & $0 \%$ & Insatisfacción total: & $0 \%$ \\
\hline
\end{tabular}

Análisis: Después de haber realizado el análisis de Expectativa Vs. Percepción de las personas encuestadas, la brecha de satisfacción que nos muestra el resultado final para el Aspecto de la evaluación sobre el Grado de conocimiento que tienen los empleados para resolver las inquietudes de los usuarios en la Dirección de Obras Particulares de ambas Municipalidades, nos muestra que los usuarios de la ciudad de Ensenada se sienten algo más que satisfechos con el $38 \%$ y con tendencia positiva hacia bastante más que satisfechos; mientras que en la ciudad de la Plata se evidencio una percepción contraria de los usuarios hacia algo insatisfechos con un $36 \%$ pero con tendencia positiva a Satisfechos. Por consiguiente podemos definir que los usuarios determinaron que el Grado de conocimiento que tienen los empleados para resolver las inquietudes de los usuarios de la Dirección de Obras Particulares es mejor Municipalidad de Ensenada; mientras que en la ciudad de la Plata vemos un criterio contrario pero con tendencia negativa.

Grafica Comparativa del nivel de satisfacción total de la Dimensión IV

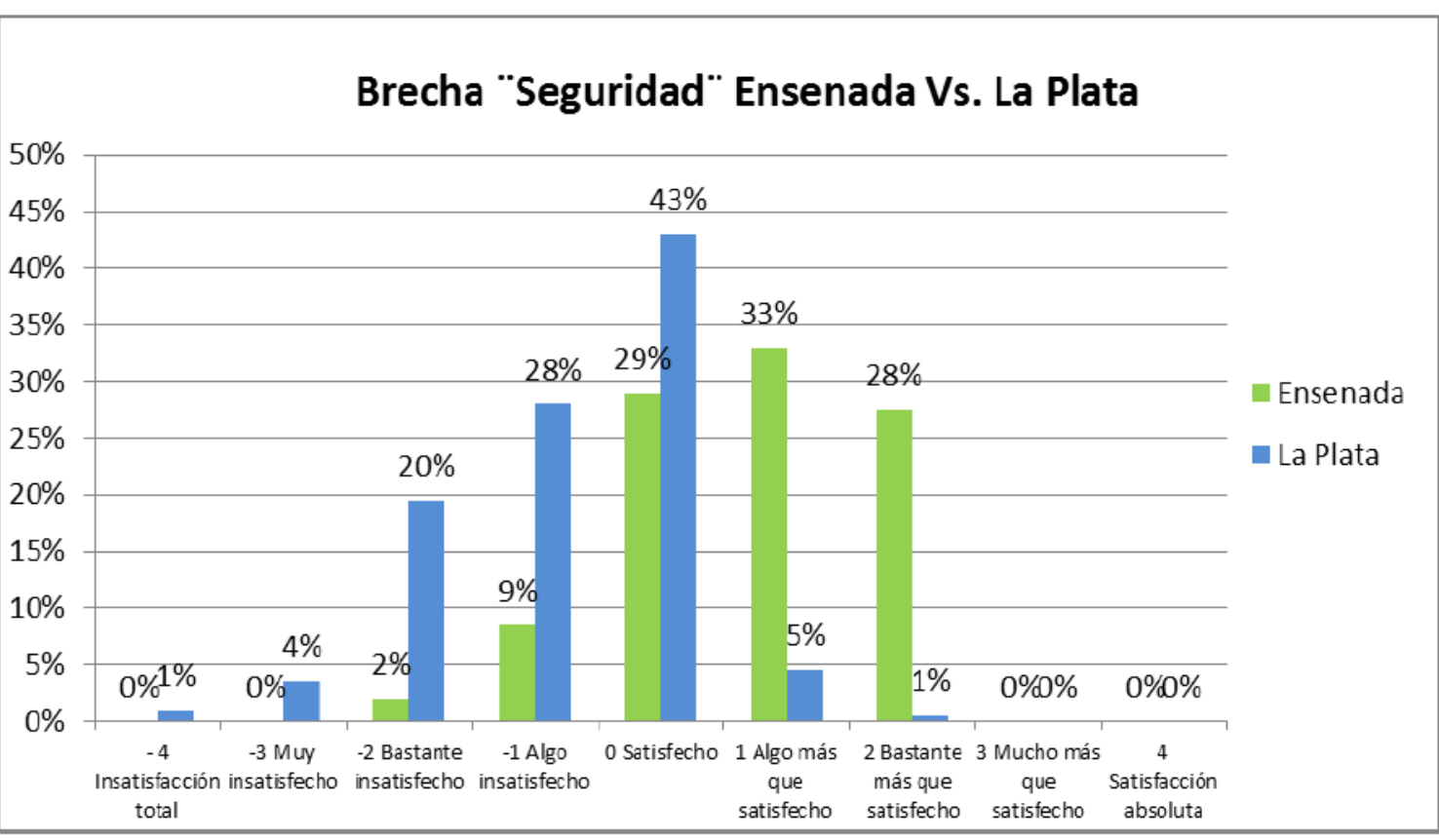

Nivel de Satisfacción

\begin{tabular}{c|c|c}
\hline Dimensión IV & Ensenada & La Plata \\
\hline Seguridad & 0.755 & $-0,76$ \\
\hline
\end{tabular}




\subsubsection{Dimensión V: Empatía}

Atención individualizada que ofrece la organización a los clientes.

\begin{tabular}{|c|c|}
\hline \multicolumn{2}{|c|}{ Dimensión V: Empatía } \\
\hline \multicolumn{2}{|c|}{ Nivel de individualización de la prestación del servicio } \\
\hline Ensenada & La Plata \\
\hline Muy satisfecho: $\quad 0 \%$ & Muy satisfecho: \\
\hline Bastante más que satisfecho: $16 \%$ & Bastante más que satisfecho: $0 \%$ \\
\hline Algo más que satisfecho: & Algo más que satisfecho: \\
\hline Satisfecho: & Satisfecho: \\
\hline Algo Insatisfecho: & Algo Insatisfecho: \\
\hline Bastante Insatisfecho: & Bastante Insatisfecho: \\
\hline Muy Insatisfecho: & Muy Insatisfecho: \\
\hline Insatisfacción total: & Insatisfacción total: \\
\hline \multicolumn{2}{|c|}{$\begin{array}{l}\text { Análisis: Después de haber realizado el análisis de Expectativa Vs. Percepción de las } \\
\text { personas encuestadas, la brecha de satisfacción que nos muestra el resultado final } \\
\text { para el Aspecto de la evaluación sobre el Nivel de individualización de la prestación } \\
\text { del servicio en la Dirección de Obras Particulares de ambas Municipalidades, nos } \\
\text { muestra que los usuarios de la ciudad de Ensenada se sienten Algo más que } \\
\text { satisfecho y satisfechos en un } 32 \% \text { respectivamente; mientras que en la ciudad de la } \\
\text { Plata se evidencio una percepción de los usuarios que mayoritariamente se sienten } \\
\text { satisfechos con el } 72 \% \text {. Por consiguiente podemos definir que los usuarios } \\
\text { determinaron que el Nivel de individualización de la prestación del servicio de la } \\
\text { Dirección de Obras Particulares es mejor percibido en la Municipalidad de Ensenada; } \\
\text { mientras que en la ciudad de la Plata vemos un buen indicador al tener un alto } \\
\text { porcentaje de usuarios satisfechos. }\end{array}$} \\
\hline \multicolumn{2}{|c|}{ Conveniencia de los Horarios de trabajo } \\
\hline Ensenada & La Plata \\
\hline Muy satisfecho: & Muy satisfecho: \\
\hline Bastante más que satisfecho: $18 \%$ & Bastante más que satisfecho: $0 \%$ \\
\hline Algo más que satisfecho: & Algo más que satisfecho: \\
\hline Satisfecho: & Satisfecho: \\
\hline Algo Insatisfecho: & Algo Insatisfecho: \\
\hline Bastante Insatisfecho: & Bastante Insatisfecho: \\
\hline
\end{tabular}




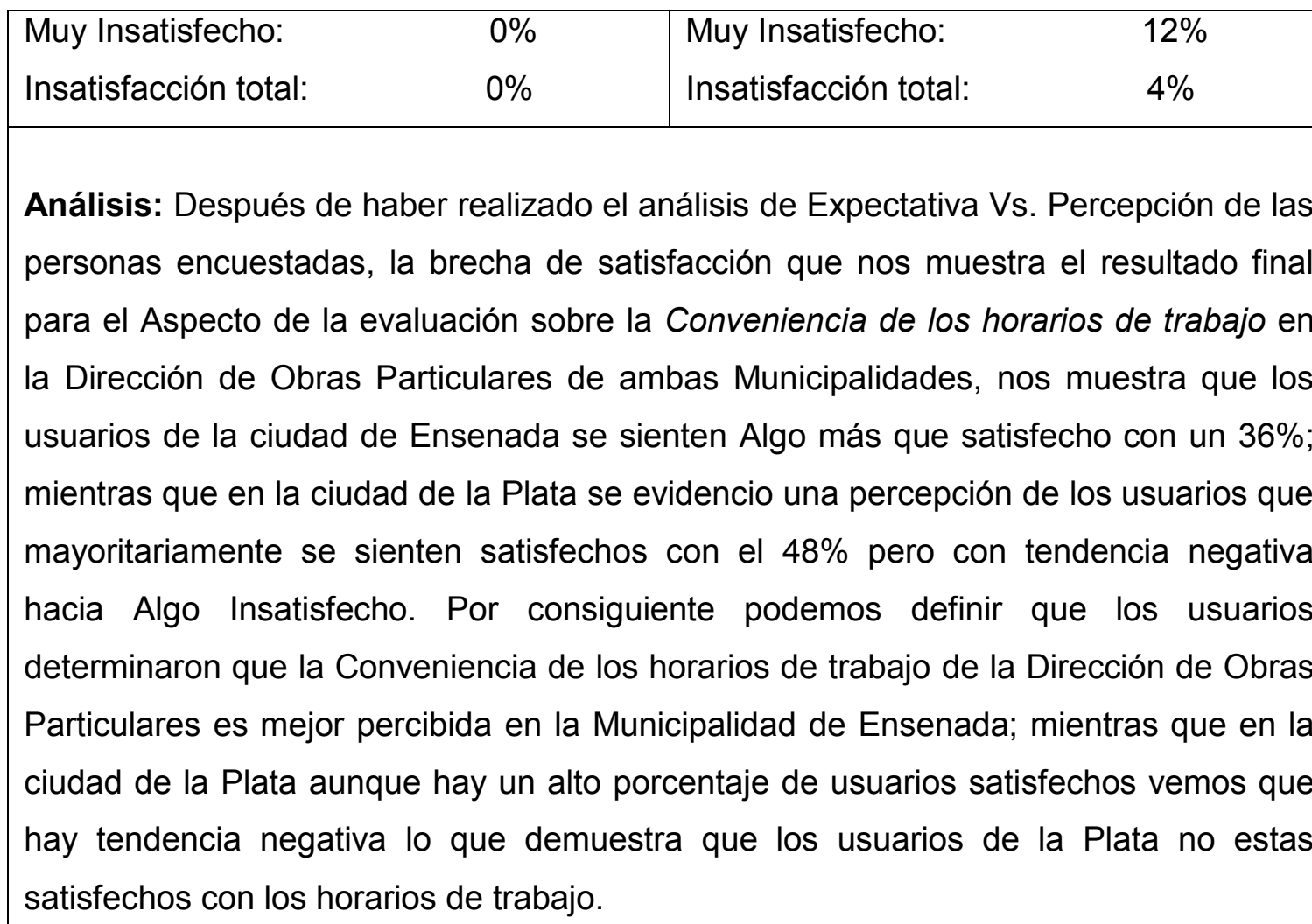

\section{Nivel de personalización en la atención del servicio}

\begin{tabular}{|ll|lc|}
\hline \multicolumn{2}{|c|}{ Ensenada } & \multicolumn{2}{c|}{ La Plata } \\
\hline Muy satisfecho: & $0 \%$ & Muy satisfecho: & $0 \%$ \\
Bastante más que satisfecho: & $22 \%$ & Bastante más que satisfecho: & $0 \%$ \\
Algo más que satisfecho: & $26 \%$ & Algo más que satisfecho: & $4 \%$ \\
Satisfecho: & $22 \%$ & Satisfecho: & $58 \%$ \\
Algo Insatisfecho: & $20 \%$ & Algo Insatisfecho: & $18 \%$ \\
Bastante Insatisfecho: & $10 \%$ & Bastante Insatisfecho: & $8 \%$ \\
Muy Insatisfecho: & $0 \%$ & Muy Insatisfecho: & $6 \%$ \\
Insatisfacción total: & $0 \%$ & Insatisfacción total: & $6 \%$ \\
\hline
\end{tabular}

Análisis: Después de haber realizado el análisis de Expectativa Vs. Percepción de las personas encuestadas, la brecha de satisfacción que nos muestra el resultado final para el Aspecto de la evaluación sobre la Nivel de personalización en la atención del servicio en la Dirección de Obras Particulares de ambas Municipalidades, nos muestra que los usuarios de la ciudad de Ensenada se sienten Algo más que satisfecho con un $26 \%$; mientras que en la ciudad de la Plata se evidencio una percepción de los usuarios que mayoritariamente se sienten satisfechos con el 58\% pero con tendencia negativa hacia Algo Insatisfecho. Por consiguiente podemos definir que los usuarios determinaron que Nivel de personalización en la atención del servicio de la Dirección de Obras Particulares es mejor percibida en la Municipalidad de Ensenada; mientras 


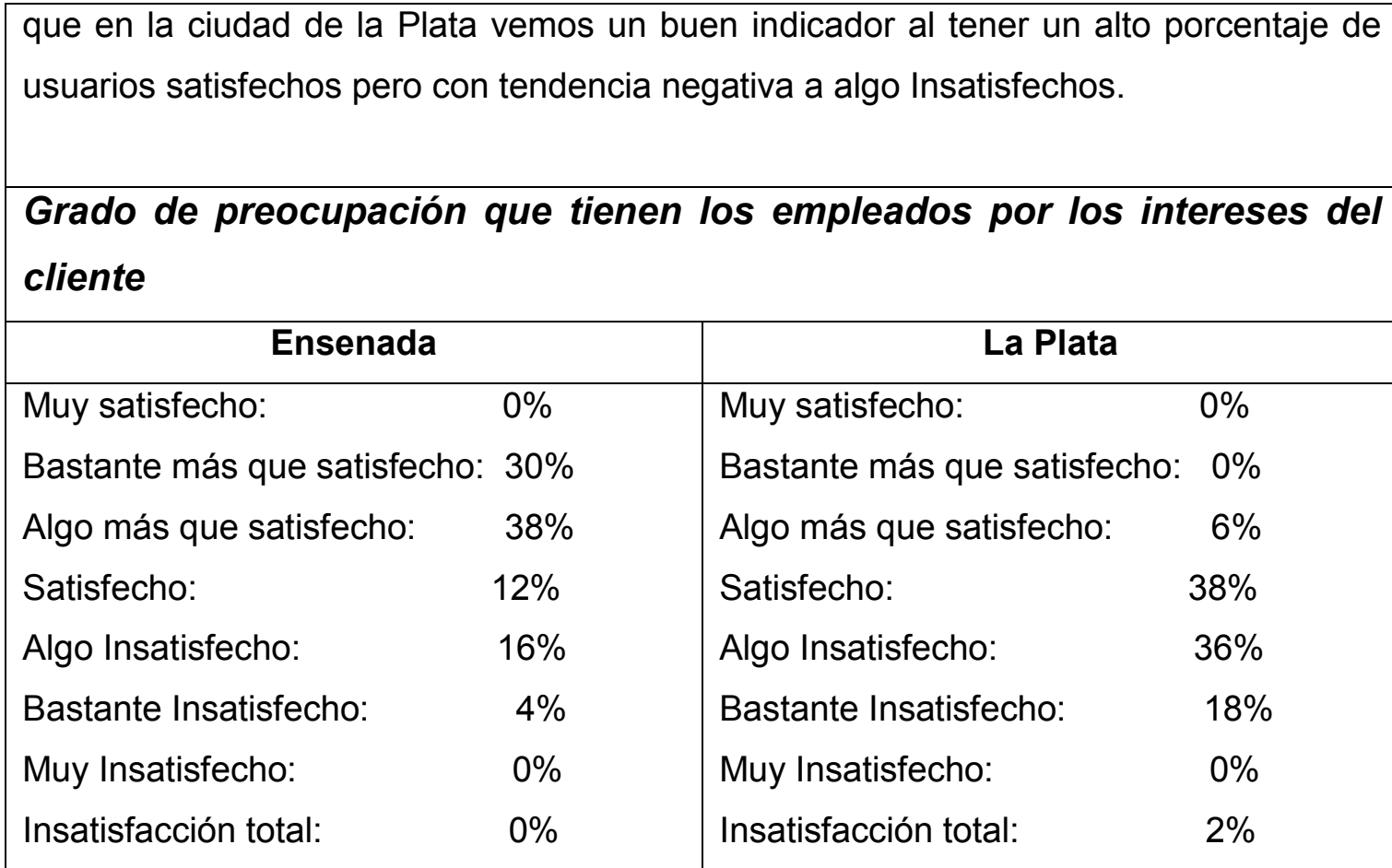

Análisis: Después de haber realizado el análisis de Expectativa Vs. Percepción de las personas encuestadas, la brecha de satisfacción que nos muestra el resultado final para el Aspecto de la evaluación sobre el Grado de preocupación que tienen los empleados por los intereses del cliente en la Dirección de Obras Particulares de ambas Municipalidades, nos muestra que los usuarios de la ciudad de Ensenada se sienten algo más que satisfechos con el $38 \%$ y con tendencia positiva hacia bastante más que satisfechos; mientras que en la ciudad de la Plata se evidencio una percepción contraria de los usuarios de satisfechos con un $38 \%$ pero con tendencia negativa a algo insatisfechos. Por consiguiente podemos definir que los usuarios determinaron que el Grado de preocupación que tienen los empleados por los intereses del cliente de la Dirección de Obras Particulares es mejor en la Municipalidad de Ensenada; frente a los datos obtenidos en la ciudad de la Plata.

\section{Grado en que el servicio comprende las necesidades del cliente}

\begin{tabular}{|lc|lc|}
\hline \multicolumn{2}{|c|}{ Ensenada } & \multicolumn{2}{c|}{ La Plata } \\
\hline Muy satisfecho: & $0 \%$ & Muy satisfecho: & $0 \%$ \\
Bastante más que satisfecho: & $34 \%$ & Bastante más que satisfecho: & $0 \%$ \\
Algo más que satisfecho: & $30 \%$ & Algo más que satisfecho: & $0 \%$ \\
Satisfecho: & $32 \%$ & Satisfecho: & $34 \%$ \\
Algo Insatisfecho: & $4 \%$ & Algo Insatisfecho: & $32 \%$ \\
Bastante Insatisfecho: & $0 \%$ & Bastante Insatisfecho: & $28 \%$ \\
Muy Insatisfecho: & $0 \%$ & Muy Insatisfecho: & $6 \%$ \\
Insatisfacción total: & $0 \%$ & Insatisfacción total: & $0 \%$ \\
\hline \multicolumn{2}{|l}{} \\
\hline
\end{tabular}


Análisis: Después de haber realizado el análisis de Expectativa Vs. Percepción de las personas encuestadas, la brecha de satisfacción que nos muestra el resultado final para el Aspecto de la evaluación sobre el Grado en que el servicio comprende las necesidades del cliente en la Dirección de Obras Particulares de ambas Municipalidades, nos muestra que los usuarios de la ciudad de Ensenada se sienten Bastante más que satisfechos con el 34\%; mientras que en la ciudad de la Plata se evidencio una percepción contraria de los usuarios de satisfechos con un $34 \%$ pero con tendencia negativa a algo insatisfechos con un $32 \%$. Por consiguiente podemos definir que los usuarios determinaron que el Grado en que el servicio comprende las necesidades del cliente de la Dirección de Obras Particulares es mejor en la Municipalidad de Ensenada; frente a los datos obtenidos en la ciudad de la Plata.

\section{Grafica Comparativa del nivel de satisfacción total de la Dimensión IV \\ Brecha “Empatía” Ensenada Vs. La Plata}

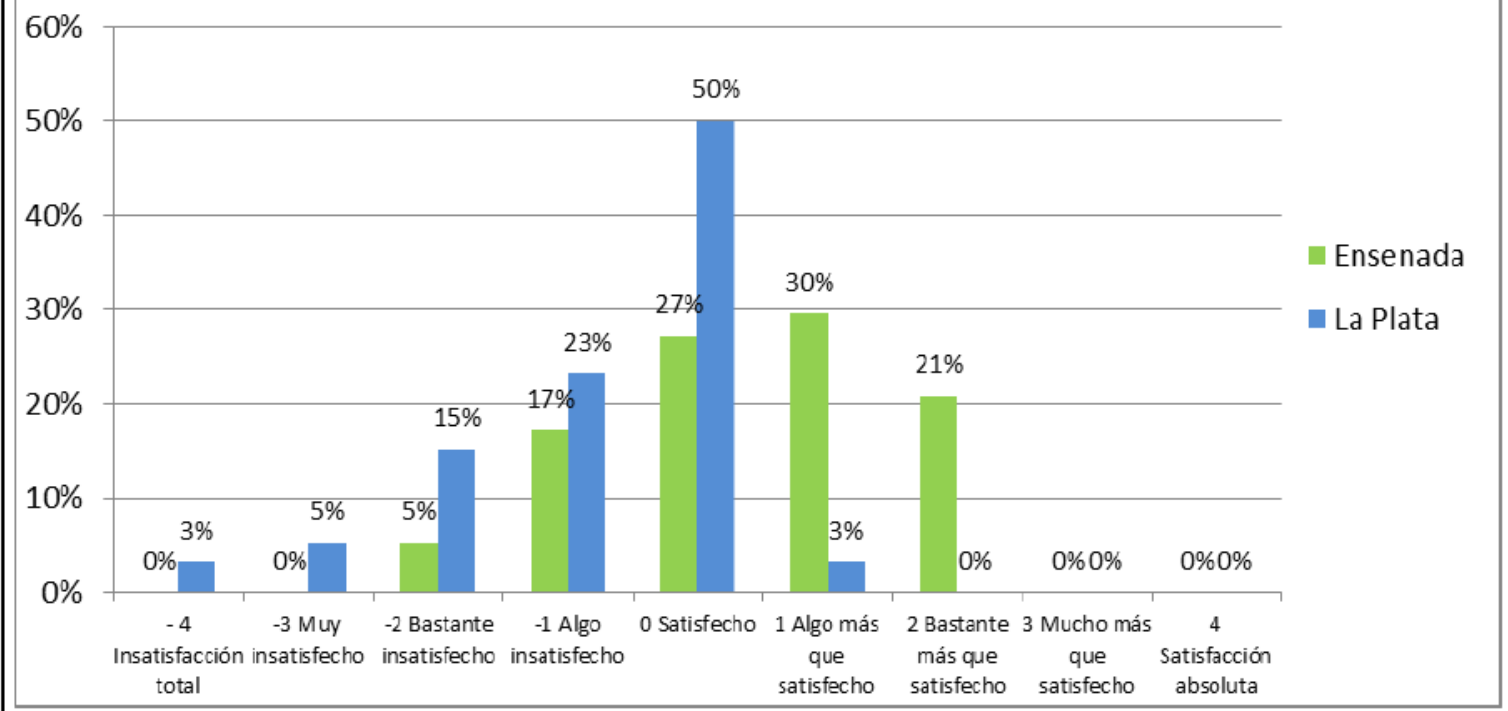

Nivel de Satisfacción

\begin{tabular}{c|c|c}
\hline Dimensión V & Ensenada & La Plata \\
\hline Empatía & 0.436 & $-0,788$
\end{tabular}

\subsection{Comparación del resultado total por dimensiones según la importancia.}

En ambas municipalidades el resultado obtenido fue diferente, mientras que en la Municipalidad de Ensenada la dimensión más importante para los usuarios 
del servicio fue la Dimensión III: Capacidad de respuesta, para la ciudad de La Plata fue la dimensión V: Empatía.

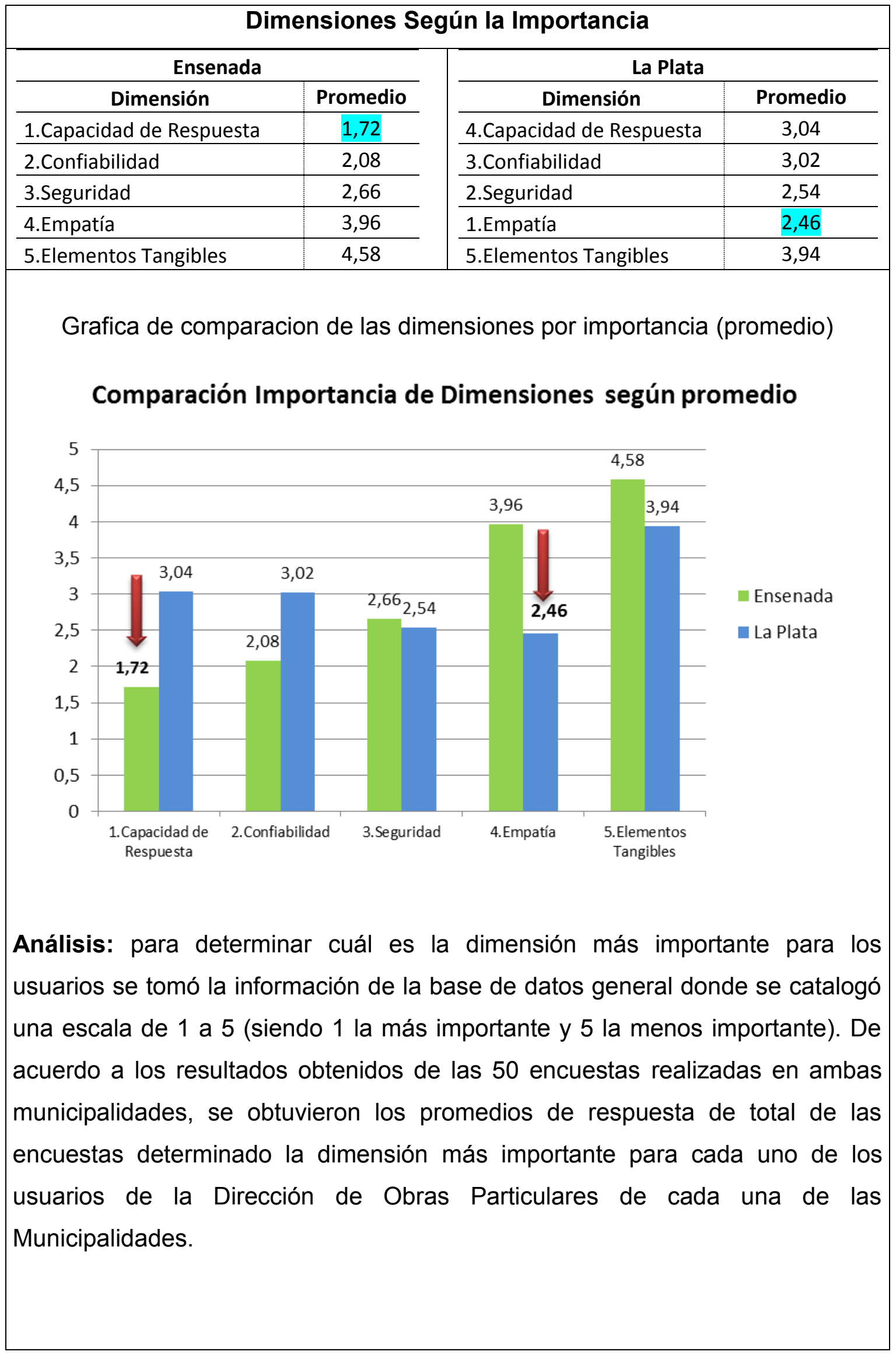


Para los usuarios de la municipalidad de Ensenada la dimensión más importante es la Capacidad de Respuesta con un promedio de 1.72 mientras que para los usuarios de la municipalidad de La Plata la dimensión más importante es la empatía con 2,46.

Es importante destacar que en ambas municipalidades la dimensión de elementos Tangibles quedo en último lugar; indicando que para los usuarios de ambas ciudades es la dimensión de menor importancia a la hora de demandar los servicios de la Dirección de Obras Particulares.

Adicionalmente a esta comparación por promedio, vamos a ver también la importancia de las dimensiones según su frecuencia.

\begin{tabular}{|c|c|c|c|c|c|}
\hline \multicolumn{6}{|c|}{ Importancia de las Dimensiones Según su Frecuencia } \\
\hline \multicolumn{3}{|c|}{ Ensenada } & \multicolumn{3}{|c|}{ La Plata } \\
\hline Dimensión & Frecuencia & Porcentaje & Dimensión & Frecuencia & Porcentaje \\
\hline 1.Capacidad de Respuesta & 29 & $58 \%$ & 4.Capacidad de Respuesta & 7 & $14 \%$ \\
\hline 2.Confiabilidad & 15 & $30 \%$ & 3.Confiabilidad & 9 & $18 \%$ \\
\hline 3.Seguridad & 6 & $12 \%$ & 2.Seguridad & 10 & $20 \%$ \\
\hline 4.Empatía & 0 & $0 \%$ & 1.Empatía & 19 & $38 \%$ \\
\hline 5.Elementos Tangibles & 0 & $0 \%$ & 5.Elementos Tangibles & 5 & $10 \%$ \\
\hline TOTAL & 50 & $100 \%$ & TOTAL & 50 & $100 \%$ \\
\hline
\end{tabular}

Grafica de comparacion de las dimensiones por importancia (Frecuencia)

\section{Comparación Importancia de Dimensiones según Frecuencia}

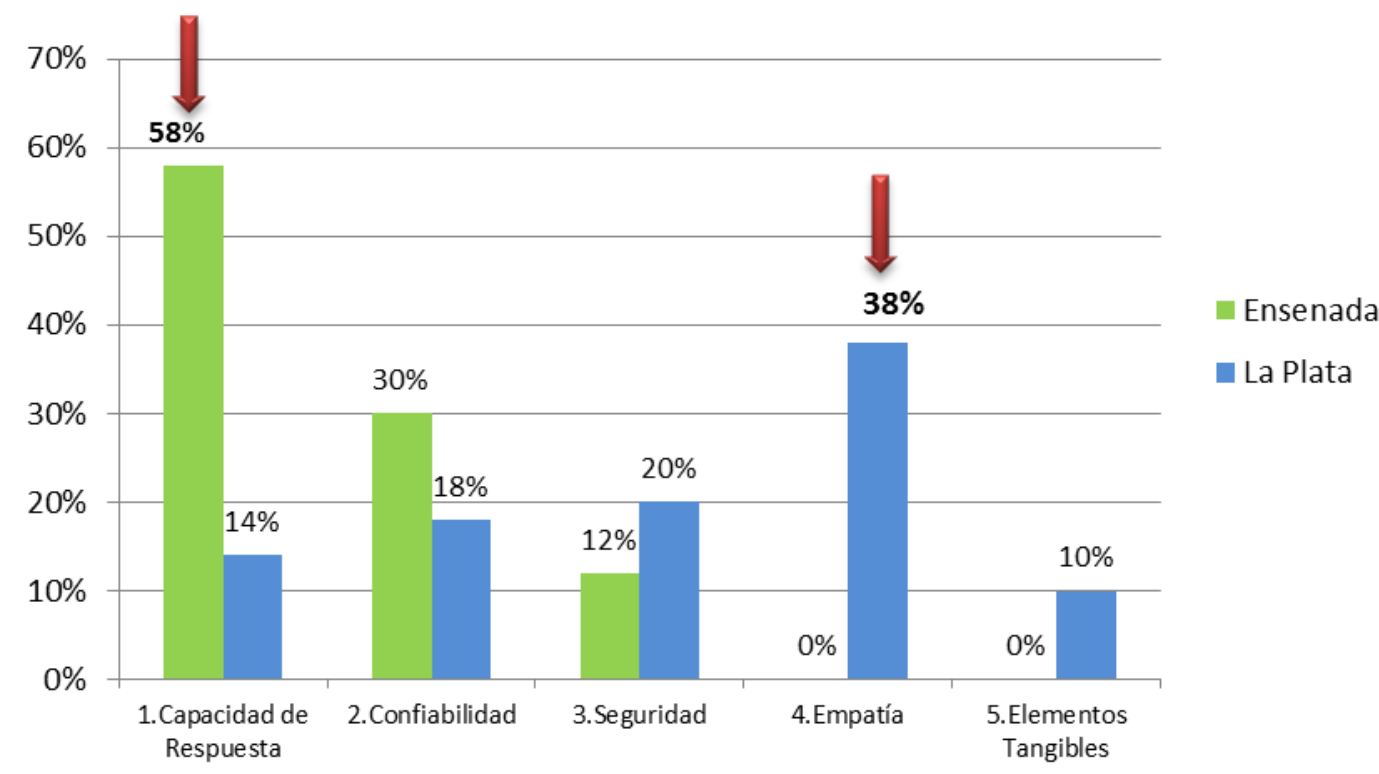


Tanto por frecuencia, procentaje o promedio, podemos identificar que el orden de importancia se mantiene para ambas municipalidades. Siendo elementos tangibles la mas importante para los usuarios de la municipalidad de Ensenada con un 58\% y la "Empatia" para los usuarios de la municipalidad de La Plata con un $38 \%$

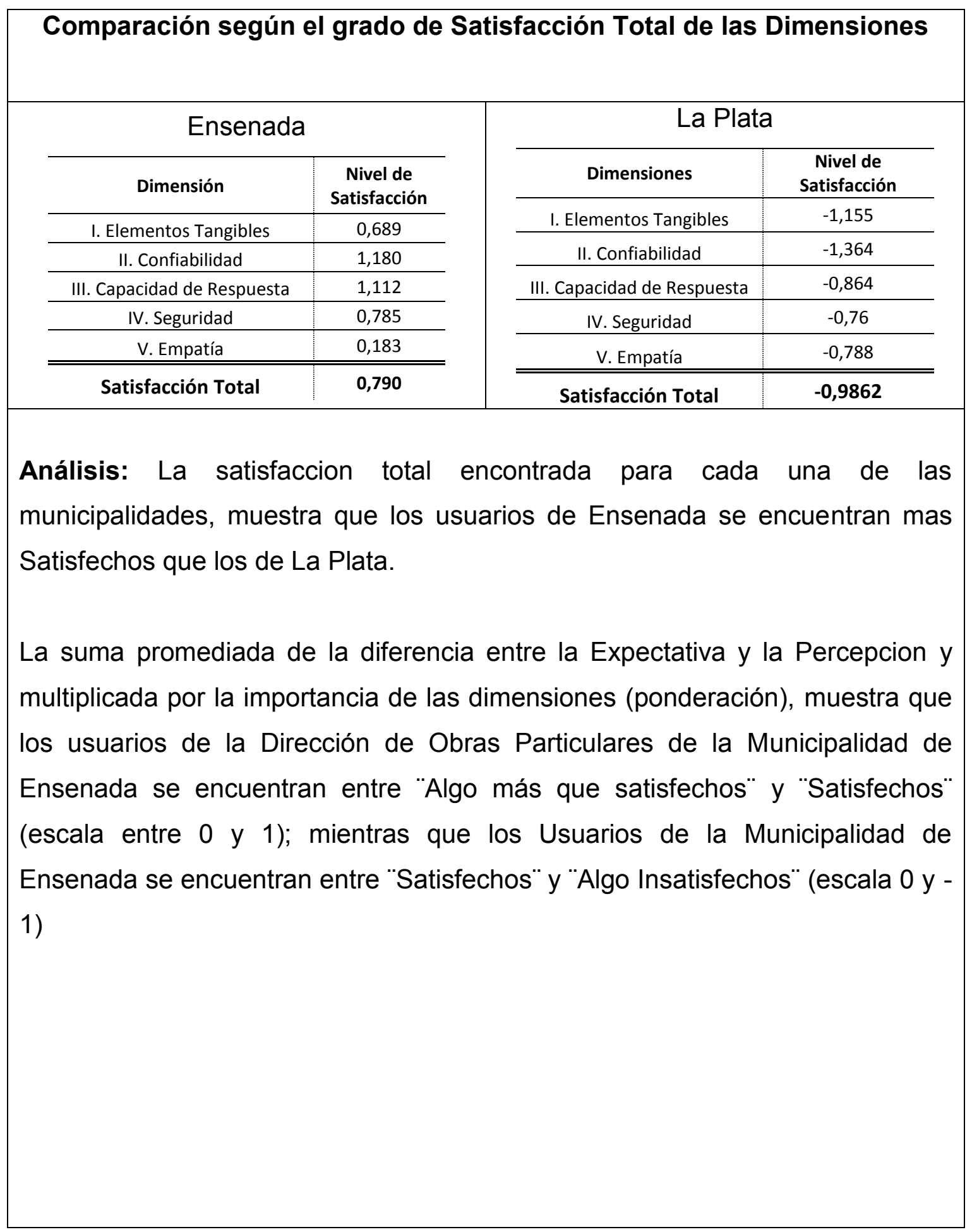




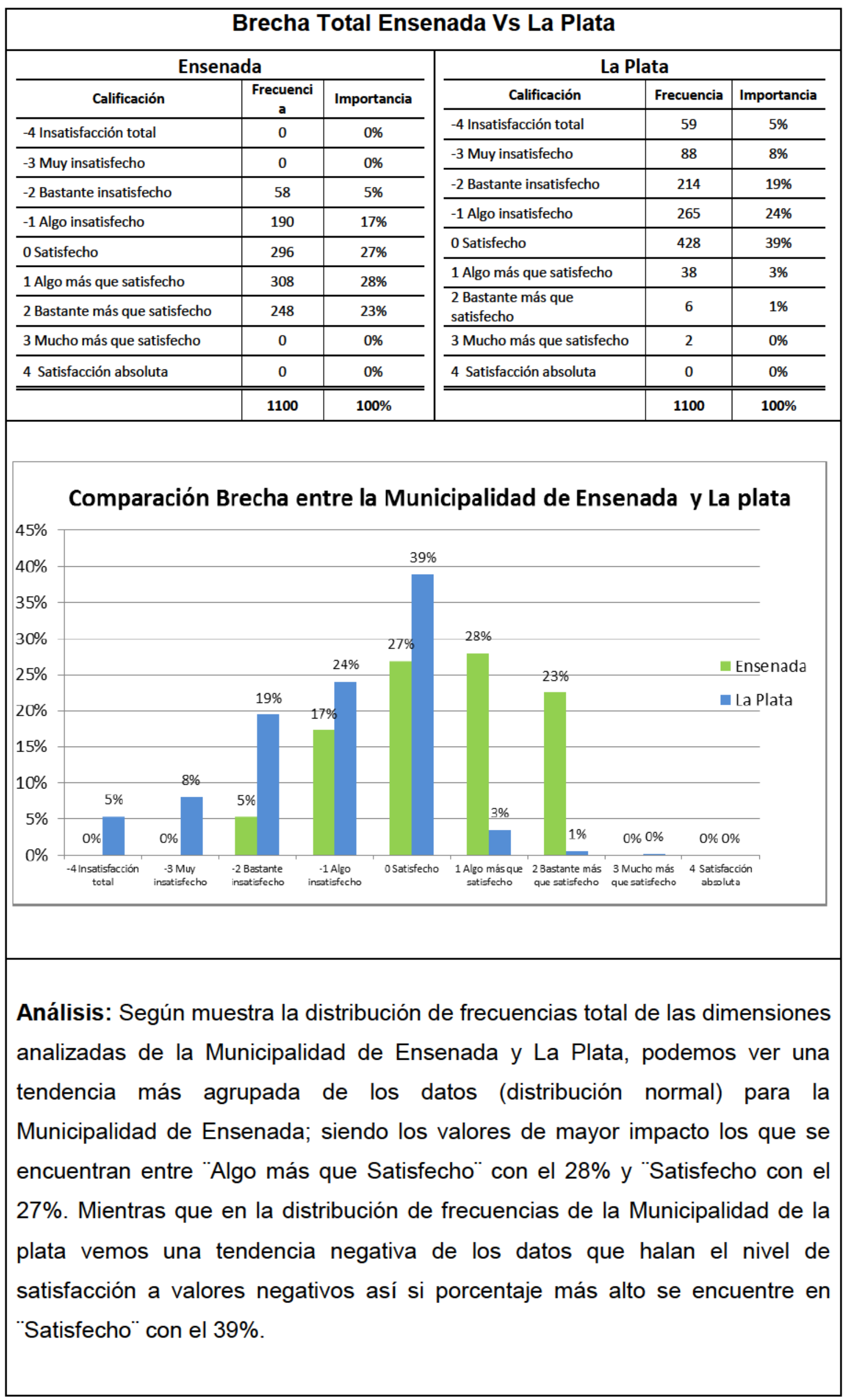




\section{Conclusiones}

En atención a los 3 objetivos propuestos en este trabajo, podemos concluir que:

- Después de evaluar el nivel de satisfacción de los usuarios del Servicio de Obras Particulares de la Municipalidad de Ensenada y de analizar como evalúan los usuarios las diferentes dimensiones al hacer uso del servicio; los usuarios califican a la organización del servicio en general de "Algo más que Satisfecho" a "Satisfecho" con una Calificación Global de satisfacción de 0,456 . Pero cuando ahondamos en todas y cada una de las dimensiones del servicio podemos observar lo siguiente:

Dimensión I, se ve que esta es la dimensión que los usuarios calificaron como la menos importante de todas analizada desde la percepción de los usuarios encuestados. Ya dentro del análisis interno de la dimensión elementos tangibles, se concluye que la apariencia de los equipos fue la que tuvo el menor grado de satisfacción "Algo insatisfecho" con el $28 \%$. Mientras que el resto de los aspectos consultados (Instalaciones físicas, la apariencia de los empleados y apariencia visual de los elementos de comunicación) tuvieron el mismo nivel de satisfacción; donde los usuarios encuestados se sintieron satisfechos después de la utilización del servicio. Lo cual arroja una media aritmética positiva pero a su vez es la más baja de todas, lo que indica que se tendrán que hacer cambios para mejorar los elementos tangibles del Servicio de Obras Particulares. El nivel de satisfacción para esta Dimensión fue de 0,21 .

Dimensión II, la Confiabilidad es considerada por los usuarios encuestados como la segunda en importancia, lo que dice que aspectos como la Eficacia del Servicio, el Tiempo de Cumplimiento o el Interés de los empleados en solucionar las distintas problemáticas; son aspectos muy bien valorados por los usuarios a la hora de recibir las respuestas a sus inquietudes y problemas. 
Ya dentro del análisis interno de la dimensión, se destaca la eficacia del servicio donde los usuarios encuestados se sienten más que satisfechos en un 30\%; mientras que los restantes (Cumplimiento de los Empleados de lo Prometido, Interés de los Empleados en Solucionar Problemas, Tiempo de Cumplimiento de los Empleados y, Eficiencia del Servicio) se mantiene un nivel de satisfecho. De esta forma podemos decir que el nivel de satisfacción de la dimensión es positivo con un 0,404.

Dimensión III: La Capacidad de respuesta, fue considerada por los usuarios encuestados como la dimensión más importante de acuerdo a los requerimientos que los usuarios demandan a la hora de tomar el servicio.

Claramente se ve que las percepciones globales alcanzan a las expectativas de los usuarios y que los diferentes aspectos tocados en esta dimensión como la velocidad del servicio, la disponibilidad en la atención y la atención inmediata son factores que los usuarios del servicio valoran más de lo normal; ya que para los clientes o usuarios que demandan cualquier clase de servicio el tiempo se convierte en factor determinante. El nivel de satisfacción de la dimensión es positivo con un 0,475 .

Dimensión IV: seguridad, fue considerada según la percepción de los usuarios encuestados como la tercera en importancia.

La diferencia entre expectativa y percepción muestra una brecha en la que la percepción supero las expectativas de forma positiva en todos los aspectos (Confianza que brinda el Comportamiento de los Empleados, Seguridad en las transacciones, Amabilidad de los Empleados y Conocimiento de los Empleados) de la dimensión mostro niveles altos de satisfacción con un 0,755

Finalmente, la dimensión V: empatía, no género grandes expectativas en los usuarios siendo la penúltima en importancia de las dimensiones. Pero por el lado de la satisfacción mostro diferencias significativas de forma positiva entre las expectativas que se tenían del servicio frente a 
lo que percibieron los usuarios a la hora de tomarlo. Solo se destaca por debajo el "grado de preocupación que tienen los empleados por los intereses del cliente" en donde se evidencio algo de insatisfacción.

Siendo el resto de los aspectos consultados positivos, donde la mayoría se han sentido algo más que satisfechos con un valor de 0,436

- Después de realizada las distintas comparaciones de los usuarios del servicio de Obras particulares de la Municipalidad de Ensenada y la Municipalidad de La Plata, se observa que los usuarios de la ciudad de Ensenada tienen un mayor grado de satisfacción con los servicios prestados por la Dirección de Obras Particulares. Pues el nivel de satisfacción de la Ciudad de Ensenada se encuentra entre "Algo más que Satisfecho" y "Satisfecho" con una calificación global de 0.456 ; mientras que los usuarios de la Ciudad de La Plata ven el servicio de "Algo Insatisfecho" a "Satisfecho" con una calificación global de -0,986.

Finalmente, luego de ver los resultados conseguidos tanto en el análisis de la información obtenida de las encuestas y de la comparación hecha entre las municipalidades de Ensenada y La Plata; se recomienda como opción de mejora a la municipalidad de ensenada, iniciar un proceso de implementación de conocimiento de la satisfacción de sus usuarios para determinar si los servicios prestados por la municipalidad son apto y satisfacen las necesidades de sus usuarios o es necesario que se implemente un sistema de gestión de la calidad apoyado en la adopción de un enfoque de normalización y estandarización de procesos enfocados al usuario, diseñando un modelo de calidad basado en las normas ISO:9000 y apalancados por las diferentes Instituciones con las que cuenta el Estado Argentino.

Aunque los resultados observados y obtenidos en general por los usuarios encuestados en el Servicio de Obras Particulares de la Municipalidad de Ensenada, los ciclos de la mejora continua nunca paran y es allí donde podemos empezar a buscar una mayor eficiencia, eficacia y efectividad que sea percibida cada vez mejor por los usuarios que demanden el servicio. 


\section{Bibliografía}

- ARELLANO CUEVA, Rolando Marketing; enfoque América Latina.

- MOYADO ESTRADA, Francisco Gestión pública y calidad; Hacia la mejora continua y el rediseño de las instituciones del sector público.

- EVANS, James R. y LINDSAY, William M. Administración y control de la calidad.

- PETRACCI, Mónica La medición de la calidad y la satisfacción del ciudadano-usuario de servicios públicos privatizados.

- DA VIÁ, Ana Control de calidad: Introducción a las modernas filosofías de gestión, Cátedras virtuales, Sistemas de Control de Gestión.

- Armido I. P. Bonelli - Evolución de la Gestión de la Calidad en el Sector Público Nacional 1994 - 2010

- "Cero defectos". EVANS, James R. y LINDSAY, William M., op. cit.

- SCHWEINHEIM, Guillermo Política y Gestión Pública Primera parte.

- GARCÍA DELGADO, Daniel Estado y Sociedad; Del Estado de Bienestar al Estado Post-social.

- OSZLAK, Oscar Transformación estatal y gobernabilidad en el contexto de la globalización: el caso argentino.

- ABAL MEDINA, Juan M. Lineamientos estratégicos para la innovación de la gestión en Argentina.

- CLAD, UNA NUEVA GESTIÓN PÚBLICA PARA AMÉRICA LATINA; documento oficial 1.998 .

- Carta Iberoamericana de calidad en la gestión pública (San Salvador, El Salvador, del 29 al 31 de octubre de 2008).

- REFORMA DEL ESTADO - ETAPAS Cátedras Virtuales Organización y Gestión del Estado Documentos.

- ESTESO, Roberto y CAO, Horacio LA REFORMA DE LAS ADMINISTRACIONES PÚBLICAS PROVINCIALES: BALANCE DE LA DÉCADA DE LOS '90 Y NUEVA AGENDA.

- LÓPEZ, Andrea La Nueva Gestión Pública: Algunas Precisiones para su Abordaje Conceptual.

- REFORMA DEL ESTADO-ETAPAS Cátedras Virtuales Organización y Gestión del Estado Documentos

- Paginas WEB: www.sgp.gob.ar - www.worldbank.org www.fcp.edu.ar. 


\section{Anexos}

Anexo 1: ENCUESTA

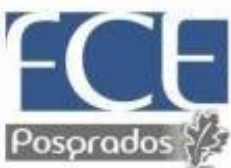

\section{Facultad de}

Ciencias Económicas

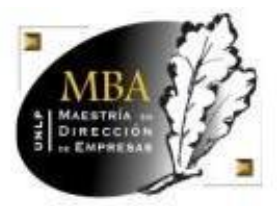

MAESTRIA EN

DIRECCIÓN DE EMPRESAS

Encuesta $\mathrm{N}^{\circ}$

Encuesta dirigida a clientes del servicio de Defensa del Consumidor de la Municipalidad de La Plata.

\section{OBJETIVO}

Medir la satisfacción de los clientes del servicio de Defensa del Consumidor de la Municipalidad de La Plata.

1.- ¿Con que frecuencia utiliza el servicio de Defensa del Consumidor?

\begin{tabular}{|l|l|}
\hline 1) A diario & \\
\hline 2) Varias veces a la semana & \\
\hline 3) Una vez al mes & \\
\hline 4) Una vez cada seis meses & \\
\hline 5) Una vez al año & \\
\hline 6) Cada varios años & \\
\hline
\end{tabular}

2.- ¿Cómo calificaría la organización del servicio de Defensa del Consumidor?

\begin{tabular}{|l|l|}
\hline 1) Excelente & \\
\hline 2) Bueno & \\
\hline 3) Regular & \\
\hline 4) Malo & \\
\hline 5) Pésimo & \\
\hline
\end{tabular}

3.- En las siguientes preguntas, califique de 1 a 5 según corresponda

Dimensión 1: Elementos Tangibles

\begin{tabular}{|c|l|l|}
\hline $\begin{array}{c}\text { Apariencia de las instalaciones físicas, equipos, personal y } \\
\text { materiales de comunicación }\end{array}$ & Expectativa & Percepción \\
\hline Los equipos con que cuenta el servicio son... [1 = Modernos a $5=$ & & \\
\hline
\end{tabular}




\begin{tabular}{|l|l|l|}
\hline Obsoletos] & & \\
\hline Las instalaciones físicas del servicio son $[1=$ Atractivas a $5=$ & & \\
Desagradables] & & \\
\hline La apariencia física de los empleados es... [1 = Pulcra a $5=$ & & \\
Desaseada] & & \\
\hline $\begin{array}{l}\text { La apariencia visual de los elementos materiales de comunicación es... } \\
1=\text { Atractivos a } 5=\text { Desagradables }]\end{array}$ & & \\
\hline
\end{tabular}

\section{Dimensión 2: Confiabilidad}

\begin{tabular}{|l|l|l|}
\hline $\begin{array}{l}\text { Habilidad para ejecutar el servicio prometido de forma confiable y } \\
\text { cuidadosa }\end{array}$ & Expectativa & Percepción \\
\hline $\begin{array}{l}\text { Los empleados del servicio municipal cumplen lo que prometen... [1 = } \\
\text { Siempre Cumplen a } 5=\text { Nunca Cumplen] }\end{array}$ & \\
\hline $\begin{array}{l}\text { El interés que tienen los empleados del servicio en solucionar los } \\
\text { problemas de los clientes es... [1 = Total Interés a } 5=\text { Completo } \\
\text { Desinterés }]\end{array}$ & \\
\hline $\begin{array}{l}\text { La eficacia del servicio municipal es... [1 = Realiza el trabajo bien a la } \\
\text { primera vez a } 5=\text { nunca lo hace bien] }\end{array}$ & \\
\hline $\begin{array}{l}\text { El tiempo del cumplimiento del trabajo es... [1 = Siempre a tiempo a 5 } \\
\text { Nunca a tiempo] }\end{array}$ & \\
\hline $\begin{array}{l}\text { El trabajo que el servicio mantiene según su eficiencia es... [1 = Exento } \\
\text { de errores a } 5=\text { Con serias deficiencias] }\end{array}$ & \\
\hline
\end{tabular}

\section{Dimensión 3: Capacidad de Respuesta}

\begin{tabular}{|l|l|l|}
\hline $\begin{array}{c}\text { Disposición y voluntad de los empleados para ayudar al cliente y } \\
\text { proporcionar el servicio }\end{array}$ & Expectativa & Percepción \\
\hline $\begin{array}{l}\text { El nivel de comunicación que tiene con los empleados es... [1 = } \\
\text { Excelente a 5 = Pésimo] }\end{array}$ & & \\
\hline La velocidad del servicio es... [1 = Muy Rápido a 5 = Muy Lento] & & \\
\hline $\begin{array}{l}\text { El nivel de disponibilidad de atención es... [1 = Siempre Disponible a 5 = } \\
\text { Nunca Disponible] }\end{array}$ & & \\
\hline $\begin{array}{l}\text { El grado de disponibilidad para atención inmediata frente a otras } \\
\text { actividades es... [1 }=\text { Siempre disponible a } 5=\text { Nunca Disponible] }\end{array}$ & & \\
\hline
\end{tabular}

\section{Dimensión 4: Seguridad}

\begin{tabular}{|l|l|l|}
\hline $\begin{array}{c}\text { Conocimiento y atención mostrados por los empleados y sus } \\
\text { habilidades para inspirar credibilidad y confianza }\end{array}$ & Expectativa & Percepción \\
\hline $\begin{array}{l}\text { La confianza que brinda el comportamiento de los empleados es... [1 = } \\
\text { Completa Confianza a 5 = Absoluta Desconfianza] }\end{array}$ & & \\
\hline El nivel de seguridad que usted siente en sus transacciones con el & & \\
\hline
\end{tabular}


servicio es... [1 = Muy seguro a 5 = Muy Inseguro]

El nivel de amabilidad que muestran los empleados del servicio es... [1 = Muy Amable a 5 = Muy descortés]

El grado de conocimiento que tienen los empleados para resolver sus inquietudes es... [1 = Totalmente Conocedor a $5=$ Absolutamente Ignorante]

\section{Dimensión 5: Empatía}

\begin{tabular}{|c|c|c|}
\hline Atención individualizada que ofrece la organización a los clientes & Expectativa & Percepción \\
\hline $\begin{array}{l}\text { La atención del servicio según su individualización es... [1 }= \\
\text { Individualizada a } 5 \text { = Colectiva }]\end{array}$ & & \\
\hline $\begin{array}{l}\text { Los horarios de trabajo }- \text { por conveniencia- son... }[1=\text { Muy } \\
\text { convenientes o } 5=\text { Muy Inconvenientes }]\end{array}$ & & \\
\hline $\begin{array}{l}\text { La atención del servicio según su personalización es... [1 } \\
\text { Personalizada a } 5=\text { Común] }\end{array}$ & & \\
\hline $\begin{array}{l}\text { El grado de preocupación que tienen los empleados con sus intereses } \\
\text { es... [1 = Mucha Preocupación a } 5=\text { Despreocupación }]\end{array}$ & & \\
\hline $\begin{array}{l}\text { El grado en que el servicio comprende sus necesidades específicas } \\
\text { es... [1 = Excelente a } 5=\text { Pésima }]\end{array}$ & & \\
\hline
\end{tabular}

\section{4.- Distribuya del 1 al 5 según el grado de importancia que las siguientes dimensiones} ocupan para usted en este servicio

\begin{tabular}{|l|l|}
\hline Elementos tangibles & \\
\hline Confiabilidad & \\
\hline Capacidad de respuesta & \\
\hline Seguridad & \\
\hline Empatía & \\
\hline
\end{tabular}

\section{5.- Perfil del encuestado}

Sexo $\quad 1 \square$ Hombre $2 \square$ Mujer

$$
\text { Edad } \begin{aligned}
& \quad 1 \square \text { Hasta } 20 \text { años } \\
& 2 \square \text { Más de } 20 \text { y hasta } 30 \text { años } \\
& 3 \square \text { Más de } 30 \text { y hasta } 40 \text { años } \\
& 4 \square \text { Más de } 40 \text { y hasta } 50 \text { años } \\
& 5 \square \text { Más de } 50 \text { y hasta } 60 \text { años } \\
& 6 \square \text { Más de } 60 \text { años }
\end{aligned}
$$

Ocupación $\quad 1 \square$ Independiente $2 \square$ Empleado $3 \square$ Jubilado $4 \square$ Desempleado $5 \square$ Otros (especifique): 


\section{Anexo 2}

Tablas de frecuencia de datos

\section{Expectativa de los usuarios de la Dirección de Obras Particulares}

\begin{tabular}{|c|c|c|c|c|c|c|c|c|c|c|c|c|c|c|c|c|c|c|c|c|c|}
\hline \multicolumn{22}{|c|}{ Dimensiones } \\
\hline \multicolumn{4}{|c|}{$\begin{array}{l}\text { Elementos } \\
\text { Tangibles }\end{array}$} & \multicolumn{5}{|c|}{ Confiabilidad } & \multicolumn{4}{|c|}{$\begin{array}{c}\text { Capacidad de } \\
\text { Respuesta }\end{array}$} & \multicolumn{4}{|c|}{ Seguridad } & \multicolumn{5}{|c|}{ Empatía } \\
\hline & 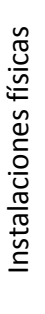 & 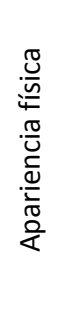 & $\begin{array}{l}\bar{\pi} \\
\frac{\pi}{2} \\
\frac{0}{2} \\
\frac{\pi}{U} \\
\frac{\pi}{0} \\
\frac{0}{2} \\
\frac{0}{2} \\
\frac{0}{4}\end{array}$ & 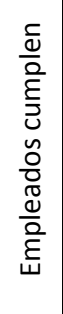 & 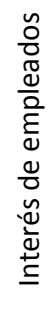 & 宽 & 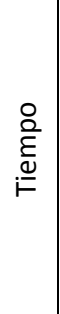 & 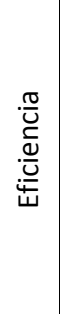 & 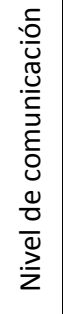 & $\begin{array}{l}\frac{0}{\pi} \\
\frac{\pi}{y} \\
\frac{0}{0} \\
\frac{0}{2}\end{array}$ & 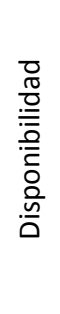 & 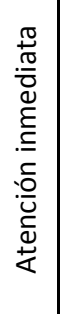 & 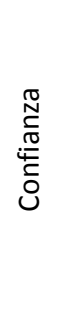 & 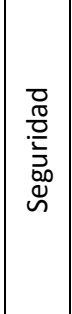 & 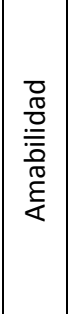 & 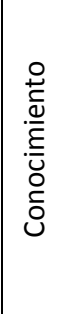 & 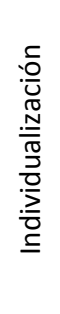 & $\begin{array}{l}\text { 은 } \\
\frac{0}{0} \\
\text { 오 }\end{array}$ & 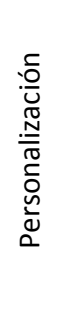 & 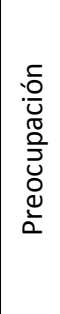 & 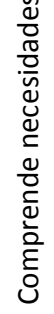 \\
\hline & 1.2 & 1.3 & 1.4 & 2.1 & 2.2 & 2.3 & 2.4 & 2.5 & 3.1 & 3.2 & 3.3 & 3.4 & 4.1 & 4.2 & 4.3 & 4.4 & 5.1 & 5.2 & 5.3 & 5.4 & 5.5 \\
\hline & 6 & 10 & 2 & 15 & 8 & 8 & 11 & 12 & 11 & 13 & 15 & 3 & 13 & 11 & 9 & 14 & 11 & 7 & 12 & 16 & 12 \\
\hline & 6 & 19 & 9 & 11 & 16 & 17 & 7 & 16 & 16 & 11 & 10 & 7 & 14 & 12 & 15 & 12 & 15 & 9 & 12 & 11 & 15 \\
\hline & 17 & 11 & 12 & 13 & 15 & 14 & 9 & 12 & 13 & 10 & 12 & 8 & 12 & 21 & 19 & 21 & 16 & 22 & 13 & 9 & 19 \\
\hline & 5 & 7 & 12 & 9 & 9 & 7 & 12 & 7 & 9 & 9 & 10 & 15 & 7 & 5 & 7 & 3 & 5 & 6 & 12 & 12 & 4 \\
\hline & 16 & 3 & 15 & 2 & 2 & 4 & 11 & 3 & 1 & 7 & 3 & 17 & 4 & 1 & 0 & 0 & 3 & 6 & 1 & 2 & 0 \\
\hline 5 & 50 & 50 & 50 & 50 & 50 & 50 & 50 & 50 & 50 & 50 & 50 & 50 & 50 & 50 & 50 & 50 & 50 & 50 & 50 & 50 & 50 \\
\hline
\end{tabular}
Siendo 1 la mejor valoración.

\section{Percepción de los usuarios de la Dirección de Obras Particulares}

\begin{tabular}{|c|c|c|c|c|c|c|c|c|c|c|c|c|c|c|c|c|c|c|c|c|c|}
\hline \multicolumn{22}{|c|}{ Dimensiones } \\
\hline \multicolumn{4}{|c|}{$\begin{array}{c}\text { Elementos } \\
\text { Tangibles }\end{array}$} & \multicolumn{5}{|c|}{ Confiabilidad } & \multicolumn{4}{|c|}{$\begin{array}{c}\text { Capacidad de } \\
\text { Respuesta }\end{array}$} & \multicolumn{4}{|c|}{ Seguridad } & \multicolumn{5}{|c|}{ Empatía } \\
\hline 号 & 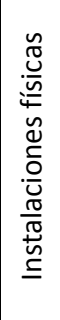 & 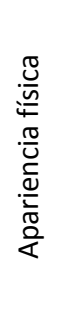 & $\begin{array}{l}\overline{\frac{\pi}{2}} \\
\frac{0}{2} \\
\frac{\pi}{4} \\
\frac{\pi}{0} \\
\frac{0}{2} \\
\frac{\pi}{2} \\
\frac{2}{4}\end{array}$ & 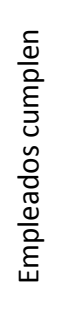 & 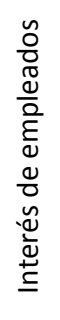 & 离 & 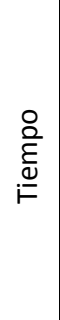 & 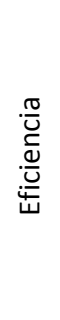 & 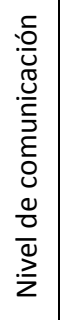 & $\begin{array}{l}\frac{0}{0} \\
\frac{\pi}{0} \\
\frac{0}{0} \\
>\end{array}$ & 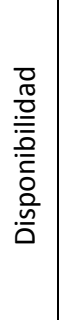 & 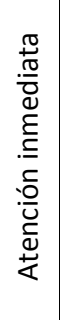 & 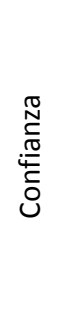 & 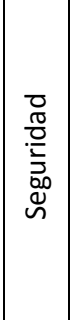 & $\begin{array}{l}\frac{0}{\pi} \\
\frac{\pi}{0} \\
\frac{0}{\overline{0}} \\
\frac{0}{\pi} \\
\frac{1}{4}\end{array}$ & 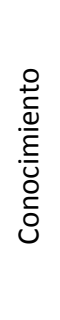 & 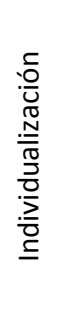 & 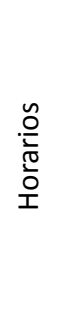 & 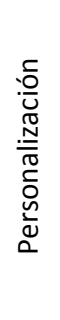 & 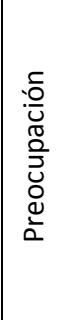 & 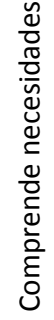 \\
\hline 1.1 & 1.2 & 1.3 & 1.4 & 2.1 & 2.2 & 2.3 & 2.4 & 2.5 & 3.1 & 3.2 & 3.3 & 3.4 & 4.1 & 4.2 & 4.3 & 4.4 & 5.1 & 5.2 & 5.3 & 5.4 & 5.5 \\
\hline 0 & 1 & 16 & 0 & 17 & 6 & 10 & 1 & 7 & 20 & 2 & 12 & 2 & 15 & 15 & 32 & 36 & 7 & 2 & 5 & 5 & 35 \\
\hline 2 & 3 & 26 & 2 & 22 & 25 & 29 & 14 & 29 & 25 & 22 & 20 & 11 & 22 & 24 & 15 & 12 & 31 & 27 & 29 & 26 & 12 \\
\hline 29 & 30 & 8 & 26 & 11 & 14 & 10 & 28 & 14 & 5 & 18 & 15 & 25 & 10 & 11 & 3 & 2 & 12 & 19 & 14 & 14 & 3 \\
\hline 18 & 15 & 0 & 19 & 0 & 5 & 1 & 7 & 0 & 0 & 7 & 3 & 10 & 3 & 0 & 0 & 0 & 0 & 2 & 2 & 5 & 0 \\
\hline 1 & 1 & 0 & 3 & 0 & 0 & 0 & 0 & 0 & 0 & 1 & 0 & 2 & 0 & 0 & 0 & 0 & 0 & 0 & 0 & 0 & 0 \\
\hline 50 & 50 & 50 & 50 & 50 & 50 & 50 & 50 & 50 & 50 & 50 & 50 & 50 & 50 & 50 & 50 & 50 & 50 & 50 & 50 & 50 & 50 \\
\hline
\end{tabular}

Siendo 1 la mejor valoración.

\section{Brecha generada entre la Expectativa y la percepción}




\begin{tabular}{|c|c|c|c|c|c|c|c|c|c|c|c|c|c|c|c|c|c|c|c|c|c|c|}
\hline \multirow[b]{2}{*}{ 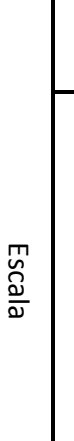 } & \multicolumn{4}{|c|}{$\begin{array}{l}\text { Elementos } \\
\text { Tangibles }\end{array}$} & \multicolumn{5}{|c|}{ Confiabilidad } & \multicolumn{4}{|c|}{$\begin{array}{l}\text { Capacidad de } \\
\text { Respuesta }\end{array}$} & \multicolumn{4}{|c|}{ Seguridad } & \multicolumn{5}{|c|}{ Empatía } \\
\hline & $\begin{array}{l}\stackrel{\text { o }}{\bar{z}} \\
\text { 章 }\end{array}$ & 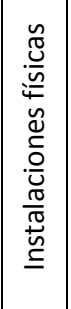 & 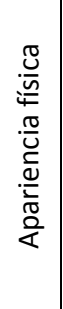 & 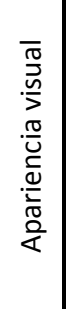 & 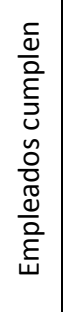 & 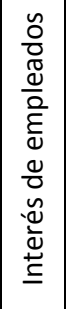 & 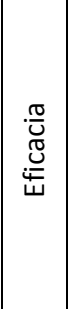 & 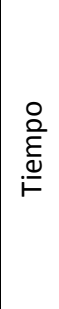 & 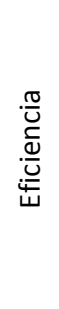 & 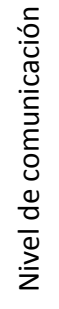 & $\begin{array}{l}\bar{D} \\
\frac{\pi}{0} \\
\frac{0}{\bar{O}} \\
\frac{0}{v} \\
\end{array}$ & 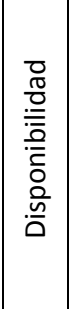 & 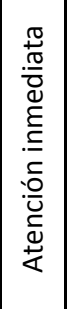 & 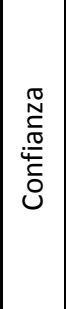 & 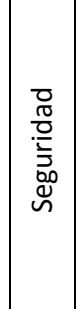 & 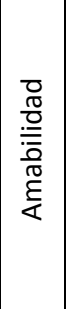 & 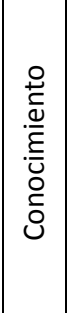 & 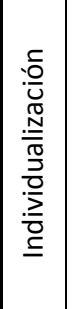 & $\begin{array}{l}\frac{n}{0} \\
\frac{0}{0} \\
\text { 혼 }\end{array}$ & 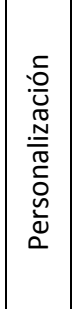 & 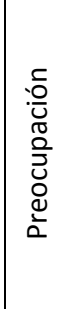 & 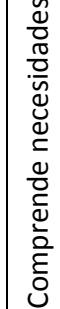 \\
\hline & 1.1 & 1.2 & 1.3 & 1.4 & 2.1 & 2.2 & 2.3 & 2.4 & 2.5 & 3.1 & 3.2 & 3.3 & 3.4 & 4.1 & 4.2 & 4.3 & 4.4 & 5.1 & 5.2 & 5.3 & 5.4 & 5.5 \\
\hline 4 & 0 & 0 & 0 & 0 & 0 & 0 & 0 & 0 & 0 & 0 & 0 & 0 & 0 & 0 & 0 & 0 & 0 & 0 & 0 & 0 & 0 & 0 \\
\hline 3 & 0 & 0 & 0 & 0 & 0 & 0 & 0 & 0 & 0 & 0 & 0 & 0 & 0 & 0 & 0 & 0 & 0 & 0 & 0 & 0 & 0 & 0 \\
\hline 2 & 7 & 9 & 12 & 8 & 12 & 8 & 15 & 11 & 9 & 15 & 11 & 9 & 15 & 9 & 10 & 18 & 18 & 8 & 9 & 11 & 7 & 17 \\
\hline 1 & 11 & 11 & 15 & 10 & 13 & 13 & 11 & 12 & 13 & 15 & 8 & 17 & 19 & 17 & 16 & 18 & 15 & 16 & 18 & 13 & 12 & 15 \\
\hline 0 & 11 & 14 & 16 & 16 & 18 & 14 & 15 & 13 & 15 & 13 & 9 & 10 & 6 & 15 & 16 & 13 & 14 & 16 & 12 & 11 & 13 & 16 \\
\hline-1 & 14 & 10 & 7 & 12 & 5 & 14 & 7 & 8 & 11 & 7 & 17 & 10 & 8 & 7 & 7 & 1 & 2 & 7 & 10 & 10 & 14 & 2 \\
\hline-2 & 7 & 6 & 0 & 4 & 2 & 1 & 2 & 6 & 2 & 0 & 5 & 4 & 2 & 2 & 1 & 0 & 1 & 3 & 1 & 5 & 4 & 0 \\
\hline-3 & 0 & 0 & 0 & 0 & 0 & 0 & 0 & 0 & 0 & 0 & 0 & 0 & 0 & 0 & 0 & 0 & 0 & 0 & 0 & 0 & 0 & 0 \\
\hline & 0 & 0 & 0 & 0 & 0 & 0 & 0 & 0 & 0 & 0 & 0 & 0 & 0 & 0 & 0 & 0 & 0 & 0 & 0 & 0 & 0 & 0 \\
\hline & 50 & 50 & 50 & 50 & 50 & 50 & 50 & 50 & 50 & 50 & 50 & 50 & 50 & 50 & 50 & 50 & 50 & 50 & 50 & 50 & 50 & 50 \\
\hline
\end{tabular}

